FINAL REPORT

FHWA/IN/JTRP-2004/34

\title{
AN EVALUATION OF THE COST-EFFECTIVENESS OF WARRANTY CONTRACTS IN INDIANA
}

\author{
By \\ Priyanka Singh \\ Graduate Research Assistant \\ Samuel Labi \\ Visiting Assistant Professor \\ Bob G. McCullouch \\ Research Scientist \\ And \\ Kumares C. Sinha \\ Olson Distinguished Professor \\ School of Civil Engineering \\ Purdue University
Joint Transportation Research Program
Project No. C-36-67SS
File No.: 9-10-70
SPR-2776 \\ Prepared in Cooperation with the \\ Indiana Department of Transportation and \\ The U.S. Department of Transportation \\ Federal Highway Administration
}

The contents of this report reflect the views of the authors who are responsible for the facts and the accuracy of the data presented herein. The contents do not necessarily reflect the official views of the Federal Highway Administration and the Indiana Department of Transportation. The report does not constitute a standard, a specification, or a regulation.

Purdue University

West Lafayette, Indiana, 47907

February 2005 


\section{TECHNICAL Summary}

INDOT Research

Technology Transfer and Project Implementation Information

TRB Subject Code: 33-1 Construction Control

Publication No.: FHWA/IN/JTRP-2004/34, SPR-2776

February 2005

Final Report

\section{An Evaluation of the Cost-Effectiveness of Warranty Contracts in Indiana}

\section{Introduction}

In a bid to ensure cost-effective highway construction practices, highway agencies constantly seek ways to accelerate project design and delivery through implementation of innovative contracting and procurement practices. The concept of warranties is one of such promising practices and shifts the burden of construction quality control, product performance and product maintenance from the owner to the contractor. As such, warranty projects are expected to enhance product quality and service life, and ultimately, reduced life-cycle cost. The expected benefits of warranty projects, however, could be offset by their general higher agency costs. It is therefore necessary to evaluate the costs and benefits of warranty contracts vis-à-vis traditional contracts so that the more costeffective practice can be identified and implemented for purposes of decision-making.

\section{Findings}

The present study reviewed the practice of warranties in highway construction contracts in Indiana and elsewhere, selected pairs of contracts that generally differ only by their contracting method (warranty versus traditional), and carried out statistical analyses to evaluate the relative costs, effectiveness and cost-effectiveness of these two alternative contracting practices. Effectiveness was measured in terms of average pavement condition and pavement service life, and costs were expressed in annualized costs per lane-mile that were duly corrected for inflation and economy of scale.

On the basis of effectiveness only, it was found that warranty pavements exhibit superior pavement condition (in terms of roughness, rutting, and cracking) and greater service life. Using existing performance data and established performance thresholds, it was determined that the projected treatment life of warranty contract pavement was 25 years while similar traditional contract pavements were expected to have a service life of 15 years.

On the basis of agency cost, warranty contracts generally have higher cost compared to traditional contracts. However, it was determined that the average construction period and associated workzone user costs are lower for warranty contract pavements.

On the basis of cost-effectiveness over a relatively short period of 5 years, the warranty pavement contracts were found to be $27-30 \%$ less cost-effective than their traditional counterparts. However, over the long-term (treatment service life), the warranty contracts were found to be 70 $90 \%$ more cost-effective on the basis of service life, and $58-65 \%$ more cost-effective on the basis of both service life and pavement condition. Furthermore, irrespective of analysis period and measure of effectiveness, warranty contracts were found to be more cost-effective when both agency and user costs are used in the analysis.

The study results suggest that the longterm superiority of warranty projects is more discernible when both cost and effectiveness are viewed over the entire life of the pavement treatment and when both agency and user costs (rather than agency costs only) are used in the analysis. 


\section{Implementation}

This report establishes that the practice of warranties in Indiana is generally more costeffective in the long run and could therefore be continued. Secondly, in presenting the results of the comparative evaluation on the basis of cost, effectiveness, and cost-effectiveness, this research report sets the stage upon which criteria for selection of warranty projects may be developed. Also, the study results, which involve standard indicators for pavement performance and established methods for treatment life estimation, may be used as a starting point for reviewing existing guidelines for assessing the performance of warranty projects. In addition, this research report provides an insight into agency and industry perspectives on the use of warranties in highway construction. Finally, responses to the questionnaire highlighted a number of warranty benefits and concerns shared by the agency personnel and the contractors. These include the perceived superior performance, lower levels of agency resources for testing and inspection, and reduced construction time for warranty pavements, complete contractor control of the entire construction process (resulting in more effective utilization of materials and equipment to produce a better quality product). The agency and contractor perspectives also helped identify possible threats to successful implementation of warranties. Such threats are related to issues such as the length of the warranty period (which is currently perceived by agency personnel as being too short but is seen by the contractors as being too long), and high initial agency costs. The perceived threats also include possible implications of diminished agency control over materials and processes, consequences of inadequate or inaccurate subsurface engineering studies or design, unforeseen site conditions, and decreased competition (due to possible inability of smaller firms to purchase requisite warranty bond). Such issues are relevant for a future overall review of the past practice of warranties in Indiana. Furthermore, it is important to consider such issues if the practice of warranties is to be continued and expanded.

Implementation assistance will be available from Purdue University by contacting the JTRP office or Dr. Bob McCullouch (bgm@ecn.purdue.edu, 765-494-0643).

\section{Contacts}

For more information:

\section{Dr. Bob G. McCullouch}

Principal Investigator

Purdue University School of Civil Engineering

West Lafayette IN 47907

Phone: (765) 494-0643

Fax: (765) 494-0644

E-mail: bgm@ecn.purdue.edu

Prof. Kumares C. Sinha

Co-Principal Investigator

Purdue University School of Civil Engineering

West Lafayette IN 47907

Phone: (765) 494-2211

Fax: (765) 496-7996

E-mail: sinha@ecn.purdue.edu

\section{Dr. Samuel Labi}

Research Engineer

Purdue University School of Civil Engineering

West Lafayette IN 47907

Phone: (765) 494-5926

Fax: (765) 496-7996

E-mail: labi@ecn.purdue.edu

\author{
Indiana Department of Transportation \\ Division of Research \\ 1205 Montgomery Street \\ P.O. Box 2279 \\ West Lafayette, IN 47906 \\ Phone: (765) 463-1521 \\ Fax: (765) 497-1665

\section{Purdue University} \\ Joint Transportation Research Program \\ School of Civil Engineering \\ West Lafayette, IN 47907-1284 \\ Phone: (765) 494-9310 \\ Fax: (765) 496-7996 \\ E-mail: jtrp@ecn.purdue.edu \\ http://www.purdue.edu/jtrp
}


TECHNICAL REPORT STANDARD TITLE PAGE

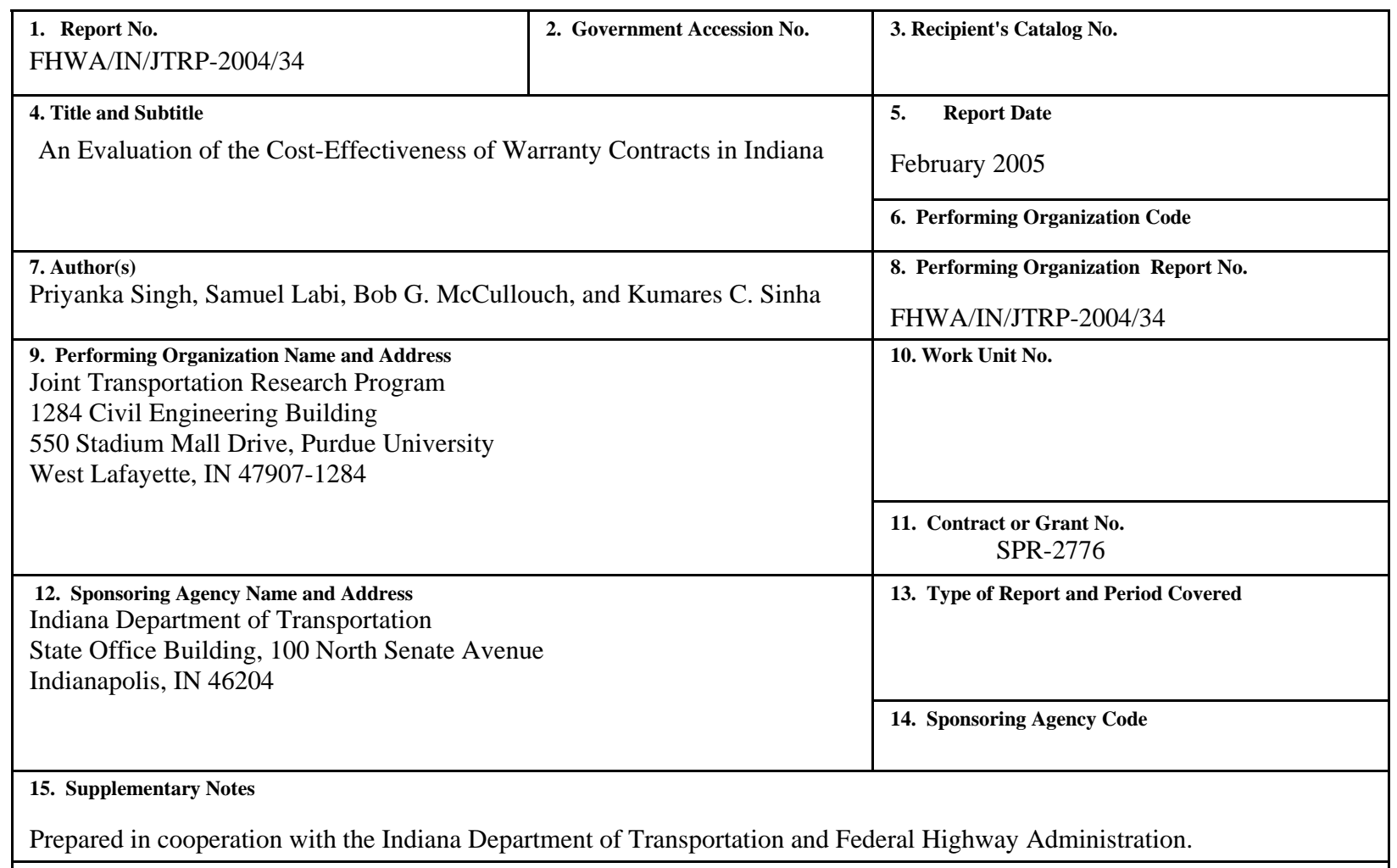

\section{Abstract}

In a bid to ensure cost-effective highway construction practices, highway agencies constantly seek ways to accelerate project design and delivery through implementation of innovative contracting and procurement practices. The concept of warranties, which is one of such promising practices, involves a shift of the burden of construction quality control, product performance and product maintenance from the owner to the contractor. As such, warranty projects are expected to enhance product quality and service life, and ultimately, reduced life-cycle cost. The expected benefits of warranty projects, however, could be offset by their historically higher construction costs. It is therefore necessary to evaluate the costs and benefits of warranty contracts vis-à-vis traditional contracts so that the more cost-effective practice can be identified. The present study reviewed the state of warranty practice in highway pavement construction in Indiana and elsewhere, collects data on warranty and traditional contracts, and carried out statistical analyses to evaluate the relative costs, effectiveness and cost-effectiveness of these two alternative contracting practices. Effectiveness was measured in terms of average pavement condition and pavement service life, and costs were expressed in annualized costs per lane-mile. All costs were adjusted for inflation and economy of scale. The study confirmed that the warranty contracts generally have higher agency costs than traditional contracts, but produced pavements that were superior to their traditional counterparts in terms in average pavement condition (rutting, cracking and roughness) and service life. It was determined that the typical projected treatment life of warranty contract pavement was 25 years while similar traditional contract pavements had a service life of 15 years. Also, the average construction period and resulting workzone user costs were lower for warranty contract pavements. The medium-term cost-effectiveness analysis showed that when the analysis is carried out over a relatively short period of 5-years (the typical warranty period), the warranty pavement contracts are not as cost-effective as their traditional counterparts. However, the long-term cost-effectiveness analysis (which used treatment service life as the analysis period) clearly indicated that the warranty contracts are generally more cost-effective than traditional contracts. The study results suggest that the superiority of warranty projects over traditional projects is more discernible when both cost and effectiveness are viewed over the entire life of the pavement treatment.

\begin{tabular}{|c|c|c|c|c|}
\hline \multicolumn{2}{|c|}{$\begin{array}{l}\text { 17. Key Words } \\
\text { Pavement Warranty, Cost-effectiveness, Contracting. }\end{array}$} & \multicolumn{3}{|c|}{$\begin{array}{l}\text { 18. Distribution Statement } \\
\text { No restrictions. This document is available to the } \\
\text { public through the National Technical Information } \\
\text { Service, Springfield, VA } 22161\end{array}$} \\
\hline 19. Security Classif. (of this report) & \multicolumn{2}{|c|}{ 20. Security Classif. (of this page) } & 21. No. of Page & 22. Price \\
\hline Unclassified & \multicolumn{2}{|c|}{ Unclassified } & 179 & \\
\hline
\end{tabular}

Form DOT F 1700.7 (8-69) 


\section{ACKNOWLEDGMENTS}

The authors hereby acknowledge the contributions and constant support provided by all study advisory committee members including Dave Andrewski of INDOT Materials and Tests Division, Samy Noureldin and Dave Ward of INDOT Research Division, and Victor Gallivan of the FHWA. Also, the authors recognize the support given by William Flora and Mike Yamin, pavement management engineers of INDOT Program Development Division, Shuo Li of INDOT Research Division, Dennis Kuchler of INDOT Operations Support Division. The overall support provided by Barry Partridge, Chief of INDOT’s Research Division is very much appreciated, and we are also grateful to the JTRP coordinator, Karen Hatke, for her role. 


\section{TABLE OF CONTENTS}

Page

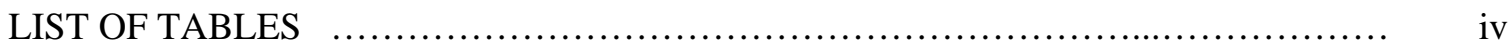

LIST OF FIGURES .............................................................. vii

\section{CHAPTER 1 INTRODUCTION}

1.1 Background and Problem Statement........................................ 1

1.2 Current Status of Warranty Projects in Indiana................................ 6

1.3 Objectives of the Present Study ........................................... 8

1.4 Scope of the Study ........................................................... 9

1.5 Overview of Study Approach.......................................... 10

1.6 Organization of this Report.............................................. 12

\section{CHAPTER 2 LITERATURE REVIEW}

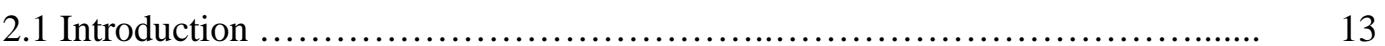

2.2 Definitions and Issues ................................................... 14

2.3 Historical Background and Legislative Impetus............................ 17

2.4 Warranty Contracting in the United States................................... 18

2.5 Warranty Contracting in Europe.......................................... 26

2.6 Sureties for Warranty Contracts ................................................. 31

2.7 Advantages of Warranties ........................................................... 31

2.8 Concerns of About the Use of Warranties ........................................... 32

2.9 Chapter Summary ............................................................... 33

\section{CHAPTER 3 STUDY METHODOLOGY}

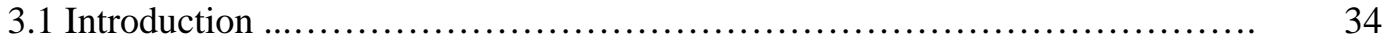

3.2 Identification of Warranty Contracts ...................................... 35

3.3 Methodology for Estimation of Costs ................................... 36

3.4 Methodology for Estimation of Effectiveness.............................. 45

3.4.1 Temporal Scope of Effectiveness Evaluation..................... 45 
Page

3.4.2 Performance Indicators for Assessment of Effectiveness............. 46

3.5 Methodology for Evaluation of Cost Effectiveness......................... 50

3.5.1 Medium-Term (5-year) Evaluation............................ 50

3.5.2 Long-Term (Treatment Life-Cycle) Evaluation.................... 53

3.6 Methodology for Evaluation of Average Pavement Condition................. 56

3.7 Chapter Summary ..................................................... 59

\section{CHAPTER 4 DATA COLLECTION AND COLLATION}

4.1 Introduction ........................................................... 60

4.2 Description of Data ................................................. 60

4.3 Chapter Summary ................................................... 65

\section{CHAPTER 5 RESULTS OF THE ANALYSIS}

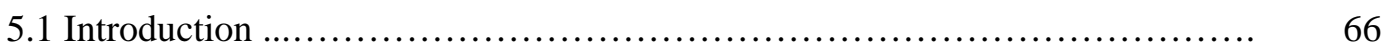

5.2 Comparison Set 1 (Warranty Project: R-22232 and Control Project R-21607) 67

5.2.1 General Contract Information for Comparison Set 1 ............. 67

5.2.2 Performance Analysis for Comparison Set 1 ................... 67

5.2.3 Evaluation of Cost Effectiveness for Comparison Set 1 ........... 76

5.3 Comparison Set 2 (Warranty Project: R-22854 and Control Project R-21602) 86

5.3.1 General Contract Information for Comparison Set 2 .............. 86

5.3.2 Performance Analysis for Comparison Set 2 ................... 87

5.3.3 Evaluation of Cost Effectiveness for Comparison Set 2 ........... 95

5.3.4 Summary of the Analysis Results for Comparison Set 2 .......... 97

5.4 Comparison Set 3 (Warranty Project: R-22925 and Control Project R-22912) 104

5.4.1 General Contract Information for Comparison Set 3 .............. 104

5.4.2 Performance Analysis for Comparison Set 3 ................... 105

5.4.3 Evaluation of Cost Effectiveness for Comparison Set 3 ........... 112

5.4.4 Summary of the Analysis Results for Comparison Set 3 ........... 121

5.5 Comparison Set 4 (Warranty Project: R-23390 and Control Project R-21607) 122

5.5.1 General Contract Information for Comparison Set 4 ............. 122

5.5.2 Performance Analysis for Comparison Set 4 ................... 122

5.5.3 Evaluation of Cost Effectiveness for Comparison Set 4 ........... 130 
5.5.4 Summary of the Analysis Results for Comparison Set 4 .......... 137

5.6 Comparison Set 5 (Warranty Project: R-23898 and Control Project R-22923) 139

5.6.1 General Contract Information for Comparison Set 5 .............. 139

5.6.2 Performance Analysis for Comparison Set 5 .................... 140

5.6.3 Evaluation of Cost Effectiveness for Comparison Set 5 ........... 147

5.6.4 Summary of the Analysis Results for Comparison Set 5.... 154

5.7 Chapter Summary ...................................................................... 157

\section{CHAPTER 6 AGENCY AND CONTRACTOR SURVEY}

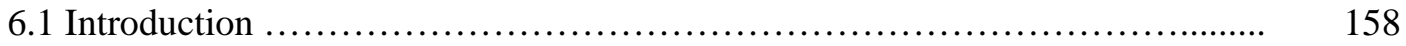

6.2 INDOT Personnel Survey.............................................. 158

6.3 Results of the Contractor Survey...................................... 162

6.4 Chapter Summary .................................................................. 164

\section{CHAPTER 7 SUMMARY, CONCLUSIONS AND RECOMMENDATIONS}

7.1 Summary of the Methodology ........................................ 165

7.2 Summary of Results for Each Comparison Pair .......................... 166

7.3 Summary for All Comparison Sets and Discussion ....................... 168

7.4 Results of the Questionnaire Survey ................................. $\quad 170$

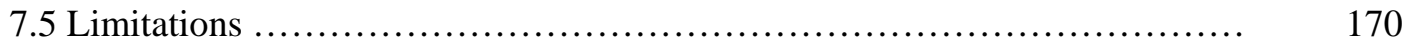

7.6 Implementation Issues and Recommendations for Future Work ............. 171

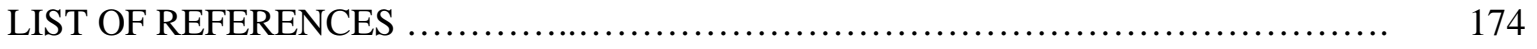

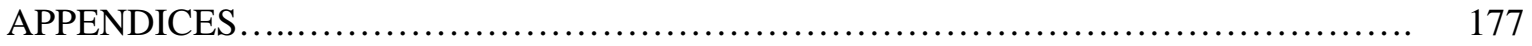




\section{LIST OF TABLES}

Table

Page

Table 2.1: Differences between Warranty and Traditional Contracts.................... 16

Table 2.2: Typical Cost Items in Traditional and Warranty Contracts.................... 17

Table 3.1: $\quad$ Warranty Contracts used in Analysis ...................................... 35

Table 3.2: $\quad$ AAMEX Model for Overlay Pavements ....................................................... 37

Table 3.3: $\quad$ Value of Time ..........................................................................................

Table 3.4: Temporal Scope of Effectiveness Evaluation................................................... 46

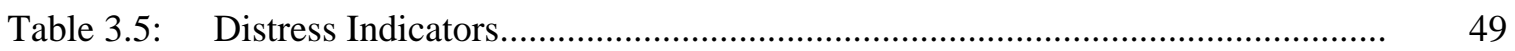

Table 4.1: Data Types and Sources for Warranty and Control Projects............................ 61

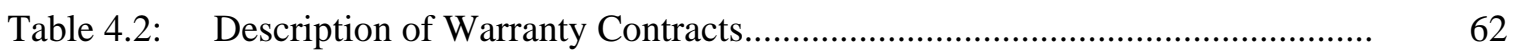

Table 4.3: $\quad$ Cost of Warranty Projects (Current Dollar for year of letting)......................... 62

Table 4.4: Comparison Sets of Warranty and Traditional Projects...................... 63

Table 5.1: Characteristics of Projects Constituting Comparison Set 1.................... 67

Table 5.2: $\quad$ IRI of Constituent Pavements in Comparison Set 1.......................... 68

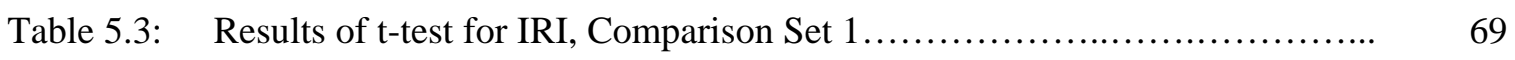

Table 5.4: Annual Pavement Condition (PSI), Comparison Set 1..................... 70

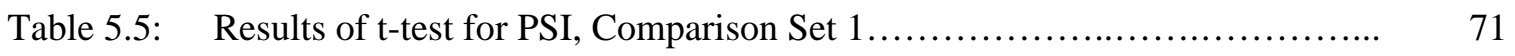

Table 5.6: Rut Depth of Constituent Pavements, Comparison Set $1 \ldots \ldots \ldots \ldots \ldots \ldots \ldots \ldots \ldots \ldots \ldots$

Table 5.7: $\quad$ Results of t-test for Rutting Depth of Comparison 1....................... 73

Table 5.8: $\quad$ PCR of Constituent Pavements, Comparison Set 1....................... 74

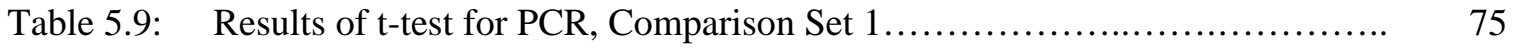

Table 5.10: Medium-Term Agency Costs, Comparison Set 1......................... 76

Table 5.11: Medium-Term User Costs, Comparison Set 1.......................... 77

Table 5.12: Medium-Term Cost-Effectiveness Evaluation, Comparison Set 1............ 82

Table 5.13: Long-Term Agency Costs of Constituent Pavements, Comparison Set 1..... 84

Table 5.14: Long-Term User Costs of Constituent Pavements of Comparison Set 1...... 84

Table 5.15: Long-Term Cost Effectiveness of Constituent Pavements, Comparison Set $1 \quad 84$

Table 5.16: Characteristics of Projects Constituting Comparison Set 2 $\ldots \ldots \ldots \ldots \ldots \ldots \ldots \ldots \ldots$

Table 5.17: IRI of Constituent Pavements, Comparison Set 2 ......................... 87

Table 5.18: Results of t-test for IRI, Comparison Set $2 \ldots \ldots \ldots \ldots \ldots \ldots \ldots \ldots \ldots \ldots \ldots \ldots \ldots \ldots \ldots \ldots$ 
Table 5.19: $\quad$ Annual Pavement Condition (PSI), Comparison Set 2...................... 89

Table 5.20: Results of t-test for PSI of Comparison Set 2........................... 90

Table 5.21: Rut Depth of Constituent Pavements, Comparison Set 2.................... 91

Table 5.22: Results of t-test for Rutting Depth, Comparison Set 2...................... 92

Table 5.23: PCR of Constituent Pavements, Comparison Set 2 ........................ 93

Table 5.24: Results of t-test for PCR, Comparison Set 2............................ 94

Table 5.25: Medium-Term Agency Costs, Comparison Set 2......................... 95

Table 5.26: Medium-Term User Costs, Comparison Set 2............................. 96

Table 5.27: Medium-Term Cost-Effectiveness Evaluation, Comparison Set 2............ 100

Table 5.28: Long-Term Agency Costs, Comparison Set 2........................... 102

Table 5.29: Long -Term User Costs, Comparison Set 2............................ 102

Table 5.30: Long-Term Cost-Effectiveness Evaluation, Comparison Set 2............... 103

Table 5.31: Characteristics of Projects Constituting Comparison Set 3.................. 104

Table 5.32: IRI of Constituent Pavements, Comparison Set 3.......................... 105

Table 5.33: Results of t-test for IRI, Comparison Set 3........................... 106

Table 5.34: PSI of Constituent Pavements, Comparison Set 3........................ 107

Table 5.35: Results of t-test for PSI, Comparison Set 3............................ 108

Table 5.36: Rut Depth of Constituent Pavements in Comparison Set 3.................. 108

Table 5.37: Results of t-test for Rutting Depth of Comparison Set 3.................... 110

Table 5.38: PCR of Constituent Pavements, Comparison Set 3........................ 110

Table 5.39: Results of t-test for PCR, Comparison Set 3.............................. 111

Table 5.40: Medium-Term Agency Costs, Comparison Set 3.......................... 112

Table 5.41: Medium-Term User Costs, Comparison Set 3............................ 113

Table 5.42: Medium-Term Cost-Effectiveness Evaluation, Comparison Set 3............ 118

Table 5.43: Long-Term Agency Costs, Comparison Set 3............................. 119

Table 5.44: Long -Term User Costs, Comparison Set 3............................. 120

Table 5.45: Long-Term Cost-Effectiveness Evaluation, Comparison Set 3............... 120

Table 5.46: Characteristics of Projects Constituting Comparison Set 4.................... 122

Table 5.47: IRI of Constituent Pavements, Comparison Set 4.......................... 123 
Table

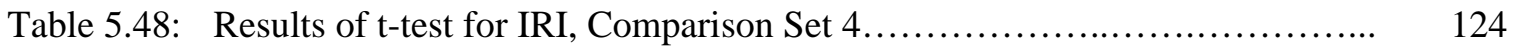

Table 5.49: $\quad$ PSI of Constituent Pavements in Comparison Set 4........................ 124

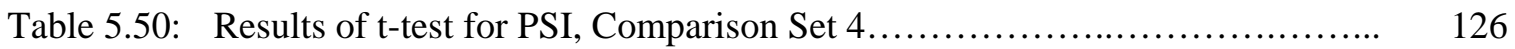

Table 5.51: Rut Depth of Constituent Pavements in Comparison Set 4.................. 126

Table 5.52: Results of t-test for Rutting Depth of Comparison Set 4.................... 128

Table 5.53: $\quad$ PCR of Constituent Pavements, Comparison Set 4........................ 128

Table 5.54: Results of t-test for PCR, Comparison Set 4............................. 130

Table 5.55: Medium-Term Agency Costs, Comparison Set 4........................ 131

Table 5.56: Medium-Term User Costs, Comparison Set 4.............................. 132

Table 5.57: Medium-Term Cost-Effectiveness Evaluation, Comparison Set 4............ 136

Table 5.58: Long-Term Agency Costs, Comparison Set 4............................ 137

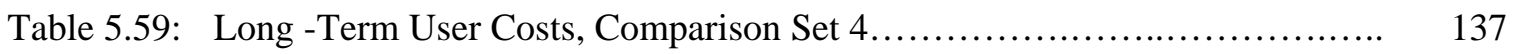

Table 5.60: Long-Term Cost-Effectiveness Evaluation, Comparison Set 4............... 138

Table 5.61: Characteristics of Projects Constituting Comparison Set 5.................... 139

Table 5.62: IRI of Constituent Pavements, Comparison Set 5......................... 140

Table 5.63: Results of t-test for IRI, Comparison Set 5........................... 141

Table 5.64: PSI of Constituent Pavements, Comparison Set 5....................... 142

Table 5.65: Results of t-test for PSI, Comparison Set 5............................ 143

Table 5.66: Rut Depth of Constituent Pavements in Comparison Set 5.................. 143

Table 5.67: Results of t-test for Rutting Depth of Comparison Set 5................... 145

Table 5.68: PCR of Constituent Pavements, Comparison Set 5........................ 145

Table 5.69: Results of t-test for PCR, Comparison Set 5........................... 147

Table 5.70: Medium-Term Agency Costs, Comparison Set 5........................ 148

Table 5.71: Medium-Term User Costs, Comparison Set 5........................... 148

Table 5.72: Medium-Term Cost-Effectiveness Evaluation, Comparison Set 5............ 153

Table 5.73: Long-Term Agency Costs, Comparison Set 5........................... 154

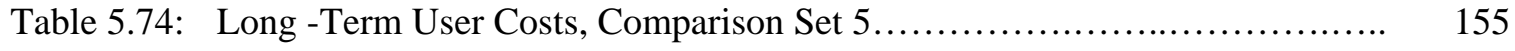

Table 5.75: Long-Term Cost-Effectiveness Evaluation, Comparison Set 5............... 155

Table 7.1: $\quad$ Summary of Medium-Term Cost-effectiveness Evaluation ................... 169

Table 7.2: $\quad$ Summary of Long-Term Cost-effectiveness Evaluation ................. 169 


\section{LIST OF FIGURES}

Figure

Page

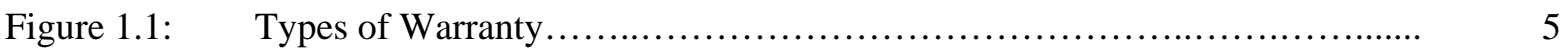

Figure 1.2: $\quad$ Study Framework ..................................................... 11

Figure 3.1: $\quad$ Common Mathematical Forms of Unit Cost Functions Illustrating Economy 39

Figure 3.2: $\quad$ Illustration of Unit Costs Relationships among Projects of Small, Large, and 40

Figure 3.3: Unit Cost Adjustment to Reflect Economy of Scale Effects where Given Unit Cost Does not Lie on Established Unit Cost Function.................

Figure 3.4: $\quad$ Possible Locations of Contract with Respect to Unit Cost Function and

Figure 3.5: Conceptual Area under the IRI vs. Age Curve for Medium-Term Evaluation. 51

Figure 3.6: Conceptual Area under the PQI vs. Age Curve for Medium-Term Evaluation 52

Figure 3.7: $\quad$ Alternate Models for Warranty Pavement Performance Trends ............... $\quad 54$

Figure 3.8: $\quad$ Alternative Models for Traditional Pavement Performance Trends ............ 54

Figure 3.9: $\quad$ Estimated Service Lives of Warranted and Traditional Pavements ............. 55

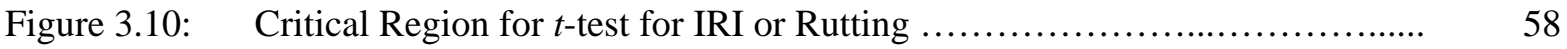

Figure 3.11: $\quad$ Critical Region for $t$-test for PSI or PCR …............................ 59

Figure 5.1: $\quad$ IRI Trends of Warranty and Control Pavements, Comparison Set 1.......... 68

Figure 5.2: Comparison of Load-based Deterioration (IRI) Curves, Comparison Set 1... 69

Figure 5.3: $\quad$ PSI Trends of Warranty and Control Pavements, Comparison Set $1 \ldots \ldots \ldots \ldots . \quad 70$

Figure 5.4: $\quad$ Comparison of Load-based Deterioration (PSI) Curves, Comparison Set 1.... 71

Figure 5.5: $\quad$ Rutting Trends of Warranty and Control Pavements, Comparison Set 1..... 73

Figure 5.6: $\quad$ Comparison of Load-based Deterioration (Rut) Curves, Comparison Set 1.... 73

Figure 5.7: $\quad$ PCR Trends of Warranty and Control Pavements, Comparison Set 1........ $\quad 74$

Figure 5.8: $\quad$ Comparison of Load-based Deterioration (PCR) Curves, Comparison Set 1.. 75

Figure 5.9: $\quad$ Area under IRI-Age Curve of Warranty Pavement, Comparison Set 1......... 78

Figure 5.10: $\quad$ Area under IRI-Age Curve of Control Pavement, Comparison Set 1............ 78

Figure 5.11: $\quad$ Area under IRI-ESAL Curve of Warranty Pavement, Comparison Set 1.... $\quad 78$ 
Figure Page

Figure 5.12: Area under IRI-ESAL Curve of Control Pavement, Comparison Set 1........ 79

Figure 5.13: Area under PQI-Age Curve of Warranty Pavement in Comparison Set 1.... 80

Figure 5.14: Area under PQI-Age Curve of Control Pavement, Comparison Set 1.......... 80

Figure 5.15: Area under PQI-ESAL Curve of Warranty Pavement, Comparison Set 1.... 81

Figure 5.16: Area under PQI-ESAL Curve of Control Pavement, Comparison Set 1........ 81

Figure 5.17: Time-Based Medium-Term Cost-Effectiveness, Comparison Set 1......... 82

Figure 5.18: Load-Based Medium-Term Cost-Effectiveness, Comparison Set 1......... 83

Figure 5.19: Treatment Life-based Long-Term Cost-Effectiveness, Comparison Set 1... 85

Figure 5.20: Time-Based Long-Term Cost-Effectiveness, Comparison Set 1............ 85

Figure 5.21: IRI Trends of Warranty and Control Pavements, Comparison Set 2............ 87

Figure 5.22: Comparison of Load-based Deterioration (IRI) Curves, Comparison Set 2... 88

Figure 5.23: PSI Trends of Warranty and Control Pavements, Comparison Set 2........... 89

Figure 5.24: Comparison of Load-based Deterioration (PSI) Curves, Comparison Set 2... 90

Figure 5.25: Rutting Trends of Warranty and Control Pavements, Comparison Set 2..... 91

Figure 5.26: Comparison of Load-based Deterioration (Rut) Curves, Comparison Set 2.. 92

Figure 5.27: PCR Trends of Warranty and Control Pavements, Comparison Set 2......... 93

Figure 5.28: Comparison of Load-based Deterioration (PCR) Curves, Comparison Set 2.. 94

Figure 5.29: Area under IRI-Age Curve of Warranty Pavement, Comparison Set 2......... 96

Figure 5.30: Area under IRI-Age Curve of Control Pavement, Comparison Set 2............ 97

Figure 5.31: Area under IRI-ESAL Curve of Warranty Pavement, Comparison Set 2...... 97

Figure 5.32: Area under IRI-ESAL Curve of Control Pavement, Comparison Set 2....... 98

Figure 5.33: Area under PQI-Age Curve of Warranty Pavement in Comparison Set 2..... 98

Figure 5.34: Area under PQI-Age Curve of Control Pavement, Comparison Set 2.......... 99

Figure 5.35: Area under PQI-ESAL Curve of Warranty Pavement, Comparison Set 2..... 99

Figure 5.36: Area under PQI-ESAL Curve of Control Pavement, Comparison Set 2........ 100

Figure 5.37: Time-Based Medium-Term Cost-Effectiveness, Comparison Set 2.......... 101

Figure 5.38: Load-Based Medium-Term Cost-Effectiveness, Comparison Set 2.......... 101

Figure 5.39: Treatment Life-based Long-Term Cost-Effectiveness, Comparison Set 2... 103

Figure 5.40: Time-based Long-Term Cost-Effectiveness, Comparison Set 2............ 103

Figure 5.41: IRI Trends of Warranty and Control Pavements, Comparison Set 3............. 105

Figure 5.42: Comparison of Load-based Deterioration (IRI) Curves, Comparison Set 3... 106

Figure 5.43: PSI Trends of Warranty and Control Pavements, Comparison Set 3........... 107 
Figure Page

Figure 5.44 Comparison of Load-based Deterioration (PSI), Comparison Set $3 \quad 107$

Figure 5.45: Rutting Trends of Warranty and Control Pavements, Comparison Set 3..... 109

Figure 5.46: Comparison of Load-based Deterioration (Rut) Curves, Comparison Set 3.. 109

Figure 5.47: PCR Trends of Warranty and Control Pavements, Comparison Set 3.......... 111

Figure 5.48: Comparison of Load-based Deterioration (PCR) Curves, Comparison Set 3.. 111

Figure 5.49: Area under IRI-Age curves of Warranty Pavement, Comparison Set 3.......... 114

Figure 5.50: Area under IRI-Age curves of Control Pavement, Comparison Set 3............ 114

Figure 5.51: Area under IRI-ESAL curve of Warranty Pavement, Comparison Set 3........ 115

Figure 5.52: Area under IRI-ESAL curve of Control Pavement, Comparison Set 3......... 115

Figure 5.53: Area under PQI-Age curve of Warranty Pavement in Comparison Set 3...... 116

Figure 5.54: Area under PQI-Age curve of Control Pavement, Comparison Set 3............ 116

Figure 5.55: Area under PQI-ESAL curve of Warranty Pavement, Comparison Set 3...... 117

Figure 5.56: Area under PQI-ESAL curve of Control Pavement, Comparison Set 3......... 117

Figure 5.57: Time-Based Medium-Term Cost-Effectiveness, Comparison Set 3........... 118

Figure 5.58: Load-Based Medium-Term Cost-Effectiveness, Comparison Set 3........... 119

Figure 5.59: Treatment Life-based Long-Term Cost-Effectiveness, Comparison Set 3.... 120

Figure 5.60: Time-based Long-Term Cost-Effectiveness, Comparison Set 3............. 121

Figure 5.61: IRI Trends of Warranty and Control Pavements, Comparison Set 4............ 123

Figure 5.62: Comparison of Load-based Deterioration (IRI) Curves, Comparison Set 4... 123

Figure 5.63: PSI Trends of Warranty and Control Pavements, Comparison Set 4........... 125

Figure 5.64: Comparison of Load-based Deterioration (PSI) Curves, Comparison Set 4... 125

Figure 5.65: Rutting Trends of Warranty and Control Pavements, Comparison Set 4...... 127

Figure 5.66: Comparison of Load-based Deterioration (Rut) Curves, Comparison Set 4.. 127

Figure 5.67: PCR Trends of Warranty and Control Pavements, Comparison Set 4.......... 129

Figure 5.68: Comparison of Load-based Deterioration (PCR) Curves, Comparison Set 4.. 129

Figure 5.69: Area under IRI-Age curve of Warranty Pavement, Comparison Set 4.......... 132

Figure 5.70: Area under IRI-Age curves of Control Pavement, Comparison Set 4............ 132

Figure 5.71: Area under IRI-ESAL curve of Warranty Pavement, Comparison Set 4........ 133

Figure 5.72: Area under IRI-ESAL curve of Control Pavement, Comparison Set 4......... 134

Figure 5.73: Area under PQI-Age curve of Warranty Pavement in Comparison Set 4...... 134

Figure 5.74: Area under PQI-Age curve of Control Pavement, Comparison Set 4............ 134

Figure 5.75: Area under PQI-ESAL curve of Warranty Pavement, Comparison Set 4...... 135 
Figure

Figure 5.76: $\quad$ Area under PQI-ESAL curve of Control Pavement, Comparison Set 4......... 135

Figure 5.77: Time-Based Medium-Term Cost-Effectiveness, Comparison Set 4.......... 136

Figure 5.78: $\quad$ Load-Based Medium-Term Cost-Effectiveness, Comparison Set 4.......... 136

Figure 5.79: $\quad$ Treatment Life-based Long-Term Cost-Effectiveness, Comparison Set 4... 138

Figure 5.80: $\quad$ Time-based Long-Term Cost-Effectiveness, Comparison Set 4............ 138

Figure 5.81: $\quad$ IRI Trends of Warranty and Control Pavements, Comparison Set 5............ $\quad 140$

Figure 5.82: Comparison of Load-based Deterioration (IRI) Curves, Comparison Set 5.... 141

Figure 5.83: $\quad$ PSI Trends of Warranty and Control Pavements, Comparison Set 5........... 142

Figure 5.84: Comparison of Load-based Deterioration (PSI) Curves, Comparison Set 5... 142

Figure 5.85: $\quad$ Rutting Trends of Warranty and Control Pavements, Comparison Set 5..... 144

Figure 5.86: Comparison of Load-based Deterioration (Rut) Curves, Comparison Set 5.. 144

Figure 5.87: $\quad$ PCR Trends of Warranty and Control Pavements, Comparison Set 5......... 146

Figure 5.88: Comparison of Load-based Deterioration (PCR) Curves, Comparison Set 5.. 146

Figure 5.89: Area under IRI-Age curve of Warranty Pavement, Comparison Set 5......... 149

Figure 5.90: $\quad$ Area under IRI-Age curve of Control Pavement in Comparison Set 5......... 149

Figure 5.91: $\quad$ Area under IRI-ESAL curve of Warranty Pavement, Comparison Set 5....... 150

Figure 5.92: $\quad$ Area under IRI-ESAL curve of Control Pavement, Comparison Set 5......... 150

Figure 5.93: Area under PQI-Age curve of Warranty Pavement in Comparison Set 5...... 151

Figure 5.94: Area under PQI-Age curve of Control Pavement, Comparison Set 5........... 151

Figure 5.95: Area under PQI-ESAL curve of Warranty Pavement in Comparison Set 5... 152

Figure 5.96: Area under PQI-ESAL curve of Control Pavement in Comparison Set 5...... 152

Figure 5.97: Time-Based Medium-Term Cost-Effectiveness, Comparison Set 5.......... 153

Figure 5.98: Load-Based Medium-Term Cost-Effectiveness, Comparison Set 5.......... 154

Figure 5.99: Treatment Life-based Long-Term Cost-Effectiveness, Comparison Set 5... 156

Figure 5.100 Time-based Long-Term Cost-Effectiveness, Comparison Set 5........... 156 


\section{GLOSSARY OF TERMS}

Performance Indicator This is used to assess the performance or physical condition of the pavement. Examples include the International Roughness Index, Pavement Quality Index, Present Serviceability Index, Rut Depth, and Pavement Condition Index.

Effectiveness

This is measured in terms of the average pavement condition in the years following treatment (expressed in terms of performance indicators), treatment life (in years or accumulated traffic loading) or area bounded by the pavement performance curve (which incorporates both pavement condition and treatment life).

Agency Cost The cost incurred by INDOT in constructing and maintaining a facility. Initial construction costs are generally available at INDOT databases. Historical maintenance cost data for all pavements may not be available but can be estimated using appropriate models.

User Cost

The cost incurred to the users during facility construction (workzones) or during the use of the facility. In the present study, only the workzone user costs are considered as the normal operation user costs are considered to be negligible for young pavements.

Cost Effectiveness This is the ratio of the benefit (effectiveness) of a treatment to its cost. Given that benefits and costs can be expressed in various alternative ways as described above, there are several ways by which cost-effectiveness can be estimated.

Economy of Scale A reduction in unit costs brought about especially by increased dimensions of production facilities. Higher unit cost of a warranty project, for example, could be due to its shorter contract length compared to the corresponding traditional contract, and not necessarily due to its inherent characteristics. In comparing two pavement projects of different lengths, economy of scale bias needs to be corrected by considering a standard length to which both projects are assumed to be constructed.

Medium Term

For purposes of the present study, "medium term" is defined as the length of the warranty period (currently 5 years for pavement projects in Indiana).

Long Term

For purposes of the present study, "long term" is defined as the length of treatment service life. Due to differences in treatment service lives of warranty and traditional pavements, their comparative evaluation should be carried out using the equivalent annualized values.

Control Contract

This is the same as the non-warranty contract or project which involved the use of the traditional bidding and contracting system. 


\section{CHAPTER 1 INTRODUCTION}

\subsection{Background and Problem Statement}

Highway agencies at all levels of government are charged with the responsibility of effectively managing available resources for reconstruction and rehabilitation of highway facilities such as pavements, bridges, traffic infrastructure, and erosion control systems. With increasing commercial and personal travel demand vis-à-vis uncertainty of resources, this task is more critical than ever before. Resources expended on the construction, rehabilitation and maintenance of highway facilities account for a large portion of state and local transportation agency budgets. Every year, the state of Indiana incurs several hundred millions of dollars in capital works and maintenance for state highway facilities [FHWA, 1993-1999]. At this rate, it is not certain that the state will be able to sustain adequate funding of pavement construction to ensure acceptable levels of service on its entire network. Also, the recent issuance of Government Accounting Standards Board Statement 34 (GASB34) established new financial reporting requirements for state and local governments to ensure safekeeping and appropriate use of public resources and operational accountability [GASB, 1999]. Due to such trends and developments, most states continually seek to identify and implement any measures aimed at increasing the cost-effectiveness of highway facility construction and rehabilitation activities so that maximum benefit can be obtained from each dollar expended on such activities. State and local highway agencies are continually exploring and experimenting new techniques to enhance timeliness and quality of project design and delivery, and are also implementing innovative contracting and procurement practices to keep abreast with the demand for quality transportation facilities. As part of such efforts, there is currently a strong nationwide interest in alternative contracting practices in the construction industry. An example of such efforts is renewed interest in the concept of highway construction warranties. 
Traditional construction practices for highways have been characterized by design-bid-build contracts. Under this approach, projects are awarded to the best pre-qualified bidder who meets established criteria of responsibility with the lowest total price. The total cost is based on unit prices of pay items corresponding to various work types. The project specifications are strictly laid down by the owner or owner's agent, and the contractor has to comply accordingly. Such type of contracts are supported by Title 23, United States Code (USC), Section 112 and Title 23 CFR 635 under which a transportation agency is required to award construction projects based on a free, open, and competitive bidding process [FHWA, 1995]. However, agencies are granted flexibility to adopt other alternate bidding processes if they can demonstrate that such alternate processes are more cost-effective. The contractor is required to complete the project in accordance with the plans and specifications, and is not responsible for the performance of the product after an initial "defects liability period". The quality of each constructed item is evaluated by comparing with a standard specified by the owner. The owner is required to undertake extensive inspection of the finished product. Most of the nation's highways were built using the traditional design-bid-build process in an attempt to deliver physical transportation infrastructure at the lowest possible price.

There are several problems associated with the traditional process. It is slow and often causes construction delays and inconvenience to the traveling public. Furthermore, there is little opportunity for contractor input and innovation in the design and construction procedure. Also, highway agencies continually face staff reductions and loss of skilled manpower to supervise traditional construction projects. Warranty projects can possibly eliminate many of these problems. The inception of construction warranty practice in the United States can be traced to the turn of the century (1890's to 1920's) with the use of patented HMA. At that time, the warranty covered material and workmanship and lasted over a period of 10-15 years. An example was the "Warrenite bitulithic" pavement material that was patented by Warren Brothers in 1903. By the 1920's, the period 
of patent protection for most of such projects had expired and the practice of pavement warranties was consequently discontinued. The use of warranties in recent times started with the implementation of FHWA's Special Experimental Project (SEP) No. 14 - Innovative Contracting Practices, in 1990. Initially, the use of warranties was restricted on Federal-aid projects to electrical and mechanical equipment under the regulation 23 CFR 635.413 [FHWA, 1995]. The rationale behind this regulation was to prevent the diversion of Federal-aid funds for routine maintenance work which is prohibited by law. The restriction was made flexible by the Intermodal Surface Transportation Efficiency Act of 1991 (ISTEA) which permits a state to exempt itself for projects that are off the National Highway System (NHS). Under these conditions, warranty clauses may be used in contracts in accordance with state procedures. Further development expansion of the use of warranties on Federal-aid highway construction projects. Under the NHS act, states were allowed to include warranty clauses in Federalaid NHS contracts with prior approval of the FHWA Division Administrator [AASHTO, 2001]. Since then, many contracts with warranty clauses have been let out by many state highway agencies. The concept of construction warranties is getting such increased attention among highway agencies because of its demonstrated potential to reduce the amount of agency resources required for a highway project, reallocation of performance risk from agency to contractor, and improvement in the quality of the constructed projects at places where warranties have been implemented, such as Europe [FHWA, 2002].

A warranty is an assurance for the integrity of the product such that the product will serve its useful life and that if there is any deficiency the contractor will undertake remedial action. Analogies can be drawn in the area of retailing, where suppliers of goods strive to provide quality products with guarantee certificates or return policies in order to ensure consumer satisfaction. The goods are packaged with a warranty/guarantee for a certain period of time during which the product may be returned to the retailer if found unsatisfactory. Warranty contracts are based on such concept of guaranteeing product quality based on prescribed 
performance levels over the predetermined warranty period. The contractor is required to provide maintenance for the product after it has been delivered. This may lead to potential savings in maintenance for the state agency as contractors are made to assume greater responsibility for their work, and are liable for any deficiencies resulting from inferior quality materials or poor workmanship thereof. Also, warranty contracts typically foster increased contractor innovation and ultimately reduce overall life-cycle costs of pavement construction, rehabilitation, and maintenance. The successful use of warranties in other countries, particularly in Europe, has prompted renewed interest in warranty construction practices in the United States.

The major advantage of warranty contracts is that they are compatible with the traditional method. A warranty clause can be added in the traditional bidding documents. The contractor is responsible for the performance of the product and required to perform all the necessary tests for materials and workmanship. As a result, the use of warranties can substantially reduce the number of agency personnel required for inspection and testing of the product. Under warranty contracts, there can be an increase in the quality of the end product because threshold levels are established by both agency and the contractor. The contractor is responsible for repairing or replacing any work that does not meet the requirements. The contractor has the freedom to select appropriate materials and construction techniques without being encumbered by specification restrictions by the client and is encouraged to use innovative practices. Innovation from contractors may improve product quality and reduce life-cycle cost.

The requirement for contractors to provide warranty for their work is not an entirely new concept. Many agencies, even under the traditional bidding process, require a one-year performance bond covering materials and workmanship. However, longer periods ( 5 years or more) for warranty items have not been common. The use of warranty provisions in highway contracting is often associated with higher bid amounts compared to traditional projects of similar 
type and scale. As such, it has been argued that with warranty contracts, agencies are expected to pay more for the same high quality of work that is anyway expected even under the traditional system. However, it is hypothesized that warranty contracts will lead to considerable overall savings in life-cycle costs resulting from higher quality pavements.

Warranties may be of different types based on the warranty items (coverage) and the warranty period, as illustrated in Figure 1-1 [Aschenbrener and DeDios, 2001].

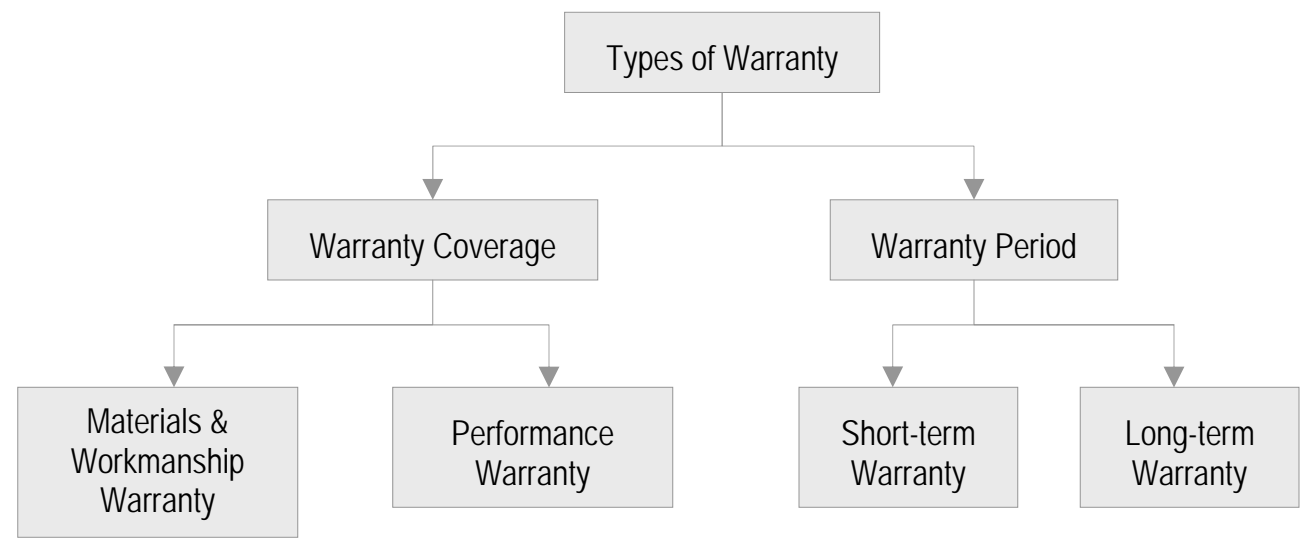

Figure 1-1 Types of Warranty

Materials and Workmanship Warranties: Under these types of warranties, the contractor is responsible correcting defects arising from poor workmanship. Additional responsibilities for quality control of materials are shifted from the owner to the contractor. The pavement design is the responsibility of the owner. Materials and workmanship warranty provisions are only short-term; it is only during the construction phase that the contractors are liable for the work they undertake. There are several agencies that currently let out contracts with only workmanship warranties.

Performance Warranties: These are typically long-term warranties under which the contractor assumes full responsibility of pavement performance during the 
warranty period. Thresholds for performance in terms of distress parameters are established by the owner, and the contractor is required to remedy any defects if the thresholds are not met. Performance warranties generally cover a period of at least five years after the construction of the facility.

Within the realm of the above warranty types, there may also be other warranty provisions. For instance, in the Prepaid Maintenance Warranty, the owner is responsible for the design, materials and workmanship of the pavement work, and the contractor is required to follow all the specifications and to provide a guarantee of pavement quality up to a certain specified period.

At the current time, there is considerable optimism regarding the practice of warranty contracts. However, the industry is approaching such practice with great deal of caution and debate [ODOT, 1999]. Relatively little work on the assessment of cost-effectiveness of construction warranty projects has been carried out with field data. Warranty projects are generally more expensive than traditional projects in terms of initial agency construction costs. In investigating the benefits of warranty projects, increased project cost has to be weighed vis-àvis increased pavement quality and longevity. As states are increasingly implementing warranty contracts, a number of challenges are also being identified: First, there is concern that the states may lose valuable in-house expertise as they reduce their involvement in project construction in terms of staff and testing activities [ODOT, 2000]. Another issue is the required level of testing that should be included in warranty contract clauses to ensure long-term performance, as most warranties provide for premature failure only. There is also some apprehension among surety companies in providing long term bonds for large projects. Ultimately, there is a need to evaluate whether warranties will lead to overall improvement in the quality and service life of pavement, whether they will lead to increased construction costs and/or increased disputes, and whether they are cost-effective in the long run.

\subsection{Current Status of Warranty Projects in Indiana}


The state of Indiana began the practice of warranty contracting with the objective of encouraging contractor innovation while compensating for decrease in agency personnel required for testing [FHWA, 2003a]. The state has used the concept of warranties for several projects involving hot mix asphalt (HMA) paving, bridge painting, and erosion control. The concept of warranties was first introduced in the state under an innovative bidding process called $A+B+C$. The ' $A$ ' component represents the costs (materials and labor), the ' $\mathrm{B}$ ' component consists of the cost of disruption of activity due to construction activities, and the ' $\mathrm{C}$ ' component includes a warranty clause which requires the contractor to provide a 5-year warranty for the work they undertake [FHWA, 1996]. Such contracts also include incentives and penalties in a bid to decrease project delivery time. Based on the quality-control/quality-assurance (QC/QA) specifications, Indiana has developed warranty specifications for hot mix asphalt (HMA) pavement. The first project with warranty specifications was let on I-70, East of Indianapolis in 1996 [Gallivan et al., 2004]. As of January 2003, the Indiana Department of Transportation (INDOT) has undertaken thirteen projects whose contracts include warranty clauses. Most of such projects were at high-volume Interstate routes and involved structural hot mix asphalt (HMA) overlay on crack-and-seated or rubblized PCC pavements. From the year 2001, warranty specifications were made applicable to projects on multi-lane NHS routes. The specifications are outlined by a joint team of INDOT, FHWA and industry representatives. The final selection of the bid is made by INDOT. The minimum quality requirements for aggregate, binder, and asphaltic mixture are established by INDOT. Performance of the pavement is based on the levels of the following distresses: cracking, rutting, friction, and roughness.

The contractor is responsible for quality control and no field inspection on the warranty pavement is required to be undertaken by the agency. However, the agency is responsible for conducting Independent Assurance (IA) verification of construction material samples. Coring, milling and other destructive test procedures have to be approved by INDOT prior to implementation. The bond 
amount is based on the estimation of the cost to completely remove and replace the warranty pavement. A Conflict Resolution Team (CRT), consisting of two contractor representatives, two agency (INDOT) representatives and one mediator, is set up to resolve any differences between the participating agencies [FWHA, 2003].

In the past, there has been two INDOT warranty projects that had required some remedial works after contract completion; the contractors had to remove the surface course and replace it in accordance with the warranty provisions due to lower-than-acceptable friction numbers. The contractor on the I-70 contract carried out some preventive maintenance work on the East-bound lane with a remove-and-replace but returned in the final year to carry out remedial work which was an overlay of the entire contract. The same was done on the I-65 contract. There have been attempts to compare the performance of warranty pavements and traditional (non-warranty) pavement projects. Performance analyses have indicated that warranty pavements exhibit less rutting and roughness as compared to traditional non-warranty pavements [Gallivan et al., 2004]. Initial surveys have indicated that contractors are increasingly placing greater emphasis on quality than before because they are responsible for the pavement performance during the warranty period (typically 5 years after project completion) [FHWA, 2000]. With the "successful" use of warranties for hot mix asphalt pavements, INDOT has now let out some PCC pavement construction contracts on a warranty basis. A complete listing of INDOT's completed and ongoing warranty projects as of January 2003 , is provided in Appendix A. This list does not include contracts let out after that date.

\subsection{Objectives of the Present Study}

The most widely claimed benefit of warranty contracts is that the shift of the burden of quality control from the agency to the contractor results in better performance and longer service life of the end product. Furthermore, it has been hypothesized that the reallocation of responsibility between the agency and the contractor results in decrease of overall level of resources required by INDOT for 
project delivery. However, warranty clauses call for added cost due to the bond acquired by the contractor. Such bonds take any potential future risks into account. The major concern is whether the added cost is offset by the benefits of warranty. Against this background, the objectives of this study are as follows:

- A literature review covering the state of practice of warranty contracts and the experiences in the different parts of the United States to identify the areas where guidance can be provided for successful implementation of warranty contracts in Indiana.

- Development and implementation of an analytical methodology to evaluate the cost-effectiveness of warranty specifications in highway contracting in Indiana, either using pavement performance and/or service life.

- Investigation of the trends in various features of typical warranty contracts in Indiana (warranty period, warranty items, type of bond, testing and performance evaluation required by the contractor, distress indicators and threshold values for acceptance, etc).

- Survey of agency personnel and contractors to get an insight of their viewpoints on warranty practices.

The evaluation will focus on the benefits and the associated costs of the warranty contracts undertaken by INDOT versus those of traditional contracting practices. In the course of addressing the above issue, it is also hoped that the study will provide a better understanding of the concept of warranties.

\subsection{Scope of the Study}

The scope of the present study was carefully defined in order to address the problem statement in a comprehensible manner while maintaining a realistic approach based on availability of data. Various aspects within the study scope are hereby described.

Coverage: INDOT has used warranty provisions with contracts involving hot mix asphalt pavements, erosion control projects, and micro-surfacing. The present study focuses only on pavement warranty projects. A few traditional (non- 
warranty) projects were selected to serve as control projects for the analysis. These projects were selected on the basis of similar work done, year of construction, and traffic characteristics. The experiences of other states and European countries were also examined and documented in literature review.

Analysis period: A study period starting from 1996 (when INDOT first let out contract with warranty provisions) to 2002 , was selected. For the purpose of the present study, only those projects that have completed their warranty period (or are in at least the third year of their warranty period) were considered in the analysis. This decision was based on the need for establishing reasonable performance trends and the availability of condition data of the pavements. However, information for all the contracts was reviewed to get a better insight into the status of warranty practice at INDOT.

Work description or rehabilitation strategy: INDOT has let out warranty contracts for pavement work as well as projects related to erosion control. The pavement contracts mainly consist of resurfacing work in accordance to $3 \mathrm{R}$ projects (resurfacing, restoration and rehabilitation) or 4R projects (resurfacing, restoration, rehabilitation and reconstruction). Projects related to various treatments of existing concrete pavements prior to overlay (crack \& seat, and rubblized) were also considered in the present study.

\subsection{Overview of Study Approach}

An overview of the study approach used to address the problem statement is shown in Figure

1-2. The first step was to establish the study objectives. This was followed by an extensive review of all published literature on warranties in order to document the current status of such contracts in the highway industry, to assess the position of INDOT's warranty program in relation to other states, and to describe the experiences of other states in the United States and abroad. A comprehensive and systematic study framework was developed and the data needs were 
carefully assessed in order to fulfill the study objectives. Based on the availability of data and feedback from various sources, the study methodology was modified at various stages to address the research objectives in a generic manner. The main aspect of the study was the cost-effectiveness evaluation which therefore involved in-depth analyses of the cost of each project and the derived benefits. Costs and benefits of warranty and traditional (non-warranty) contracts were therefore identified and quantified. The analysis was also supplemented by a survey that was conducted to obtain information on the experiences, observations and evaluations on the effectiveness of construction warranties on Indiana pavement projects. The participants of the survey were personnel from INDOT and highway contractors who have been involved in the warranty program. The final part of the study summarizes the findings, provides concluding remarks, and gives directions for future research in order to provide a decision support system for warranty projects at INDOT that would enable continual evaluation of warranty project cost-effectiveness. 


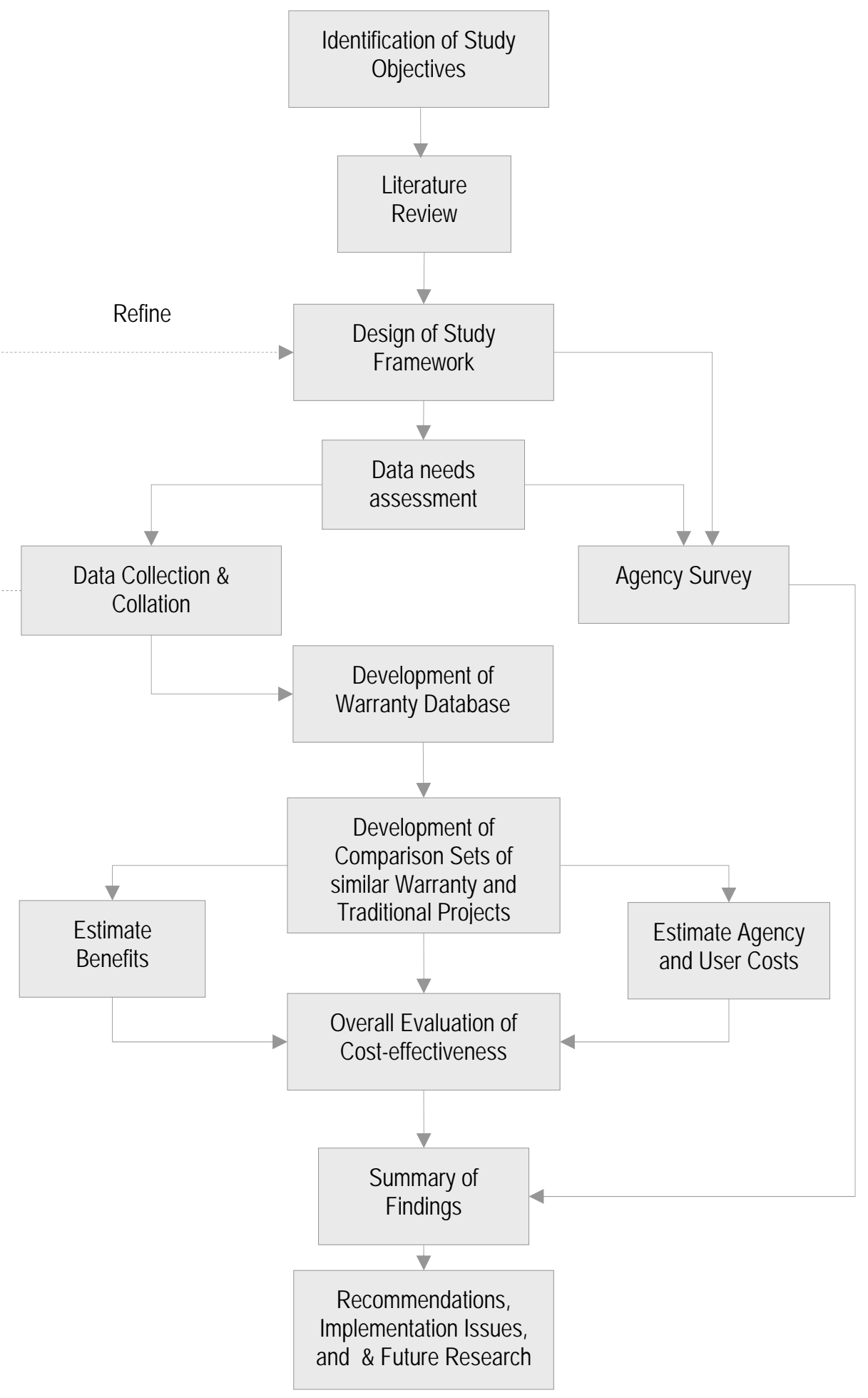

Figure 1-2 Study Framework 


\subsection{Organization of this Report}

Chapter 1 of this report introduces the concepts and practice of warranties in highway pavement contracting and highlights the extent to which warranties have been used on INDOT's highway projects. The chapter also outlines the objectives and scope of the study and provides an overview of the study framework. Chapter 2 provides an account of warranty state of practice in the United States and at European countries, and discusses the experiences and past findings of assessment of warranty contracts with respect to traditional contracts. A detailed framework of the study methodology is presented in Chapter 3. This section also explains the theoretical basis of the concepts used in the analyses. Chapter 4 discusses the data collection and the development of warranty contracts evaluation database. Chapter 5 presents case studies involving selected pairs of warranty and traditional (non-warranty) projects, provides comparative analyses of benefits and costs associated these contracting systems. In Chapter 6 , the results of the questionnaire survey of INDOT personnel involved in warranty projects and highway contractors are provided. This chapter highlights the perspective of the construction industry in Indiana regarding the practice of pavement warranties. The report concludes with Chapter 7 where the summary of findings and recommendations for future research are presented. 


\section{CHAPTER 2 LITERATURE REVIEW}

\subsection{Introduction}

Science and technology have contributed to various advances in the construction industry in terms of economical and improved performance materials, and efficient and time-saving construction procedures. Highway construction delivery is also being enhanced by the implementation of alternate and innovative contracting and procurement techniques. New or continued implementation of any novelty contracting method in highway construction should be preceded by a review of available literature related to the use of such methods. In the present study, an attempt has been made to document all information on warranty contracts in the United States (particularly in the state of Indiana) and Europe. The literature review was undertaken to achieve the following objectives:

- Development of a basic understanding of the concept of warranties and its variations (such as specification types and warranty period).

- Documentation and review of the experiences of state agencies that have used warranties in highway contracting, in order to identify the potential impacts of warranty practice in Indiana.

- Synthesis of the methods used by various institutions and agencies in assessing the cost-effectiveness of warranty contracts, in order to develop an insight into the current practices and validate to the results of the present study.

- Acquisition of an understanding of the perspective of the surety companies and contractors, in order to highlight the concerns of the nonagency stake-holders regarding the use of warranties in the highway construction industry. 


\subsection{Definition and Issues}

A warranty is defined as a guarantee of the integrity of a product and of the maker's responsibility for the repair or replacement of deficiencies [Hancher, 1994]. The manufacturer (in current context, the contractor) is responsible for the performance of the product over a certain period of time. Under a warranty contract, the contractor is held liable for any pavement deficiencies arising due to improper materials or workmanship. In some cases, the contractor is also responsible for the maintenance of the pavement until the end of the warranty period. As such, the agency/owner does not undertake any maintenance (routine or periodic) during the warranty period. Thus the concept of warranties is based on shifting of the entire risk and responsibility of end product performance from the owner (highway agency) to the contractor [Thompson et al., 2002].

The contractor is required to secure a warranty bond for the entire warranty period in addition to the performance bond required in a traditional contract. The bond amount is typically a percentage of the initial bid amount. The performance of the end product is evaluated on the basis of established distress parameters defined in the warranty provisions, and the contractor is required to maintain his or her work within the acceptable standards. The warranty bond provides an assurance to the owner/agency that the contractor will undertake requisite remedial action in the case of non-compliance contract specifications during the warranty period. The performance of the product is typically evaluated by the agency on an annual basis or at scheduled intervals during the warranty period. If any defect, distress or failure is found, the contractor is obligated repair it within a specified time frame [DeStazio, 1999]. A Conflict Resolution Team (CRT) is typically formed to resolve any dispute between the agency and the contractor. The CRT comprises of two agency/owner representatives, two contractor representatives, and a mutually acceptable third party representative whose expenses are equally borne by the agency and contractor. If the contractor fails 
to undertake any necessary repair work, the bond amount is forfeited. The main differences between warranty and traditional contracts are shown in Table 2-1. [Anderson and Russell, 2001].

Warranties are perceived to have higher initial costs, but may result in lower overall life-cycle costs compared to traditional contracts [Hancher, 1999]. On the other hand, warranties are believed to result in better quality products because the contractor runs the risk of having to replace the work in case of failure to meet the threshold levels, and therefore has a greater financial incentive to initially produce a high quality product [Anderson and Russell, 2001]. It may be argued that spending millions of dollars to gain benefits (in terms of long-lasting and higher quality products or facilities) may not be justified in view of the budgetary constraints of any state agency. Furthermore, pavement managers are increasingly going beyond just agency costs but are also considering user perspectives (often reflected through user costs) and facility condition. The present study therefore investigates the issue from the viewpoint of costeffectiveness of warranty contracts. Table 2-2 shows the different costs items associated with warranty and traditional contracts. 
Table 2-1 Differences between Warranty and Traditional Contracts

\begin{tabular}{|c|c|c|}
\hline Attribute & Warranty Contract & Traditional Contract \\
\hline $\begin{array}{l}\text { Award of } \\
\text { Contract }\end{array}$ & $\begin{array}{l}\text { Lowest responsible bidder, and/or } A+B+C \\
\text { bidding system. }\end{array}$ & Lowest responsible bidder. \\
\hline Bonds & $\begin{array}{l}\text { Performance bond and additional warranty } \\
\text { bond for the warranty period obtained from } \\
\text { surety company. }\end{array}$ & $\begin{array}{l}\text { Performance bond of specified } \\
\text { amount paid to the owner before } \\
\text { commencement of construction. } \\
\text { Covers only construction period and a } \\
\text { short period (typically 1-year) after } \\
\text { construction. }\end{array}$ \\
\hline $\begin{array}{l}\text { Agency } \\
\text { Responsibilitie } \\
\text { s }\end{array}$ & $\begin{array}{l}\text { Annual condition survey of end product during } \\
\text { the warranty period to measure performance. } \\
\text { Notify contractor if any remedial action is } \\
\text { required within the predetermined time frame. }\end{array}$ & $\begin{array}{l}\text { Quality Assurance (QA) testing } \\
\text { Sampling of tests performed by } \\
\text { contractor. } \\
\text { Monitoring control charts. }\end{array}$ \\
\hline $\begin{array}{l}\text { Contractor } \\
\text { Responsibilitie } \\
\text { s }\end{array}$ & $\begin{array}{l}\text { Develop a Quality Control (QC) plan and } \\
\text { submit to the agency. } \\
\text { Provide a copy of all QC data to the agency. } \\
\text { Undertake any remedial work and } \\
\text { maintenance throughout the warranty period. }\end{array}$ & $\begin{array}{l}\text { Maintain a QC program and submit all } \\
\text { QC data to the agency. }\end{array}$ \\
\hline Maintenance & $\begin{array}{l}\text { Contractor is responsible for all maintenance } \\
\text { work including any necessary remedial action } \\
\text { during the warranty period to keep the product } \\
\text { within acceptable standards. }\end{array}$ & $\begin{array}{l}\text { Contractor is responsible for the } \\
\text { maintenance of the product only } \\
\text { during construction (between letting } \\
\text { date acceptance date). }\end{array}$ \\
\hline $\begin{array}{l}\text { Performance } \\
\text { Indicators }\end{array}$ & $\begin{array}{l}\text { Performance Indicators are established to } \\
\text { measure the performance of the end product } \\
\text { during the warranty period }\end{array}$ & $\begin{array}{l}\text { No need for establishing performance } \\
\text { indicators for purposes of monitoring } \\
\text { construction quality. }\end{array}$ \\
\hline $\begin{array}{l}\text { Conflict } \\
\text { Resolution } \\
\text { Team (CRT) }\end{array}$ & $\begin{array}{l}\text { CRT comprising of } 2 \text { owner representatives, } 2 \\
\text { contractor representatives, and one mutually } \\
\text { agreed representative, is established to } \\
\text { resolve any dispute between owner and }\end{array}$ & None. \\
\hline
\end{tabular}

Source: Anderson and Russell, 2001 
Table 2-2 Typical Cost Items in Traditional and Warranty Contracts

\begin{tabular}{|l|l|}
\hline Traditional Contracts & Warranty Contracts \\
\hline Mixture bid price & Warranty asphalt pavement bid price \\
Asphalt bid price & Conflict resolution team costs \\
Tack coat bid price & State delivery costs \\
Quality management bid price & Extra distress surveys and reports \\
State delivery costs & Extra tests for disputes and traffic counts \\
State maintenance costs for warranty period & \\
\hline
\end{tabular}

Source: Krebs et al., 2001

\subsection{Historical Background and Legislative Impetus}

The use of warranties in highway contracting is not entirely new. Its inception can be traced back to the early twentieth century and more recently, to beginning of the last decade when state highway agencies had begun experimenting with innovative and best value contracting practices as an alternative to (or as a complement to) the traditional method of awarding the contract to the lowest responsive bidder. These were part of overall efforts to meet the needs of the highway user in terms of timely construction with minimal traffic disruptions and enhanced ride comfort and safety. In January 1988, a Transportation Research Board task force, comprising of state and federal highway officials, contractors, consultants, surety companies, and academic institutions, was initiated to explore and evaluate innovative contracting practices in U.S and European countries which affect product quality, construction time and costs. The findings of the task force (which focused on bidding procedures, materials and quality control, and insurance and surety issues) led to the 1990 implementation of FHWA's Special Experimental Project No. 14 (SEP 14) - Innovative Contracting Practices. The purpose of SEP 14 was to identify contracting practices based on the task force recommendations which have a potential to reduce life-cycle costs while improving quality of highway construction, and to implement such practices on an experimental basis. Inclusion of a warranty clause was among four innovative 
contracting techniques that were proposed at the time and has since been used by a number of agencies. Eight states, (California, Indiana, Michigan, Missouri, Montana, North Carolina, Washington, and Wisconsin) evaluated the use of warranties under SEP 14. Initially, the use of warranties was restricted to electrical and mechanical equipment on Federal-aid projects under the 23 CFR 635.413 regulation [FHWA, 1995]. The rationale of this regulation was to prevent the diversion of Federal-aid funds for routine maintenance work which is prohibited by law. The restriction was made flexible by the Intermodal Surface Transportation Efficiency Act of 1991 (ISTEA) which permits a state to exempt itself projects off the National Highway System (NHS). Under these conditions, warranty clauses may be used in contracts in accordance with state procedures. The FHWA adopted the Interim Final Rule (IFR) in August 1995, expanding the use of warranties on Federal-aid highway construction projects. Under this regulation, states were allowed to include warranty clauses in Federal-aid NHS contracts with prior approval of the FHWA Division Administrator. The warranty provision was made available for specific construction product or feature within the control of the contractor. In April 1996, the regulation was adopted as the Final Rule which made warranty clauses operational in the sense that FHWA no longer requires evaluation of warranties. Since then, final rule making, an additional seventeen states have evaluated the use of warranty specifications in highway contracting [AASHTO, 2001].

Many highway agencies have shown a keen interest in the use of warranties in highway construction. However, there is some amount of apprehension among contractors and surety companies largely because with warranty contracting, only a very small number of construction companies (which are typically large and well-established) may be able to participate in the bidding process. Surety companies are expectedly reluctant to provide bonds for smaller companies because they perceive little or no guarantee that the small companies would still be in business by the end of the warranty period. 


\subsection{Warranty Contracting in the United States}

In the past, transportation agencies in the United States have been conservative in their highway construction and contracting practices. A large portion of the nation's highway system was built under the traditional low-bid concept. The rationale behind this concept was to provide an environment for fair competition to all bidders on equal basis, and to secure the best services to the public at the lowest possible cost [Harp, 1990]. For a long time, the American highway industry adhered to this practice and shied away from other alternative contracting practices. However, close examination of the traditional lowest bidder concept has revealed that this contracting practice may not necessarily the best method to procure the most cost-effective product. The need for innovative practices was further propelled by increased perceptions and demands of the highway system users. As a result, transportation agencies began to examine other innovative methods of contracting and procurement, and started looking beyond the cost factor to address quality and durability of products. The concept of warranties clearly provides promises of innovative practices and a broader perspective of the contracting environment.

Since the initiation of the SEP 14 in 1990, warranties have come a long way in the United States. Section 2.2 of the present report provides a background of warranties in the United States. Since 1996, state highway agencies used warranty provisions for hot-mix asphalt projects [Hughes, 2000]. Currently, a number of agencies have implemented warranty provisions for many projects based on state procedures and requirements. The experiences of various states have been documented in the following sections for a better understanding of the warranty concept and its pros and cons.

\section{Indiana}

The Indiana Department of Transportation (INDOT) developed warranty specifications for hot mix asphalt (HMA) pavements in conjunction with $A+B+C$ bidding process in 1996. The 'A' component takes into account all costs of labor 
and materials, while the ' $\mathrm{B}$ ' component is the cost associated with the disruption of traffic due to construction activities. The warranty provision is included as the ' $C$ ' component which requires contractors to provide a guarantee of their work for a period of 5 years [FHWA, 1996]. The first project with warranty specifications was let at I-70, East of Indianapolis in 1996 [Gallivan et al., 2004]. As of January 2003, the Indiana Department of Transportation (INDOT) had undertaken thirteen projects whose contracts include warranty clauses. Most of such projects were at high-volume Interstate routes and involved a structural hot mix asphalt (HMA) overlay on crack-and-seated or rubblized PCC pavements. Starting the year 2001, warranty specifications were made applicable to projects on multi-lane NHS routes. The specifications are outlined by a joint team of INDOT, FHWA and industry representatives. The final selection of the bid is made by INDOT. The minimum quality requirements for aggregate, binder, and asphaltic mixture are established by INDOT. During the warranty period, the performance of the pavement is evaluated in terms of roughness, cracking, rutting, and surface friction. The threshold values for the distress parameters are based on the data collected by INDOT's Management System (PMS). Incentives for faster project delivery are also added along with the warranties. Like other states, INDOT perceives the warranty process as a way to encourage contractor innovation and also to compensate for decreasing strength of agency's testing and maintenance personnel [FHWA, 2003].

There have been attempts to compare the performance of the warranty pavement to that of a traditional (non-warranty) project. Performance analyses have indicated that warranty pavements exhibit less rutting and roughness as compared to traditional non-warranty pavements [Gallivan, et al., 2004]. Initial surveys have indicated that in warranty projects, contractors place greater emphasis on quality than before because they are responsible for the pavement performance during the warranty period (typically 5 years after project completion) [FHWA, 2000]. After using warranties for hot-mix asphalt pavements, INDOT is now considering letting out PCC pavement construction contracts on a 
warranty basis. A complete listing of INDOT's completed and ongoing warranty projects, as of January 2003, is provided in Appendix A.

\section{California}

The transportation agency of the state of California (CALTRANS) has developed warranty provisions for preventive maintenance projects for warranty period of one year. CALTRANS has experienced an increase of 32 percent in bid prices as compared with 19 percent savings in maintenance [FHWA, 2002]. Ten percent of the initial bid amount is retained as coverage for any contractor default during the warranty period. If performance is within the established standards during the warranty period, the average amount is reduced annually [Hastak, 2003]. Performance of the product is evaluated on the basis of rutting, raveling, delamination, and cracking. There has been a noticeable difference in the performance of the projects, although minor repairs have been necessary in some of the projects.

\section{Florida}

The Florida Department of Transportation (FDOT) has a warranty period of 5 years for pavement preservation projects. Pavement thickness is determined by FDOT and the contractor has to follow FDOT's mix design, and all specifications for production and placement. No sampling or testing is done by the agency [FHWA, 2002].

\section{Wisconsin}

As one of the first states to implement warranty provisions in highway contracting, Wisconsin has been a major player in the field of warranty contracting.. Rapid advancements in the pavement construction industry and introduction of the quality control/quality assurance (QC/QA) concept saw shifts in the quality related responsibilities from WisDOT to the contractor. By 1994, several WisDOT contracts were functioning under an extensive QC/QA program 
where the contractor performed quality control tests while WisDOT carried out surveys to verify test results and to ensure compliance with quality and performance specification. In 1995, WisDOT ventured into the field of innovative contracting practices with the support of the Wisconsin Asphalt Pavement Association (WAPA) and the FHWA Wisconsin Division Office [Krebs et al., 2001]. The purpose of that joint venture was to develop a comprehensive plan to incorporate warranty specifications into highway construction contracts for asphaltic concrete pavements. The three parties involved in the process (WisDOT, WAPA, and FHWA) defined the purpose of the warranty specifications as one that focused on the condition and actual performance of the final product without concentrating much on the ingredients and the processes involved in getting the product. The specification therefore allowed the contractor to decide how to construct the pavement, thereby paving the way for contractor innovation to accomplish the prescribed levels of performance within the given time. Under this concept, "contractors became full partners in the road-building process" [Shober et al., 1996]. WisDOT also viewed this concept as a way of reducing the costs related to testing, and supervision by agency staff in the construction process, while maintaining performance standards. The concept of "shared risks" was also introduced, with WisDOT bearing the risk of pavement performing below the acceptable levels and the contractor bearing the risk of remedying any defect within the warranty period.

The threshold level (maximum acceptable level) for each indicator of pavement distress was established by using historical data from WisDOT's pavement management system (PMS), thereby conforming to performance levels typically attained by AC pavements in Wisconsin. The conflict resolution team for each project comprises of two WisDOT representatives, two contractor representatives and a third person mutually agreed upon by WisDOT and the contractor. This team was given the final authority in case of any dispute between WisDOT and the contractor. 
To assess the overall cost-effectiveness of warranty contracts in Wisconsin, a complete evaluation with respect to the performance of the pavements in terms of ride quality, maintenance, etc. (at the end of the warranty period), was undertaken in 2000 for 18 warranty projects constructed from 1995 to 1999. Over a period of five years following construction, the performance of the warranty pavement in terms of Pavement Distress Index (PDI) and the International Roughness Index (IRI) over a period of five years was significantly better than the non-warranty pavements. A comparative analysis based on the performance trends of typical pavements was done to see whether the total project cost was offset by the extra benefit (better pavement performance) derived from the warranties. Based on the cost analysis, it was found that the standard projects cost $\$ 28.04 /$ ton including state delivery costs, while the warranty projects averaged at $\$ 24.34 /$ ton for the period from 1995 to 1999 . A separate analysis was done for the year 2000 to take into account the increase in asphalt prices and the inclusion of ancillary pavements in the warranty specifications. The results revealed that the costs of the warranty contracts were slightly higher than expected. A life-cycle cost analysis was also performed based on the performance data of the warranty pavements and using deterioration models to predict the pavement life. The present worth of the life-cycle cost of the warranty pavement was then compared to that of a standard pavement and was found that even though the warranty pavements cost $7 \%$ more initially, the overall costs over the pavement life were lower than the non-warranty pavements [Krebs et al., 2001]. However, such an evaluation technique does not provide any information on the overall cost-effectiveness of the pavements, as the analysis is based on only the cost items. A broader perspective can be gained by incorporating "effectiveness" or assessment of performance.

\section{Ohio}

At the early stages of development of warranty provisions in highway contracting in the United States, the state of Ohio was deeply involved and has since 
become a front-runner in warranty practices. The Ohio Department of Transportation (ODOT) participated in the FHWA initiative to formulate contract documents for warranty pavement projects in 1992. This was followed by the 1996 development of asphalt pavement warranty for pilot projects which was based on Indiana and Wisconsin DOT guidelines [ODOT, 1999]. Finally, ODOT was required to formulate warranty contract requirements in response to a state senate bill in July 1999 . The bill covered the warranty provisions in a temporary section and a permanent section. Under the permanent law, 20 percent of the department's construction project contracts require warranty provisions and 10 percent of the department's capital construction budget has to be let under a pavement warranty contract. The warranty period was defined for different work items: at least seven years for new pavement construction; at least five years for pavement resurfacing and rehabilitation; and at least two years for pavement preventative maintenance, bridge painting, pavement markings, guardrail, and other project items [ODOT, 1999]. Under the warranty specifications, the contractor is required to secure a bond, varying from 30 to 90 percent of the total bid amount for the entire warranty period during the contractor has to deliver the minimum material and quality control requirements [ODOT, 2000]. In 2000, 69 contracts in Ohio were let out with warranty provisions. However, this did not meet the target of 20 percent of projects as required by law because most of the projects had already been designed and it was too late to incorporate warranty provisions. There was a general consensus in the construction industry that warranty specifications would not be added to existing project after the project has been let. ODOT emphasized project selection based on an analysis of the existing conditions to determine whether the particular work item could be let with warranty provision. This was necessary to prevent the use of warranty to alleviate problems associated with old projects; as such approach by designers would increase the potential of litigation. An evaluation of the warranty projects conducted in 2000 indicated that ODOT experienced higher bid prices, with 8.5 
percent increase for asphalt pavements and 11 percent increase for concrete pavements in comparison to similar non-warranty pavements [ODOT, 2000].

\section{Michigan}

The Michigan Department of Transportation (MDOT) has awarded over 300 projects with warranty provisions. The warranty period is for 5 years for bridge painting, asphalt pavements, and concrete pavements [FHWA, 2002c]. Michigan uses warranty specifications for preventive maintenance activities. Pavement performance is evaluated on the basis of ride quality, longitudinal and transverse cracking, and rutting. Long term (10-year) warranties are also being considered. Based on the performance of the highest quality pavements, MDOT, since 2002, has begun to use higher threshold values for performance evaluation. This modification is seen as a bid to further improve pavement performance [Hastak et al., 2003].

Illinois

The Illinois Department of Transportation uses warranty provisions for asphalt and concrete pavements. The warranty period is 5 years, and performance criteria is based on roughness, cracking (longitudinal and transverse), and rutting. All disputes between the agency and the contractor are resolved by conflict resolution teams. Illinois DOT reserves the right to approve all materials and methods for warranty work, which is not the case for other state agencies [Hastak et al., 2003].

\section{Kansas}

Kansas has started implementing warranties in highway construction and is currently in the initial stages of warranty practices. The warranty bond is 50 percent of the cost of mobilization and the bid items. Performance evaluation is based on ride quality, cracking, rutting, faulting, and other distresses such as bumps, potholes, and delamination [FHWA, 2002c]. However, smoothness is the 
main criteria and contractors are awarded bonuses for pavement smoothness that exceed the established threshold levels.

\section{Missouri}

Missouri has established a warranty period of 3 years during which the contractor is responsible for all repairs and remedial work. Initially, there were some problems when two projects experienced failure and the contractor failed to undertake any remedial action. The conflict resolution team had to resolve resulting disputes between the agency and the contractor.

\section{Colorado}

Colorado has also been an active participant in the nation-wide effort to implement warranty specifications in highway construction. In May 1997, a Senate Bill was introduced to establish a pilot program for warranty of hot bituminous pavement (HBP) projects. Initially, the Colorado Department of Transportation (CDOT) experienced some drawbacks with the new approach of contracting. This was due to unsuccessful bids as the bid amounts significantly exceeded the engineer's estimate [Aschenbrener and DeDios, 2001]. To overcome the obstacles, CDOT highlighted the need for experimentation with short-term HBP materials and workmanship warranties along with the development of warranty provisions for other work items and ultimately let out three warranty projects in 1999/2000.CDOT requires a 3-year warranty for projects that are designed for 10 years and a 5-year warranty for projects that are designed for 20 years. The department has also developed separate long-term (10 years or more) performance warranties for both PCCP and HMA pavements [FHWA, 2002c]. Based on the evaluation and recommendations of the a joint CDOT and industry task force, a set of guidelines on project selection was developed to ensure the successful bidding of warranty projects. The warranty specification requires the formation of three-member Pavement Evaluation Team, one representative from CDOT, one from industry, and one from an 
independent engineering firm, to conduct annual pavement distress surveys. A Cost-Benefit Evaluation Committee has also been formed, which includes representatives from CDOT and the asphalt paving industry. This committee has performed an extensive assessment of six warranty projects in comparison to similar traditional projects, in terms of performance, costs (initial and maintenance), level of competition (number of bidders, spread in bids), etc. The differences in costs of warranty and traditional contracts were found to be negligible [Aschenbrener and DeDios, 2001].

\section{New Mexico}

The New Mexico State Highway and Transportation Department (NMSHTD) has awarded a 146-mile section of State Route 44 with warranty provisions over a 20-year period, to Koch Materials Company, as a part of a new innovative financial scheme called the Design-Build-Operate-Maintain. The 20-year warranty includes performance-based specifications with established threshold values for distresses such as cracking, rutting, and roughness. The warranty provision is considered void if the level of traffic during the warranty period exceeds the predetermined design level. NMSHTD expects that that the initial warranty cost of $\$ 62$ million will save $\$ 89$ million in maintenance expenditure over the warranty period. The surety bond is established at $\$ 114$ million which decreases annually [Hughes, 2000].

\subsection{Warranty Contracting in Europe}

The use of warranties is widespread in Europe. In recent years, the European practice (which requires the contractor to provide post-construction quality assurance and satisfactory product performance) is receiving immense attention from transportation agencies in the United States. To acquire knowledge about European contracting methods, and innovations in design and materials, a team of experts on asphalt concrete pavements from the United States, in 1990, visited six European countries (Sweden, Denmark, Germany, Italy, France, and 
the United Kingdom) [AASHTO, 1991]. The team observed that the pavements were in excellent condition with little rutting, cracking and pothole distresses. It is important to add that European countries typically provide good subgrade and thick bases for their pavements with adequate provision for active drainage. Although each country has its unique contracting procedures, two major features common to all European countries, but different from the United States' practice at that time, were identified. These were the use of broader specifications to allow the contractor more flexibility to choose materials and designs, and the use of warranties for 1 to 5 years after the completion of the work (thereby holding contractors accountable for their work). Furthermore, the design life of the pavements is 40 years in most European countries, instead of the 20-year design life typically used in the United States [AASHTO, 1991]. Several European agencies incorporate maintenance and rehabilitation plans with the initial pavement cost in the 40-year design life. There are extensive research and development activities undertaken by governmental agencies and contractors. There was evidence of contractor innovation, particularly with the use of modifiers and additives, use of high-quality aggregates, and new mix designs. Another important observation of the study tour was that any dispute between government and the contractor is resolved within the periphery of the administration, leaving very little scope of litigation.

The 1990 European Study Tour was followed by the 1992 U.S. Tour of Concrete Highways (US TECH) [AASHTO, 2001]. The purpose of the tour was to review the European concrete pavement in terms of design, construction, maintenance, performance, finance, and related research. The team of experts met with representatives from France, Austria, Germany, Netherlands and Belgium. At these countries where the contractors are required to provide a warranty/guarantee for the pavement for a period ranging from two to seven years (during which a small amount of the contract price was retained), there is a preponderance of evidence of warranty benefits. If any problem or defect should occur during the warranty period, the contractor is obligated to undertake 
remedial action at no cost to the agency. The contractor is given more freedom to innovate and propose materials. In Germany, for instance, the contractor is even allowed to choose between an asphalt concrete (AC) or a portland cement concrete (PCC) pavement from the design catalog for a particular project. However, the members of the study tour were of the opinion that many aspects of European warranty practice need further research before implementation in the United States. The present study is such an attempt to conduct an overall cost-effectiveness based on the pavement performances and associated costs. A key issue arising from the European Tour was based on the findings related to owner-contractor relationship, materials and design specifications, size of the construction company, etc.: the word "warranty" may have a different meaning to the Europeans. It was cautioned that the better quality of European pavements could be attributed to the longer design life and broader specifications and not necessarily due to the use of construction warranties.

Due to the keen interest shown by the various sectors of the highway industry in exploring the different methods of European contracting practices, another study tour was conducted on Contract Administration Techniques for Quality Enhancement (CATQEST) in 1993. The team, comprising of Federal, State, and industry representatives, visited Germany, France, Austria, and Spain. An attempt was made to determine the contribution of innovative contract administration practices to the excellent quality of pavements. The study team met with government transportation representatives, contractors, trade associations, regional road administrative personnel, consultants, and independent testing laboratory officials from each country. It was found that contractors were required to warrant their work for at least one year after construction and to remedy any defects resulting from the poor workmanship or materials during that period. The review of the use of warranties in all the countries brought to the focus the difference in opinion regarding the contribution of warranties to the quality of highways. Such differences were evident across country boundaries and even within individual countries. Some upheld the value 
of warranties with a strong belief that they have a positive influence on the high quality of pavements. However, others were of the opinion that the quality would not diminish if warranties were eliminated, thereby giving due credit to the well established standards of quality and performance resulting from the design and specification criteria.

In Germany, warranty provisions in all federal and state projects were made mandatory by law. All sectors of the highway industry expressed immense satisfaction with the success of warranties. However, the contractors also indicated that they would not perform a lesser quality work in the absence of warranty as they wanted to maintain their reputation and remain eligible for future bidding process. There was a common belief that the use of warranties was critical to delivering a quality product as contractors generally prefer to deliver initial high quality work rather than to undertake remedial work at a later stage during the warranty period.

France operates under a more flexible warranty contracting practice, in terms of warranty period, amount, and method of securing warranty, particularly for toll motorways. In that country, non-toll facilities are subjected to a standard 1-year materials and workmanship warranty. Survey respondents from Austria expressed great satisfaction with the warranty provisions in the contracts, and indicated the use of other contract administration requirements that are very similar to those in the United States. A review of highway contracting in Spain revealed that work is warranted for 1 or 2 years under government regulations, and a percentage of the contract amount is secured as a bond until the end of the warranty period. In some cases, the bond amount of bond is as high as 20 percent of the contract price, especially if the successful bid is over 10 percent below the average bid or if the state believes that the contractor requires additional coverage. The tour team noted that there had been cases when the contractor failed to undertake remedial action and the state had to perform the required work at their own expense. In such cases, the contractor suffered loss of bond and an additional 20 percent penalty, and lost the chance to bid for future 
projects. The Spanish indicated that they would like to continue with the current warranty provisions in the contract system.

Further information in European contracting practices were obtained when a team representing federal and state agencies, contracting industry and academia traveled to Portugal, Netherlands, France, and England in June 2001. The purpose of that tour was to collect details on the length of typical warranty periods, and the type of items covered by the warranty provisions [Cox et al., 2002]. However, the team was unable to get much information on the use of long-term warranties.

Europe again opened a window to its contracting practices in September 2002 when a U.S. panel, sponsored by the FHWA and the AASHTO under the guidance of the NCHRP, was assembled to conduct a study of European warranty practices in asphalt pavement techniques [FHWA, 2003]. The purpose of that effort was to review and document the strategies used in Europe and promote the implementation of the best practices that might benefit U.S. practitioners. Emphasis was also laid on methodologies to determine risk assessment for the government agency and contractor, criteria for successful asphalt pavement warranties and analytical tools to establish pavement performance and distress. The panel met with representatives from Spain, Germany, Denmark, Sweden and the United Kingdom, countries that have used warranties on pavement construction for many years, with warranty periods ranging from 10-40 years. The U.S. panel observed different types of warranties which have improved the quality of the highway systems of the host nations. All the countries use material and workmanship warranties with their traditional contracts. The contractor is required to build the pavement as specified by the owner and to undertake remedial actions for any defects resulting from the use of improper or inferior materials. Performance indicators for rutting, cracking, and durability are used on such warranties [FHWA, 2002]. Performance warranty contracts as well as traditional contracts are widely used in Denmark and Sweden. UK has also shown to employ such contracts in recent years. The 
performance of the asphalt pavement is incorporated with material and workmanship, since the contractor assumes responsibility for some or all of the pavement design. Such type of warranties have allowed for contractor innovation to a varying degree. All the host countries use the best-value procurement instead of low bid. Under such contracts, technical and performance criteria such as safety, innovation and environmental impacts, are added along with the cost. Best-value procurement paves the way for coordination and trust between the agency and contractor. Based on the experience of the host countries, the panel of experts provided recommendations to implement warranty contracts in the U.S. These recommendations included federal involvement for the success of such programs development of awareness by all parties and understanding of the issues and associated risks with the use of warranties in highway contracting.

\subsection{Sureties for Warranty Contracts}

Most state agencies require that the contractor secure a surety bond for the entire warranty period. The bond serves as an assurance in case of contractor default. Typically, the bond amount is a percentage of the contract amount or a predetermined amount. The contractors may also be required to secure a lien bond to cover subcontractors [Johnson, 1999]. Sureties are designed to prequalify contractors based on the contractor's reputation, experience, and financial stability [Hancher, 1994]. This requirement for a surety bond is a major issue due to the associated risk in large projects, and legal problems expected with disputes, particularly for smaller companies. The surety companies are wary of the uncertainty that the smaller companies will be in business after 3 or 4 years. As such, surety companies may be unwilling to provide long-term bonds required for large projects.

With warranty practices gaining momentum in highway contracting, surety companies are faced with the challenge of providing bonds on a number of projects for longer warranty periods. As a result, the bonding companies are 
taking extra caution for long-term warranties, and give greater consideration to the past experiences of a client (contractor) [DeStazio, 1999].

\subsection{Advantages of Warranties}

The rationale behind the use of warranties or any other innovative contracting practice is to yield overall higher benefits for both the agency and road user, compared to traditional contracts. Many state agencies have identified potential benefits with the implementation of warranties in highway contracting. The main advantages of warranty contracts are [Johnson, 1999]:

- Reduction of agency resources and personnel for testing and maintenance, and potential savings in maintenance costs.

- Higher quality product as compared to traditional projects as the contractor has greater responsibilities, resulting in greater service lives and reduction in life-cycle costs.

- Lower owner's risk based on the assurance that the contractor will undertake repairs and remedial work to correct failures resulting from materials or poor workmanship.

- Contractor innovation, as the contractors are given more flexibility.

- Increased involvement of contractors in the design and construction process. This reduces claims and disputes between owner and contractor, and ensures a more effective bidding process.

\subsection{Concerns of Using Warranties}

Many state agencies and the construction industry have voiced concern over the use of warranties. The following issues have been identified that may hamper the successful use of warranties [ODOT, 2000]:

- Uncertainty of whether the contractor will be in business for the entire warranty period.

- Decrease in competition among contractors, as smaller companies will be eliminated form the bidding process if they are unable to secure surety bonds. 
- Premature failure of warranty product due to unforeseen or extenuating site circumstances such as poor subgrade. Under such situations, the warranty provisions are voided. As such, it is important to of select work items that are consistent with the warranty criteria in order to render high-performance highways to the public with minimum driver delays [Shober et al., 2001].

- Traffic loads that exceed the design ESALs on the warranty pavements may void the warranty provisions.

- Loss of agency control of warranty product during the process. The responsibility of quality control is entirely shifted to the contractor. As such, the agency has very little involvement during the construction phase and practically no control over the use of materials and construction procedure.

- Potential for increased litigation between agency and contractor.

\subsection{Chapter Summary}

The successful use of warranties in the European countries has helped to pave the way for warranty contracting in the United States. Various representatives from federal, state, industry and academia visited European countries to learn from their experiences. The concept of warranty contracting is viewed as a way of deriving higher benefits in terms of better product performance and reducing agency maintenance costs. Contractor innovation is also seen as an opportunity for higher productivity.

There is some apprehension from the industry regarding the issue of long-term surety bonding that is associated with warranties. Securing a bond for a period exceeding 5 years may be difficult for the smaller construction companies in comparison to larger companies. This is major concern as many smaller companies (even those with a good work record) are likely to be left out of the competition. Furthermore, the warranty is valid until the time the contractor and the surety company are in business. The surety companies also expressed 
disquiet regarding the bonding period and questioned the ability of companies to handle multiple projects. These concerns were based on the uncertainty of risks involved in the process.

However, there is general enthusiasm in the industry as the warranty process provides an opportunity for the contractors to be fully involved in the roadbuilding process while being responsible for their work. There is optimism that the life-cycle costs of the warranty product would be greatly reduced. Many state agencies have noted that warranty projects are causing contractors to place a greater emphasis on the quality of work and put extra effort to determine projectspecific requirements in terms of quantity and type of materials, and the use of equipment. 


\section{CHAPTER 3 STUDY METHODOLOGY}

\subsection{Introduction}

This chapter presents the methodology adopted for the study and discusses the theoretical basis of evaluation of cost-effectiveness of the warranty projects. A conceptual background for all fundamental principles used in the evaluation procedure is also provided. The task of performing a cost-effectiveness assessment of any project is one of identifying the benefits derived from the project and the costs incurred in the project, and then determining if the additional costs (if any) are offset by the benefits gained, for both agency and user. The evaluation process has been carried out on a comparative basis, where each warranty project is examined vis-à-vis a comparable traditional (non-warranty) project, with similar characteristics. The study incorporates the costs and benefits associated with warranty and traditional projects undertaken by INDOT to highlight the differences between contracts awarded under these two contracting systems.

The total cost of any transportation project incurred by the agency includes the capital costs and the maintenance costs, while the costs borne by the facility user primarily include vehicle operating costs, delay costs, and costs related to safety. Vehicle operating cost is directly associated with the performance of the facility: a pavement in excellent physical condition will cause little operating cost to the user. Any savings in user cost can be considered as a benefit derived from a project that improves the facility condition. For the present study, benefits are measured in terms of the pavement performance over the warranty period. A detailed discussion on the costs and benefits of the evaluation process is provided in subsequent sections, followed by an explanation of the systematic approach used for overall assessment of cost-effectiveness.

Averaging the data for all warranties and for all corresponding traditional contacts and then making comparisons between the costs and benefits of each of the groups would tend mask vital differences between the two contracting systems. Therefore, in a bid to obviate the occluding effect of such aggregations of data in each contracting system, the analysis was carried out in the form of pair-wise comparisons of the costs and benefits of each set of warranty and traditional projects. As such, five "comparison set" were established for the analysis. Within each comparison set is a pair of warranty and the traditional contract projects that are similar in their basic attributes (project type, thickness, traffic, etc.) thus enabling a rational means of comparing their relative cost-effectiveness on the basis of pavement performance and project costs. 


\subsection{Identification and Selection of Warranty Contracts}

The first step was to identify the highway projects under Indiana's warranty program and to select appropriate non-warranty projects for purposes of comparison. Five projects with warranty provisions were selected on the basis of the feasibility of establishing performance trends from available data for at least 3 years. Most of the selected projects have completed their warranty periods. Table 3-1 presents the warranty projects considered in the present study as well as their warranty status as of 2002. A list of all warranty contracts awarded by INDOT, as of January 2003, is provided in Appendix A.

Table 3-1 Warranty Contracts Used in Analysis

\begin{tabular}{|c|c|c|c|c|}
\hline $\begin{array}{c}\text { Contract } \\
\text { Identification } \\
\text { Number }\end{array}$ & Location & Length (miles) & $\begin{array}{l}\text { Start Year of } \\
\text { Construction }\end{array}$ & $\begin{array}{l}\text { Warranty Status } \\
\text { as of } 2002\end{array}$ \\
\hline $\mathrm{R}-22232$ & $\begin{array}{l}\text { I-70, East of SR-9, Hancock } \\
\text { County }\end{array}$ & 4.21 & 1996 & Complete \\
\hline $\mathrm{R}-22854$ & $\begin{array}{l}\text { I- } 65 \text {, North of US-31, } \\
\text { Bartholomew County }\end{array}$ & 4.56 & 1997 & Complete \\
\hline R-22925 & $\begin{array}{l}\text { I- } 69 \text {, North of SR-8, Dekalb } \\
\text { County }\end{array}$ & 8.68 & 1997 & Complete \\
\hline R-23390 & $\begin{array}{l}\text { I-74, East of SR-9, Shelby } \\
\text { County }\end{array}$ & 11.01 & 1998 & 4 years \\
\hline R-23898 & $\begin{array}{l}\text { I-74, West of SR-267, } \\
\text { Hendricks County }\end{array}$ & 3.96 & 1999 & 3 years \\
\hline
\end{tabular}

All the above projects involved hot mix asphalt (HMA) overlays over existing PCC pavements. The warranty status shown in the table corresponds to the year 2002. As such, data up to the year 2002 has been used in the evaluation process. Each warranty contract is compared with a similar traditional project to highlight the differences in pavement performance and cost components. The traditional projects are designated as "control" projects and were selected on the basis of the similarity of work done, pavement thickness, traffic, and year of construction. While it is preferable to select warranty and traditional projects that have identical dimensions (particularly, contract length and pavement thickness) it was not practical to do so. Comparison of the projects unequal length could render the analysis vulnerable to economy of scale distortion. Geographical location of the projects was considered. As much as possible, constituent projects in each comparison pair were proximal. A detailed description of each warranty and control project is provided in Chapter 5. 


\subsection{Methodology for Estimation of Costs}

The estimation of all costs associated with a construction project is as important as the assessment of the product performance in order to fully analyze determine project cost-effectiveness of the project. A pavement may exhibit excellent performance but at a prohibitive cost. On the other hand, a warranty contract may have a higher initial bid as compared to a traditional contract, but may yield a better performing pavement and subsequently relatively lower life cycle costs. For the present study, both agency and user costs are considered. All future stream cost components - agency and user - were converted to the present value using the economic indicator Equivalent Uniform Annual Costs (EUAC). A discount rate of 4 percent is used.

\subsubsection{Agency Costs}

Agency costs involve the final construction cost of the project (labor, material etc.) and the cost of maintenance activities undertaken by the highway agency. The initial bid amounts of contracts let out under the two contracting systems were carried out to acquire a perspective of the differences in such values. The major difference in the bid amount is the unit cost of the warranty pay item "warranty asphalt pavement" or "warranty asphalt mixtures".

The other important aspect of the cost analysis relates to the maintenance costs incurred by the highway agency to ensure that the pavement performs to acceptable standard. These costs may be due to annual routine maintenance or periodic maintenance, and may be of preventive or corrective nature. For warranty projects, the contractor is liable for the product performance throughout the warranty period and consequently bears all maintenance costs over the entire warranty period. For traditional projects however, the responsibility of the contractor ceases after the completion of the project (or at most one year after project completion) and the highway agency bears all maintenance costs thereafter. In the state of Indiana, the warranty period typically lasts for five years. During the warranty period, INDOT is not required to undertake any maintenance job for the warranty product. By considering only the initial cost of a contract, it cannot be determined if the contract is truly cost-effective; the initial cost of the project may be relatively small compared to the other, but its overall cost may be large due to a large maintenance expenditure. For warranty projects, there is no maintenance expenditure incurred by INDOT during the warranty period. As such, for the present study, only the initial construction cost was considered for a warranty project. On the other hand, for a corresponding traditional (non-warranty) project, both the initial construction cost and the maintenance costs were taken into account. The initial construction cost is the total cost paid by the agency to the contractor for all work done, material and labor, mobilization costs, etc.

The average annual maintenance costs for the traditional projects were determined using models developed by Labi and Sinha (2002) that estimate the level of maintenance that a pavement section is 
expected to receive over a period of time, based on the type of the pavement, geographical location, functional class, etc. The general form of the model is given by:

$$
A A M E X=E X P\left[A_{0}+\sum_{i=1}^{N}\left(A_{i} X_{i}\right)\right]
$$

where

$A A M E X=$ Average annual maintenance expenditure per lane-mile, in 1995 constant dollar

$A_{0}=$ constant term

$A_{i}=$ coefficient of term $X_{i}$

$X_{i}=$ explanatory variable $i$

$N=$ number of significant variables

These models were used in the present study due to the unavailability of actual maintenance data for the pavements under study. The AAMEX model for Overlay Pavements is used based on the type of pavement surface of the warranty projects considered for analysis. The model results are shown in Table $3-2$.

Table 3-2 AAMEX Model for Overlay Pavements

\begin{tabular}{|l|c|c|l|}
\hline \multicolumn{1}{|c|}{ Predictor } & $\begin{array}{c}\text { Coefficient } \\
\text { Estimate }\end{array}$ & t-statistic & \multicolumn{1}{|c|}{ Meaning of Predictor Symbol } \\
\hline Constant & 5.8515 & 35.1424 & Constant term \\
\hline INT CLSS & -0.4275 & -4.5193 & $\begin{array}{l}1 \text { if Interstate } \\
0 \text { if Otherwise }\end{array}$ \\
\hline AREA CLSS & -0.2252 & -2.9627 & $\begin{array}{l}1 \text { if Rural } \\
0 \text { if Urban }\end{array}$ \\
\hline SOUTH F & -0.3278 & -4.4908 & $\begin{array}{l}1 \text { if Pavement in located in Southern Indiana } \\
0 \text { if Otherwise }\end{array}$ \\
\hline PRIOR F & 0.2403 & 1.7624 & $\begin{array}{l}1 \text { if no PCC treatment prior to overlay } \\
0 \text { if Crack-and-Seat or Rubblized }\end{array}$ \\
\hline AGE & 0.0364 & 4.3831 & $\begin{array}{l}\text { Number of Years since Last Rehabilitation } \\
\text { or Construction }\end{array}$ \\
\hline
\end{tabular}

Source: Labi and Sinha, 2002.

The response variable is the natural logarithm of the average maintenance costs given in dollars per lane-mile, incurred annually by INDOT. This includes all types of maintenance regardless of the role (preventive and corrective), work source (in-house and contractual) or work cycle (routine and periodic). 
The model indicates that expected average annual maintenance expenditure is generally lower for rural interstates compared to urban interstates and also higher for northern pavements than southern pavements. In the present study, all the sections are interstates. The model also shows that traditional overlay pavements are generally more expensive to maintain than crack-and-seat or rubblized pavements. In the crack-and-seat, and rubblized method, the existing concrete pavement is crushed to smaller pieces prior to the hot mix asphalt overlay. All the control projects selected for the study are overlay pavements with similar surface type to their warranty counterparts. The AGE variable is the age of the pavement after the end of reconstruction or rehabilitation. Using the above model, the annual maintenance expenditures for the traditional projects were estimated. Unlike construction costs, maintenance costs are largely carried out by in-house forces and therefore are not subject to fixed/variable cost relationships associated with different work loads which in turn give rise to economies of scale.

\subsubsection{Adjustments of Construction Costs to Account for Economy of Scale Effects}

In comparing the cost of two alternative transportation "systems" (that is, structures, practices, processes, or policies) it is often implicitly assumed that a linear relationship exists between the cost of each system and its size. With such implicit assumptions, cost comparisons have often proceeded on the basis of the cost per unit dimension of each facility (e.g., cost per mile of pavements of different surface type, cost per square ft. of different bridge types, cost per passenger-mile for different transit systems). A few past researchers in infrastructure management have shown that the relationship between project cost and project dimension is generally non-linear: the greater the project dimension, the lower the unit cost (cost per lane-mile). In other words, economies of scale generally exist in system costs. However, in many studies that involved comparison of alternative system costs, such economy of scale effects have not been duly considered and as such may have led to significant bias in the results against the alternative that has smaller project dimensions. For example, comparing the unit costs (per lane-mile cost) of a 20mile pavement of type $\mathrm{X}$ to a 3-mile pavement of type $\mathrm{Y}$ (all other characteristics being equal) would be unfair because pavement type $\mathrm{X}$, by virtue of its greater length, is likely to yield a smaller unit cost and consequently higher cost effectiveness compared to pavement type $Y$. There is therefore a need to duly consider economy of scale effects when carrying out comparisons of this kind, such as the present study.

In comparing the given aggregate costs of alternative transportation systems or processes, economy of scale effects can be resolved by establishing a correction factor by which unit costs corresponding to a certain dimension can be adjusted to yield unit costs corresponding to a certain specified standard project dimension. This section of the report develops a methodology by which the given contract costs of warranty and traditional contracts can be adjusted to normalized values that are devoid of economy of scale effects. 
First, we consider a generalized hypothetical unit cost function that relates the cost per unit dimension (such as cost per lane-mile) of the pavement project while keeping the other dimensions constant (such as thickness, width or number of lanes). The economy of scale effects (decreasing unit cost as project dimension increases) can be graphically manifest in a number of ways, depending on the data, as shown in Figure 3-1 below.

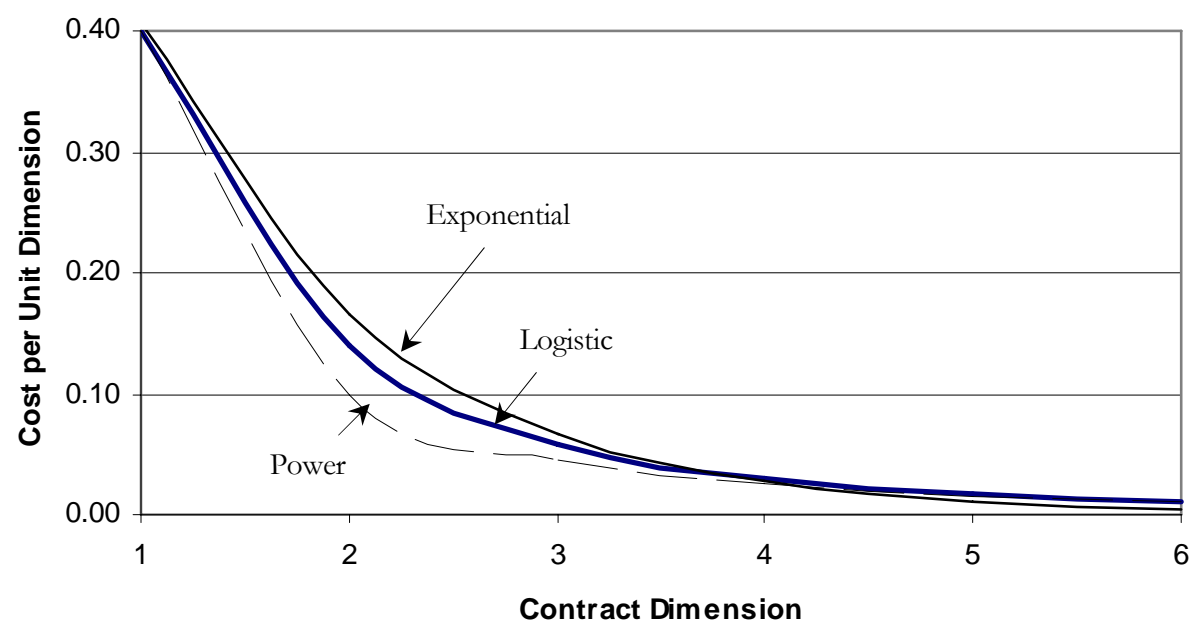

Figure 3-1: Common Mathematical Forms of Unit Cost Functions Illustrating Economy of Scale Effects

Common trend lines for economy of scale effects are as follows:

$C=A^{*} e^{-L} \quad$ (Exponential function)

$C=\frac{A}{B+C^{*} L} \quad$ (Logistic function)

$C=k L^{a} \quad$ (Power function) This is specific form of the Cobb-Douglas mathematical form which is expressed as follows: $C=A N^{\mathrm{a}} * B L^{\mathrm{b}} * C T^{\mathrm{c}}$.

Unit cost functions can be developed using historical data on construction contract total costs and project dimension (such as number of miles). Separate function can be developed for each contract type (in this case, warranty and traditional). Then within each contract type, separate models can be developed for different surface, pavement thickness, and number of lanes. Therefore, a considerable amount of data may be needed to generate separate curves for each of the several categories. In practice, there are relatively few variations in the number of lanes.

Secondly, the most common contract dimension (the ordinate axis in Figure 3-1) for which unit costs are developed is project length. However, it is worth noting that the contract dimension may be thickness (in which case we are investigating the decrease in cost per unit thickness as pavement 
thickness increases, all other dimensions and factors being constant). The dimension may also be road width/number of lanes, in which case we are investigating the decrease in cost per unit width or number of lanes as the pavement width increases, all other factors staying the same.

In comparing the unit costs of two alternative families, systems or practices, (in this case, traditional and warranty contracts), it is not unusual to have unit cost functions that differ in shape.

After identifying the various contract categories or families for developing the unit cost functions, the next step is to choose a standard dimension, $L_{\mathrm{a}}$, to which all the dimensions of various contract families should be translated for purposes of comparison. $L_{\mathrm{a}}$ may take on any value, provided it is uniform for all contract families under investigation. In the context of the present study, a contact family is warranty pavement of a given functional class and a given pavement thickness and road width. For practical and convenience purposes, $L_{\mathrm{a}}$ may simply be the average dimension of all contracts of that family that has historically been let out by INDOT.

Consider two contracts $\mathrm{X}$ and $\mathrm{Y}$ of dimensions (lengths) $L_{\mathrm{X}}$ and $L_{\mathrm{Y}}$, respectively. Assume they have unit costs $U C_{\mathrm{X}}$ and $U C_{\mathrm{Y}}$, respectively.

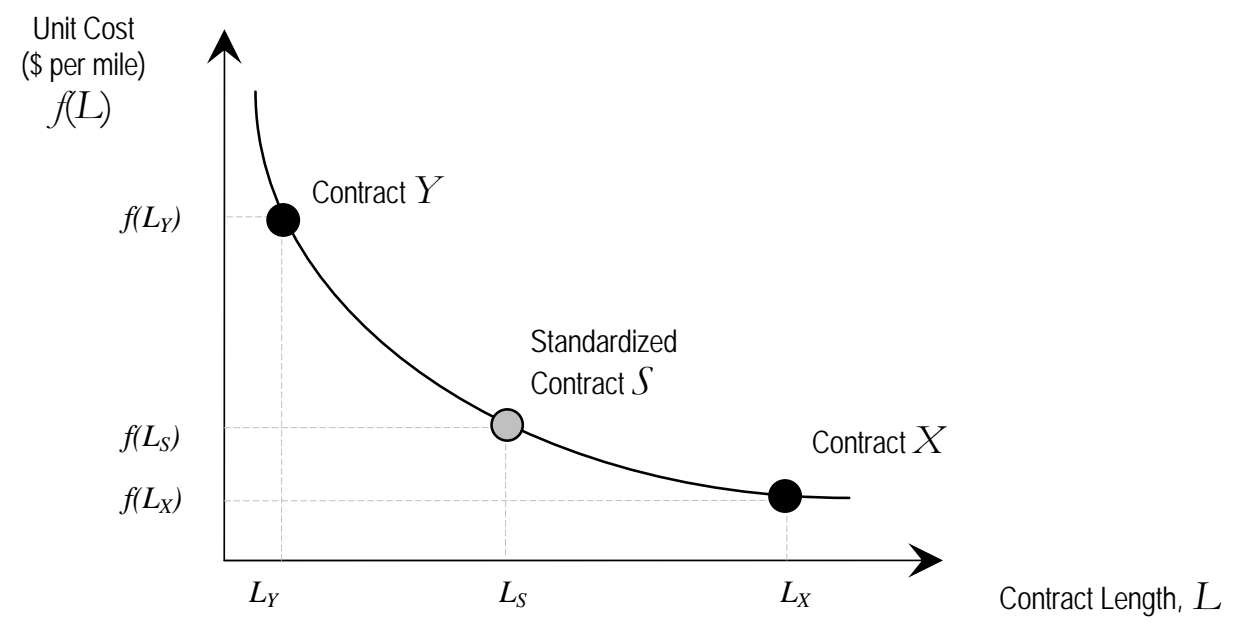

Figure 3-2: Illustration of Unit Costs Relationships among Projects of Small, Large, and Standard Dimension

As seen from Figure 3-2, contract $X$ has large dimension and therefore has a relatively small unit cost while contract $Y$ has a small dimension and has a relatively large unit cost. Assume that both contracts differ only in contracting practice (warranty vs. traditional) and therefore have the same width, thicknesses, surface type, etc. If these two contracts represent two different contracting practices, then a conclusion that the contracting practice corresponding to $X$ is less costly or less cost-effective than that of $Y$ would be incorrect as such "relative cost" may be due not to inherent superiority of $X$ but the economy of scale effects arising from the larger dimension of $Y$. If $X$ and $Y$ are constructed to the same 
dimension, the economy of scale effects on the comparative analysis would be obviated. While it is not possible or even necessary to enforce such restrictions in practice, it is possible to translate the costs of the alternative contacts to a certain standardized dimension $\mathrm{S}$, in order to make a fair comparison of their costs and cost-effectiveness. Obvious choices for such standard dimension include the arithmetic average the two dimensions, the most common dimension to which such contracts are typically constructed in agency practice, or the any one of the two dimensions, $L_{\mathrm{X}}$ and $L_{\mathrm{Y}}$.

In order to do this, it is necessary to establish the cost functions. This involves the collection of historical contract data for each of the two alternative systems under investigation. For each alternative system (such as traditional contracts), the contracts may be grouped by road width, pavement thickness, surface type, and other basic characteristics. Then, within each group, develop a graph that shows the relationship between the unit cost (cost per mile) and the contract length. Comparison of the costs should be made between similar groups across the alternative systems, (for example, compare warranty pavements in a group with 2-lanes, 9-inch thickness, full depth HMA, Interstate, to traditional pavements in a group having the same characteristics. The above method will yield a large number of models, each for every different combination of contract characteristics.

A more rigorous method to develop the unit cost functions is to develop a single unit cost function for all contracts by estimating unit costs as a function of contract length, width, thickness, functional class, surface type, etc. Then differentiating such function with respect to the dimension under investigation (in this case, contract length) would yield the unit cost function with respect to the preferred dimension. This would simplify the analysis. However, possible interactions between the variables (contract characteristics) such as thickness and functional class, if not corrected for, may introduce some bias in the analysis.

There are two cases involving such translation of unit costs of contracts to a standardized value:

(i) when the contract has coordinates (unit cost and length) that lie exactly on the established unit cost function, such as shown in Figure 3-2. In such as case, the given unit cost of the contract is irrelevant in the determination of the standardized cost. The standardized cost is simply obtained by substituting the value of the standard length into the unit cost function.

(ii) when the contract has coordinates (unit cost and length) that do not lie on the established unit cost function (Figure 3-3). This is the more generalized and more practical formulation of the problem. 


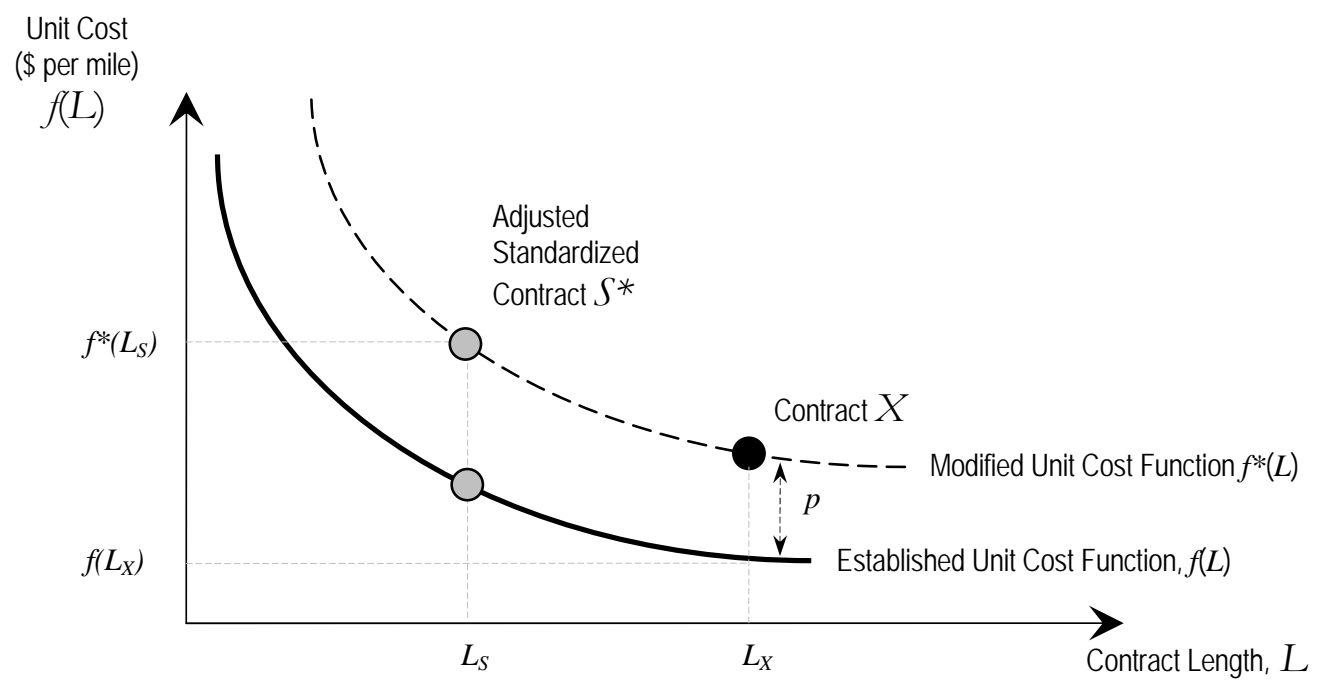

Figure 3-3: Unit Cost Adjustment to Reflect Economy of Scale Effects, where Given Unit Cost Does Not Lie on Established Cost Function

In Figure 3-3, the coordinates of the contract being adjusted is shown such that it is above the unit cost function, and is also downstream of the position of the standardized contract. This is for illustrative purposes only. Contracts may be located below the unit cost function and may also be located upstream of the position of the standardized contract (Figure 3-4).

The magnitude and direction of the unit cost adjustment illustrated in Figure 3-3 depend on

- the value of $p$ (how much the given unit cost of the contract deviates from the unit cost of a similar contract of the same length),

- the functional form and parameters of the established unit cost function, 


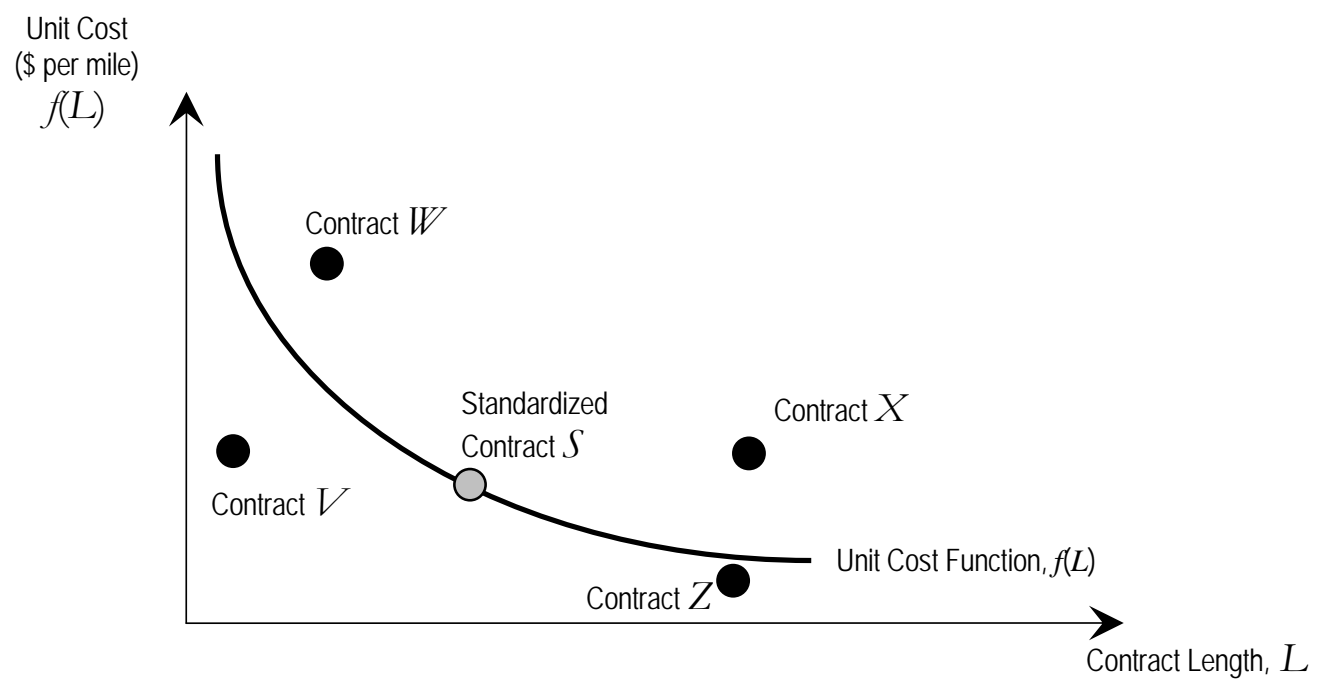

Figure 3-4: Possible Locations of Contract with Respect to Unit Cost Function and Standardized Contract

Another way to look at the adjustment procedure for unit costs of contracts that do not lie on the cost function is to shift the established user cost function upwards or downwards to meet the given contract coordinate, then to slide up or down the function to the point of the adjusted standardized contract. Mathematically, this means that we translate the established unit cost function, $f$, by a vector $p$, to get a new a new unit cost function, $f$, and then substitute the value of the standard length, $L_{\mathrm{S}}$ in the new unit cost function.

Example: If the established unit cost function is: $f(L)=y=e^{-k L_{X}}$

and $p,=$ the given unit cost of the contract - the unit cost of the contract corresponding to the given contract length.

$$
=C_{\mathrm{X}}-f\left(L_{\mathrm{X}}\right)
$$

Then the modified function is: $f(L)+p=y=e^{-k L_{X}}+p$

$$
\text { or } \begin{aligned}
y-p & =e^{-k L_{X}} \\
y^{*} & =e^{-k L_{X}}
\end{aligned}
$$

Given $L_{\mathrm{X}}$ and $\mathrm{y}^{*}$, the adjusted value of $k, k^{*}$, can be found and substituted to yield an adjusted unit cost function. Using this adjusted function, the standardized unit cost, $f^{*}\left(L_{\mathrm{S}}\right)$, corresponding to the given contract unit cost X, can be determined. Such translations of an established unit cost function can be done for any contract given its unit cost. The first case discussed above (where when the contract has coordinates (unit cost and length) that lie exactly on the established unit cost function) is a specific case of the latter, more general case where $p$ is zero. It can be seen that with the given coordinates of the contract under investigation, it is was rather easy to determine the adjusted unit cost function because the 
chosen mathematical form involves only one unknown parameter, $\mathrm{k}$, that needs to be determined so that the function could be fully described. For mathematical forms that involve 2 parameters, at least two points (unit cost and lengths of contracts of the given type) are needed in order to fully define the adjusted unit cost function.

The above methodology was used to adjust all the given unit costs in the current study in order to remove any bias due to economy of scale effects.

\subsubsection{User Costs}

The user costs associated with the delay experienced during the work zone duration, was considered in the analysis. The work zone user costs are influenced by the timing, duration, and frequency of construction and rehabilitation strategies, the volume of traffic disrupted due to the work zone, along with the predetermined cost rates [Walls and Smith, 1998]. The delay costs reflect the delay experienced by the motorists due to reduction of roadway capacity resulting from work zones. Crash costs have not been considered in the present study, as past research has determined that workzone crash rates are typically low [NJDOT, 2001] and may be excluded from such analysis. The overall cost of each project is then expressed in terms of agency and user costs.

Traffic has to be considered in the analysis as user costs are dependent on the volume of traffic. Any obstruction in the form of work zone will directly affect the flow of traffic reflected in user delays. For calculating the user costs associated with each project, the same average Annual Average Daily Traffic (AADT) as well as the same average truck percentage was used for both warranty and traditional projects in order to allow a fair comparison.

The 1996 dollar values of time in vehicle per hour converted to Year 2000 constant dollar, associated with the different classification of vehicles are shown in Table 3-3.

Table 3-3 Value of Time

\begin{tabular}{|c|c|c|}
\hline Vehicle Class & $\begin{array}{c}\text { Value of time }(\$ / \text { Veh-Hr }) \\
(1996)\end{array}$ & $\begin{array}{c}\text { Value of time }(\$ / \text { Veh-Hr }) \\
(2000)\end{array}$ \\
\hline Passenger Car & 11.58 & 12.41 \\
\hline Single Unit Trucks & 18.54 & 19.88 \\
\hline Combination Trucks & 22.31 & 23.92 \\
\hline
\end{tabular}

Source: Walls and Smith, 1998

A speed limit of $65 \mathrm{mph}$ was assumed for normal operating condition, while a speed of $45 \mathrm{mph}$ was assumed when the work zone is in place. All the project sections have two lanes in each direction during normal operating condition, and a closure of one lane in each direction was considered when the 
work zone was in place. Speed reduction from $65 \mathrm{mph}$ to $45 \mathrm{mph}$ in the work zone results in a travel time difference of $24.6 / \mathrm{sec}$ or $0.0068 / \mathrm{hr}$.

User Cost per Auto/mile $=0.0068 \times \$ 124.41$

User Cost per Single Unit Truck $/$ mile $=0.0068 \times \$ 19.88$

User Cost per Combination Truck $/$ mile $=0.0068 \times \$ 23.92$

The unit costs were multiplied by the appropriate percentage of AADT and work zone duration gives the total user associated with each project.

The work zone duration is an important aspect for computing user costs because it leads to increased user costs. This duration is the total number of days the work zone will be in place. For the present study, the analysis is based on each-lane mile of each contract section to account for differences in the project length. As such, the work zone duration per lane-mile (days) was computed from the contract duration using a model developed by Lamptey et al. [2004] that predict work-one duration as a function of contract length as shown:

$$
y=100.56 x^{-0.9314} ; \quad \mathrm{R}^{2}=0.755 \quad \text { for Road Reconstruction (3R/4R Standards) }
$$

where $x$ is length of contract section in miles, $y$ is contract duration per lane-mile

The contract duration is the total number of days from the date of contract award to the date of acceptance of the finished work by the agency. From anecdotal sources, it was assumed that workzone duration is $60 \%$ of the contract duration, for both warranty and the control (traditional) projects.

\subsection{Methodology for Estimation of Effectiveness}

The effectiveness of a pavement is reflected in the performance exhibited after the completion of construction of the project. Performance is evaluated in terms of the distresses exhibited by a pavement over the years. This section discusses the temporal scope of the evaluation process and the various units (pavement distress parameters) used for the measurement of effectiveness.

\subsubsection{Temporal Scope of Effectiveness Evaluation}

For the present study, the analyses of performance and costs of the pavements were carried out over different sets of time horizons to get a clear understanding of whether the associated benefits of warranty or traditional contracts are evident immediately after construction or are accumulated over the years. As such, the evaluation of cost-effectiveness can be carried out in three different time frames - short-term, medium-term, and long-term. Short-term assessment is based on the performance of the pavement immediately after construction. As such, it indicates the "jump" in the values of the performance indicators. The associated cost for such an assessment is the initial construction cost borne by the 
agency. For the present study, short-term evaluation was not carried out as it does not provide any insight into the effectiveness of the project over time. Medium-term assessment of effectiveness takes into account the actual performance exhibited by the pavements during the 5 -year warranty period and the costs incurred by the agency and user over that period. The costs included for such an assessment are the initial construction cost and the maintenance expenditure incurred over the warranty period. On the other hand, long term evaluation is considered over the life of the treatment, and pavement performance for future years were established by extrapolating the trends from the medium-term analysis. The user costs were also computed over the treatment life. Table 3-4 indicates the various effectiveness evaluation criteria used for each temporal scope.

Table 3-4 Temporal Scope of Effectiveness Evaluation

\begin{tabular}{|lll|}
\hline \multirow{2}{*}{ Measures of Effectiveness } & \multicolumn{2}{c|}{ Temporal Scope of Effectiveness Evaluation } \\
\cline { 2 - 3 } & $\begin{array}{l}\text { Medium Term - 5 years } \\
\text { (using actual data) }\end{array}$ & $\begin{array}{l}\text { Long Term - Treatment } \\
\text { Life-Cycle } \\
\text { (using actual data \& } \\
\text { extrapolated trends) }\end{array}$ \\
\hline Average Pavement Condition & $\checkmark$ & $\checkmark$ \\
\hline Average Pavement Life & $\checkmark$ \\
\hline $\begin{array}{l}\text { Average Area under } \\
\text { Performance Curve }\end{array}$ & $\checkmark$ & $\checkmark$ \\
\hline
\end{tabular}

\subsubsection{Performance Indicators for Assessment of Effectiveness}

The main rationale for implementing warranty provisions in highway contracting is to deliver a quality product in order to meet the increasing demand for better transportation facilities. Therefore, pavement performance has to be carefully monitored to determine whether condition of the pavement is within safe and acceptable limits without causing any discomfort to the traveling public. Various indicators are used to measure distresses in pavements which have been established to demonstrate how well a pavement is performing. For INDOT's asphalt pavements, performance is measured in terms of International Roughness Index (IRI), rutting, cracking, and surface friction, based on the specifications established by INDOT. Based on the expected life of the pavement, the threshold values of these performance indicators over the warranty period are established to reflect acceptable serviceability of the pavements [INDOT, 2002]. Each distress indicator is explained briefly in subsequent sections.

\section{International Roughness Index (IRI)}

Pavement roughness is often considered the most important indicator of pavement condition as it directly reflects pavement ride quality. Generally, roughness is measured in terms of the International Roughness 
Index (IRI). The IRI is an interpretation of the longitudinal surface profile in the wheel path of a vehicle and is computed from surface elevation data collected by a profilometer, expressed in units of inches per mile (in/mi) or meter per kilometer (m/km) [Huang, 1993]. An IRI of 0.0 means the profile is perfectly flat, while a high IRI value such as $8 \mathrm{~m} / \mathrm{km}(508 \mathrm{in} / \mathrm{mi})$ indicates that the pavement is very rough. INDOT regularly monitors IRI of all pavements on the state highway system. Profiles are collected with a van equipped with profile measurement sensors as specified in the current Highway Performance Monitoring System (HPMS) manual. The wheel path measurements are taken over 100 meter segments along the entire contract section length and the average of the left and right wheel paths values are used to calculate the IRI. Generally, reference posts, bridge posts and other landmarks are used to establish the location of the 100 meter segments. The threshold values for average IRI in any 100 meter segment are established at $2.1 \mathrm{~m} / \mathrm{km}(133 \mathrm{in} / \mathrm{mi})$ in any 100 meter segment for "crack-and-seat" overlay projects, and $1.9 \mathrm{~m} / \mathrm{km}$ (120 in/mi) for "rubblized" overlay projects [INDOT, 2002]. If the threshold is reached any time during the warranty period, then the contractor is required to undertake specified remedial action.

\section{$\underline{\text { Rutting }}$}

Rutting is another indicator used to measure the performance of warranty pavements. Rutting is basically a surface depression in the wheel paths of vehicles, caused by consolidation or lateral movement of the asphalt mix (resulting from inadequate compaction during construction) due to traffic loads (Huang, 1993). Rut depth is measured annually by INDOT along with the profiles for roughness. The sensors on the van take measurements at the right wheel path center, center of the lane, and the left wheel path center along the entire length of the warranted section. The average rut depth is calculated for 100-meter segments established for IRI. INDOT warranty specifications typically stipulate that the average rut depth in each of these segments should be less than the threshold value of $6 \mathrm{~mm}(0.24 \mathrm{in})$ for both “crack-and-seat" and "rubblized" pavement projects.

\section{Cracking}

The third indicator used to measure the performance of warranty pavements is pavement cracking. Pavement cracking is generally indicates degradation of structural performance and is caused by shrinkage of asphalt surface at low temperature or may be due to hardening of asphalt. In the case of asphalt-on-concrete composite pavements, cracking may also be caused by reflective cracks resulting from differential movements of the underlying concrete slabs. Longitudinal and transverse cracks are typically not induced by traffic loads; however traffic loading can exacerbate an initial crack by causing deterioration in the vicinity of the initial crack. Crack distresses are measured in linear feet or meters. Details of each of the two major cracking types are provided below. 


\section{Longitudinal Cracking:}

Longitudinal cracking occurs parallel to the centerline of the pavement at any part of the travel lane. It includes shoulder-lane joints, lane joints, paver seams, wheel path or mid-lane cracks [INDOT, 2002]. Longitudinal cracks are measured by INDOT at the time of annual condition survey for both rubblized and crack-and-seat pavements. The warranty pavement is visually examined for 500 feet in the travel direction at each reference post and is rated in terms of severity and extent of any longitudinal cracks. The level of cracking severity ranges from "none" (no observed cracks) to "heavy" (large open cracks). Similarly, the extent of cracking is categorized as "none" (no cracks) to "many" (continuous cracking along the warranted segment). Based on these criteria, the threshold for longitudinal cracking is established at a severity rating of MODERATE or 2 (wide open or raveled cracks) and an extent of FEW or 1 (less than or equal to fifty percent of the length of the warranted segment) [INDOT, 2002]. If these threshold values are exceeded in any sample section of the warranty project, the contractor is made to undertake appropriate remedial action.

\section{Transverse Cracking}

Transverse cracking develops perpendicular to the pavement centerline, and may be fine cracks or thermal cracks that extend across the travel way. This type of distress is measured for warranty rubblized overlay pavements only during annual routine condition survey. In such surveys, the warranty pavement is visually examined for 500 feet in the travel direction at each reference post and is rated in terms of severity and extent of the transverse cracks. The level of severity ranges from "none" (no crack) to "heavy" (large open cracks with severe spalls). The length of the crack is also noted. The detailed distress rating for transverse cracking is given in Appendix A. The thresholds are established at MODERATE or 2 (crack is greater than $1 / 4$ inch wide) severity and $5.5 \mathrm{~m}$ (18 inch) length for any continuous crack [INDOT, 2002].If these threshold values are exceeded, the contractor is made to correct the defect as per the warranty provisions.

\section{$\underline{\text { Surface Friction }}$}

Surface friction is another important indicator for evaluating condition of the pavement surface. The pavement must be provided with adequate friction to avoid skid-related problems, particularly under wet conditions. For warranty pavements, INDOT conducts annual friction tests using the Locked Wheel Trailer. Measurements are carried out in both directions at each reference post and also at the mid-point between each reference post [INDOT, 2002]. The friction number typically ranges from 10 to 60 in increasing order of friction resistance. INDOT specifies that the average friction number for each lane in both directions of the warranty segment should not be less than 35 at any time during the warranty period. The warranty provisions also establish that no three consecutive readings shall have a friction 
number of 25 or less [INDOT 2002]. As part of the warranty project management program, INDOT collects friction data for warranty projects on an annual basis. Such data collection is carried out using a special protocol established for that purpose, termed as "warranty protocol". Inventory friction data (at the network level) is collected employing a different protocol (inventory protocol). Differences in data formats arising from these different testing protocols precluded the use of friction as a performance indicator in comparing the warranty and non-warranty projects.

Table 3-5 summarizes the main distress indicators and their threshold values used to evaluate the performance of warranty projects. If the thresholds are exceeded at any time during the warranty period, the contractor is made to carry out remedial work based on the warranty provisions. Further testing and evaluation are typically required for acceptance of the project.

Table 3-5 Distress Indicators

\begin{tabular}{lll}
\hline Distress Indicator & Pavement type & \multicolumn{1}{c}{ Threshold value } \\
\hline IRI & Crack-and-seat, Rubblized & $\begin{array}{l}\text { Less than } 2.1 \mathrm{~m} / \mathrm{km}(133 \mathrm{in} / \mathrm{mi}) \\
\text { Less than } 1.9 \mathrm{~m} / \mathrm{km}(120 \mathrm{in} / \mathrm{mi})\end{array}$ \\
\hline Rut & Crack-and-seat, and Rubblized & Less than $6 \mathrm{~mm}(1 / 4 \mathrm{in})$ \\
\hline $\begin{array}{l}\text { Longitudinal } \\
\text { Cracking }\end{array}$ & Crack-and-seat, and Rubblized & $\begin{array}{l}\text { Severity: less than or equal } 6 \mathrm{~mm}(1 / 4 \text { in) } \\
\text { Extent: less than } 50 \% \text { of length }\end{array}$ \\
\hline $\begin{array}{l}\text { Transverse } \\
\text { Cracking }\end{array}$ & Rubblized only & $\begin{array}{l}\text { Severity: less than or equal } 6 \mathrm{~mm}(1 / 4 \text { in) } \\
\text { Extent: less than } 5.5 \mathrm{~m} \text { (18 in) }\end{array}$ \\
\hline Friction & Crack-and-seat, and Rubblized & Greater than or equal 35 \\
\hline Source: INDOT, 2002. & & \\
\hline
\end{tabular}

The average IRI values at each year were determined from historical records for each project. Pavement Serviceability Index (PSI) is based on the Pavement Serviceability Rating (PSR) scale which runs from 0.0 (poor condition) to 5.0 (excellent condition). PSI values were estimated from IRI using the model developed by Al-Omari and Darter [1994]:

$$
\text { PSI }=5 \times \exp (-0.0041 \times \text { IRI })
$$

where IRI is in inches per mile.

The PSI-IRI equation developed by Gulen et al. (1994), which was developed using data from Indiana pavements, was initially considered for use in the present study. However, it was found that the Gulen et al. relationship gave PSI values exceeding 5.0 (the theoretical maximum) when IRI is low. In the present study, the pavement sections that were studied were relatively young and therefore had low 
IRI. As such, use of the Gulen et al equation for the new pavements in this study tended to yield unrealistic PSI values. The PSI-IRI equation developed by Darter and Al-Omari (1994) was therefore used.

The rutting depth is measured during the annual condition survey along with the IRI, and the average values are determined in a manner similar to that for IRI. The Pavement Condition Rating (PCR) provides an overall method of identifying pavement distresses in terms of severity and extent, and is based on the visual inspection of the pavement. The PCR scale ranges from 0 to 100, 100 indicating a perfect pavement and 0 representing a pavement with all distress in the extreme levels of severity and extent. The PCR of each project at any age is the average value of PCR values of all its constituent sections. Each set of distress parameters attributed to the warranty pavement was examined over the warranty period and compared with those of the control projects. The distress indicators were then plotted with respect to time (age) to obtain a better perspective of comparative performance trends during the warranty period.

The trend of these performance indicators were also examined with the pavement traffic loading. This was done to highlight the effects of traffic and percentage trucks on pavement condition, which may not be evident in the performance-time analysis, and provided a better understanding of warranty and traditional pavement deterioration trends with increasing traffic over the years. The Equivalent Single Axle Load (ESAL) values were computed using factors, 1.3 for Multiple Unit Trucks and 0.6 for Single Unit Trucks [Gulen, et. al., 2000].

For the present study, friction could not be used in determining the effectiveness of the pavements. This is because no reliable friction data could be obtained for traditional projects included in the analysis.

\subsection{Methodology for Evaluation of Cost-effectiveness}

This section provides a discussion of the methodology adopted in the present study, and how the performance and cost elements of various warranty and traditional contracts were used for analysis. The analysis has been divided into two parts - medium-term and long-term evaluation.

\subsubsection{Medium-Term (5-year) Evaluation}

The medium-term evaluation of the warranty and traditional projects was based on the performance and cost analyses over the warranty period ( 5 years). The length of medium-term is not necessarily a fiveyear period. For purposes of this study, a five-year period was used because actual data was available only up to five years. Also, this was termed "medium-term" because 5 years may be considered the midpoint of short-term evaluation period (immediately after construction) and long-term evaluation period (which is the treatment life and generally exceeds 10 years). 
(i) Medium-Term Effectiveness Type I (Area enclosed by Performance Curve)

The areas under the performance curve were determined by plotting the IRI values with pavement age. Smooth curves were drawn representing the IRI trends. The areas were then determined by integrating the equations of the curves using the age of the pavement as limits. As IRI values increases with pavement age, effectiveness is represented by the area enclosed between the curve and the threshold line as shaded, and is determined by subtracting the area under the curve from the total area of the rectangle (Figure 3-5). Thus,

Area enclosed by IRI curve $=$ Area of rectangular region $(\mathrm{OABC})-\int_{0}^{n} f(x) d x$

where $n$ (pavement age) $=5$ years.

The threshold value of IRI indicated in the figure is the maximum IRI value as specified by INDOT's warranty criteria.

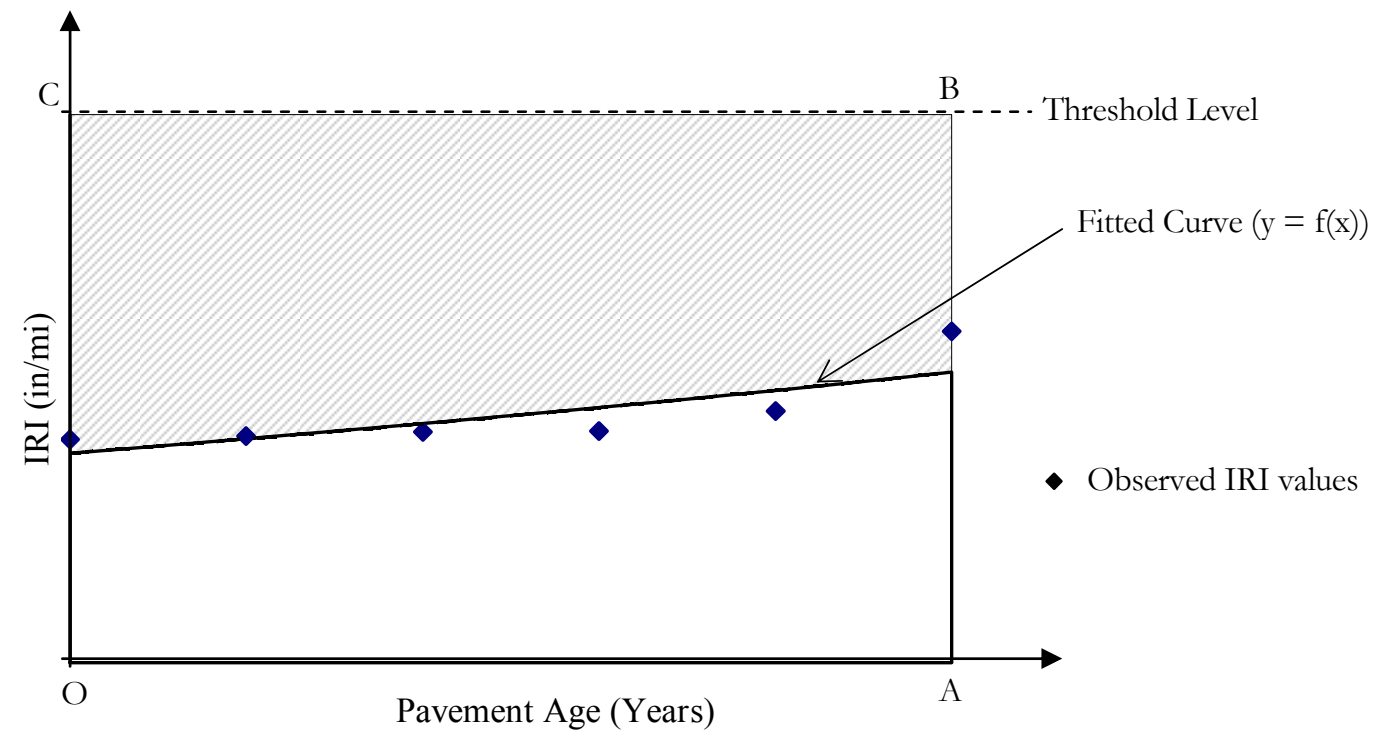

Figure 3-5 Conceptual Area bounded by the IRI vs. Age Curve for Medium-Term Evaluation

Effectiveness was also measured in terms of Pavement Quality Index (PQI). PQI is a function of PSI, PCR and Rutting and is given by the formula [INDOT 2001]:

$P Q I=10 * P S I+0.5 * P C R-25 * R u t$

where Rut is in inches.

PQI rating ranges from 100 to 0 , pavements in the range 90 to 100 are considered excellent; pavements 
in 90 to 80 range are good and pavements below 70 are considered to be in poor condition [INDOT, 2001]. Figure 3-6 shows a representation of the area under the curve corresponding to the PQI values of the pavements. The shaded region represents the effectiveness of the pavement treatment.

Area under PQI curve $=\int_{0}^{n} f(x) d x$, where $n$ (pavement age $)=5$ years

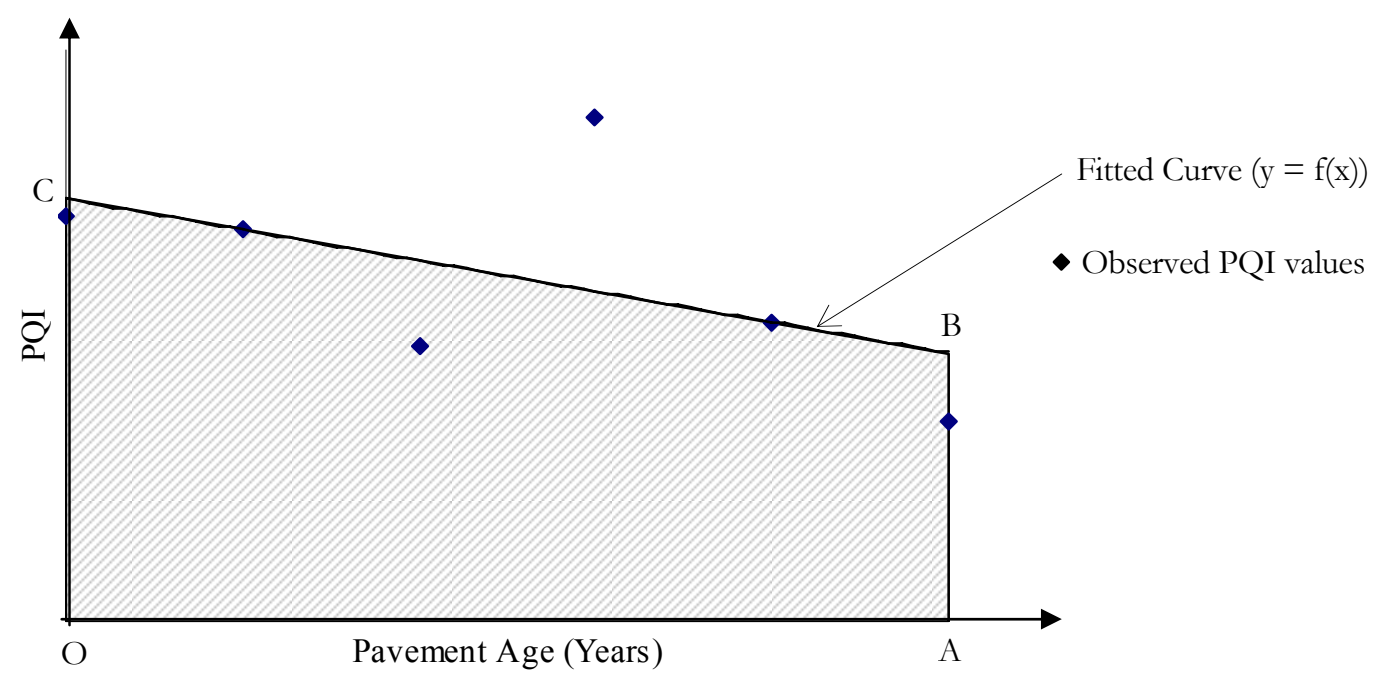

Figure 3-6 Conceptual Area under the PQI vs. Age Curve for Medium-Term Evaluation

(ii) Medium-Term Cost-effectiveness

After the cost and the performance analyses were carried out, the next step was to perform an overall assessment of cost-effectiveness for both warranty and traditional projects. The benefits were measured in terms of pavement performance over a period of time. For the purpose of the present study, costeffectiveness (CE) is defined as follows.

$\mathrm{CE}_{1}=\frac{\text { Area under the IRI }- \text { Time curve }}{\text { EUAC }}$

$\mathrm{CE}_{2}=\frac{\text { Area under the IRI }- \text { ESAL curve }}{\text { EUAC }}$

$\mathrm{CE}_{3}=\frac{\text { Area under the PQI - Time curve }}{\text { EUAC }}$

$\mathrm{CE}_{4}=\frac{\text { Area under the PQI - ESAL curve }}{\text { EUAC }}$

where EUAC $=$ Equivalent Uniform Annual Cost during the warranty period. 
The cost-effectiveness of each project is therefore expressed in quantitative terms, thereby providing a rational basis for comparison. The above formulations of cost-effectiveness defined above were applied to warranty and the control projects in each comparison set. The project with a higher value is considered more cost-effective.

\subsubsection{Long-Term (Treatment Life-Cycle) Evaluation}

The previous section discusses a methodology for warranty cost-effectiveness evaluation over the medium-term. However, some schools of thought may consider it more appropriate to investigate warranty project cost-effectiveness over a period exceeding 5 years. As such, a long-term analysis was also carried out in the present study to identify the better contracting method in terms of project costs and pavement performance. Life-cycle cost analysis (LCCA) is defined as "a process for evaluating the total economic worth of a usable project segment by analyzing initial costs and discounted future cost, such as maintenance, reconstruction, rehabilitation, restoring, and resurfacing costs, over the life of the project segment" [Lee, 2002]. For the present study, the analysis is carried out only till the end of the service life of the initial construction activity rather than the pavement life. All the costs components incurred on a project by agency and user over the period was considered and the differential costs between the two alternatives - warranty and traditional - were determined.

\section{(i) Treatment Service Life}

The long-term analysis was carried out over the expected treatment service life of each treatment. For the present study, treatment service life is defined as the period from the initial work done on the pavement till the time when the pavement reaches a specified terminal serviceability level. The treatment service lives were determined using observed performance data of the pavements during the first five years after initial construction. The performance trends were established by plotting trend lines for the average IRI values of all contract segments for all the projects over the age of the pavement. Figures 3-7 and 3-8 show the projected treatment life of the warranty and traditional projects, respectively. 


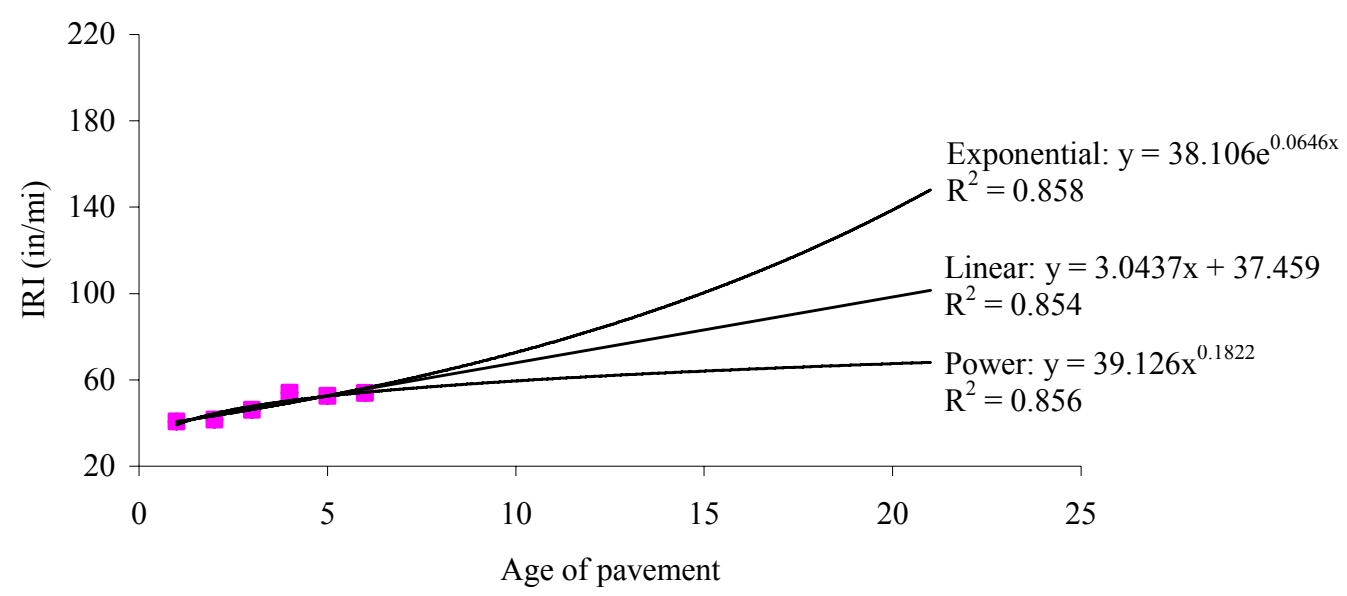

Figure 3-7 Alternative Models for Warranty Pavement Performance Trends

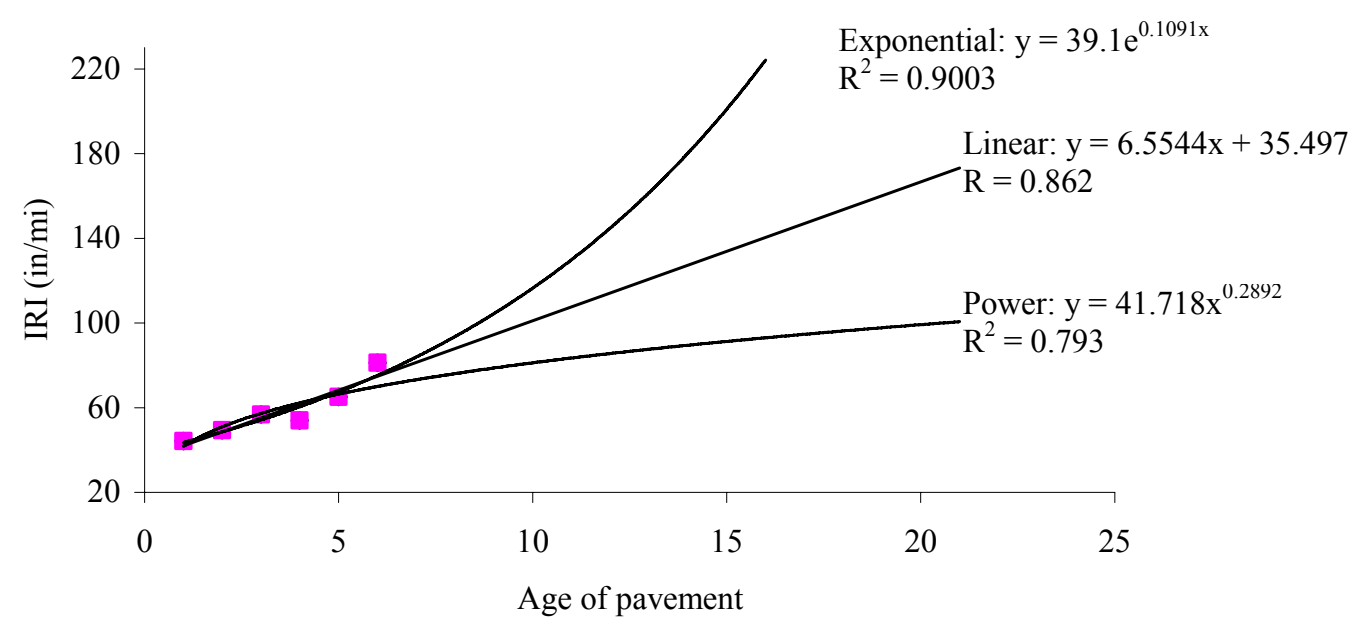

Figure 3-8 Alternative Models for Traditional Pavement Performance Trends

For each alternative contracting method, the exponential functional form was selected over the linear and power forms projecting the performance trends to yield service lives, as it indicated the highest fit to the data (R-square values of 0.86 for warranty and 0.90 for traditional projects). The curves were extrapolated to an IRI value of $200 \mathrm{in} / \mathrm{mi}$, which was considered as terminal serviceability for the present study, as: pavements with IRI values exceeding 200 are considered to be in poor condition in Indiana [INDOT, 2002]. Figure 3-9 shows projected service lives of the warranty and the traditional projects. 


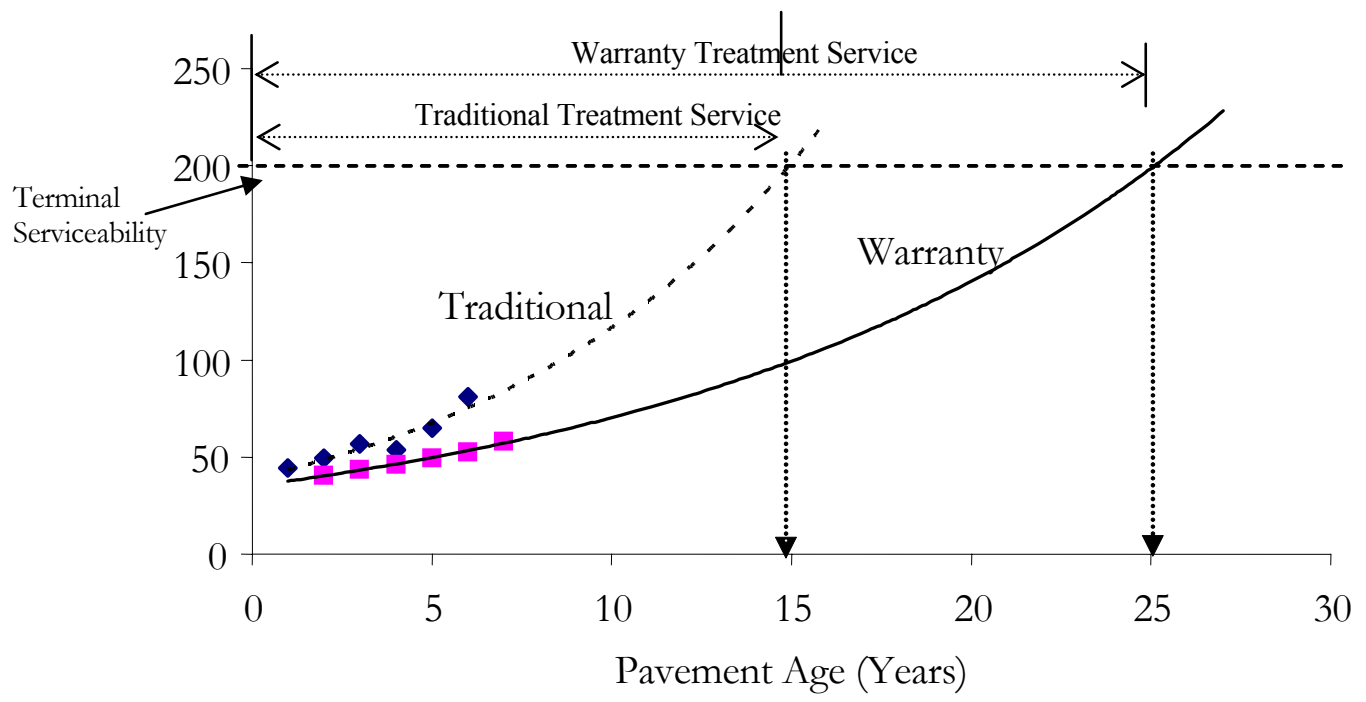

Figure 3-9 Estimated Service Lives of Warranted and Traditional Pavements

Based on performance trends developed from observed data, the treatment service life of the warranty project was established at 25 years. For the traditional project, the projected treatment service life was found as 15 years, which seems to be consistent with the established performance period of the rehabilitation treatments based on the design life of HMA overlay [INDOT, 1998]. The above performance trends were established on the assumption that the performance trend of the warranty pavements beyond the warranty period (when the contractor is not responsible for the pavement) will be consistent with the pattern exhibited during the warranty period.

\section{(ii) Treatment Life Cycle Effectiveness (Area under Performance Curve)}

For the long-term evaluation, the area under the performance curve was determined using trends developed from actual 5-year data. The performance trends for IRI and PQI were extrapolated up to the terminal serviceability level for each warranty and corresponding control project. The areas were then determined by integrating the curves over the treatment service life. Thus,

Area under IRI curve $=$ Area of rectangular region $(\mathrm{OABC})-\int_{0}^{n} f(x) d x$

where $n$ is the treatment service life $=25$ years for warranty pavement

Similarly, the PQI values are plotted with respect to the age of the pavements and the area under the curve is determined. 
Area under PQI curve $=\int_{0}^{n} f(x) d x$

where $n$ is defined above.

Determination of Long-term Cost-effectiveness

For the purpose of the present study, long term cost-effectiveness (CE) of a project is defined in the following ways.

$\mathrm{CE}_{5}=\frac{\text { Treatment Service Life }}{\text { EUAC }}$

$\mathrm{CE}_{6}=\frac{\text { Area under the IRI }- \text { Time curve }}{\text { EUAC }}$

$\mathrm{CE}_{7}=\frac{\text { Area under the PQI - Time curve }}{\text { EUAC }}$

where EUAC $=$ Equivalent Uniform Annual Cost over Treatment Service Life

A numerical value was attributed to the long-term cost-effectiveness of each project, therefore provides a rational basis for cost-effectiveness evaluation. The project with the higher value was considered to be more cost-effective in comparison to the other. In this case, the costs are annualized over the projected treatment lives.

\subsection{Methodology for Evaluation of Average Pavement Condition}

Statistical analyses were carried out to obtain a more rational basis for evaluating the cost-effectiveness of warranty contracts, (in terms of average pavement condition) and subsequently to determine if the use of warranties leads to significant improvement in pavement quality. Significance tests were carried out to ascertain whether any significant differences exist in the performance levels of warranty and traditional (non-warranty) projects. For the present study, paired sample t-tests were performed for sets of warranty and traditional contracts. The traditional projects selected for comparison with the warranty projects were chosen with great care so that their characteristics matched those of the corresponding warranty project as closely as possible, to obviate the effect of any occluding factors on the analysis. 
The two-sample paired $t$-test determines whether there is a difference between the means of the two samples at a given level of confidence. It is based on the null hypothesis that the population means of the paired differences of the two samples is zero. This is equivalent to performing a one-sample t-test on the paired differences. An advantage of this test is that the variation in the data is reduced by considering the mean differences. The test assumes that the paired differences are independent and normally distributed, but does not assume that the variances of the populations are equal.

The $t$ statistic is given by:

$$
\mathrm{t}^{*}=\frac{\mathrm{D}}{\mathrm{S}\{\mathrm{D}\}}, \text { with } n-1 \text { degrees of freedom }
$$

where

$n$ is the number of pairs, D is the difference between the mean performance indicators of the two samples (warranty and traditional), and $S\{D\}$ is the standard error of the mean difference. The $t$ statistic, $\mathrm{t}^{*}$ is compared to the critical value of the student's $t$ distribution, $t_{c}$ at the desired level of significance.

If $\mathrm{t}^{*}>\mathrm{t}_{\mathrm{c}}$, then the null hypothesis is rejected

If $\mathrm{t}^{*} \leq \mathrm{t}_{\mathrm{c}}$, then the null hypothesis is not rejected

The above tests were carried out on the basis of the following pavement performance parameters: International Roughness Index (IRI), Rutting depth, and Pavement Condition Rating (PCR). For each comparison set, performance data from the warranty and traditional contracts were tested to determine if there is a significant difference between the performances exhibited by the pavements associated with these contractual methods.

\section{Pair-wise Comparison using IRI and Rutting}

Lower values of IRI and rutting correspond to higher levels of pavement performance. As such, the analysis for these performance indicators involved determining whether warranty pavements exhibit superior pavement performance. This corresponds to a one-tailed $t$-test to check if warranties have lower IRI or rutting values. Each pair of observation represents IRI or rutting of traditional and warranty pavements at a certain age, i.e., for example the IRI of the warranty pavement at age 1 is paired with the IRI of a similar traditional pavement at the same age, and so forth. For such non-decreasing performance indicators, the hypotheses tested are:

$\mathrm{H}_{\mathrm{o}}: \mu_{\mathrm{W}}-\mu_{\mathrm{T}}=0$ (there is no difference between the IRI or rutting values of warranty and traditional pavements) $\mathrm{H}_{\mathrm{a}}: \mu_{\mathrm{W}}-\mu_{\mathrm{T}}<0$ (warranty pavements have lower IRI or rutting values compared to traditional pavements) 
The level of significance is $\alpha$.

$\mu_{\mathrm{W}}$ is the mean value of non-decreasing performance indicator for warranty project

$\mu_{\mathrm{T}}$ is the mean value of non-decreasing performance indicator for traditional project.

The null hypothesis, $\mathrm{H}_{\mathrm{o}}$ is rejected if the calculated value of $t$ statistic is less than the negative value of the critical or threshold value. Figure 3-10 shows the rejection region for the one-tailed test for the means of IRI or rutting of warranty and traditional projects.

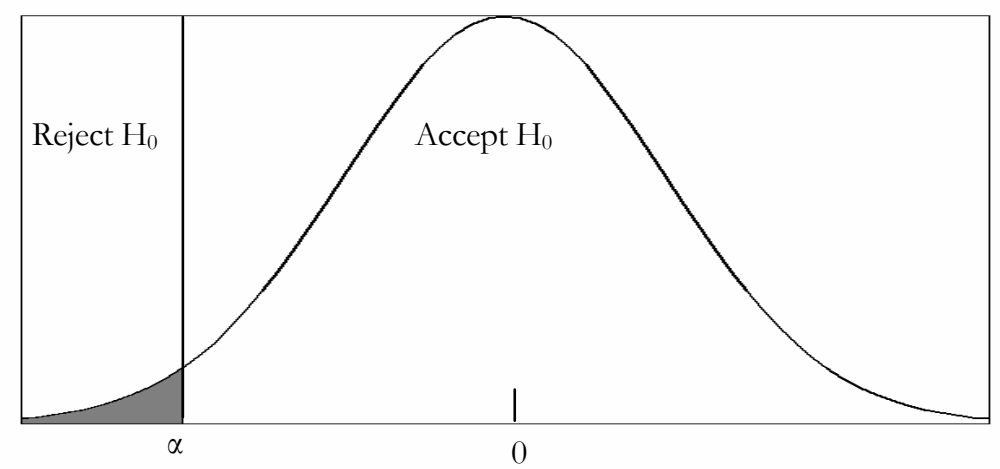

Figure 3-10 Critical Region for t-test for Non-decreasing Distresses (such as IRI and Rutting)

\section{Pair-wise Comparison using PSI or PCR}

Higher PSI or PCR values indicate better pavement performance. Each value of PSI or PCR of the warranty project at any pavement age is paired with the value of PSI or PCR of the corresponding traditional project at that age. For such non-decreasing performance indicators, the hypotheses tested are:

$\mathrm{H}_{\mathrm{o}}: \mu_{\mathrm{W}}-\mu_{\mathrm{T}}=0$ (there is no difference between the PSI or PCR values of warranty and traditional pavements) $\mathrm{H}_{\mathrm{a}}: \mu_{\mathrm{W}}-\mu_{\mathrm{T}}>0$ (warranty pavements have higher PSI or PCR values compared to traditional pavements)

at level of significance $\alpha$, where:

$\mu_{\mathrm{W}}$ is the mean value of non-decreasing performance indicator for warranty project $\mu_{\mathrm{T}}$ is the mean value of non-decreasing performance indicator for traditional project.

The null hypothesis, $\mathrm{H}_{\mathrm{o}}$ is rejected if the absolute value of the $t$ statistic is greater than the $t$ critical value at the given level of significance. Figure 3-11 shows the rejection region for the test. 


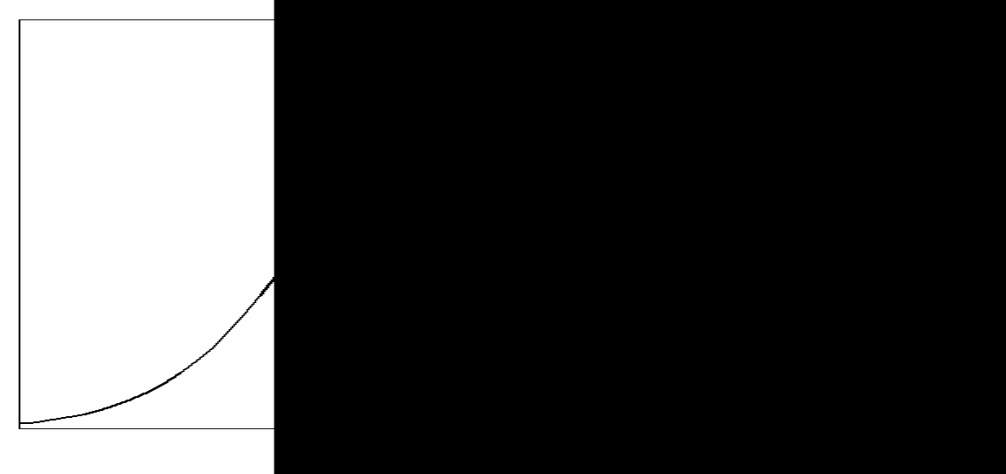

Figure 3-11 Critical Region for $t$ test for Non-Increasing Distresses (such as PSI and PCR)

\subsection{Chapter Summary}

The methodology described in this chapter was used to evaluate the cost-effectiveness of each of the two contracting systems. The medium-term evaluation is based on the assessment of pavement performance and the associated costs of projects during the warranty period. Pavement performance or effectiveness is measured in terms of International Roughness Index (IRI) and Pavement Quality Index (PQI) among others. The agency costs include the initial construction cost and the maintenance costs. While the initial construction cost was based on actual data, the maintenance costs were estimated using the AAMEX models due to the unavailability of project-specific maintenance costs data. The evaluation of costeffectiveness was also carried over the respective treatment service life of the pavements. Pavement performance was estimated based on the IRI trends established during the warranty period. The agency costs include initial construction costs and maintenance. User costs were also taken into consideration in the long-term evaluation process. It should be noted that the long term evaluation of cost-effectiveness was based on estimated performance trends and projected service lives, which directly influence the frequency of rehabilitation.

Statistical tests of significance were also carried out to ascertain whether any significant differences exist in the performance levels of warranty and control (non-warranty) projects. The twosample paired $t$-test determines whether there is a difference between the means of the two samples warranty and control - at a given level of confidence. 


\section{CHAPTER 4: DATA COLLECTION AND COLLATION}

\subsection{Introduction}

A complete assessment or evaluation of any construction project with respect to cost-effectiveness, as in the present study, requires the acquisition of all information regarding construction costs, maintenance costs, and performance trends over time. In order to implement the study methodology presented in Chapter 3, data related to warranty projects and their cost-effectiveness evaluation was collected and collated into a single dataset. This included data on pavement-related characteristics for all warranty projects undertaken by INDOT. Similar data related to traditional projects (non-warranty) was also collected. The main source of data was the INDOT Pavement Management System (PMS) database, INDIPAVE 2000, and INDOT's Contract Division. Details of pavement condition over the entire warranty period were acquired from INDOT’s 2002 Pavement Condition Database. Information regarding the cost of each project was directly obtained from personnel directly involved with INDOT's warranty program. Also, INDOT's Research Division provided data on the physical condition of the pavements over the warranty period.

\subsection{Description of Data}

The data needs identified and collected from various sources are shown in Table 4-1. This is followed by detailed description of each data category as well as the data sources.

\section{Data Collection for Warranty Projects}

The first step in the data collection process was to identify the contracts that were let out by INDOT with warranty provisions. The information was made available by INDOT's Contracts and Construction Division. The data gave a preliminary idea of the extent of use of warranties in highway contracting in the state of Indiana. A list of all the warranty contracts undertaken by INDOT to date is provided in Appendix A.

All project costs and pavement condition data that were available up to the year 2002 were collected. For purposes of the present study, only those projects that had completed the warranty period or were at least in their third year of warranty at the time of the study were considered for the evaluation of costeffectiveness. This was done primarily to gather enough data-points to establish performance trends based on the distress indicators. In other words, it would not be reasonable to establish a project's overall costeffectiveness based on its performance during only the initial post construction years. Unavailability of 
recent data (for 2003) also restricted the number of projects that could be selected for analysis. Based on the selection criteria, six projects were identified for the present study. Table 4-1 shows the details of the warranty projects selected from the list of INDOT’s warranty contracts.

Table 4-1 Data Types and Sources for Warranty and Control Projects

\begin{tabular}{|c|c|c|}
\hline Data Type & Details & Source \\
\hline Warranty Project Identification & $\begin{array}{l}\text { Contract number, location, construction year, } \\
\text { project length }\end{array}$ & $\begin{array}{l}\text { INDOT Contracts and Construction } \\
\text { Division }\end{array}$ \\
\hline Control Project Selection & Contract number, location, construction year & $\begin{array}{l}\text { INDOT Contracts and Construction } \\
\text { Division, INDIPAVE } 2003\end{array}$ \\
\hline $\begin{array}{l}\text { Road Segment and classification } \\
\text { data }\end{array}$ & $\begin{array}{l}\text { Reference points, Mileposts, County, District, } \\
\text { Functional Class, number of lanes }\end{array}$ & $\begin{array}{l}\text { INDOT Pavement Management } \\
\text { System, INDIPAVE } 2003\end{array}$ \\
\hline Pavement Condition Data & $\begin{array}{l}\text { International Roughness Index, Pavement } \\
\text { Serviceability Index, Rutting, Pavement } \\
\text { Condition Rating }\end{array}$ & $\begin{array}{l}\text { INDOT Pavement Management } \\
\text { System, INDIPAVE } 2003\end{array}$ \\
\hline $\begin{array}{l}\text { Operating Characteristics Data } \\
\text { (Traffic volumes, vehicle } \\
\text { classification, average speed, } \\
\text { etc) }\end{array}$ & $\begin{array}{l}\text { AADT, \% Trucks, Average speed, traffic } \\
\text { growth factors, ESAL }\end{array}$ & INDIPAVE 2003 \\
\hline Pavement Structure Data & $\begin{array}{l}\text { Surface layer type, thickness, base and sub- } \\
\text { base layer characteristics }\end{array}$ & INDIPAVE 2003 \\
\hline Agency/Construction Costs & Construction costs for each pavement section & $\begin{array}{l}\text { INDOT Program Development } \\
\text { Division, INDOT Contracts and } \\
\text { Construction Division, INDIPAVE } \\
2003\end{array}$ \\
\hline Rehabilitation Costs & $\begin{array}{l}\text { Historical rehabilitation type and associated } \\
\text { costs (per lane-mile) for each pavement } \\
\text { section }\end{array}$ & $\begin{array}{l}\text { INDOT Program Development } \\
\text { Division, INDOT Contracts and } \\
\text { Construction Division }\end{array}$ \\
\hline Maintenance Costs & $\begin{array}{l}\text { Historical average annual maintenance costs } \\
\text { for each pavement section }\end{array}$ & $\begin{array}{l}\text { AAMEX models [Labi \& Sinha, } \\
\text { 2002] }\end{array}$ \\
\hline User Costs & $\begin{array}{l}\text { Value of time for vehicle classification, work } \\
\text { zone duration, work zone period }\end{array}$ & $\begin{array}{l}\text { FHWA LCCA Design Guide [FHWA, } \\
\text { 1998] }\end{array}$ \\
\hline
\end{tabular}

The study methodology outlined for the evaluation process is based on a comparative analysis of the warranty contracts with similar traditional contracts. As mentioned in Chapter 3, traditional projects similar to the warranty projects in terms of type of work done, functional classification, surface thickness, etc were taken into consideration. However, Contract R-23500 (a concrete overlay over existing concrete pavement on a section of I-65 located north of Lafayette) was unique because no traditional contract data with similar work description was available for comparison. As such, it was excluded from the study. All 
the other projects that were analyzed involved new hot-mix asphalt (HMA) pavement, and the costs associated with each project as well as the data on the warranty item and quantity used in the project are shown in Table 4-3. In the analysis of each project, the final as-built cost, instead of the bid amount was considered to account for any cost overruns. All costs were converted to 2000 constant dollar.

Table 4-2 Description of Warranty Contracts

\begin{tabular}{|c|c|c|c|c|c|c|}
\hline Contract & $\begin{array}{c}\text { Year of } \\
\text { Letting }\end{array}$ & Location & County & Work Description & $\begin{array}{c}\text { Length } \\
\text { (miles) }\end{array}$ & $\begin{array}{c}\text { Warranty Status } \\
\text { (as of 2003) }\end{array}$ \\
\hline R-22232 & 1996 & $\begin{array}{c}\text { I-70 } \\
\text { East of SR-9 }\end{array}$ & Hancock & $\begin{array}{c}\text { Pavement Rehabilitation } \\
\text { (3R/4R Standard) }\end{array}$ & 4.21 & Complete \\
\hline R-22854 & 1996 & $\begin{array}{c}\text { I-65 } \\
\text { North of US-31 }\end{array}$ & Bartholomew & $\begin{array}{c}\text { Pavement Rehabilitation } \\
\text { (3R/4R Standard) }\end{array}$ & 4.56 & Complete \\
\hline R-22925 & 1997 & $\begin{array}{c}\text { I-69 } \\
\text { North of SR-8 }\end{array}$ & Dekalb & $\begin{array}{c}\text { Mill Bit, Crack \& Seat } \\
\text { W/Mod. And Safety }\end{array}$ & 8.68 & Complete \\
\hline R-23390 & 1998 & $\begin{array}{c}\text { I-74 } \\
\text { East of SR-9 }\end{array}$ & Shelby & $\begin{array}{c}\text { Pavement Rehabilitation } \\
\text { (3R/4R Standard) }\end{array}$ & 11.01 & 4 years \\
\hline R-23898 & 1998 & West of SR-267 & Hendricks & $\begin{array}{c}\text { Pavement Rehabilitation } \\
\text { (3R/4R Standard) }\end{array}$ & 3.96 & 3 years \\
\hline
\end{tabular}

Table 4-3: Cost of Warranty Projects (Current Dollar for Year of letting)

\begin{tabular}{|c|l|c|c|c|}
\hline Contract \# & Warranty Item & $\begin{array}{c}\text { Unit Price of } \\
\text { Warranty Item }\end{array}$ & $\begin{array}{c}\text { Bid Amount of } \\
\text { Warranty Item }\end{array}$ & Total Cost of Project \\
\hline R-22232 & Asphalt Pavement Mixtures & $\$ 34.00$ & $\$ 1,132,030$ & $\$ 7,837,000$ \\
\hline R-22854 & Asphalt Pavement Mixtures & $\$ 32.00$ & $\$ 2,296,416$ & $\$ 10,772,000$ \\
\hline R-22925 & Asphalt Pavement Mixtures & $\$ 35.00$ & $\$ 2,366,245$ & $\$ 13,251,000$ \\
\hline R-23390 & Asphalt Pavement Mixtures & $\$ 32.50$ & $\$ 2,415,888$ & $\$ 15,113,000$ \\
\hline R-23898 & Asphalt Pavement Mixtures & $\$ 34.00$ & $\$ 965,603$ & $\$ 11,549,000$ \\
\hline
\end{tabular}




\subsection{Data Collection for Control (Traditional) Projects}

A comparative analysis was carried out for of each warranty project on one-to-one basis with a previously identified similar traditional (non-warranty) project. Similarity was determined on the basis of FHWA classification, thickness of the new layer, type of work, design traffic (ESALs) and other features. The data for the control projects was acquired from INDOT's PMS database, INDIPAVE 2000 and INDOT's Contracts and Construction Division. Table 4-4 shows the comparison sets considered for costeffectiveness evaluation. Details on the control projects are given in Chapter 5.

Table 4-4: Comparison Sets of Warranty and Traditional Projects

\begin{tabular}{|c|c|c|}
\hline Comparison Set & $\begin{array}{c}\text { Warranty Project } \\
\text { (contract \#) }\end{array}$ & $\begin{array}{c}\text { Control Project } \\
\text { (contract \#) }\end{array}$ \\
\hline 1 & R-22232 & R-21607 \\
\hline 2 & R-22854 & R-21602 \\
\hline 3 & R-22925 & R-22912 \\
\hline 4 & R-23390 & R-21607 \\
\hline 5 & R-23898 & R-22923 \\
\hline
\end{tabular}

\subsection{Data Items Collected for Each Contacting Type}

\section{(i) Road Segment Data}

The road segments in the PMS and INDIPAVE 2000 databases can be identified either by their Milepost Segment Identification numbers or by their Contract Segment Identification numbers. The original numbers as established in INDIPAVE 2000 have been retained in the present study to maintain consistency. The milepost number corresponds to the reference number established by INDOT's Linear Referencing System (LRS) for each individual 1-mile pavement section on the network. On the other hand, the contract segment number corresponds to the code number of the last rehabilitation contract carried out on that particular section.

\section{(ii) Pavement Condition}

INDOT's pavement condition data-file consists of data related to the standard performance measures used to quantify pavement deterioration: the International Roughness Index (IRI), Present Serviceability Index (PSI), Pavement Condition Rating (PCR), and Rutting depth. Pavement Quality Index (PQI) which is a function of PSI, Rut and PCR was also used in the analysis. 


\section{(iii) Operating Characteristics}

Traffic data in the INDIPAVE database include traffic volume, percentage single unit trucks, percentage multiple unit trucks, gross vehicle weight, ESAL, and Cumulative ESAL. INDOT Interstate traffic flow maps were used to obtain data on traffic volumes (Annual Average Daily Traffic (AADT)). For the warranty projects, the design traffic volume is an important consideration for the contractor particularly because the Contractor is not liable for any pavement failure resulting from traffic overloading of the pavement. Furthermore, the importance of traffic data is reflected in the fact that the traffic characteristics of a facility greatly influence the user costs and also the pavement performance.

\section{(iv) Pavement Structure Data}

Data on the pavement structure of each project were directly obtained from INDOT's PMS database and INDIPAVE 2000.The categories of data include original pavement structure in terms of the surface layer, pavement type and thickness of the laid surface layer, hot-mix asphalt content, thickness of the different layers, air voids in HMA, percentage fines, etc. Of these, only the surface type and thickness of the added layer were taken into account in selecting the control projects for purposes of comparison.

\section{(v) Agency Cost Data}

Data on the cost of each warranty and control project were obtained from INDOT Program Development Division, INDOT Contracts and Construction Division, and INDIPAVE 2003 database. The bid amount of the warranty items in the contracts was also collected. The data also includes the final as-built cost incurred by the agency for each project, as well as a description of work done and number of construction days. The final as-built cost was used to arrive at the cost per lane-mile of each project.

\section{(vi) Rehabilitation Data}

Data on the types, dates, and other details on resurfacing and other contract activities undertaken to improve pavement performance was an important aspect of the analysis. For the present study, rehabilitation strategies similar to the initial work were considered for both warranty and control projects. As such, if the initial work was HMA (hot-mix asphalt) overlay, then at the terminal serviceability level the pavement would be rehabilitated again using HMA. It is assumed that at the end of their projected service lives, a warranty pavement would be rehabilitated by warranty work, while a traditional project would be rehabilitated as a traditional project.

\section{(vii) Maintenance Data}

The maintenance costs are incurred by the agency on all activities done between periods of construction and resurfacing or between successive treatments to maintain the pavement within acceptable levels of performance. These activities may be routine or periodic, in-house or contractual, preventive or corrective 
[Labi and Sinha, 2002]. For warranty projects, the contractor is liable for maintaining the pavement for the duration of the warranty period. As such, there is no direct maintenance expenditure incurred by INDOT during that period. After the end of the warranty period, all maintenance costs are borne by INDOT. Actual data on annual maintenance costs for the projects were not available and were therefore estimated using Average Annual Maintenance Expenditure (AAMEX) models [Labi and Sinha, 2002]. Given the characteristics of a pavement, AAMEX models estimate the level of maintenance that the pavement section is expected to receive at any given age.

\section{(viii) User Cost Data}

User costs include vehicle operating costs, delay costs, and crash costs. Vehicle operating costs (VOC) are directly related to the physical condition of the pavement. The poorer the condition, the greater is the VOC. The delay costs reflect the delay experienced by the motorists due to reduction of roadway capacity resulting from the placement of work zones and are associated with the value of time. Value of time for vehicle classification, work zone duration, work zone period, etc. required for the computation of user costs associated with each project was obtained from FHWA LCCA Design Guide [FHWA, 1998].

\subsection{Chapter Summary}

Data needs for the investigation of the present study were identified and collected from the various sources. A large part of the data was collected from INDOT PMS database and INDIPAVE 2000. Various data types include pavement condition, traffic characteristics, pavement structure, agency construction costs, rehabilitation and maintenance costs, and data for user cost computation.

Long-term analysis rehabilitation data was unavailable for the warranty projects. This was because warranty projects are still in their early stage of pavement life and hence have received no rehabilitation since treatment (construction). As such, the long-term cost-effectiveness evaluation was carried out using projections of treatment lives.

The warranty contracts available for analysis were few, thus restricting the number of comparison sets. In spite of these problems, it is averred that the cost-effectiveness methodology described in this chapter would enable a reasonable and fair comparison between warranty and traditional projects on the basis of available data. 


\section{CHAPTER 5 RESULTS OF THE ANALYSES}

\subsection{Introduction}

The present chapter compares the cost-effectiveness of each selected INDOT warranty project with its corresponding control project. The control projects were traditional (non-warranty) contracts selected on the basis of characteristics similar to the warranty projects. In comparing the two contracting systems in the medium and long-term, measures of effectiveness included treatment service life and area bounded by the pavement performance curve after treatment. For each measure of effectiveness, performance indicators included International Roughness Index (IRI), Pavement Serviceability Index (PSI), Rutting, Pavement Condition Rating (PCR)) and Pavement Quality Index (PQI). The medium-term refers to the entire warranty period, while the long-term refers to the expected life of the pavement treatment. Such effectiveness values were then weighed vis-à-vis agency (as-built construction costs and maintenance costs) and also vis-à-vis combined agency and user cost. This was done to establish the relative cost-effectiveness of highway pavement warranty contracts in Indiana compared to the traditional contracts. For traditional contracts, the

maintenance costs borne by the agency after construction was also taken into account. For warranty contracts however, any maintenance costs over the warranty period were not considered in the analyses because such costs are not borne by the agency.

The analysis was carried out in the form of pair-wise comparisons of the costs and benefits of each set of warranty and traditional projects. Within each comparison set is a pair of warranty and the traditional contract projects that are generally similar in their basic attributes (project type, thickness, traffic, etc.) thus enabling a rational means of comparing their relative cost-effectiveness on the basis of pavement performance and project costs.

For each comparison set, this chapter implements the methodology described in Chapter 3 and discusses the resulting costs, benefits (effectiveness) and cost-effectiveness of the two alternative contracting systems and identifies the alternative that is superior on the basis of the data. This is done for each measure of effectiveness, indicator of pavement performance, and in both medium and long-term. 


\subsection{Comparison Set 1 (Warranty Project: R-22232 and Control Project R-21607)}

\subsubsection{General Contract Information for Comparison Set 1}

The first project implemented under Indiana's warranty program was contract R-22232 which was a road reconstruction. The contract, undertaken by Milestone Contractors in 1996, completed its 5-year warranty period in 2001. The project is located on I-70, from a point 0.7 mile east of SR 9 to a point 5.0 miles east of SR 9 in Hancock County, Greenfield district in the Central region of Indiana. The 4.21 mile project begins from Milepost 104.8 and ends at Milepost 108.29.

The control project selected for comparison with R-22232 is contract R-21607, located on I-69 from SR 67 intersection at Daleville to a point 0.25 mile north of SR 32 in Delaware County, Greenfield district. The control project starts at Milepost 31.28 and ends at Milepost 34.79, and has a length of 3.51 miles. Some similarities in the major characteristics of the warranty and control projects are shown in Table 5-1.

Table 5-1 Characteristics of Projects Constituting Comparison Set 1

\begin{tabular}{|l|c|c|}
\hline & $\begin{array}{c}\text { Warranty Project 1 } \\
\text { (R-22232) }\end{array}$ & $\begin{array}{c}\text { Control Project 1 } \\
\text { (R-21607) }\end{array}$ \\
\hline Work Description & $\begin{array}{c}\text { J300 } \\
\text { J300 }\end{array}$ \\
\hline $\begin{array}{l}\text { Nr. of Lanes, } \\
\text { Rural/Urban Class, and } \\
\text { Functional Class }\end{array}$ & $\begin{array}{c}\text { Four-lane Rural } \\
\text { Interstate }\end{array}$ & $\begin{array}{c}\text { Four-lane Rural } \\
\text { Interstate }\end{array}$ \\
\hline NHS & Road Reconstruction 3R4R \\
\hline Length (miles) & Y.21 & Yes \\
\hline Surface Type & HMA over & 3.54 \\
\hline Crack-and-seat PCC & $\begin{array}{c}\text { HMA over } \\
\text { Crack-and-seat PCC }\end{array}$ \\
\hline Percentage trucks & 0.625 inch & 0.625 inch \\
\hline AADT in year 2002 & 38,150 & 33,595 \\
\hline
\end{tabular}

\subsubsection{Medium-term Performance Analysis for Comparison Set 1}

As explained in Chapter 3, the performance of both warranty and control projects was investigated on the basis of the following performance indicators: International Roughness Index (IRI), Pavement Serviceability Index (PSI), depth of rutting, Pavement Condition Rating (PCR), and Pavement Quality Index (PQI). 


\subsubsection{Performance Comparison on basis of International Roughness Index (IRI)}

The average IRI values of the warranty and control projects are presented in Table 5-2 and Figure 5-1. The threshold value of the warranty pavement for the entire warranty period is $133 \mathrm{in} / \mathrm{mi}$ [INDOT, 2002]. The warranty period ended after the pavement reached an age of 5 years. Table 5-2 and Figure 5-1 suggest that on the basis of surface roughness, the warranty asphalt pavements in Comparison Set 1 performed considerably better than the control pavement. Exponential trend lines were fitted and extrapolated to yield IRI values immediately after construction (age 0 ). As seen from the figure, the warranty pavement has much lower initial IRI values compared to the traditional pavement.

Table 5-2 IRI of Constituent Pavements in Comparison Set 1

\begin{tabular}{|c|c|c|}
\hline \multirow{2}{*}{$\begin{array}{c}\text { Age } \\
\text { (years) }\end{array}$} & \multicolumn{2}{|c|}{ IRI (in/mi) } \\
\cline { 2 - 3 } & $\begin{array}{c}\text { Warranty Project 1 } \\
\text { (R-22232) }\end{array}$ & $\begin{array}{c}\text { Control Project 1 } \\
\text { (R-21607) }\end{array}$ \\
\hline 1 & 41.83 & 54.25 \\
\hline 2 & 42.53 & 55.00 \\
\hline 3 & 43.22 & 56.00 \\
\hline 4 & 44.72 & 56.25 \\
\hline 5 & 46.55 & 61.13 \\
\hline 6 & 60.22 & 80.38 \\
\hline
\end{tabular}

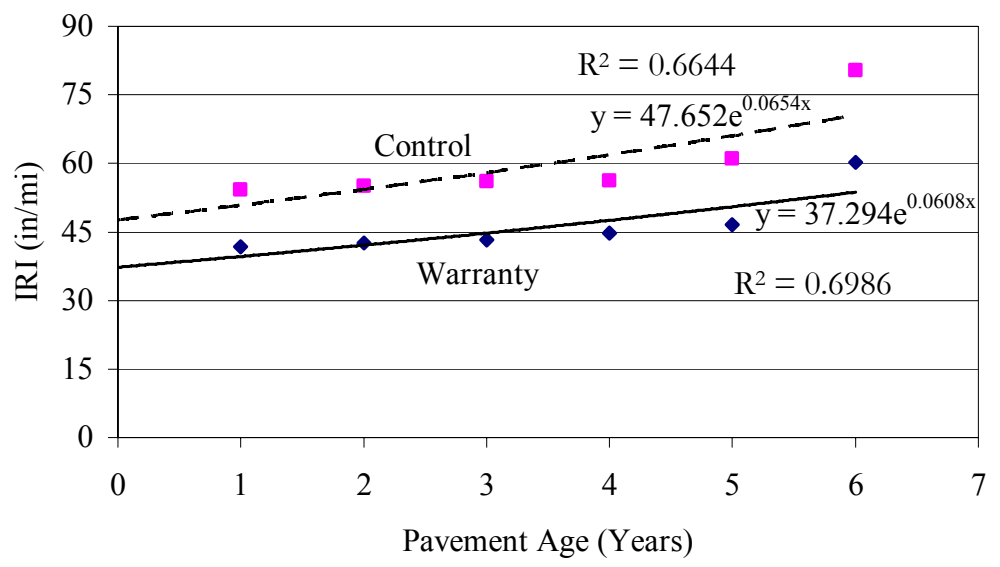

Figure 5-1 IRI Trends of Warranty and Control Pavements, Comparison Set 1

The daily traffic volume and the percentage of trucks directly influence the deterioration of the pavement. The relative performance of the warranty and traditional pavements were also evaluated based on 
cumulative traffic loading. The IRI values corresponding to the cumulative ESALs (Equivalent Single Axle Load) over the warranty period are shown in Figure. The load equivalent factors were 1.3 for Multiple Unit Trucks and 0.6 for Single Unit Trucks [Gulen et al., 2000].

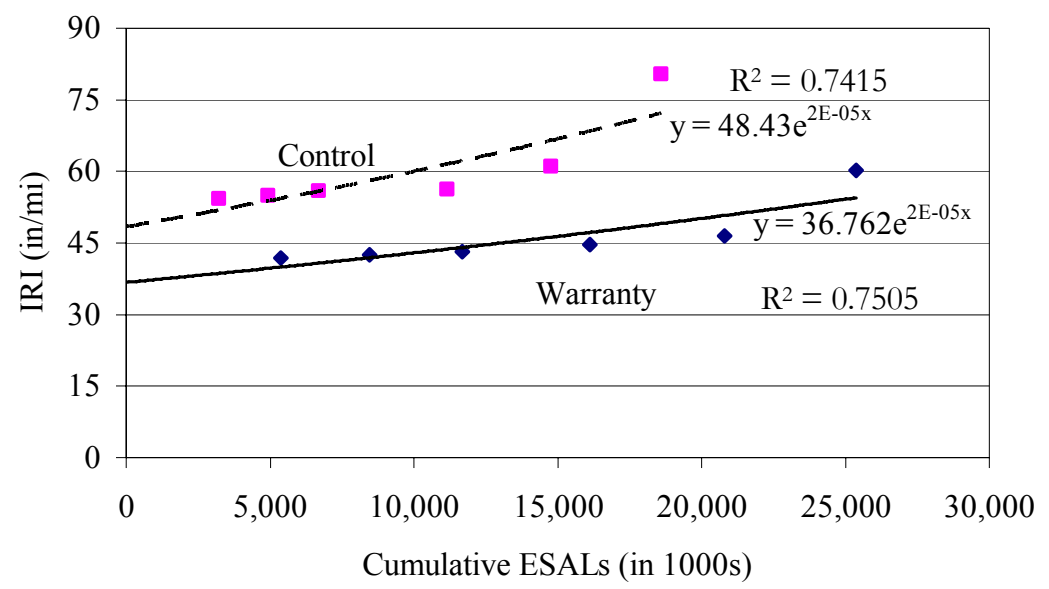

Figure 5-2 Comparison of Load-based Deterioration (IRI) curves, Comparison Set 1

The results show that in spite of the fact that the warranty pavement has higher volume of trucks compared to the control project, it exhibits better performance. A statistical test was performed to ascertain whether the IRI values of the warranty project were significantly different from those of the traditional project. Table 5-3 shows the $t$-test results for warranty and traditional project IRI values.

Table 5-3 Results of $t$-test for IRI, Comparison Set 1

\begin{tabular}{lcc}
\hline & $\begin{array}{c}\text { Variable 1 } \\
\text { (Warranty) }\end{array}$ & $\begin{array}{c}\text { Variable 2 } \\
\text { (Control) }\end{array}$ \\
\hline Mean & 46.5112 & 60.5017 \\
Variance & 47.9317 & 100.6473 \\
Observations & 6 & 6 \\
Hypothesized Mean Difference & 0 & \\
Degrees of freedom & 5 & \\
Calculated $t$ Statistic & -10.7569 & \\
P(T $\leq t$ ) one-tail & 0.0001 & \\
Critical value of $t$ (one-tail) & 2.0150 & \\
\hline
\end{tabular}


The observations at a particular age represent the mean IRI values of individual pavement sections located on the entire contract segment. The mean and the variance of the two samples are shown along with the $t$ statistic and the one-tailed critical $t$ value. The level of significance, $\alpha$ is 0.05 . Since $-10.7569<-$ 2.0150 , the null hypothesis is rejected. It can therefore be stated with $95 \%$ confidence that the warranty pavement has significantly lower IRI values compared with the control pavement.

Performance Comparison on basis of Present Serviceability Index (PSI)

The annual PSI values of the warranty and the control projects, estimated using the IRI/PSI equation (see Chapter 3 - Study Methodology) are presented in Table 5-4. It is seen that the PSI values of the warranty project exceed those of the control project, thus suggesting superior quality of the warranty pavement. Figure 5-3 shows pavement present serviceability trends of the warranty and control projects.

Table 5-4 Annual Pavement Condition (PSI), Comparison Set 1

\begin{tabular}{|c|c|c|}
\hline Age (Years) & $\begin{array}{c}\text { Warranty Project 1 } \\
\text { (R-22232) }\end{array}$ & $\begin{array}{c}\text { Control Project 1 } \\
\text { (R-21607) }\end{array}$ \\
\hline 1 & 4.21 & 4.00 \\
\hline 2 & 4.20 & 3.99 \\
\hline 3 & 4.19 & 3.97 \\
\hline 4 & 4.16 & 3.97 \\
\hline 5 & 4.13 & 3.89 \\
\hline 6 & 3.91 & 3.60 \\
\hline
\end{tabular}

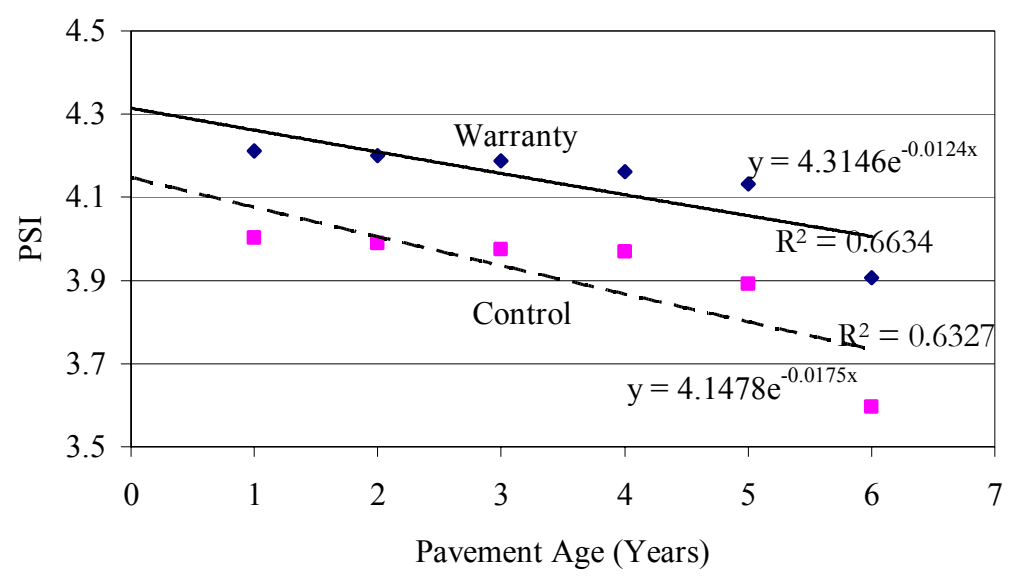

Figure 5-3 PSI Trends of Warranty and Control Pavements, Comparison Set 1 
For each contracting system, the pavement performance trend with respect to loading (cumulative ESALs) is shown in Figure 5-4. Trend lines of the exponential forms were fitted for both warranty and control projects. The difference in the degree of pavement deterioration with increasing traffic loads is clearly evident: the warranty pavement exhibits better performance.

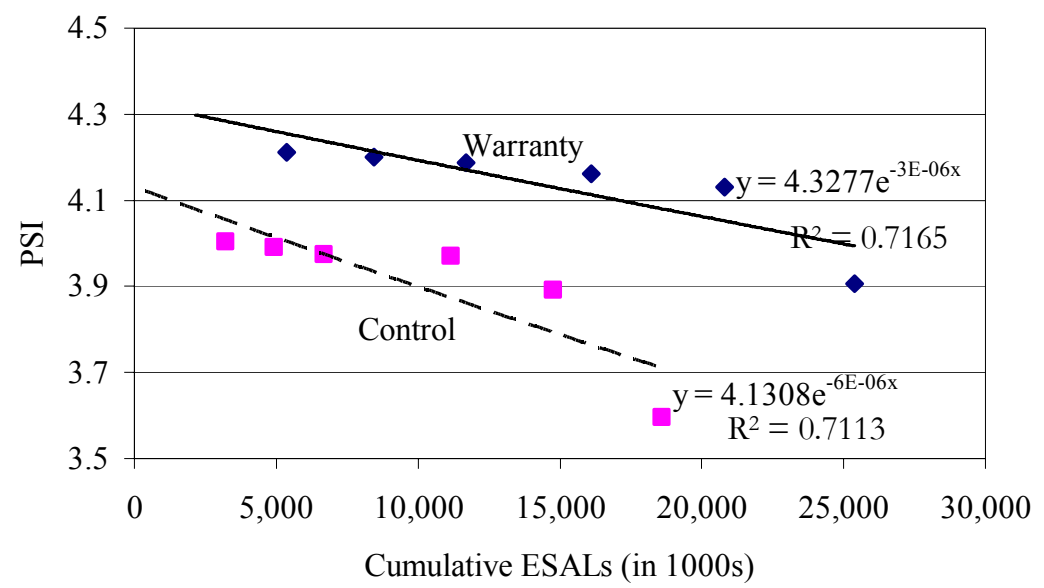

Figure 5-4 Comparison of Load-based Deterioration (PSI) curves, Comparison Set 1

Table 5-5 indicates the results of the $t$ test performed to determine whether there is a significant difference between the PSI values of warranty and control pavements of comparison set 1 . The $t$ statistic is greater than the critical value at level of significance 0.05 . Therefore the null hypothesis is rejected with $95 \%$ confidence, implying that there is a significant difference between the means of PSI of warranty and the control projects. In other words, the warranty project has significantly higher PSI compared to the control project in comparison set 1 .

Table 5-5 Results of t-test for PSI, Comparison Set 1

\begin{tabular}{lcc} 
& Variable 1 (Warranty) & Variable 2 (Control) \\
\hline Mean & 4.1333 & 3.9043 \\
Variance & 0.0132 & 0.0243 \\
Observations & 6 & 6 \\
Hypothesized Mean Difference & 0 & \\
Degrees of freedom & 5 & \\
$t$ Statistic & 13.1976 & \\
$\mathrm{P}(\mathrm{T}<=t)$ one-tail & 0.0000 & \\
$t$ Critical one-tail & 2.0150 & \\
\hline
\end{tabular}




\section{Performance Comparison on basis of Rutting}

Table 5-6 shows the annual average rut depths of the warranty and control projects. According to INDOT warranty specifications, the average rut depth of a warranty pavement should not exceed the threshold value of $6 \mathrm{~mm}$ (0.24 inch) throughout the entire warranty period [INDOT, 2002]. The results of the analysis show that compared to the control project, the warranty pavement has relatively low average rut depths throughout the warranty period. Also, the threshold rutting value is not exceeded at any time during the warranty period.

Table 5-6 Rut Depth of Constituent Pavements, Comparison Set 1

\begin{tabular}{|c|c|c|}
\hline \multirow{2}{*}{$\begin{array}{c}\text { Age } \\
\text { (years) }\end{array}$} & \multicolumn{2}{|c|}{ Average Rut Depth (in) } \\
\cline { 2 - 3 } & $\begin{array}{c}\text { Warranty Project 1 } \\
\text { (R-22232) }\end{array}$ & $\begin{array}{c}\text { Control Project 1 } \\
\text { (R-21607) }\end{array}$ \\
\hline 1 & 0.08 & 0.05 \\
\hline 2 & 0.08 & 0.05 \\
\hline 3 & 0.11 & 0.14 \\
\hline 4 & 0.09 & 0.13 \\
\hline 5 & 0.09 & 0.11 \\
\hline 6 & 0.10 & 0.08 \\
\hline
\end{tabular}

Trends of the pavement performance in terms of average rut depth of warranty and the control project with respect to age are shown in Figure 5-5. The rut depth does not show a consistent trend as seen earlier in the case of IRI and PSI. The observed fluctuations in rut depth may probably be attributed to measurement errors. Exponential trend lines were drawn and extrapolated to get the rutting depth immediately after construction. It is seen that the initial average rut depth of the warranty pavement is much lower than that for the traditional pavement.

Figure 5-6 shows the trend of the rutting depth with respect to the cumulative ESALs of the pavements. Although no strong statistical regression relationship could be observed, it can be seen that compared to the warranty pavement, the control project generally exhibits higher distress even though it has a lower level of traffic loading. 


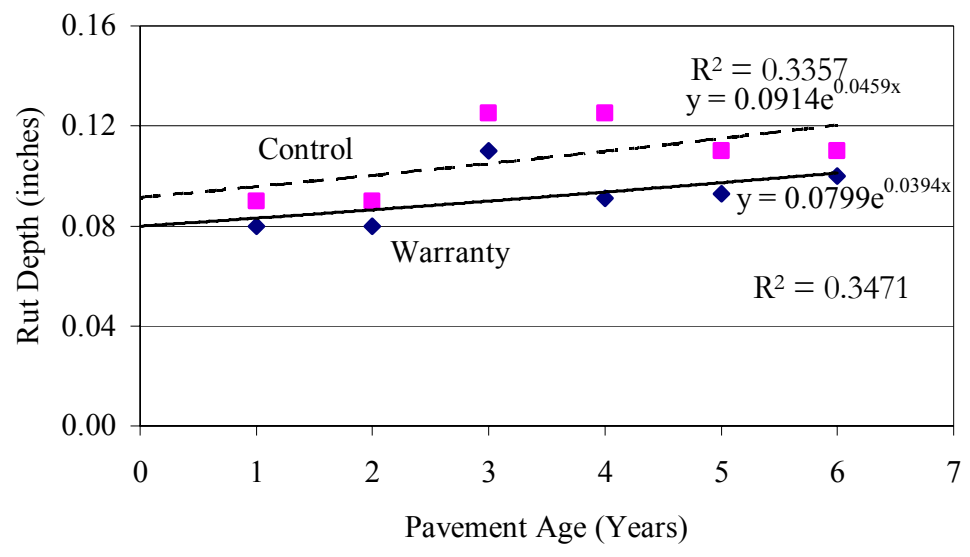

Figure 5-5 Rutting Trends for Warranty and Control Pavements, Comparison Set 1

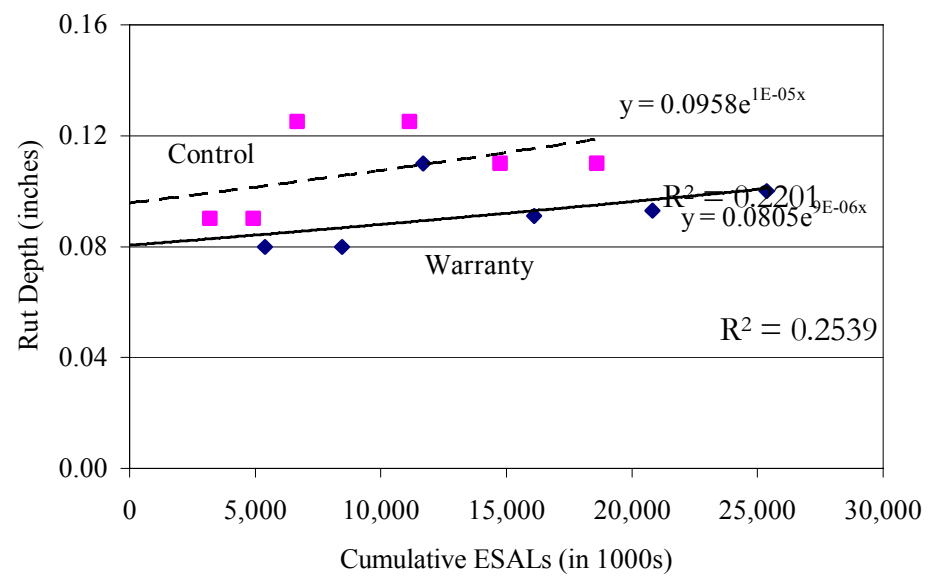

Figure 5-6 Comparison of Load-based Deterioration (Rut) Curves, Comparison Set 1

Table 5-7 Results of t-test for Rutting Depth for Comparison Set 1

\begin{tabular}{lcc}
\hline & Variable 1 (Warranty) & Variable 2 (Control) \\
\hline Mean & 0.0898 & 0.0933 \\
Variance & 0.0004 & 0.0015 \\
Observations & 6 & 6 \\
Hypothesized Mean Difference & 0 & \\
Degrees of freedom & 5 & \\
$t$ Statistic & -0.1741 & \\
$\mathrm{P}(\mathrm{T}<=t)$ one-tail & 0.4343 & \\
$t$ Critical one-tail & 2.0150 & \\
\end{tabular}


Table 5-7 shows the results of the $t$ test for rut depth of the warranty and control project. It is seen that the $t$ statistic -0.1741 at $5 \%$ significance level is higher than the negative critical $t$ value and therefore lies in the rejection region. The test was repeated for $\alpha=0.10,0.20$ but yielded similar results. Thus, there is no sufficient evidence to reject the null hypothesis. There is therefore no statistically significant difference between the mean rut depths of the warranty and control projects.

\section{Performance Comparison on basis of Pavement Condition Rating (PCR)}

The Pavement Condition Rating (PCR) provides overall method of identifying pavement distresses in terms of severity and extent. The PCR scale ranges from 0 to 100, 100 indicating a perfect pavement and 0 representing a pavement with all distress in the extreme levels of severity and extent. The PCR values of the warranty and the control projects are shown in Table 5-8 and their temporal variations are graphically illustrated in Figure 5-7. The figure highlights the differences in the overall pavement performance trends of the warranty and control projects.

Table 5-8 PCR of Constituent Pavements, Comparison Set 1

\begin{tabular}{|c|c|c|}
\hline \multirow{2}{*}{$\begin{array}{c}\text { Age } \\
\text { (years) }\end{array}$} & $\begin{array}{c}|c| \\
\text { Warranty Project 1 } \\
\text { (R-22232) }\end{array}$ & $\begin{array}{c}\text { Control Project 1 } \\
\text { (R-21607) }\end{array}$ \\
\cline { 2 - 3 } & 96.25 & 96.63 \\
\hline 2 & 95.50 & 94.88 \\
\hline 3 & 99.90 & 95.25 \\
\hline 4 & 96.30 & 93.13 \\
\hline 5 & 99.10 & 96.13 \\
\hline 6 & & \\
\hline
\end{tabular}

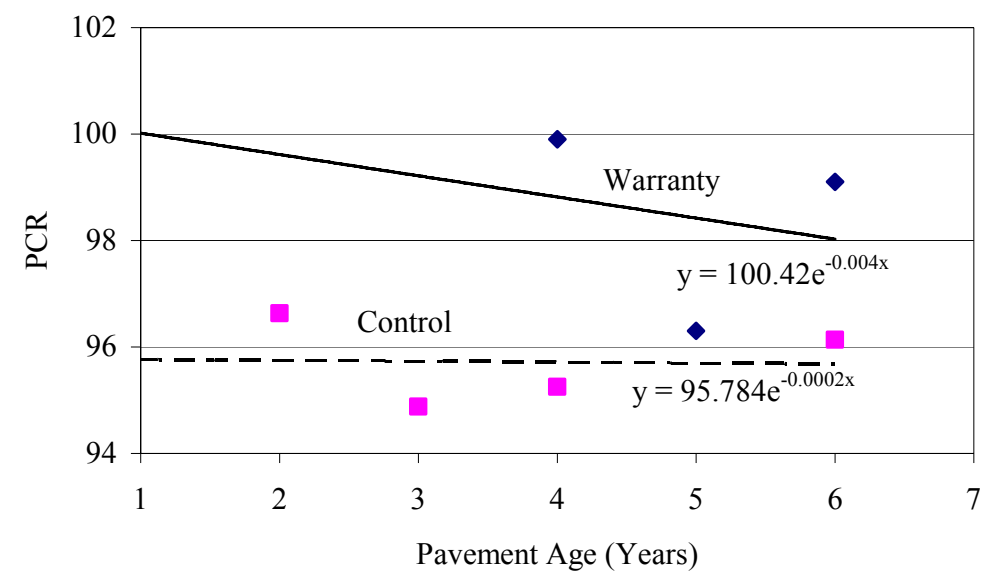

Figure 5-7 PCR Trends of Warranty and Control Pavements, Comparison Set 1 
Figure 5-7 suggests the relatively superior performance of the warranty project. Over the first six years, the warranty project has an average PCR of 98 while the control project has average PCR of 95. Figure 5-8 shows PCR trends for the warranty and control projects with respect to accumulated traffic loading over the warranty period.

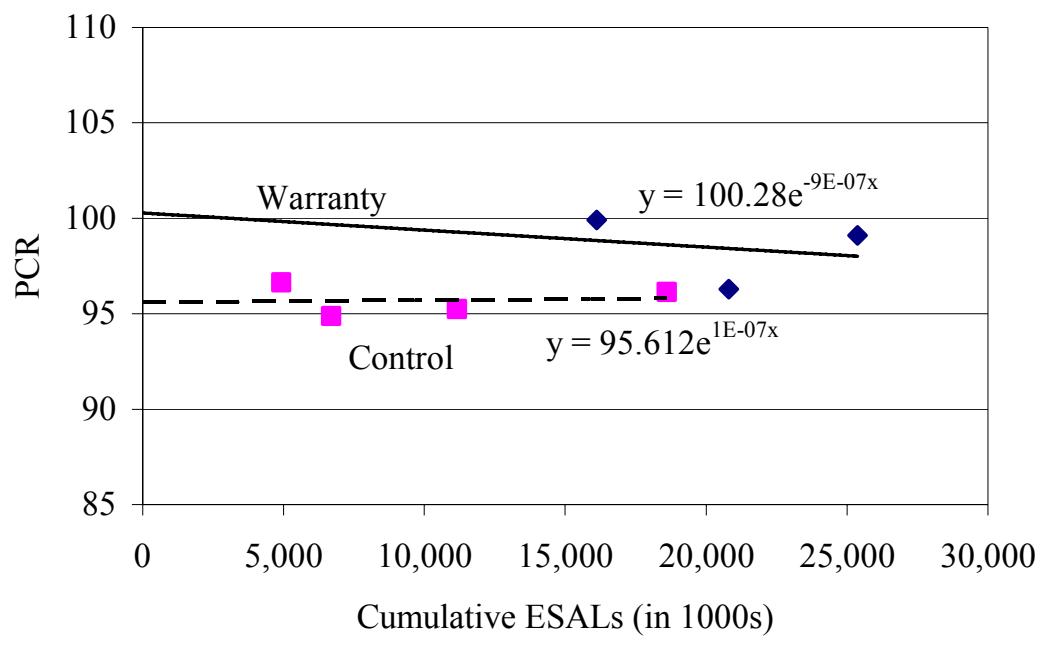

Figure 5-8 Comparison of Load-based Deterioration (PCR) Curves, Comparison Set 1

Table 5-9 shows the $t$ test results for PCR at 5\% significance level. The calculated $t$ statistic 2.4149 is greater than the $t$ critical value of 2.1318. As such, the null hypothesis is rejected, implying that compared to the traditional (control) contract, the warranty contract pavement exhibits better pavement condition (higher PCR values).

Table 5-9 Results of t-test for PCR, Comparison Set 1

\begin{tabular}{lcc}
\hline & Variable 1 (Warranty) & Variable 2 (Control) \\
\hline Mean & 97.4100 & 95.2040 \\
Variance & 3.8205 & 1.8249 \\
Observations & 5 & 5 \\
Hypothesized Mean Difference & 0 & \\
Degrees of freedom & 4 & \\
$t$ Statistic & 2.4149 & \\
$\mathrm{P}(\mathrm{T}<=t)$ one-tail & 0.0366 & \\
$t$ Critical one-tail & 2.1318 & \\
\hline
\end{tabular}




\subsubsection{Evaluation of Cost-Effectiveness for Comparison Set 1}

As stated in the study methodology (Chapter 3), the cost-effectiveness evaluation of the warranty and the control projects were carried out over two temporal scopes: medium-term and long-term.

\section{Medium Term Cost-Effectiveness Evaluation for Comparison Set 1}

The overall evaluation of cost-effectiveness of the warranty project was carried out by weighing the benefits over the entire warranty period vis-à-vis the cost of the project. The final construction costs for the warranty and the control project incurred by the state agency were considered. Annual maintenance costs estimated for the warranty period ( 5 years) were added to the initial costs for the control projects. All costs were converted to Year 2000 constant dollar using the Construction Price Index. The maintenance costs were estimated using the Average Annual Maintenance Expenditure (AAMEX) Models [Labi and Sinha, 2001] for HMA overlay pavements.

Table 5-10 provides a summary of key attributes (including agency costs) for the warranty and control projects, and also shows the Equivalent Uniform Annual Cost (EUAC) per lane-mile in Year 2000 constant dollar. Temporal cost adjustments were done on the basis of construction price indices [FHWA, 2001].

Table 5-10 Medium-Term Agency Costs, Comparison Set 1

\begin{tabular}{|l|c|c|}
\hline & $\begin{array}{c}\text { Warranty Project 1 } \\
\text { (R-22232) }\end{array}$ & $\begin{array}{c}\text { Control Project 1 } \\
\text { (R-21607) }\end{array}$ \\
\hline Length (miles) & 4.21 & 3.51 \\
\hline Number of lanes & 4 & 4 \\
\hline Initial Cost & $\$ 9,493,072$ & $\$ 4,624,801$ \\
\hline Initial Cost/lane-mile & $\$ 563,722$ & $\$ 329,402$ \\
\hline Maintenance Costs/lane-mile (5 years) & $\$ 0$ & $\$ 1,073$ \\
\hline Total agency cost/lane-mile & $\$ 563,722$ & $\$ 330,474$ \\
\hline Agency EUAC/lane-mile & $\$ 126,627$ & $\$ 74,233$ \\
\hline
\end{tabular}

Table 5-10 shows that the agency cost of the warranty project is higher than that of the corresponding control project. This is expected because of the higher initial cost associated with the warranty project to account for various tasks that were shifted to the contractor due to warranty stipulations.

To determine user costs due to work zone delay, the same AADT and the percentage trucks per lane were used for both warranty and control projects. The values of travel time for the various vehicle classifications shown in Table 3-3 in Chapter 3, were used. The user cost computations for Comparison Set 1 are shown below. All costs are given in Year 2000 constant dollar. 


\begin{tabular}{|lc|}
\hline AADT per lane & 16,361 \\
Volume of passenger cars $(72 \%)$ per lane & 11,698 \\
Volume of single-unit trucks $(10 \%)$ per lane & 466 \\
Volume of multiple-unit trucks $(18 \%)$ per lane & 863 \\
$\begin{array}{l}\text { Difference in travel time due to reduction in speed from } 65 \mathrm{mph} \text { to } 45 \\
\text { mph in the work zone }(1 / 45-1 / 65)\end{array}$ & $0.0068 \mathrm{hr} / \mathrm{mile}$ \\
$\begin{array}{l}\text { User cost for passenger car }(\$ 12.41 / \mathrm{hr} \times 0.0068 \mathrm{hr} \times 11,698) \\
\text { User cost for single-unit truck }(\$ 19.88 / \mathrm{hr} \times 0.0068 \mathrm{hr} \times 466)\end{array}$ & $\$ 992$ \\
$\begin{array}{l}\text { User cost for multiple-unit truck }(\$ 23.92 / \mathrm{hr} \times 0.0068 \mathrm{hr} \times 863) \\
\text { Total user cost per day per lane-mile }\end{array}$ & $\$ 141$ \\
\hline
\end{tabular}

Table 5-11 shows the user costs of warranty and control pavements based on the work zone duration. The costs are shown in Year 2000 constant dollar. It can be noted that warranty pavement has lower user costs due to shorter work zone duration.

Table 5-11 Medium-Term User Costs, Comparison Set 1

\begin{tabular}{|l|c|c|}
\hline & $\begin{array}{c}\text { Warranty Project 1 } \\
\text { (R-22232) }\end{array}$ & $\begin{array}{c}\text { Control Project 1 } \\
\text { (R-21607) }\end{array}$ \\
\hline Work zone duration per lane-mile & 16 days & 19 days \\
\hline Total user cost per lane mile & $\$ 19,142$ & $\$ 22,731$ \\
\hline User EUAC/lane-mile & $\$ 4,300$ & $\$ 5,106$ \\
\hline
\end{tabular}

Cost-effectiveness evaluation was carried out using performance measures as discussed below. Figures 5-9 and 5-10 present IRI-Age curves for the warranty and control pavements in Comparison Set 1, respectively. 


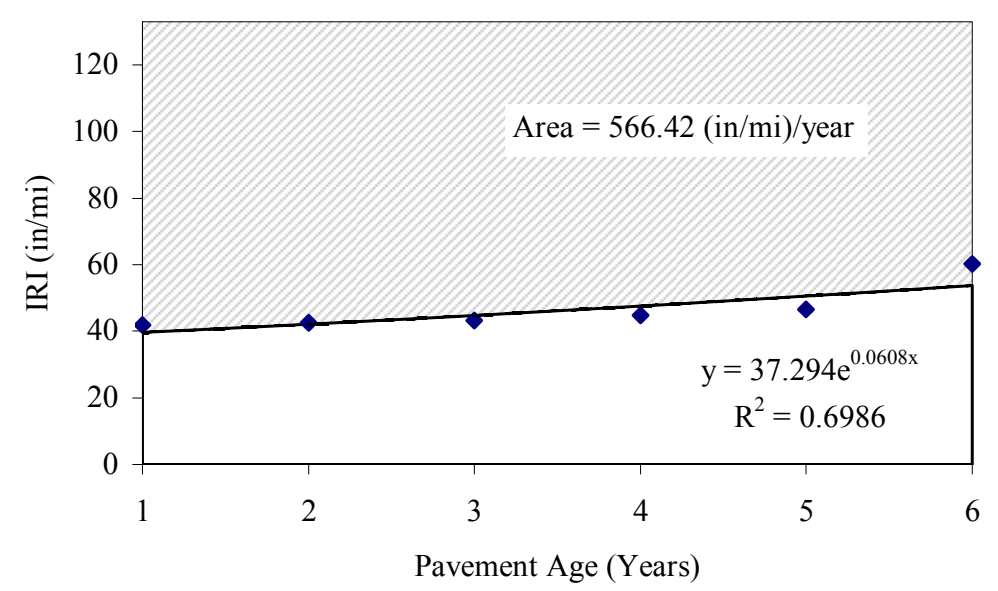

Figure 5-9 Area Bounded by IRI-Age Curve of Warranty Pavement, Comparison Set 1

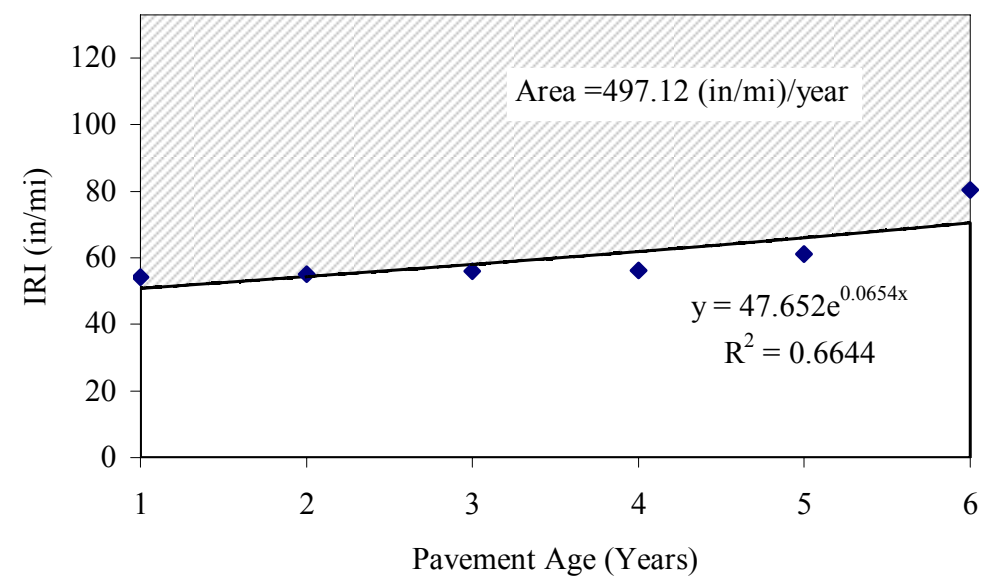

Figure 5-10 Area Bounded by IRI-Age Curve of Control Pavement, Comparison Set 1

The areas enclosed by the curves were determined by using fitted models. The models were of the exponential form, with the pavement age as the explanatory variable. Figure 5-11 and 5-12 show the trend of the IRI values corresponding to the cumulative ESALs over the warranty period for warranty and control pavement, respectively. 


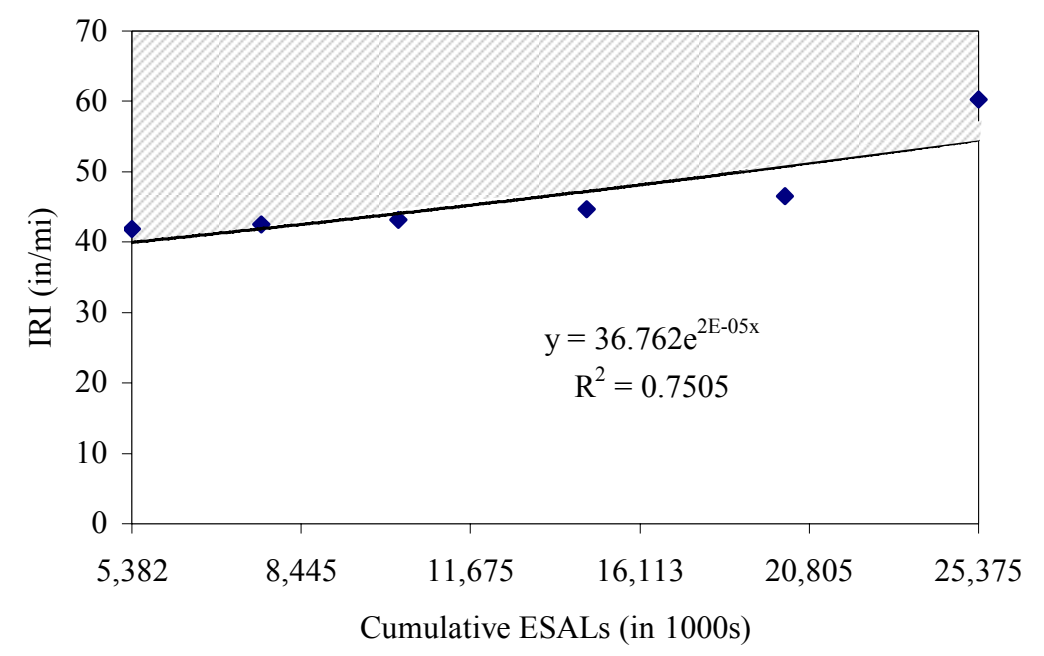

Figure 5-11 Area Bounded by IRI-ESAL Curve of Warranty Pavement, Comparison Set 1

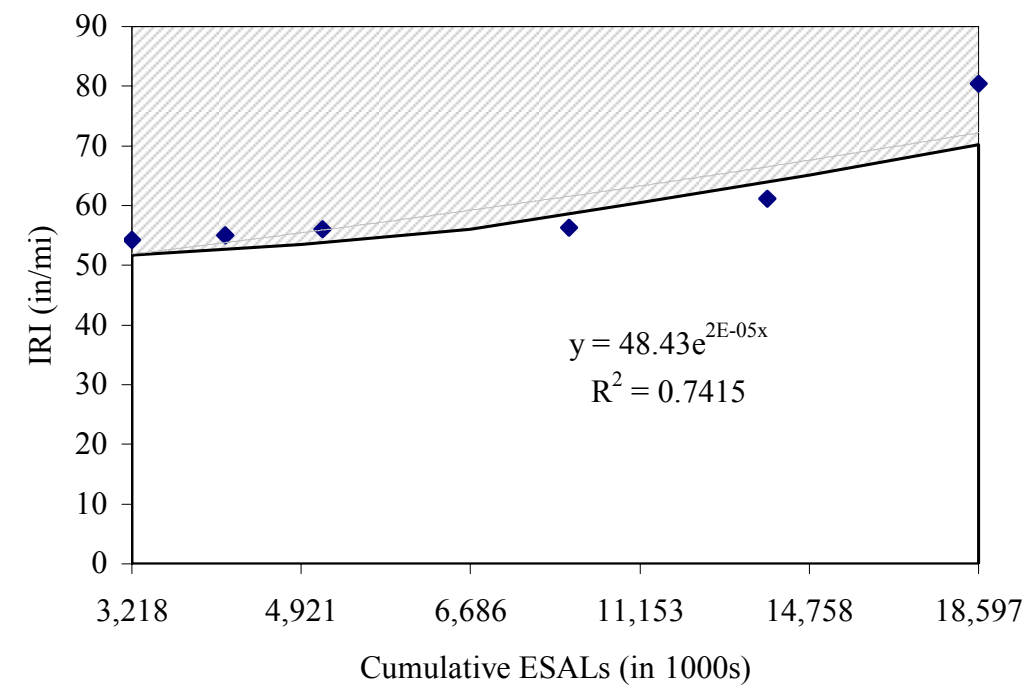

Figure 5-12 Area Bounded by IRI-ESAL Curve of Control Pavement, Comparison Set 1

Similarly, the PQI values were plotted to determine the area bounded by the curve. Figures 5-13 and 514 show the PQI values with respect to the age of the pavements. 


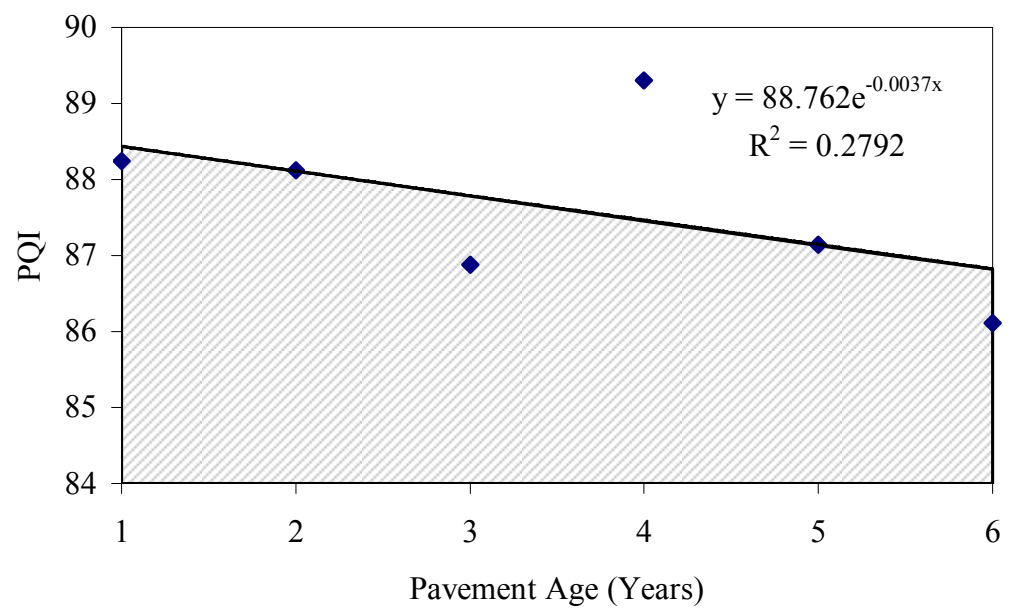

Figure 5-13 Area Bounded by PQI-Age Curve of Warranty Pavement in Comparison Set 1

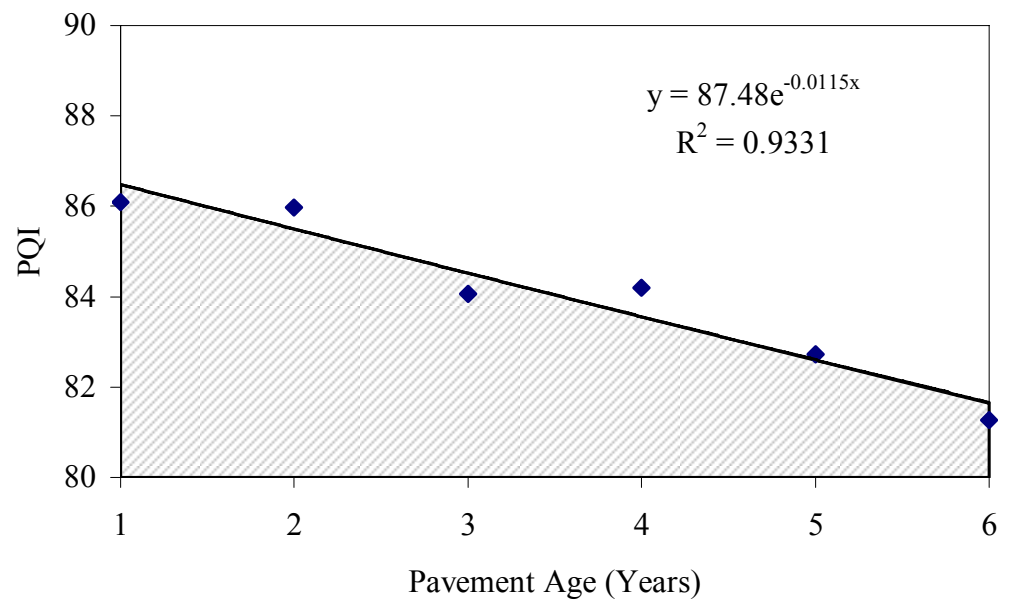

Figure 5-14 Area Bounded by PQI-Age Curve of Control Pavement, Comparison Set 1

The PQI-ESAL trends are shown in Figures 5-15 and 5-16. The effectiveness was represented by the areas bounded by the curves obtained by integrating the indicated equations. 


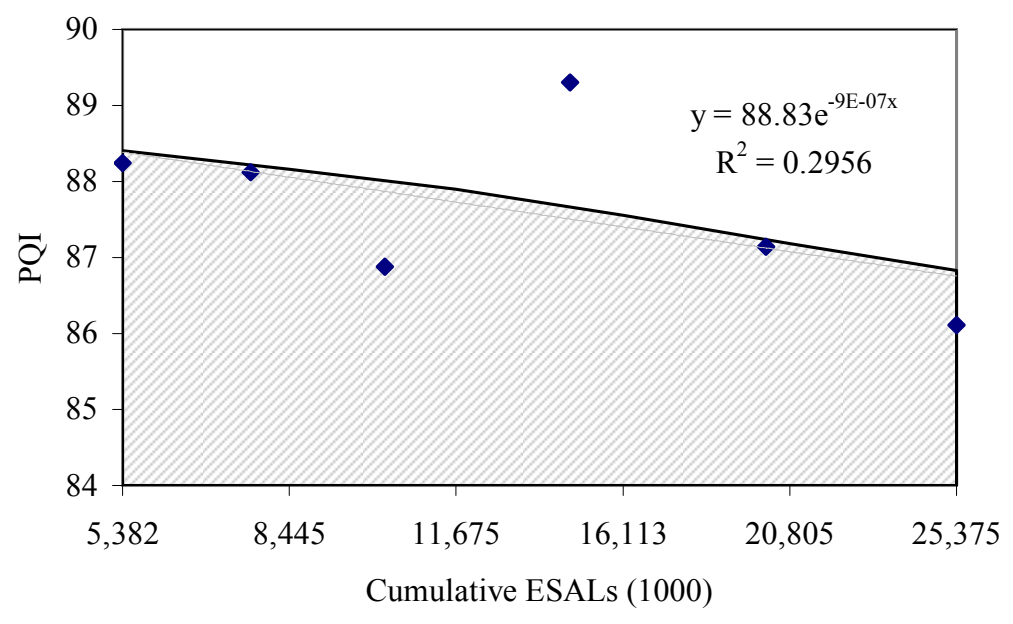

Figure 5-15 Area Bounded by PQI-ESAL Curve of Warranty Pavement, Comparison Set 1

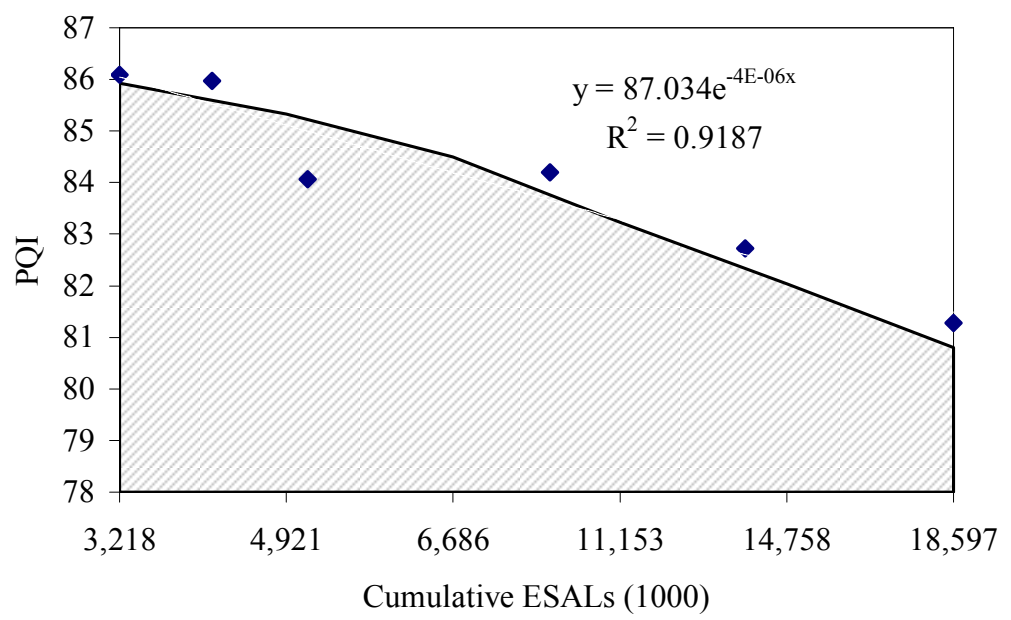

Figure 5-16 Area Bounded by PQI-ESAL Curve of Control Pavement, Comparison Set 1

A summary of the analysis results are shown in Table 5-12. Cost-effectiveness was determined first using agency costs only, and then using the sum of agency and user costs. 
Table 5-12 Medium Term Cost-effectiveness Evaluation, Comparison Set 1

\begin{tabular}{|l|c|c|c|c|}
\hline \multirow{2}{*}{\begin{tabular}{c}
\multirow{2}{*}{$\begin{array}{c}\text { Cost-effectiveness } \\
\text { (Effectiveness per unit cost) }\end{array}$} \\
\cline { 2 - 5 }
\end{tabular}} & $\begin{array}{c}\text { Warranty } \\
\text { (R-22232) }\end{array}$ & $\begin{array}{c}\text { Control } \\
\text { (R-21607) }\end{array}$ & $\begin{array}{c}\text { Warranty } \\
\text { (R-22232) }\end{array}$ & $\begin{array}{c}\text { Control } \\
\text { (R-21607) }\end{array}$ \\
\hline $\begin{array}{l}\text { Area bounded by the IRI-Age } \\
\text { curve/EUAC (\$1000) }\end{array}$ & 2.67 & 4.41 & 2.62 & 4.22 \\
\hline $\begin{array}{l}\text { Area bounded by the IRI- } \\
\text { ESAL curve/EUAC }\end{array}$ & 11.16 & 13.68 & 10.94 & 13.86 \\
\hline $\begin{array}{l}\text { Area bounded by the PQI- } \\
\text { Age curve/EUAC (\$1000) }\end{array}$ & 2.06 & 3.75 & 2.02 & 3.58 \\
\hline $\begin{array}{l}\text { Area bounded by the PQI- } \\
\text { ESAL curve/EUAC }\end{array}$ & 8.48 & 11.36 & 8.32 & 10.87 \\
\hline
\end{tabular}

Table 5-12 shows that the control project is more cost-effective than the warranty project. All four measures of cost-effectiveness gave consistent results. The difference in the cost-effectiveness of the warranty and control projects is more evident from the IRI-Age and PQI-Age evaluations than it is for the IRI-ESAL and PQI-ESAL evaluations.

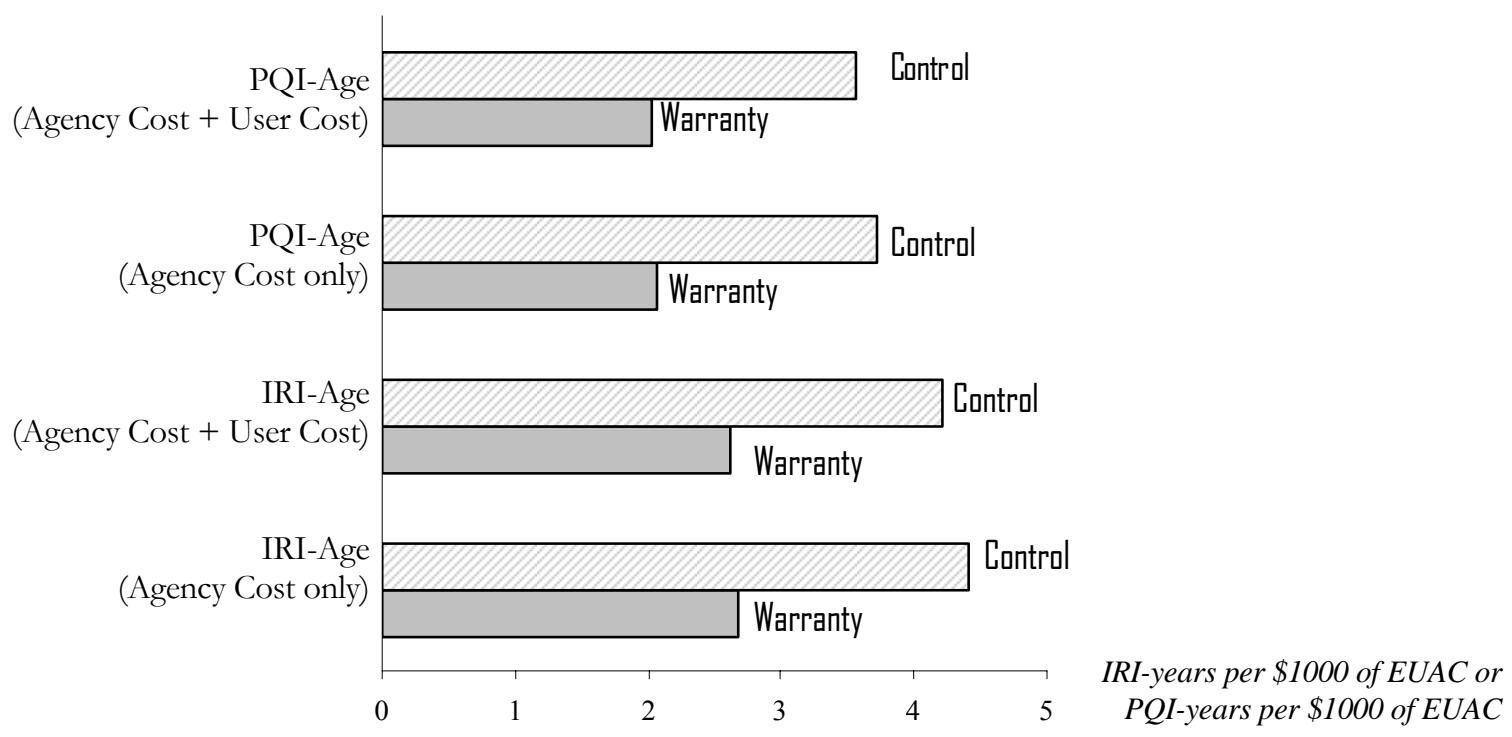

Figure 5-17 Medium-Term Cost-Effectiveness based on Performance and Time, Comparison Set 1 

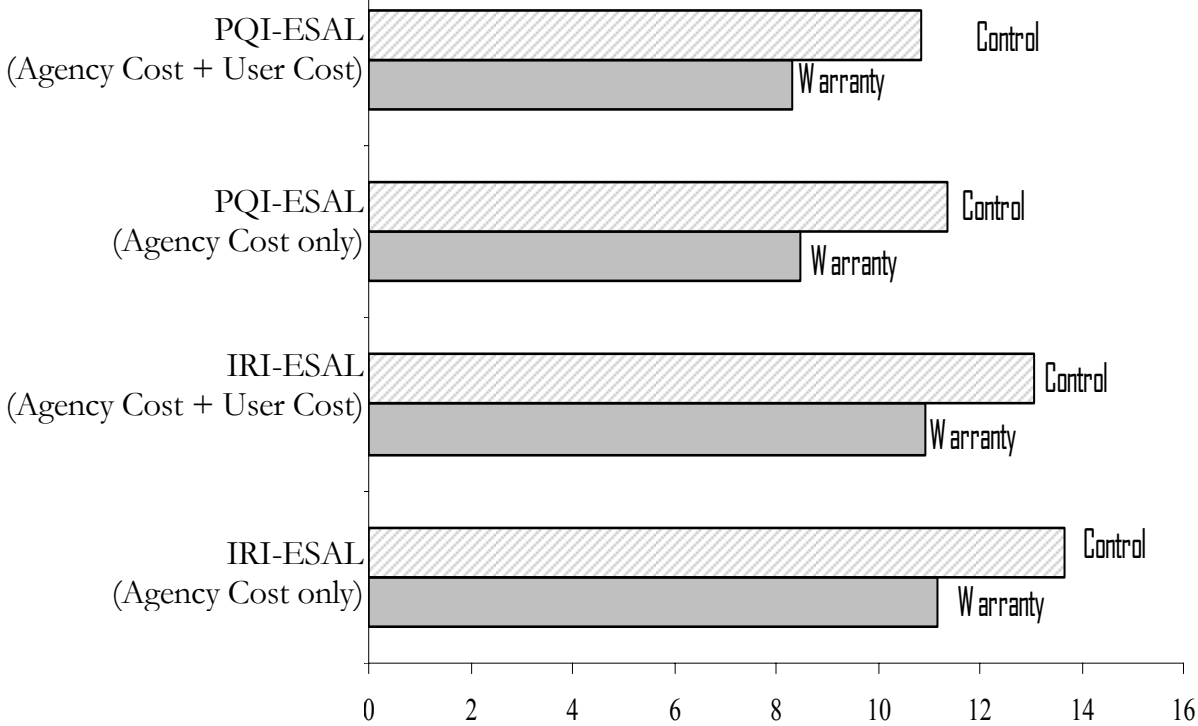

IRI-years per $\$ 1000$ of EUAC or $P Q I$-years per $\$ 1000$ of EUAC

Figure 5-18 Medium-Term Cost-Effectiveness based on Performance and Loading, Comparison Set 1

Figures 5-17 and 5-18 show the comparison of cost-effectiveness of warranty and control projects based on time (age) and accumulated loading, respectively. The values of medium-term cost-effectiveness of the warranty project based on the age-based curves were 50\% (average) lower than those of the traditional project. Based on the loading-based curves, the cost effectiveness of the warranty project was approximately $15 \%$ lower than that of the traditional project.

\subsubsection{Long-Term Cost-Effectiveness Evaluation for Comparison Set 1}

The long-term evaluation of cost-effectiveness was carried out over the projected treatment life of the pavement. The treatment life was determined using specified condition thresholds and performance trends, and was established as 25 years and 15 years for the warranty and control pavement, respectively. Maintenance costs over the treatment life were taken into consideration. Tables 5.13 and 5.14 show the various components of agency and user costs of warranty and control projects, respectively, in Year 2000 constant dollar. 
Table 5-13 Long-Term Agency Costs (Y2000\$) for Comparison Set 1

\begin{tabular}{|l|c|c|}
\hline & $\begin{array}{c}\text { Warranty Project 1 } \\
\text { (R-22232) }\end{array}$ & $\begin{array}{c}\text { Control Project 1 } \\
\text { (R-21607) }\end{array}$ \\
\hline Construction Cost/lane-mile/inch & $\$ 938,680$ & $\$ 495,070$ \\
\hline Maintenance Cost/lane-mile & $\$ 6,212^{*}$ & $\$ 7,197$ \\
\hline $\begin{array}{l}\text { Combined Agency Cost/lane- } \\
\text { mile/inch }\end{array}$ & $\$ 944,892$ & $\$ 502,267$ \\
\hline $\begin{array}{l}\text { EUAC of Combined Agency } \\
\text { Cost/lane-mile/inch }\end{array}$ & $\$ 212,248$ & $\$ 112,823$ \\
\hline
\end{tabular}

* Applicable only to warranty pavements after expiration of the warranty period.

The total agency cost of the warranty project exceeds that of the control project. The long-term user costs were computed in a manner similar to that done for medium-term user costs. However, for the longterm analysis, the costs were uniformly annualized over the projected pavement treatment lives.

Table 5-14 Long-Term User Costs (Y2000\$) for Comparison Set 1

\begin{tabular}{|l|c|c|}
\hline & $\begin{array}{c}\text { Warranty Project 1 } \\
\text { (R-22232) }\end{array}$ & $\begin{array}{c}\text { Control Project 1 } \\
\text { (R-21607) }\end{array}$ \\
\hline Work zone duration per lane-mile & 16 days & 19 days \\
\hline Total user cost per lane-mile & $\$ 19,142$ & $\$ 22,731$ \\
\hline User EUAC/lane-mile & $\$ 1,225$ & $\$ 2,044$ \\
\hline
\end{tabular}

Table 5-14 shows the user costs over the projected treatment lives. The overall cost-effectiveness of the warranty and control projects was first estimated on the basis of agency costs only, and then on the basis of both agency and user costs (Table 5-15). The effectiveness was determined as either the treatment service life or the areas bounded by the performance curves over the projected service lives.

Table 5-15 Long-Term Cost-effectiveness of Constituent Pavements, Comparison Set 1

\begin{tabular}{|l|c|c|c|c|}
\hline \multirow{2}{*}{ Cost-effectiveness } & \multicolumn{2}{|c|}{ Agency Cost only } & \multicolumn{2}{c|}{ Agency Cost + User Cost } \\
\cline { 2 - 5 } & $\begin{array}{c}\text { Warranty } \\
\text { (R-22232) }\end{array}$ & $\begin{array}{c}\text { Control } \\
\text { (R-21607) }\end{array}$ & $\begin{array}{c}\text { Warranty } \\
\text { (R-22232) }\end{array}$ & $\begin{array}{c}\text { Control } \\
\text { (R-21607) }\end{array}$ \\
\hline $\begin{array}{l}\text { Average Service life/EUAC } \\
\text { (\$1000) }\end{array}$ & 0.43 & 0.31 & 0.28 & 0.18 \\
\hline $\begin{array}{l}\text { Area bounded by the IRI-Age } \\
\text { curve/EUAC (\$1000) }\end{array}$ & 48.78 & 37.87 & 31.99 & 21.63 \\
\hline $\begin{array}{l}\text { Area bounded by the PQI- } \\
\text { Age curve/EUAC (\$1000) }\end{array}$ & 34.79 & 22.47 & 22.82 & 12.83 \\
\hline
\end{tabular}


Evaluation of long-term cost-effectiveness was based on two alternative measures of effectiveness: the average projected treatment lives and the areas under the performance trends (IRI and PQI) with respect to pavement age. The results suggest that over the long term, the warranty project is more cost-effective. Figures 5-19 and 5-20 present the comparison of cost-effectiveness of warranty and control projects based on treatment lives and time (age), respectively. It is significant to note that the contrast in the results of the long-term and medium-term evaluations.

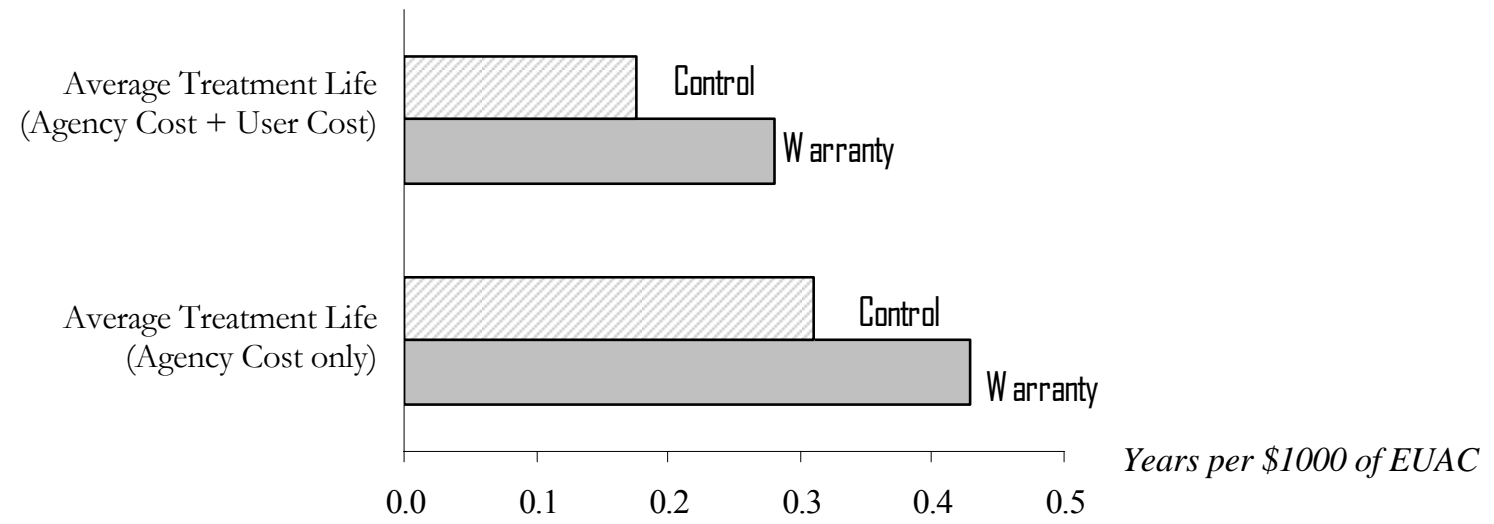

Figure 5-19 Long-Term Cost-Effectiveness based on Treatment Life Only, Comparison Set 1

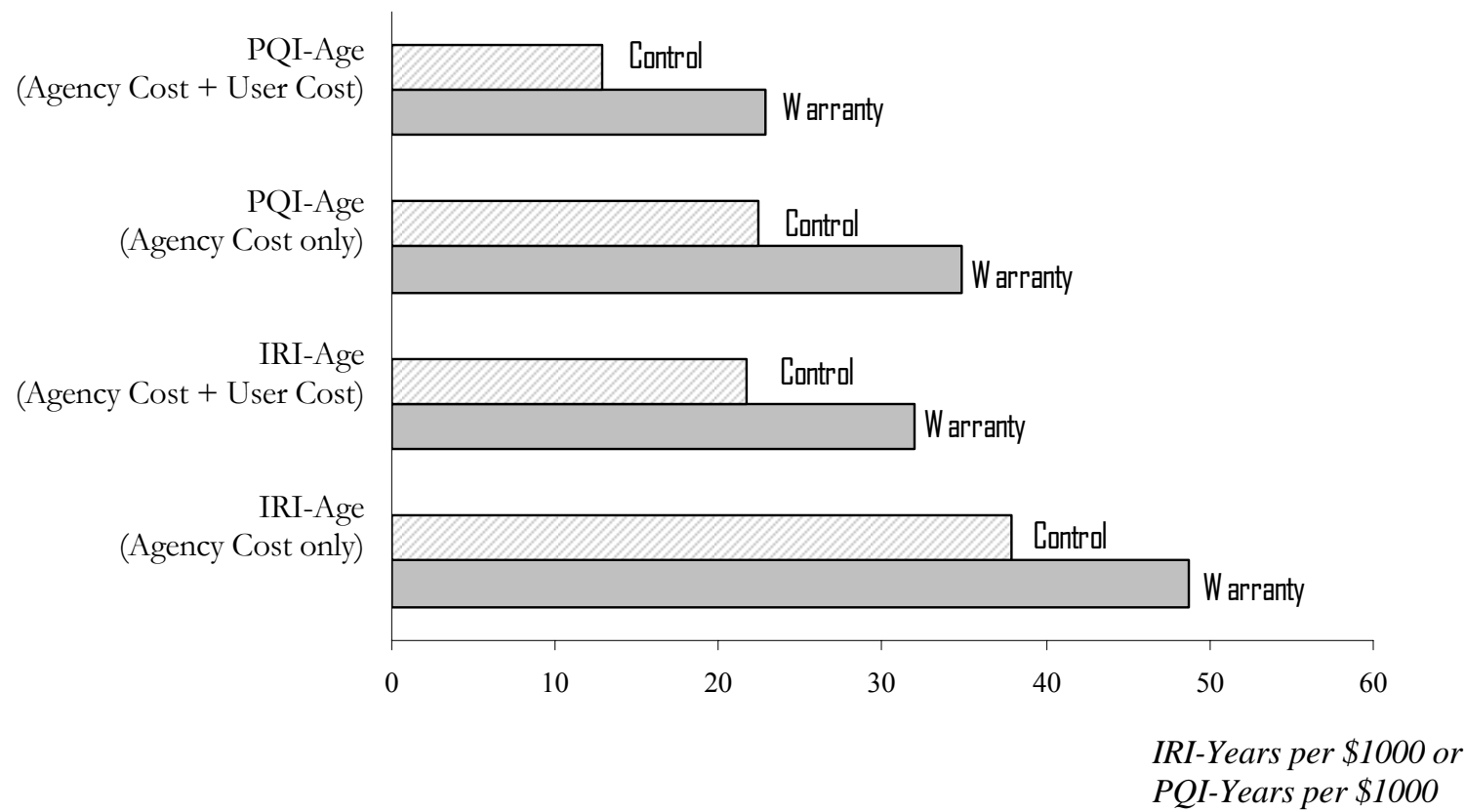

Figure 5-20 Long-Term Cost-Effectiveness based on Performance and Time, Comparison Set 1 


\subsubsection{Summary of the Analysis Results for Comparison Set 1}

On the basis of pavement condition, the comparative analysis of the warranty and traditional projects in Comparison Set 1 indicates that warranty pavement exhibits better pavement performance in spite of higher traffic loading experienced of the former. This was determined on the basis of IRI, PSI, and PCR performance indicators. No significant difference was found in the case of pavement rut depth. On the basis of costs, the warranty project had a higher construction cost (per lane-mile per inch) but lower user cost compared to the traditional project. On the basis of cost-effectiveness, it was found that the warranty project is less cost-effective in the medium term, but more cost-effective over the long term, compared to the traditional project.

\subsection{Comparison Set 2 (Warranty Project: R-22854 and Control Project R-21602)}

\subsubsection{General Contract Information for Comparison Set 2}

The second warranty project analyzed in the present study is Contract R-22854 for pavement reconstruction to 3R4R standards. The project was awarded in 1996 and has completed the warranty period. The project location is I-65 from 0.26 mile north of US 31 to 0.5 mile north of SR 252 in Bartholomew County, Seymour district. The project begins from Milepost 76.00 and extends to Milepost 80.56, over a length of 4.56 miles. The control project is Contract R-21602, a traditional project with similar treatment, functional class, rural/urban class, and pavement type. The project begins from 0.26 mile north of US 31 in Huntington County, Fort Wayne, designated by Milepost 85.84, and ends at 0.5 mile north of SR 252 at Milepost 95.77. The characteristic features of the warranty and control projects are summarized in Table 5-16.

Table 5-16 Characteristics of Projects Constituting Comparison Set 2

\begin{tabular}{|l|c|c|}
\hline & $\begin{array}{c}\text { Warranty Project 2 } \\
\text { (R-22854) }\end{array}$ & $\begin{array}{c}\text { Control Project 2 } \\
\text { (R-21602) }\end{array}$ \\
\hline Work Description & $\begin{array}{c}\text { J300 } \\
\text { Road Reconstruction 3R4R }\end{array}$ & $\begin{array}{c}\text { J300 } \\
\text { Road Reconstruction 3R4R }\end{array}$ \\
\hline Functional Class & $\begin{array}{c}\text { Four-lane Rural } \\
\text { Interstate }\end{array}$ & $\begin{array}{c}\text { Four-lane Rural } \\
\text { Interstate }\end{array}$ \\
\hline NHS & Yes & Yes \\
\hline Length (miles) & 4.56 & 9.93 \\
\hline Surface Type & $\begin{array}{c}\text { HMA over } \\
\text { Crack-and-seat PCC }\end{array}$ & $\begin{array}{c}\text { HMA over } \\
\text { Crack-and-seat PCC }\end{array}$ \\
\hline Thickness of new surface & 9.00 inch & 27,150 \\
\hline AADT in Year 2002 & 36,679 & $36 \%$ \\
\hline Percentage trucks & $32 \%$ & inch \\
\hline
\end{tabular}


The traditional contract pavement that had closest pavement thickness and other characteristics was R21602. The thickness of this pavement was 3 inches more than that of the corresponding warranty pavement, but such difference is not expected to cause any bias in the analysis as the unit costs are in terms of lane-miles per unit thickness of pavement.

\subsubsection{Medium-term Performance Analysis for Comparison Set 2}

Performance Comparison on Basis of International Roughness Index (IRI)

The average IRI values of the contract segments for projects were determined from the data collected from INDOT, as shown in Table 5-17.

Table 5-17 IRI of Constituent Pavements, Comparison Set 2

\begin{tabular}{|c|c|c|}
\hline \multirow{2}{*}{$\begin{array}{c}\text { Age } \\
\text { (years) }\end{array}$} & \multicolumn{2}{|c|}{ IRI (in/mi) } \\
\cline { 2 - 3 } & $\begin{array}{c}\text { Warranty Project 2 } \\
\text { (R-22854) }\end{array}$ & $\begin{array}{c}\text { Control Project 2 } \\
\text { (R-21602) }\end{array}$ \\
\hline 1 & 32.97 & 50.50 \\
\hline 2 & 36.04 & 52.00 \\
\hline 3 & 37.77 & 55.88 \\
\hline 4 & 39.07 & 57.13 \\
\hline 5 & 41.45 & 82.13 \\
\hline
\end{tabular}

The IRI values for the warranty project pavement were relatively low throughout the entire warranty period, ranging from $32 \mathrm{in} / \mathrm{mi}$ to $42 \mathrm{in} / \mathrm{mi}$, while that for the control project were higher - varying from 52 in/mi at Age 1 to $82 \mathrm{in} / \mathrm{mi}$ at Age 5. Figure 5-21 shows the trend of IRI with age for both pavements.

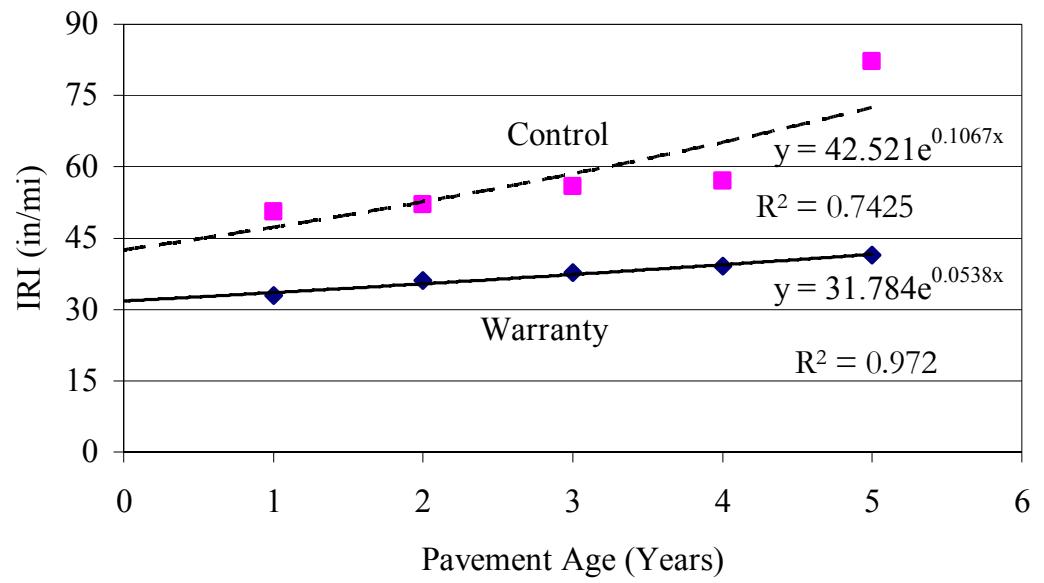

Figure 5-21 IRI Trends of Warranty and Control Pavements, Comparison Set 2 
With its relatively low IRI values, the warranty project exhibited better pavement condition compared to the control project. The trend lines were extrapolated back to the initial construction year to obtain an indication of the pavement condition immediately after construction. As seen from the figure, the warranty pavement had much lower value of initial IRI. Also, the IRI values were plotted with respect to accumulated traffic loading over the warranty period (Figure 5-22). It is seen that even though the warranty pavement had higher volume of trucks, it exhibited a performance that is superior to that of the control pavement.

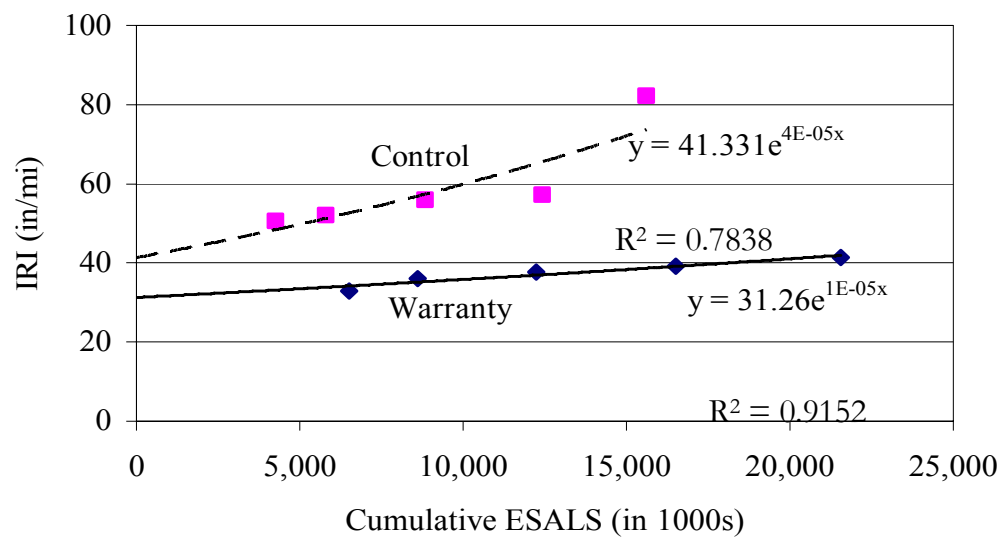

Figure 5-22 Comparison of Load-based Deterioration (IRI) Curves, Comparison Set 2

A statistical test was preformed to determine whether IRI of the warranty project was significantly different from that of the traditional project. The results of the $t$-test for IRI are shown in Table 5-18. The $t$ statistic -4.7244 is less than the negative critical value 2.1318 at $5 \%$ significance level, and hence the null hypothesis can be rejected. Therefore it can be concluded with $95 \%$ confidence that there is a statistically significant difference in the mean IRI values of the warranty and control projects. Specifically, the warranty project had lower IRI values (indicative of better pavement condition) over the medium term of 5 years.

Table 5-18 Results of t-test for IRI, Comparison Set 2

\begin{tabular}{lcc} 
& Variable 1 (Warranty) & Variable 2 (Control) \\
\hline Mean & 37.4618 & 59.5280 \\
Variance & 10.1796 & 167.0211 \\
Observations & 5 & 5 \\
Hypothesized Mean Difference & 0 & \\
Degrees of freedom & 4 & \\
$t$ Statistic & -4.7244 & \\
$\mathrm{P}(\mathrm{T}<=t)$ one-tail & 0.0046 & \\
$t$ Critical one-tail & 2.1318 & \\
\hline
\end{tabular}




\section{Performance Comparison on basis of Present Serviceability Index (PSI)}

Table 5-19 shows the average PSI values of the Comparison Set 1 warranty and the control projects for the first five years after construction, while Figure 5-23 shows the plot of IRI versus pavement age.

Table 5-19 Annual Pavement Condition (PSI), Comparison Set 2

\begin{tabular}{|c|c|c|}
\hline \multirow{2}{*}{$\begin{array}{c}\text { Age } \\
\text { (years) }\end{array}$} & \multicolumn{2}{|c|}{ PSI } \\
\cline { 2 - 3 } & $\begin{array}{c}\text { Warranty Project 2 } \\
\text { (R-22854) }\end{array}$ & $\begin{array}{c}\text { Control Project 2 } \\
\text { (R-21602) }\end{array}$ \\
\hline 1 & 4.37 & 4.06 \\
\hline 2 & 4.31 & 4.04 \\
\hline 3 & 4.28 & 3.98 \\
\hline 4 & 4.26 & 3.96 \\
\hline 5 & 4.22 & 3.57 \\
\hline
\end{tabular}

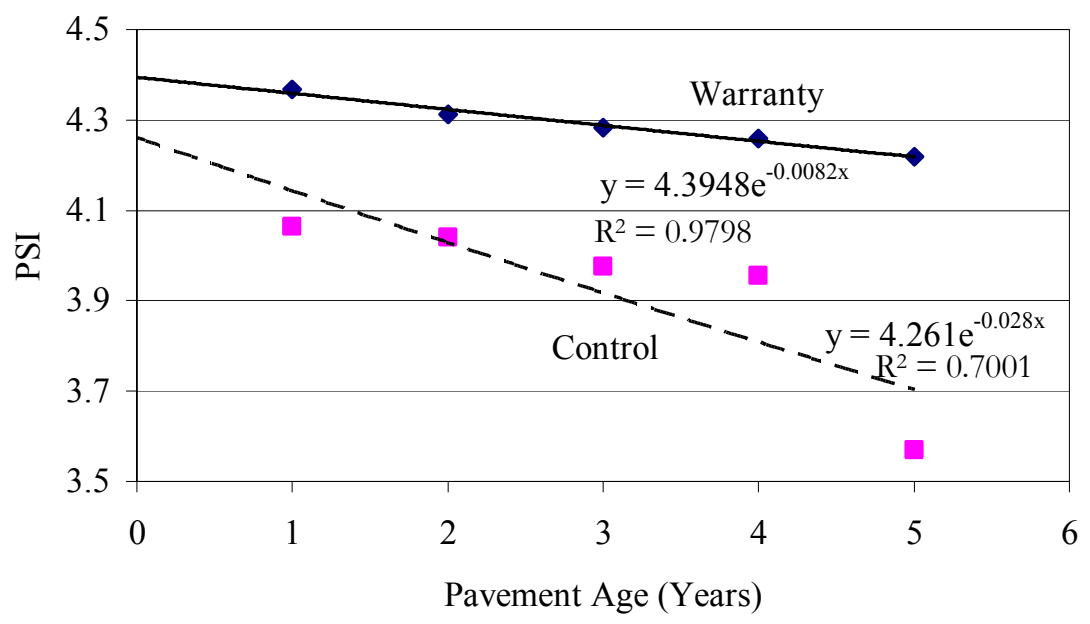

Figure 5-23 PSI Trends of Warranty and Control Pavements, Comparison Set 2

The time-based trends show that the warranty project indicated PSI values that are higher than those of the control project. At Age 5, the control project exhibited a rather sudden increase in deterioration indicated by the sharp decrease in its PSI values. The load-based trends (Figure 5-24) indicate that the warranty pavement had higher PSI values even under higher traffic loading. 


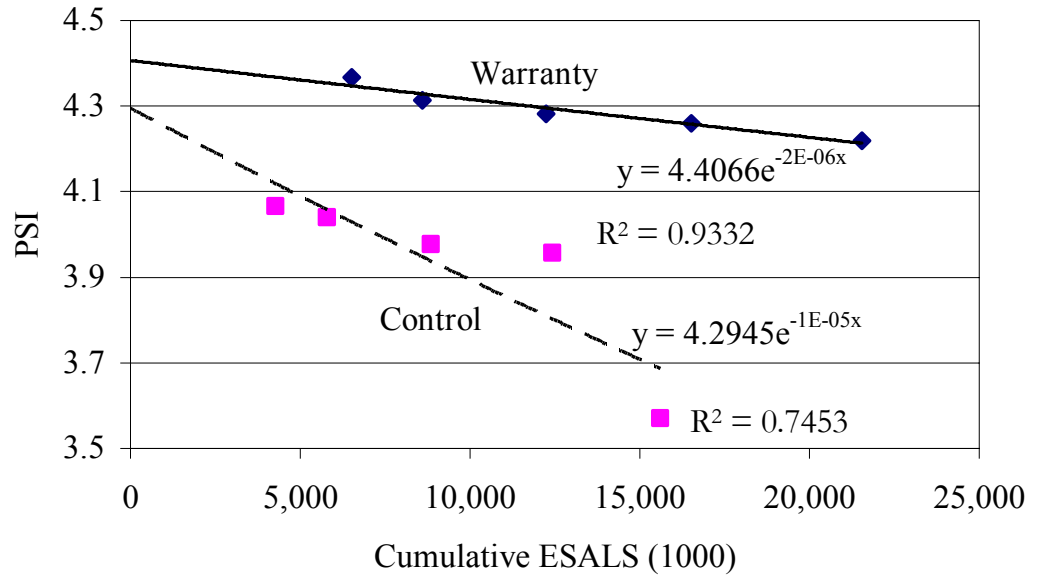

Figure 5-24 Comparison of Load-based Deterioration (PSI) Curves, Comparison Set 2

Table 5-20 shows the results of the test for PSI values. The $t$ statistic, 5.1992, is greater than the critical value of 2.1318 at $5 \%$ significance level, indicating that the null hypothesis can be rejected. Thus, there is a significant difference between the mean PSI values of the warranty and control projects.

Table 5-20 Results of t-test for PSI of Comparison Set 2

\begin{tabular}{lcc}
\hline & $\begin{array}{c}\text { Variable 1 } \\
\text { (Warranty) }\end{array}$ & $\begin{array}{c}\text { Variable 2 } \\
\text { (Control) }\end{array}$ \\
\hline Mean & 4.2884 & 3.9215 \\
Variance & 0.0032 & 0.0405 \\
Observations & 5 & 5 \\
Hypothesized Mean Difference & 0 & \\
Degrees of freedom & 4 & \\
$t$ Statistic & 5.1992 & \\
$\mathrm{P}(\mathrm{T}<=t)$ one-tail & 0.0033 & \\
$t$ Critical one-tail & 2.1318 & \\
\hline
\end{tabular}




\section{Performance Comparison on basis of Rutting}

The average rut depths of the pavements, in inches, throughout the warranty period are shown in Table 5.21 and plotted against pavement age in Figure 5-25. The rut depths of the warranty project were much lower than the threshold value of 0.24 . On the other hand, the control project had higher rut depths. It is interesting to note that of all performance indicators, rut depths seem to be associated with relatively little variability.

Table 5-21 Rut Depth of Constituent Pavements, Comparison Set 2

\begin{tabular}{|c|c|c|}
\hline \multirow{2}{*}{$\begin{array}{c}\text { Age } \\
\text { (years) }\end{array}$} & \multicolumn{2}{|c|}{ Rut Depth (in) } \\
\cline { 2 - 3 } & $\begin{array}{c}\text { Warranty Project 2 } \\
\text { (R-22854) }\end{array}$ & $\begin{array}{c}\text { Control Project 2 } \\
\text { (R-21602) }\end{array}$ \\
\hline 1 & 0.05 & 0.13 \\
\hline 2 & 0.09 & 0.11 \\
\hline 3 & 0.09 & 0.12 \\
\hline 4 & 0.09 & 0.11 \\
\hline 5 & 0.09 & 0.07 \\
\hline
\end{tabular}

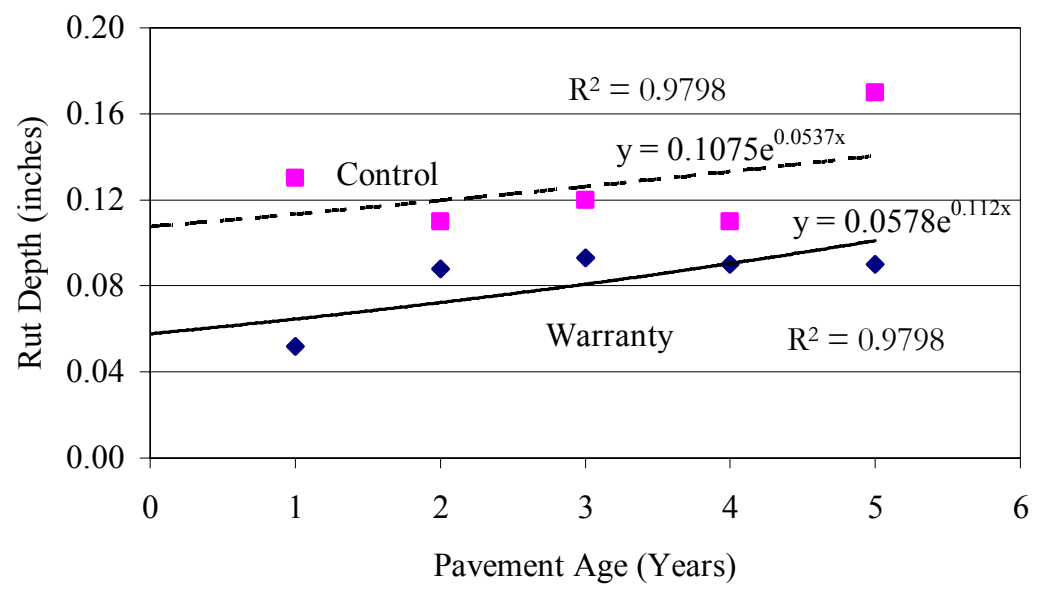

Figure 5-25 Rutting Trends of Warranty and Control Pavements, Comparison Set 2

The rutting process of the warranty project was consistent (in terms of its non-decreasing nature) during the entire warranty period, while the average rut depth of the control project increased initially and then decreased. Exponential trends were fitted and extrapolated to get the initial rut depths of the pavements. Figure 5-26 shows the trend of the rutting depth over the warranty period with respect to increasing traffic loads on the pavements. 


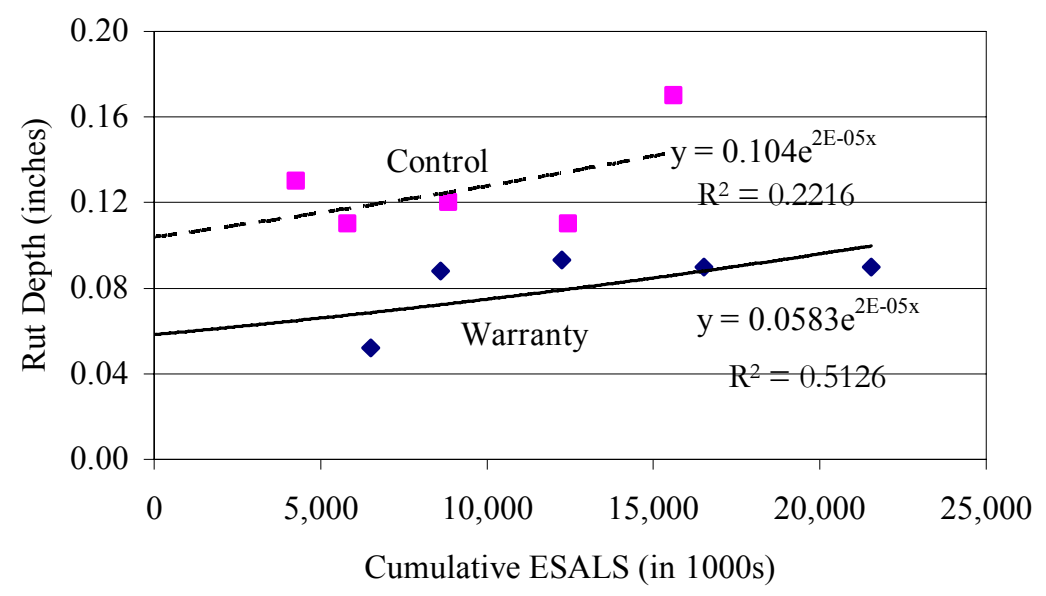

Figure 5-26 Comparison of Load-based Deterioration (Rut) Curves, Comparison Set 2

Table 5-22 Results of t-test for Rutting depth, Comparison Set 2

\begin{tabular}{lcc}
\hline & $\begin{array}{c}\text { Variable 1 } \\
\text { (Warranty) }\end{array}$ & $\begin{array}{c}\text { Variable 2 } \\
\text { (Control) }\end{array}$ \\
\hline Mean & 0.0826 & 0.1080 \\
Variance & 0.0003 & 0.0005 \\
Observations & 5 & 5 \\
Hypothesized Mean Difference & 0 & \\
Degrees of freedom & 4 & \\
$t$ Statistic & -1.6275 & \\
$\mathrm{P}(\mathrm{T}<=t)$ one-tail & 0.0895 & \\
$t$ Critical one-tail & 1.5332 & \\
\hline
\end{tabular}

Table 5-22 shows the $t$-test results for rut depth, performed at level of significance 0.10. (An earlier test at $5 \%$ significant failed to show any statistically significant differences in mean rut depths). The $t$ statistic is -1.6275 . Since $-1.6275<-1.5332$, we can easily reject the null hypothesis, and conclude that at $10 \%$ significance, there is a significant difference between the mean rut depths of the warranty and control projects. In other words, the warranty project had lower rut depths compared to the control project. 


\section{Comparison of Performance on basis of Pavement Condition Rating (PCR)}

The average PCR values of the warranty and the control project over the warranty period are given in Table 5-23 and the graphical representation is shown in Figure 5-27.

Table 5-23 PCR of Constituent Pavements, Comparison Set 2

\begin{tabular}{|c|c|c|}
\hline \multirow{2}{*}{$\begin{array}{c}\text { Age } \\
\text { (years) }\end{array}$} & $\begin{array}{c}|c| \\
\text { PCR } \\
(\mathrm{R}-22854)\end{array}$ & $\begin{array}{c}\text { Control Project 2 } \\
\text { (R-21602) }\end{array}$ \\
\cline { 2 - 3 } & 99.10 & 96.88 \\
\hline 1 & 97.86 & 95.19 \\
\hline 2 & 99.45 & 91.81 \\
\hline 3 & 98.70 & 89.00 \\
\hline 4 & 98.50 & 91.88 \\
\hline 5 & & \\
\hline
\end{tabular}

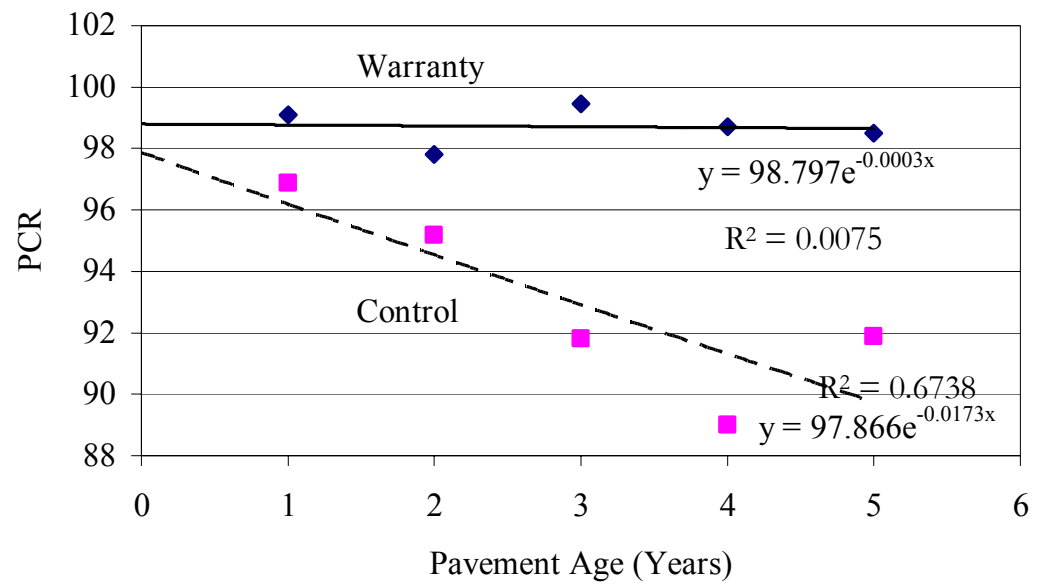

Figure 5-27 PCR Trends of Warranty and Control Pavements, Comparison Set 2

The increase in the PCR value of the warranty pavement at Age 3 may have been due to measurement errors. The warranty pavement showed excellent condition with high PCR values throughout the warranty period. The control project demonstrated considerable deterioration as shown by the decreasing values of PCR. Figure 5-28 shows the PCR values when viewed in the load domain. The contrast in pavement performance is clearly evident: the warranty pavement showed superior performance in spite of higher traffic loading. 


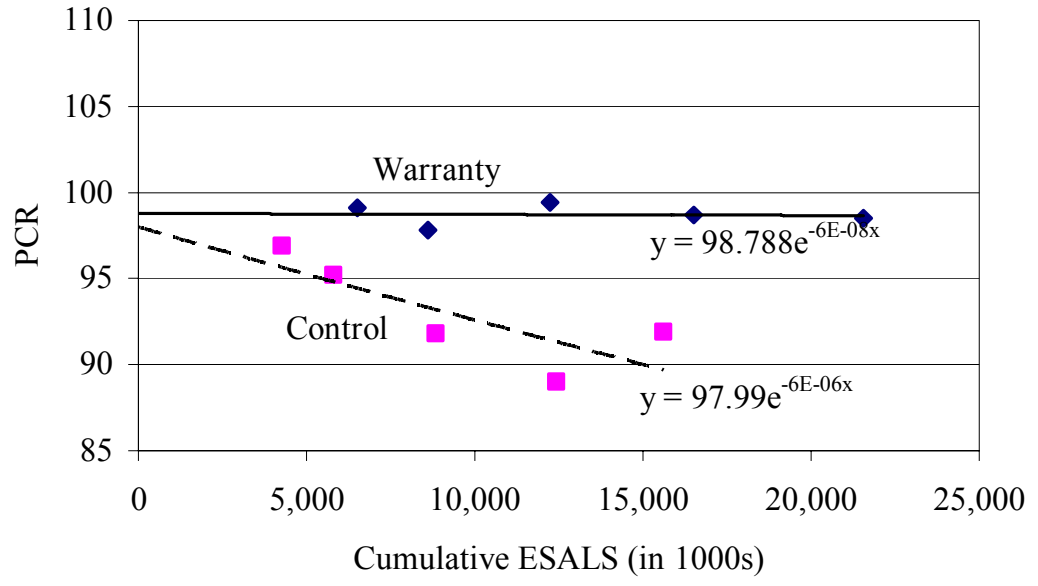

Figure 5-28 Comparison of Load-based Deterioration (PCR), Comparison Set 2

Table 5-24 Results of t-test for PCR, Comparison Set 2

\begin{tabular}{lcc}
\hline & Variable 1 (Warranty) & Variable 2 (Control) \\
\hline Mean & 98.7100 & 92.9520 \\
Variance & 0.3930 & 9.6274 \\
Observations & 5 & 5 \\
Hypothesized Mean Difference & 0 & \\
Degrees of freedom & 4 & \\
$t$ Statistic & 3.9615 & \\
P(T<=t) one-tail & 0.0083 & \\
$t$ Critical one-tail & 2.1318 & \\
\hline
\end{tabular}

Table 5-24 shows the t-test results of PCR at 5\% significance level. The results show that the calculated $t$ statistic 3.9615 is greater than the critical $t$ value of 2.1318. Thus there is enough evidence to reject the null hypothesis. Hence, the warranty pavement has higher PCR values compared to the control pavement. 


\subsubsection{Evaluation of Cost-Effectiveness for Comparison Set 2}

After analysis of the average pavement performance in the medium term, the cost-effectiveness evaluation for Comparison Set 2 was carried out. This was done in both medium and long term. The results of the analyses are presented in the subsequent sections.

\section{Medium-Term Cost-Effectiveness Evaluation for Comparison Set 2}

The agency costs for medium-term evaluation include initial construction cost and maintenance expenditure. All costs were converted to 2000 constant dollar using the Construction Price Index. Table 5-25 summarizes the various agency costs for the warranty and the control projects, and finally shows the EUAC per lanemile, computed by using $4 \%$ discount rates over 5 years.

Table 5-25 Medium-Term Agency Costs, Comparison Set 2

\begin{tabular}{|l|c|c|}
\hline & $\begin{array}{c}\text { Warranty Project 2 } \\
\text { (R-22854) }\end{array}$ & $\begin{array}{c}\text { Control Project 2 } \\
\text { (R-21602) }\end{array}$ \\
\hline Length (miles) & 4.56 & 4.17 \\
\hline Number of lanes & 4 & 4 \\
\hline Initial Cost & $\$ 13,048,280$ & $\$ 5,870,582$ \\
\hline Initial Cost/lane-mile & $\$ 715,366$ & $\$ 351,953$ \\
\hline Maintenance Costs/lane-mile (5 years) & $\$ 0$ & $\$ 1,073$ \\
\hline Total agency cost/lane-mile & $\$ 715,366$ & $\$ 353,026$ \\
\hline Agency EUAC/lane-mile & $\$ 160,691$ & $\$ 79,299$ \\
\hline
\end{tabular}

As indicated in Table 5-25, the cost of the warranty project is much higher than the control project. To determine the user costs, the same AADT and the percentage trucks was used for both warranty and control projects to provide a consistent basis for comparison. The calculation of the user costs components is shown below.

Table 5-26 shows the user costs of warranty and control pavements based on the work zone duration. The costs shown are expressed in year 2000 constant dollar. 
AADT per lane

14,607

Volume of passenger cars (70\%) per lane

10,225

Volume of single-unit trucks (14\%) per lane

614

Volume of multiple-unit trucks (16\%) per lane

701

Difference in travel time due to reduction in speed from $65 \mathrm{mph}$ to $45 \mathrm{mph}$ in the work zone $(1 / 45-1 / 65)$

$0.0068 \mathrm{hr} / \mathrm{mile}$

User cost for passenger car $(\$ 12.41 / \mathrm{hr} \times 0.0068 \mathrm{hr} \times 10,225)$

$\$ 867$

User cost for single-unit truck $(\$ 19.88 / \mathrm{hr} \times 0.0068 \mathrm{hr} \times 614)$

$\$ 83$

User cost for multiple-unit truck $(\$ 23.92 / \mathrm{hr} \times 0.0068 \mathrm{hr} \times 701)$

$\$ 115$

Total user cost per day per lane-mile

$\$ 1,065$

Table 5-26 Medium-Term User Costs, Comparison Set 2

\begin{tabular}{|l|c|c|}
\hline & $\begin{array}{c}\text { Warranty Project 2 } \\
\text { (R-22854) }\end{array}$ & $\begin{array}{c}\text { Control Project 2 } \\
\text { (R-21602) }\end{array}$ \\
\hline Work zone duration per lane-mile & 15 days & 16 days \\
\hline Total user cost & $\$ 15,976$ & $\$ 17,041$ \\
\hline User EUAC/lane-mile & $\$ 3,589$ & $\$ 3,828$ \\
\hline
\end{tabular}

Based on these formulations, the IRI values of the warranty and the control projects were plotted against pavement age, appropriate mathematical equations were used to represent the data trends, and the areas bounded by the fitted curves were estimated (Figures 5-29 and 5-30).

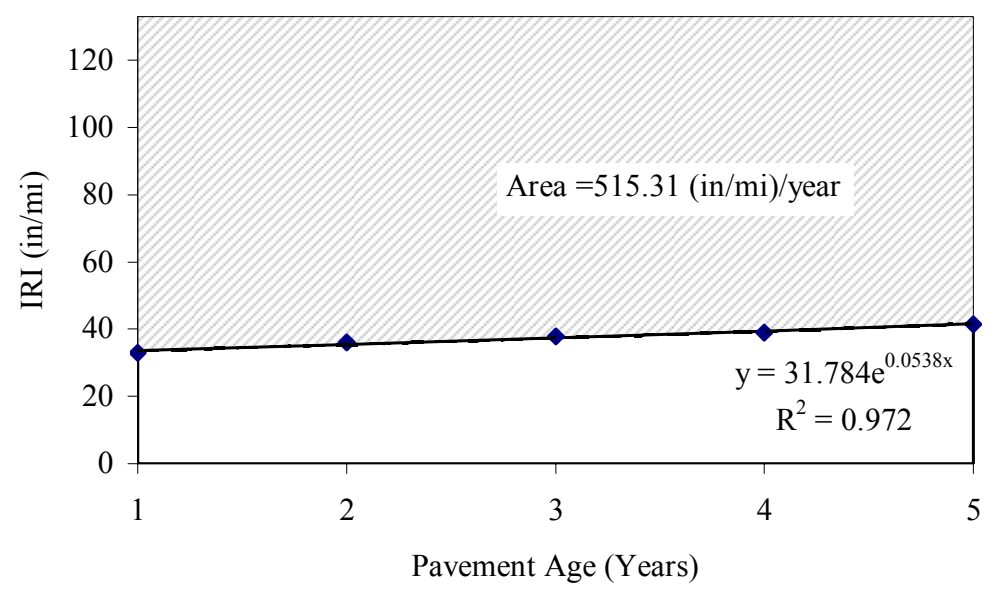

Figure 5-29Area bounded by IRI-Age curves of Warranty Pavement, Comparison Set 2 


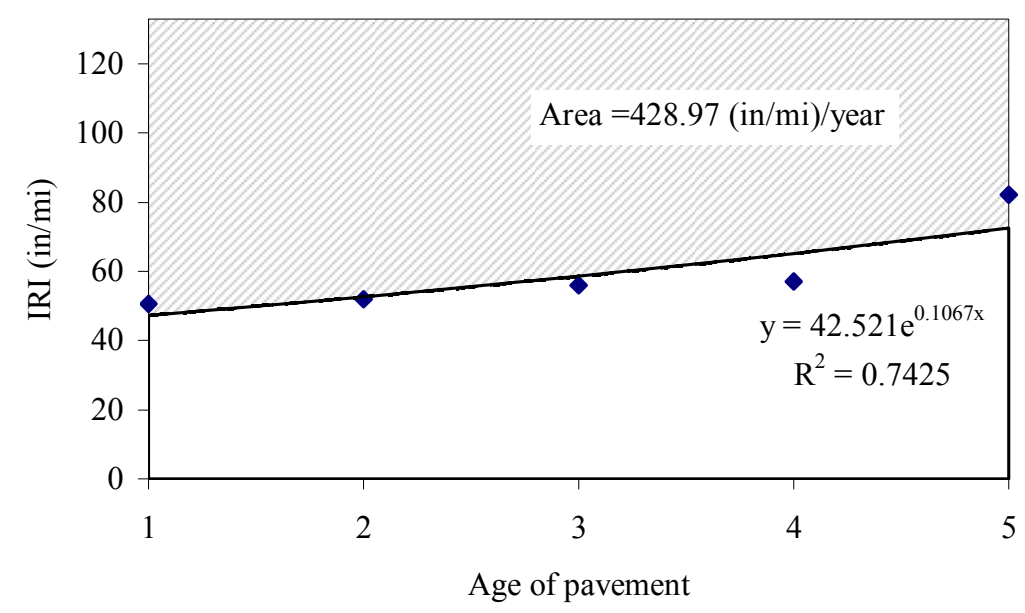

Figure 5-30 Area bounded by IRI-Age curves of Control Pavement, Comparison Set 2

Figures 5-31 and 3-32 show the trend of the IRI values corresponding to the cumulative ESALs over the warranty period for the warranty and control pavement, respectively. A linear trend line was found to best fit the warranty pavement trend while an exponential form seem best for the control pavement.

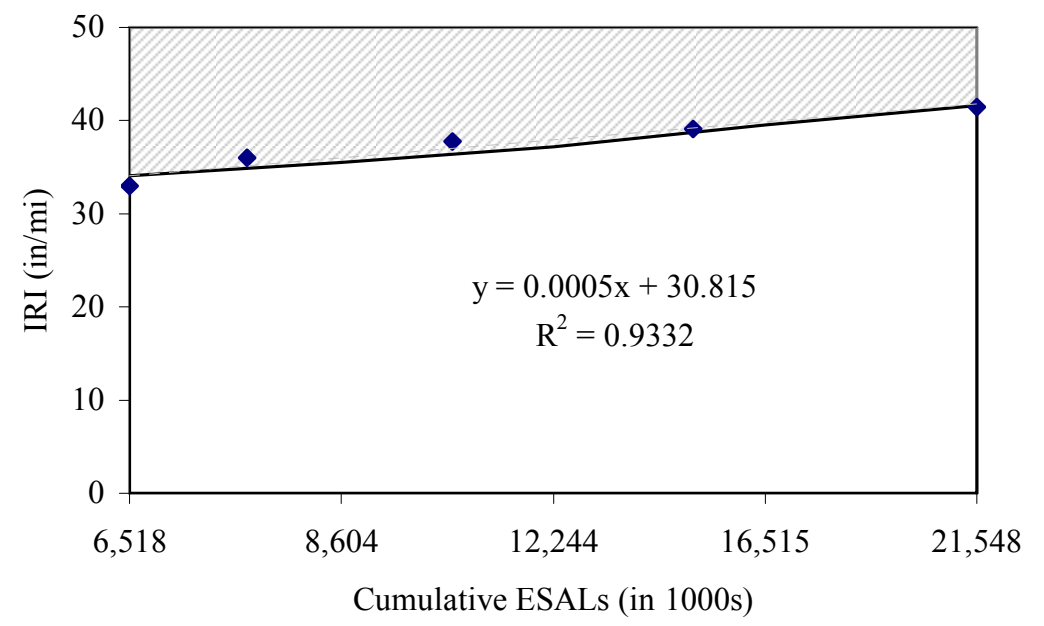

Figure 5-31 Area bounded by IRI-ESAL curve of Warranty Pavement, Comparison Set 2 


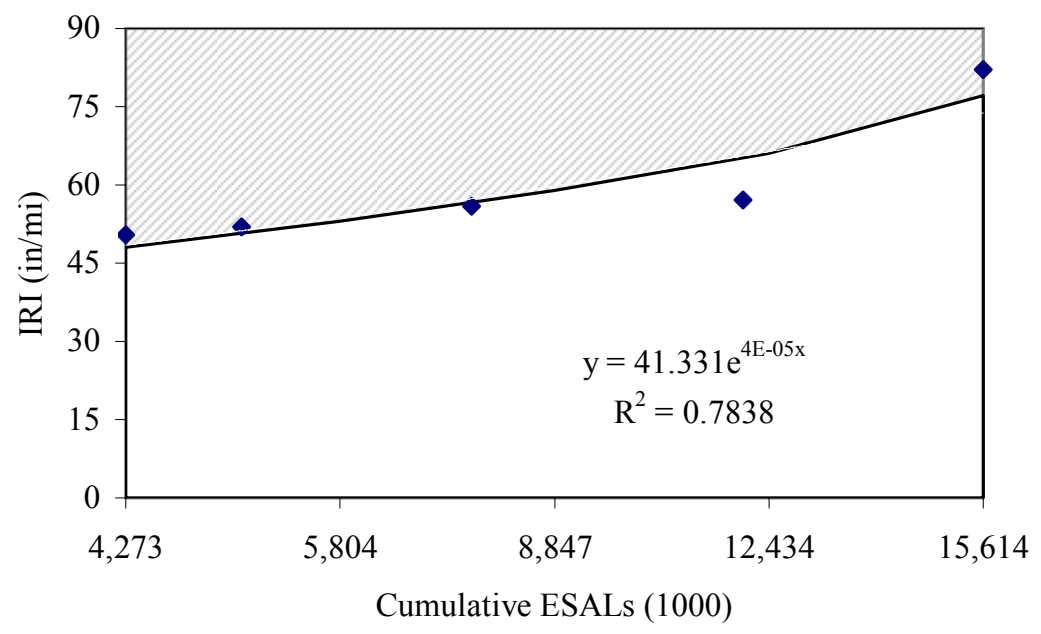

Figure 5-32 Area bounded by IRI-ESAL curve of Control Pavement, Comparison Set 2

In a manner similar to that done for IRI, PQI values were plotted to determine the effectiveness (area bounded by the curve) of the projects (Figures 5-33 and 5-34) and the resulting trend line equations were integrated over the age of the pavements to determine the treatment effectiveness.

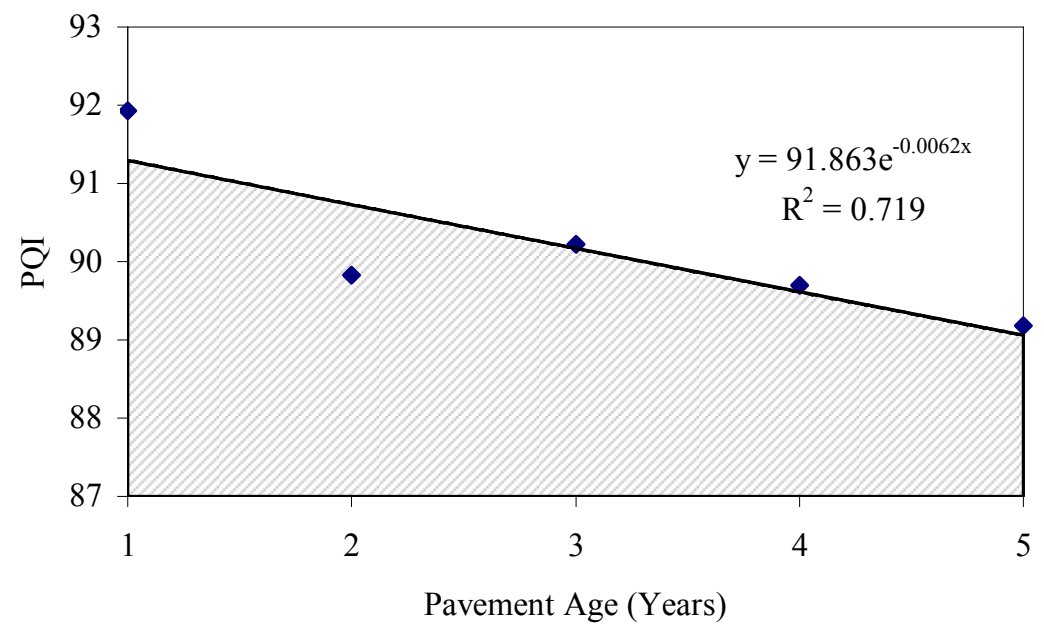

Figure 5-33 Area bounded by PQI-Age curve of Warranty Pavement, Comparison Set 2 


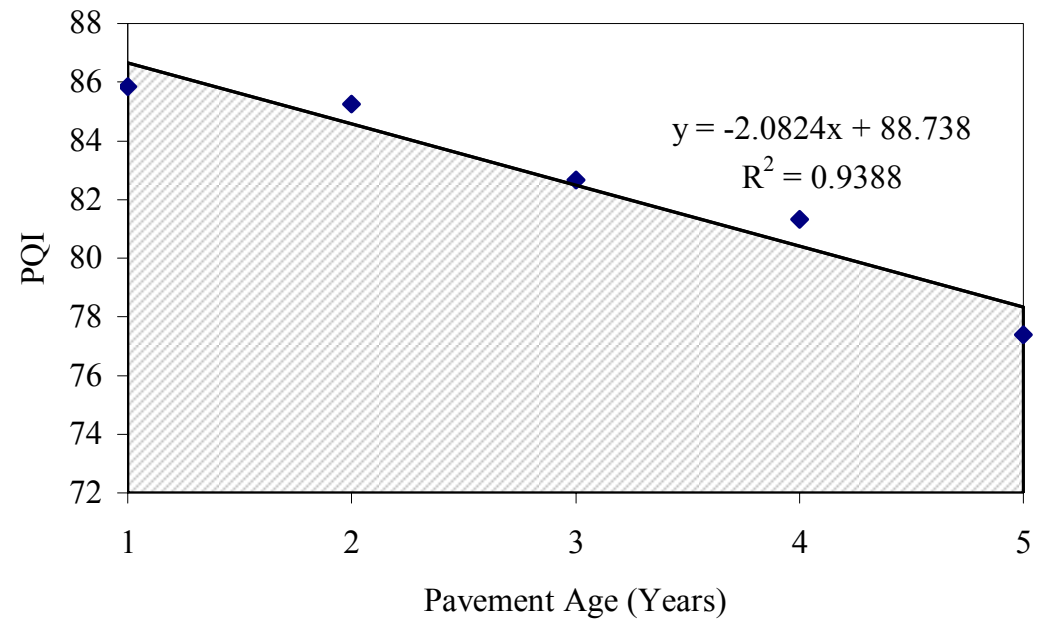

Figure 5-34 Area bounded by PQI-Age curve of Control Pavement, Comparison Set 2

The PQI trends with respect to the cumulative ESALs are shown in Figures 5-35 and 5-36, for the two pavement categories. Exponential trend lines were fitted determine the area bounded by the curves.

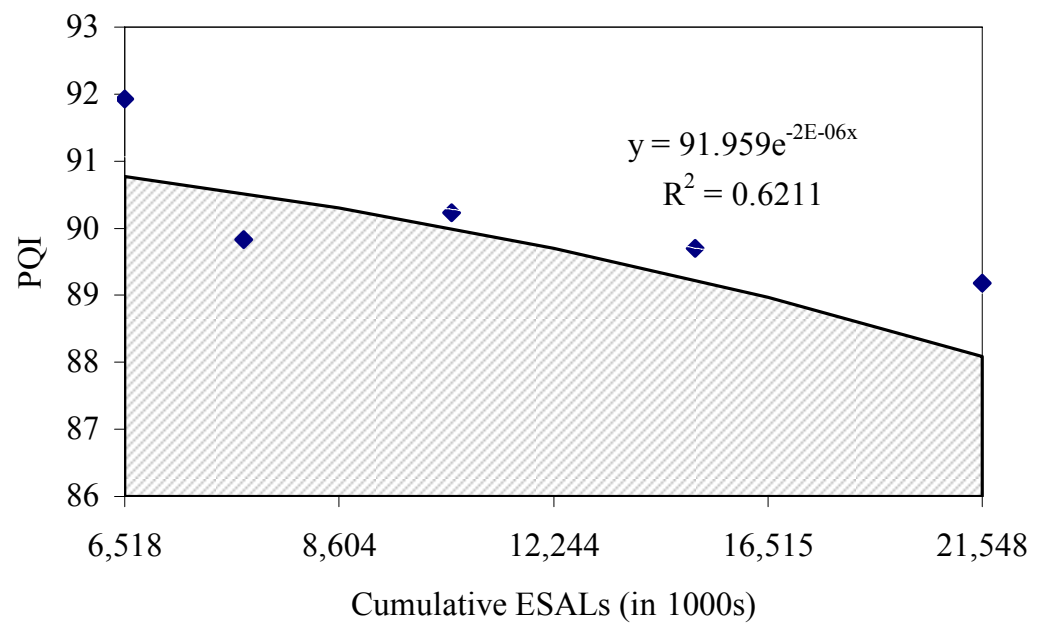

Figure 5-35 Area bounded by PQI-ESAL curve of Warranty Pavement, Comparison Set 2 


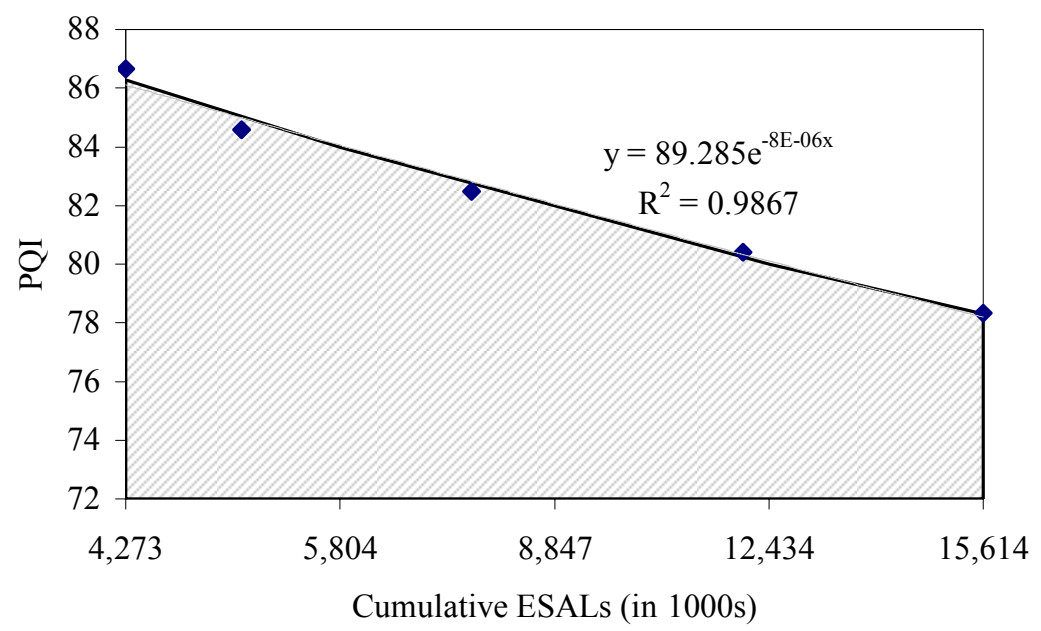

Figure 5-36 Area bounded by PQI-ESAL curve of Control Pavement, Comparison Set 2

The results of the overall analysis are shown in Table 5-27. The cost-effectiveness of the treatments under each contracting system were determined first using agency costs only, and then on the basis of both agency and user costs.

Table 5-27 Medium Term Cost-effectiveness Evaluation, Comparison Set 2

\begin{tabular}{|l|c|c|c|c|}
\hline \multirow{2}{*}{ Cost-effectiveness } & \multicolumn{2}{|c|}{ Agency Cost only } & \multicolumn{2}{c|}{ Agency Cost + User Cost } \\
\cline { 2 - 5 } & $\begin{array}{c}\text { Warranty } \\
\text { (R-22854) }\end{array}$ & $\begin{array}{c}\text { Control } \\
\text { (R-21602) }\end{array}$ & $\begin{array}{c}\text { Warranty } \\
\text { (R-22854) }\end{array}$ & $\begin{array}{c}\text { Control } \\
\text { (R-21602) }\end{array}$ \\
\hline $\begin{array}{l}\text { Area bounded by the IRI-Age } \\
\text { curve/EUAC (\$1000) }\end{array}$ & 8.10 & 15.02 & 7.67 & 13.25 \\
\hline $\begin{array}{l}\text { Area bounded by the IRI- } \\
\text { ESAL curve/EUAC }\end{array}$ & 14.30 & 17.31 & 13.98 & 16.52 \\
\hline $\begin{array}{l}\text { Area bounded by the PQI- } \\
\text { Age curve/EUAC (\$1000) }\end{array}$ & 5.67 & 11.56 & 5.37 & 10.19 \\
\hline $\begin{array}{l}\text { Area bounded by the PQI- } \\
\text { ESAL curve/EUAC }\end{array}$ & 21.13 & 32.76 & 20.00 & 28.89 \\
\hline
\end{tabular}

The results indicated a higher cost-effectiveness of the control project relative to the warranty project. Figures 5-37 and 5-38 show the comparison of cost-effectiveness of warranty and control projects based on time (pavement age) and traffic loading, respectively. 


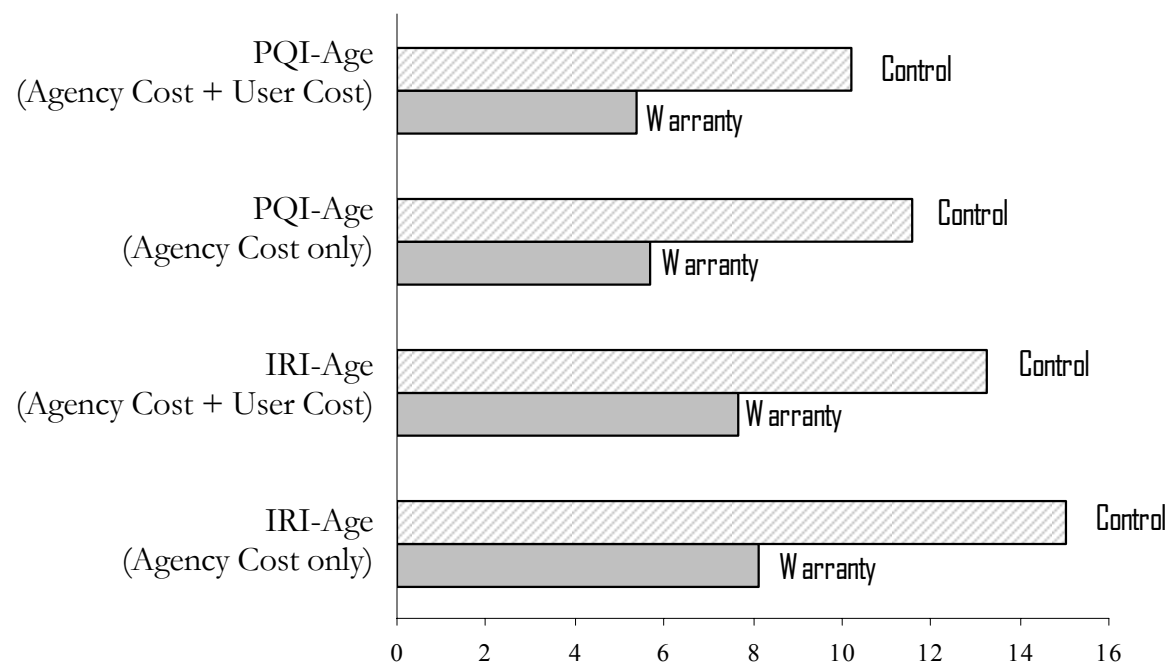

IRI-Years per $\$ 1000$ EUAC or PQI-Years per \$1000 EUAC

Figure 5-37 Medium-Term Cost-Effectiveness based on Performance and Time, Comparison Set 2

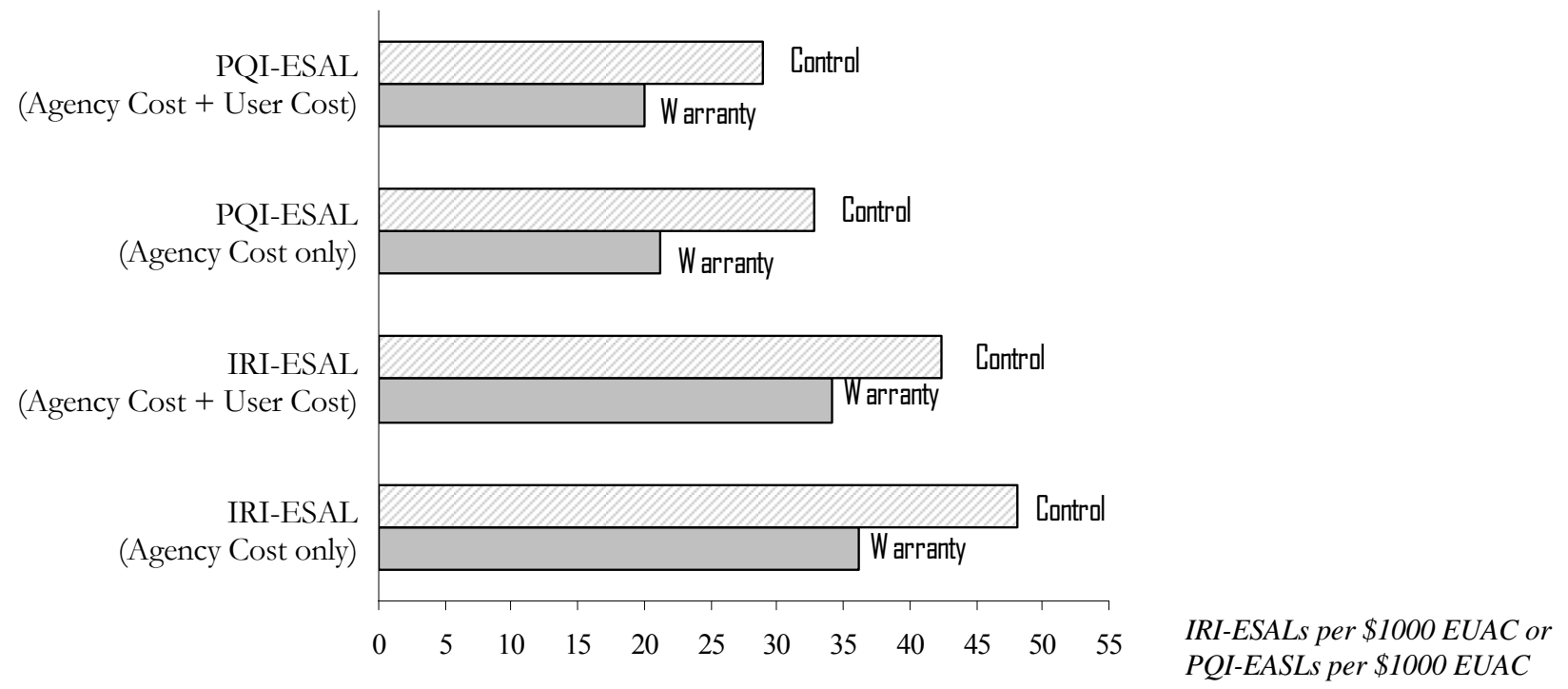

Figure 5-38 Medium-Term Cost-Effectiveness based on Performance and Load, Comparison Set 2 
The values of medium-term cost-effectiveness of the warranty project based on the age curves were on an average 75\% lower than of the control (traditional) project. Based on IRI and PQI load-curves, the costeffectiveness values for warranty project are approximately $30 \%$ lower than those of the control project.

\subsubsection{Long-Term Cost-Effectiveness Evaluation for Comparison Set 2}

The long-term evaluation of cost-effectiveness was carried out for the period spanning the entire (projected) pavement life. The various components of agency and user costs of warranty and control projects are shown in Tables 5-28 and 5-29, respectively. The costs are shown in Year 2000 constant dollar. The total agency cost of the warranty project was higher than the control project, due to the high initial construction cost.

Table 5-28 Long-Term Agency Costs, Comparison Set 2

\begin{tabular}{|l|c|c|}
\hline & $\begin{array}{c}\text { Warranty Project 2 } \\
\text { (R-22854) }\end{array}$ & $\begin{array}{c}\text { Control Project 2 } \\
\text { (R-21602) }\end{array}$ \\
\hline Construction Cost/lane-mile & $\$ 715,366$ & $\$ 351,953$ \\
\hline Maintenance Cost/lane-mile & $\$ 6,212^{*}$ & $\$ 7,197$ \\
\hline Agency cost/lane-mile & $\$ 721,578$ & $\$ 359,151$ \\
\hline Agency EUAC/lane-mile & $\$ 46,190$ & $\$ 32,302$ \\
\hline
\end{tabular}

* Applicable only to warranty pavements after expiration of the warranty period.

Table 5-29 Long-Term User Costs, Comparison Set 2

\begin{tabular}{|l|c|c|}
\hline & $\begin{array}{c}\text { Warranty Project } \\
\text { (R-22854) }\end{array}$ & $\begin{array}{c}\text { Control Project 2 } \\
\text { (R-21602) }\end{array}$ \\
\hline Work zone duration per lane-mile & 15 days & 16 days \\
\hline Total User cost per lane-mile & $\$ 15,976$ & $\$ 17,041$ \\
\hline User EUAC/lane-mile & $\$ 1,023$ & $\$ 1,533$ \\
\hline
\end{tabular}

Table 5-30 indicates the overall cost-effectiveness of the warranty and control projects based on agency costs only, and also the sum of agency and user costs. The results show that the warranty project was more cost-effective in the long term, compared to the corresponding control project. 
Table 5-30 Long Term Cost-effectiveness Evaluation, Comparison Set 2

\begin{tabular}{|l|c|c|c|c|}
\hline \multirow{2}{*}{ Cost-effectiveness } & \multicolumn{2}{|c|}{ Agency Cost only } & \multicolumn{2}{c|}{ Agency Cost + User Cost } \\
\cline { 2 - 5 } & $\begin{array}{c}\text { Warranty } \\
\text { (R-22854) }\end{array}$ & $\begin{array}{c}\text { Control } \\
\text { (R-21602) }\end{array}$ & $\begin{array}{c}\text { Warranty } \\
\text { (R-22854) }\end{array}$ & $\begin{array}{c}\text { Control } \\
\text { (R-21602) }\end{array}$ \\
\hline $\begin{array}{l}\text { Average Service life/EUAC } \\
(\$ 1000)\end{array}$ & 0.54 & 0.46 & 0.40 & 0.30 \\
\hline $\begin{array}{l}\text { Area bounded by the IRI-Age } \\
\text { curve/EUAC (\$1000) }\end{array}$ & 84.62 & 48.64 & 62.88 & 31.84 \\
\hline $\begin{array}{l}\text { Area bounded by the PQI- } \\
\text { Age curve/EUAC (\$1000) }\end{array}$ & 44.08 & 31.24 & 32.75 & 20.45 \\
\hline
\end{tabular}

Average Treatment Life (Agency Cost + User Cost)

Average Treatment Life

(Agency Cost only)

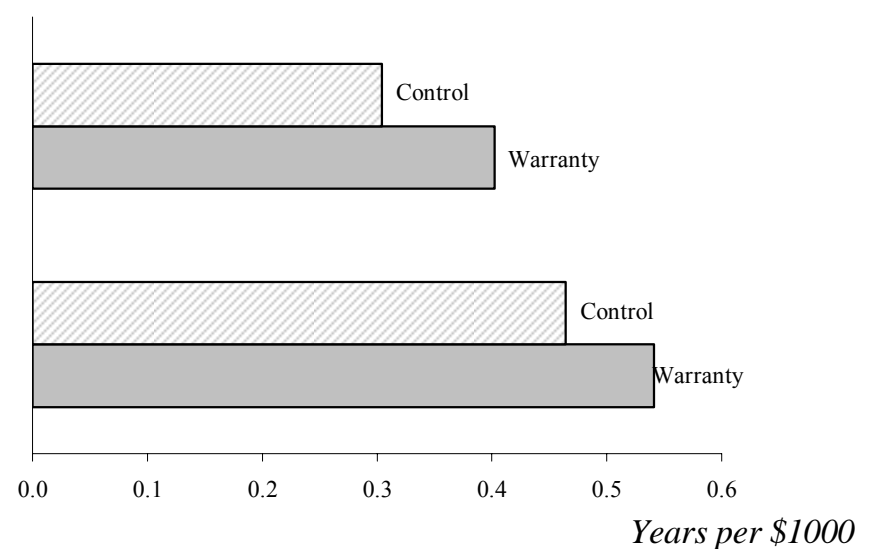

Figure 5-39 Long-Term Cost-Effectiveness based on Treatment Life Only, Comparison Set 2

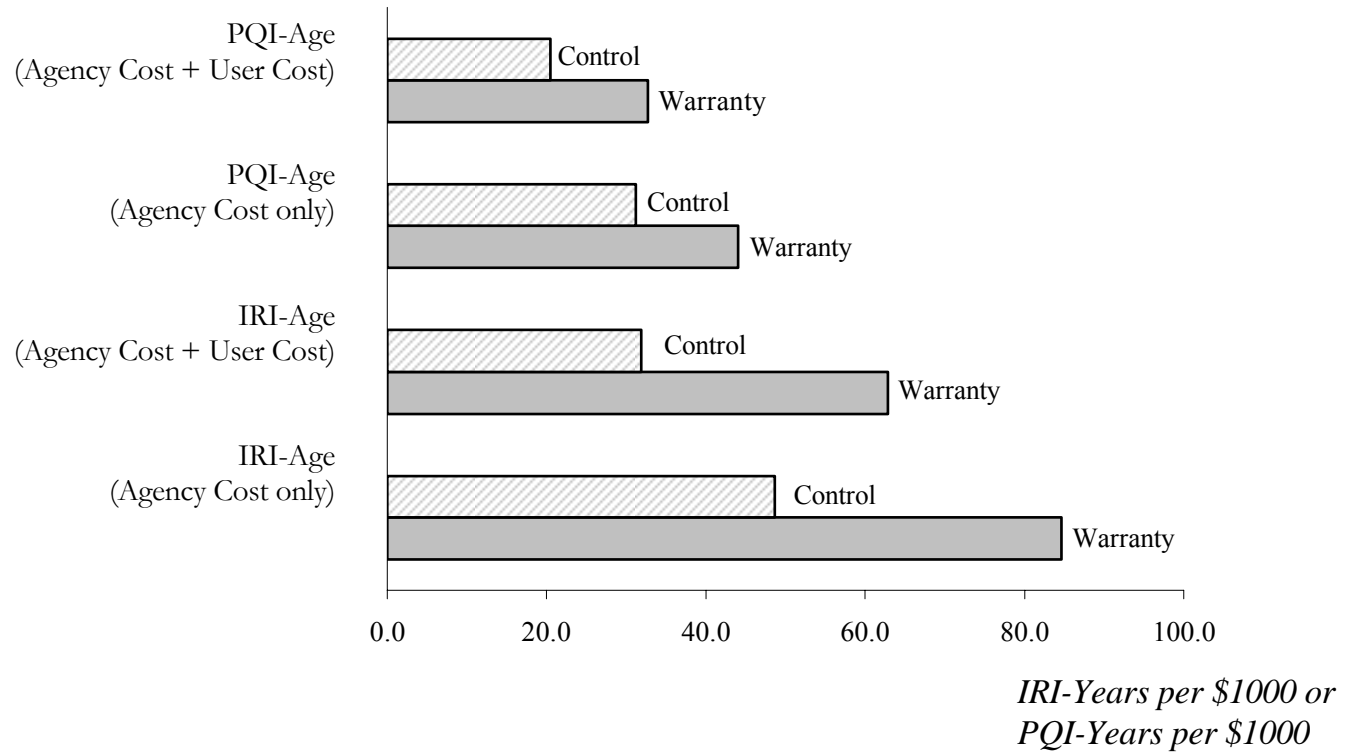

Figure 5-40 Long-Term Cost-Effectiveness based on Performance and Time, Comparison Set 2 
A comparison of cost-effectiveness of warranty and control projects based on treatment lives (Figures 5-39 and 5-40, respectively) indicate that the warranty project is clearly more cost-effective than the control (traditional) project in the long-term.

\section{Summary of Analysis Results for Comparison Set 2}

The analysis for Comparison Set 2 indicated that on the basis of performance only, the warranty project pavement exhibited better pavement performance in terms of IRI, PSI, rutting, and PCR in spite of higher traffic loading. On the basis of user cost, the warranty pavement was also found to be superior to the traditional project. On the basis of medium-term cost-effectiveness, it was found that the warranty project is less cost-effective than the control (traditional) project. However, in the long term (over the projected treatment service lives), the warranty project was found to be more cost-effective than the control project.

\subsection{Comparison Set 3 (Warranty Project: R-22925 and Control Project R-22912)}

\subsubsection{General Contract Information for Comparison Set 3}

The third warranty project studied is R-22925 which involves cracking \& seating an existing PCC pavement and Hot-mix Asphalt (HMA) Overlay, at an I-69 section in DeKalb County, Fort Wayne District. The contract was awarded in February 1997 and completed in September 1997. The warranty period ended in 2002. The project begins from 2.3 kilometers north of SR 8 to 1.5 kilometers south of SR 4 . The total length of the project is 8.68 miles between Mileposts 130.19 to 138.87 .

The control project, R-22912, begins from milepost 79.34, 1.97 miles north of SR 5 and extends up to Milepost 85.84, 0.38 mile south of US 224 in Huntington County, Fort Wayne. The physical features of the warranty project and the control project are summarized below in Table 5-31.

Table 5-31 Characteristics of Projects Constituting Comparison Set 3

\begin{tabular}{|l|c|c|}
\hline & $\begin{array}{c}\text { Warranty Project 3 } \\
\text { (R-22925) }\end{array}$ & $\begin{array}{c}\text { Control Project 3 } \\
\text { (R-22912) }\end{array}$ \\
\hline Work Description & $\begin{array}{c}\text { J 311 - Crack \& Seat Composite } \\
\text { Pavement \& HMA Overlay }\end{array}$ & $\begin{array}{c}\text { J-311 - Crack \& Seat Composite } \\
\text { Pavement \& HMA Overlay }\end{array}$ \\
\hline Functional Class & $\begin{array}{c}\text { Four-lane Rural } \\
\text { Interstate }\end{array}$ & $\begin{array}{c}\text { Four-lane Rural } \\
\text { Interstate }\end{array}$ \\
\hline NHS & Yes & Yes \\
\hline Length (miles) & 8.68 & 6.50 \\
\hline Surface Type & HMA over & HMA over \\
Crack-and-seat PCC & 6.00 inch \\
\hline Thickness of new surface & 6.00 inch & 22,798 \\
\hline AADT in Year 2002 & 28,345 & $26 \%$ \\
\hline Percentage trucks & $23 \%$ & $23 \%$ \\
\hline
\end{tabular}




\subsubsection{Medium-term Performance Analysis for Comparison Set 3}

The performance of the pavements for the warranty and the control projects in terms of IRI, PSI, rutting, and PCR, over the warranty period, were investigated and the results are presented in the following sections.

$\underline{\text { Performance Comparison on basis of International Roughness Index (IRI) }}$

Table 5-32 shows the IRI values of the warranty project and the control project over the warranty period. The threshold value of the warranty pavement is $133 \mathrm{in} / \mathrm{mi}$ [INDOT, 2002].

Table 5-32 IRI of Constituent Pavements, Comparison Set 3

\begin{tabular}{|c|c|c|}
\hline \multirow{2}{*}{$\begin{array}{c}\text { Age } \\
\text { (years) }\end{array}$} & \multicolumn{2}{|c|}{ IRI (in/mi) } \\
\hline & $\begin{array}{c}\text { Warranty Project } 3 \\
(\mathrm{R}-22925)\end{array}$ & $\begin{array}{c}\text { Control Project } 3 \\
\text { (R-22912) }\end{array}$ \\
\hline 1 & 44.08 & 49.48 \\
\hline 2 & 48.23 & 53.00 \\
\hline 3 & 48.81 & 53.09 \\
\hline 4 & 50.41 & 53.82 \\
\hline 5 & 58.40 & 65.64 \\
\hline
\end{tabular}

The warranty pavement had lower IRI throughout the warranty period; however the difference between the IRI values of the two projects does not seem to be very significant. Figure 5.41shows the trend of pavement deterioration with age in terms of IRI, while Figure 5-42 shows the trend of the IRI values of the projects corresponding to the accumulated traffic load. Table 5-33 shows the results of the t-test for IRI values of the warranty and control projects. The differences in the means of the two samples were found to be significant at level of significance 0.05 , since the $t$ statistic -7.8045 is less than the critical value of -2.1318 . Hence the null hypothesis is rejected implying that the warranty project had lower IRI value.

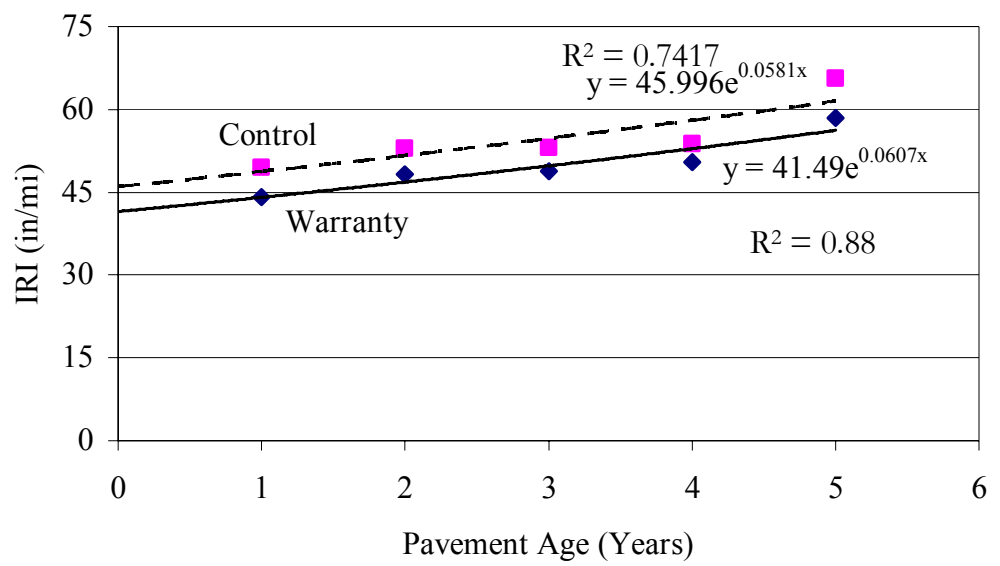

Figure 5-41 IRI Trends of Warranty and Control Pavements, Comparison Set 3 


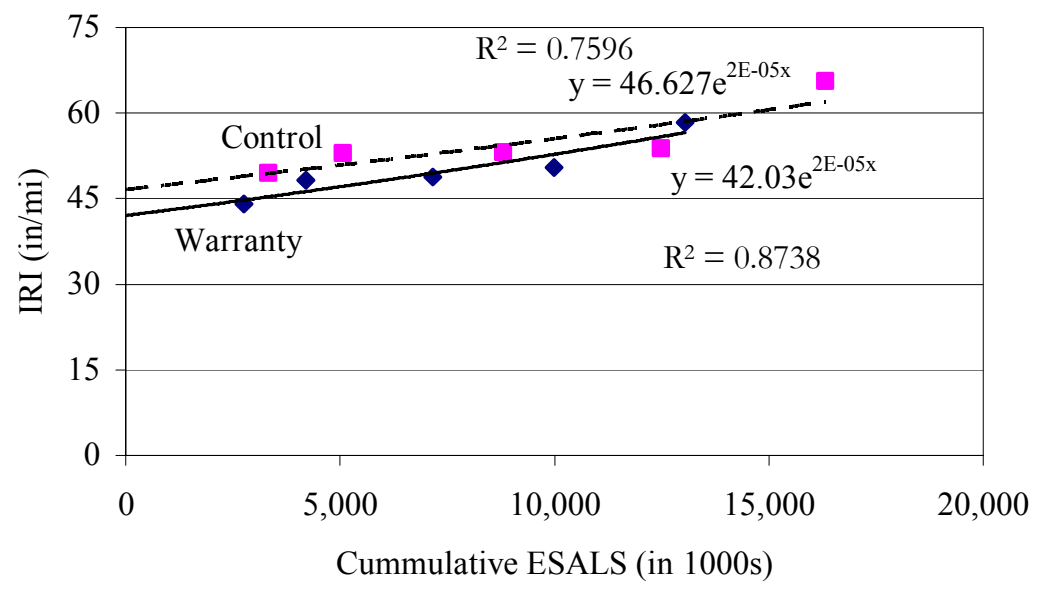

Figure 5-42 Comparison of Load-based Deterioration (IRI) Curves, Comparison Set 3

Table 5.33 Results of t-test for IRI, Comparison Set 3

\begin{tabular}{lcc}
\hline & $\begin{array}{c}\text { Variable 1 } \\
\text { (Warranty) }\end{array}$ & $\begin{array}{c}\text { Variable 2 } \\
\text { (Control) }\end{array}$ \\
\hline Mean & 49.9860 & 55.0060 \\
Variance & 27.5801 & 38.1801 \\
Observations & 5 & 5 \\
Hypothesized Mean Difference & 0 & \\
Degrees of freedom & 4 & \\
$t$ Statistic & -7.8045 & \\
$\mathrm{P}(\mathrm{T}<=t)$ one-tail & 0.0007 & \\
$t$ Critical one-tail & 2.1318 \\
\hline
\end{tabular}

Performance Comparison on basis of Present Serviceability Index (PSI)

As seen from the Table 5-34, the warranty project pavement had slightly higher PSI values compared to that of the control project. Figure 5-43 shows the trend of the PSI of the warranty pavement and the control project from Ages 1 to 5. Both pavements exhibited rather little deterioration over the 5-year period. The difference in their pavement performances was only evident after Age 4. Figure 5-44 shows the PSI variation with increasing traffic loading (in terms of accumulated ESALs) over the warranty period. 
Table 5-34 PSI of Constituent Pavements, Comparison Set 3

\begin{tabular}{|c|c|c|}
\hline \multirow{2}{*}{$\begin{array}{c}\text { Age } \\
\text { (years) }\end{array}$} & $\begin{array}{c}|c| \\
\text { Warranty Project 3 } \\
\text { (R-22925) }\end{array}$ & $\begin{array}{c}\text { Control Project 3 } \\
\text { (R-22912) }\end{array}$ \\
\cline { 2 - 3 } & 4.17 & 4.08 \\
\hline 1 & 4.10 & 4.02 \\
\hline 2 & 4.09 & 4.02 \\
\hline 3 & 3.97 & 4.01 \\
\hline 4 & 3.94 & 3.82 \\
\hline 5 & & \\
\hline
\end{tabular}

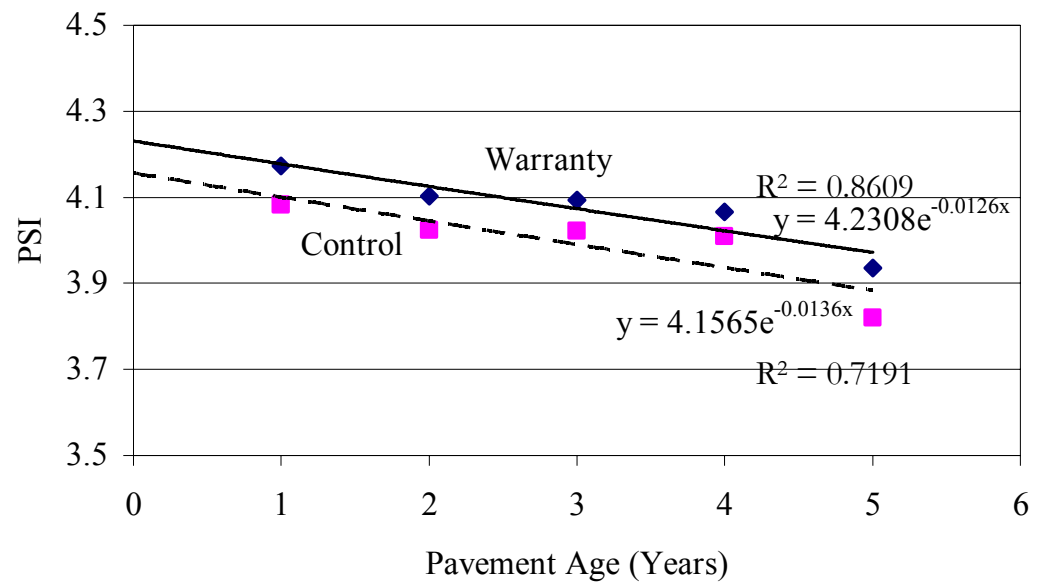

Figure 5-43 PSI Trends of Warranty and Control Pavements, Comparison Set 3

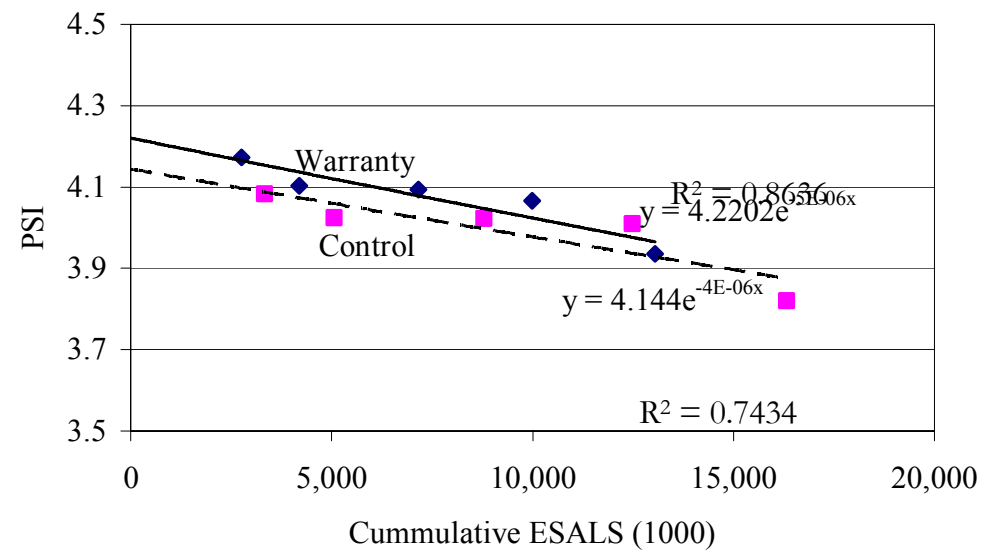

Figure 5-44 Comparison of Load-based Deterioration (PSI), Comparison Set 3 
The $t$-test was carried to discern any statistically significant differences in PSI values of the warranty and control projects, and the results are shown in Table 5-35. The values clearly indicate a significant difference in the PSI values of warranty and the control project (higher values for warrant), at 5\% significance level.

Table 5-35 Results of $t$-test for PSI, Comparison Set 3

\begin{tabular}{lcc}
\hline & $\begin{array}{c}\text { Variable 1 } \\
\text { (Warranty) }\end{array}$ & $\begin{array}{c}\text { Variable 2 } \\
\text { (Control) }\end{array}$ \\
\hline Mean & 4.0742 & 3.9915 \\
Variance & 0.0076 & 0.0099 \\
Observations & 5 & 5 \\
Hypothesized Mean Difference & 0 & \\
Degrees of freedom & 4 & \\
$t$ Statistic & 8.3636 & \\
P(T<=t) one-tail & 0.0006 & \\
$t$ Critical one-tail & 2.1318 & \\
\hline
\end{tabular}

\section{Performance Comparison on basis of Rutting Depth}

Table 5-36 and Figure 5-45 show the rut depths of the warranty and control projects for first 5 years of pavement life. The warranty pavement had much lower rut depths compared to the control pavement. The trend of the rut depth is also noticeable in Figure 5-46 showing the cumulative ESALs over the warranty period. Exponential trend lines were fitted for both pavements.

Table 5-36 Rut Depth of Constituent Pavements in Comparison Set 3

\begin{tabular}{|c|c|c|}
\hline \multirow{2}{*}{$\begin{array}{c}\text { Age } \\
\text { (years) }\end{array}$} & \multicolumn{2}{|c|}{ Rut Depth (in) } \\
\cline { 2 - 3 } & $\begin{array}{c}\text { Warranty Project 3 } \\
\text { (R-22925) }\end{array}$ & $\begin{array}{c}\text { Control Project 3 } \\
\text { (R-22912) }\end{array}$ \\
\hline 1 & 0.04 & 0.11 \\
\hline 2 & 0.11 & 0.19 \\
\hline 3 & 0.12 & 0.20 \\
\hline 4 & 0.09 & 0.16 \\
\hline 5 & 0.09 & 0.15 \\
\hline
\end{tabular}




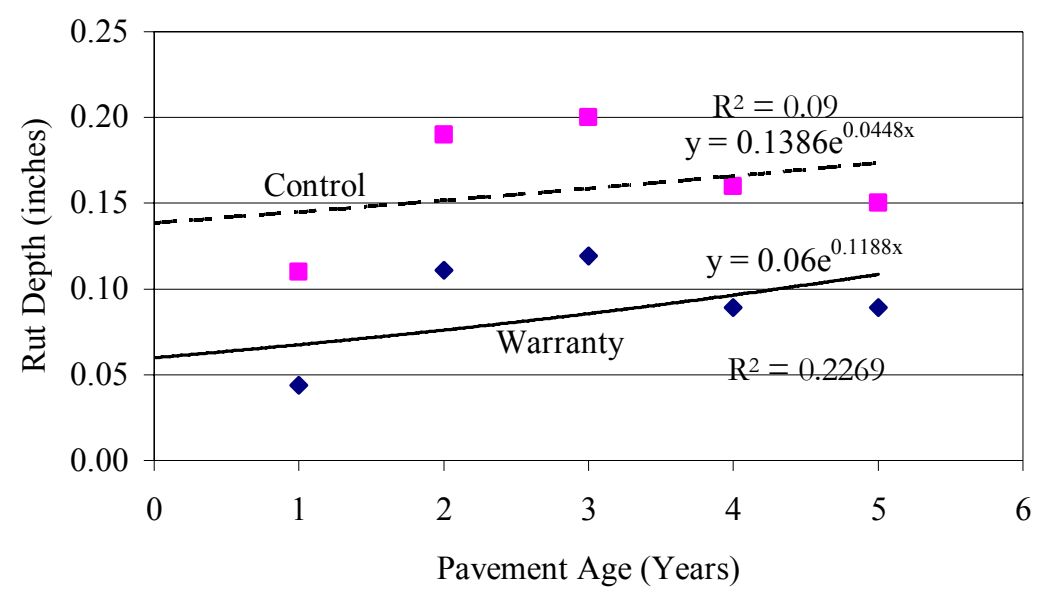

Figure 5-45 Rutting Trends of Warranty and Control Pavements, Comparison Set 3

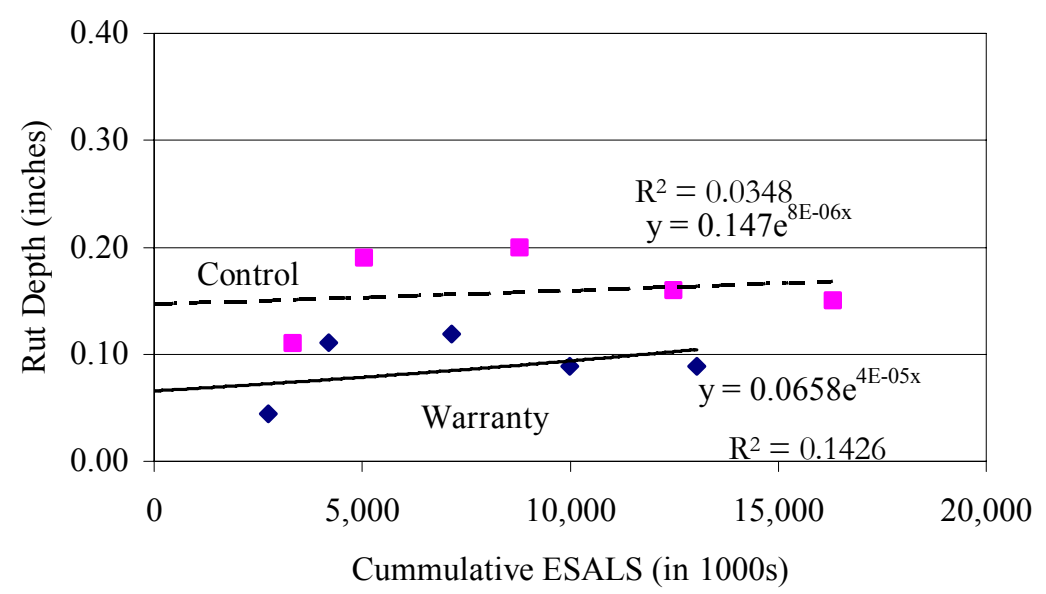

Figure 5-46 Comparison of Load-based Deterioration (Rut) Curves, Comparison Set 3

Table 5-37 shows the $t$ statistic and the critical value for the $t$-test for rut depths of the warranty and control pavements. The differences in the means of the two samples were found to be significant at level of significance 0.05 , indicated in the table below. Hence the null hypothesis was rejected implying that the warranty project had lower rut depths. 
Table 5-37 Results of $t$-test for Rutting depth of Comparison 3

\begin{tabular}{lcc}
\hline & $\begin{array}{c}\text { Variable 1 } \\
\text { (Warranty) }\end{array}$ & $\begin{array}{c}\text { Variable 2 } \\
\text { (Control) }\end{array}$ \\
\hline Mean & 0.0832 & 0.1620 \\
Variance & 0.0011 & 0.0013 \\
Observations & 5 & 5 \\
Hypothesized Mean Difference & 0 & \\
Degrees of freedom & 4 & \\
$t$ Statistic & -14.8812 & \\
$\mathrm{P}(\mathrm{T}<=t)$ one-tail & 0.0001 & \\
$t$ Critical one-tail & 2.1318 \\
\hline
\end{tabular}

\section{Performance Comparison on the basis of Pavement Condition Rating (PCR)}

The average PCR values of the pavements are shown in Table 5-37. The control project has slightly higher values than the warranty project at Ages 2 and 3, indicating better pavement condition. However, the control pavement exhibits a rather sharp increase in deterioration Age 4 (Figure 5-47). The PCR value for the warranty pavement at Age 5 is higher than that at Age 4, obviously due to measurement error. Figure 5-48 shows the overall performance of the pavements based on the PCR values with respect to the percentage of trucks over the warranty period. The warranty pavement indicated a very little variation in performance, while the control project showed significant decrease. Exponential trend lines were fitted for both pavements as shown in the figure.

Table 5-38 PCR of Constituent Pavements, Comparison Set 3

\begin{tabular}{|c|c|c|}
\hline \multirow{2}{*}{$\begin{array}{c}\text { Age } \\
\text { (years) }\end{array}$} & \begin{tabular}{c}
$|c|$ \\
PCR \\
\cline { 2 - 3 }$(\mathrm{R}-22925)$
\end{tabular} & $\begin{array}{c}\text { Control Project 3 } \\
\text { (R-22912) }\end{array}$ \\
\hline 1 & 98.53 & 98.38 \\
\hline 2 & 98.40 & 99.58 \\
\hline 3 & 98.38 & 98.96 \\
\hline 4 & 98.43 & 91.00 \\
\hline 5 & 98.95 & 93.38 \\
\hline
\end{tabular}




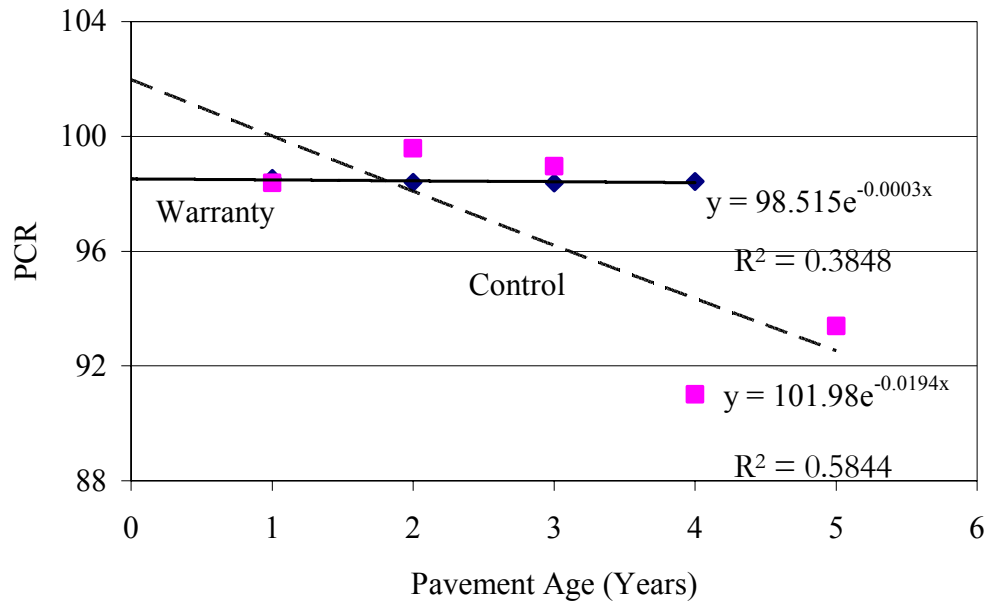

Figure 5-47 PCR Trends of Warranty and Control Pavements, Comparison Set 3

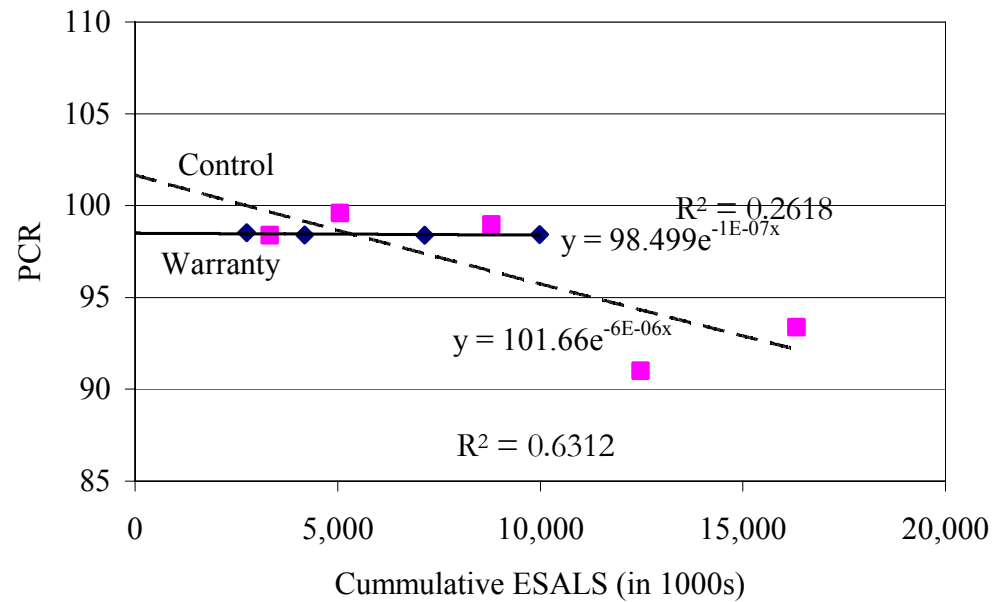

Figure 5-48 Comparison of Load-based Deterioration (PCR) Curves, Comparison Set 3

Table 5-39 Results of t-test for PCR, Comparison Set 3

\begin{tabular}{lcc}
\hline & Variable 1 (Warranty) & Variable 2 (Control) \\
\hline Mean & 98.5380 & 96.2600 \\
Variance & 0.0564 & 14.6922 \\
Observations & 5 & 5 \\
Hypothesized Mean Difference & 0 & \\
Degrees of freedom & 4 & \\
$t$ Statistic & 1.2935 & \\
$\mathrm{P}(\mathrm{T}<=t)$ one-tail & 0.1327 & \\
$t$ Critical one-tail & 1.1896 & \\
\hline
\end{tabular}


A statistical test was performed to ascertain whether there are significant differences in the PCR values of the warranty and control pavements. The results of the t-test are shown in Table 5-39 performed at 15\% significance level (tests at 5\% and 10\% significance yielded no differences at those levels of significance) Since the $t$ statistic 1.2935 is greater than the critical $t$ value of 1.1896 , the null hypothesis was rejected, implying that the warranty project had higher PCR values.

\subsubsection{Evaluation of Cost-Effectiveness for Comparison Set 3}

In a manner similar to other comparison sets, the cost-effectiveness of the warranty and control projects in Comparison Set 3 was done by the comparing the benefits (effectiveness) of the treatments with the project costs. The results of the analysis of the medium-term and long-term cost-effectiveness evaluation are presented in the subsequent sections.

\section{Medium-Term Cost-Effectiveness Evaluation for Comparison Set 3}

The medium-term analysis was carried out over the warranty period. No maintenance expenditure was considered for the warranty project during the warranty period, as the contractor is responsible for addressing all pavement defects within that period.

Table 5-40 Medium-Term Agency Costs, Comparison Set 3

\begin{tabular}{|l|c|c|}
\hline & $\begin{array}{c}\text { Warranty Project 3 } \\
\text { (R-22925) }\end{array}$ & $\begin{array}{c}\text { Control Project 3 } \\
\text { (R-22912) }\end{array}$ \\
\hline Length (miles) & 8.68 & 6.50 \\
\hline Number of lanes & 4 & 4 \\
\hline Initial Cost & $\$ 14,772,937$ & $\$ 8,223,167$ \\
\hline Initial Cost/lane-mile & $\$ 425,488$ & $\$ 316,276$ \\
\hline Maintenance Costs/lane-mile (5 years) & $\$ 0$ & $\$ 1,001$ \\
\hline Total agency cost/lane-mile & $\$ 425,488$ & $\$ 317,277$ \\
\hline Agency EUAC/lane-mile & $\$ 95,576$ & $\$ 71,269$ \\
\hline
\end{tabular}

Table 5-40 summarizes the various agency costs for the warranty and the control project, and finally shows the equivalent uniform annual costs (EUAC) per lane-mile in Year 2000 constant dollar. The agency cost of the warranty project in Year 2000 constant dollar is higher than that of the control project. The calculation of user cost components is shown below. 


\begin{tabular}{lc|} 
AADT per lane & 12,786 \\
Volume of passenger cars $(70 \%)$ per lane & 8,950 \\
Volume of Single-unit trucks $(4 \%)$ per lane & 153 \\
Volume of Multiple-unit trucks $(26 \%)$ per lane & 997 \\
Difference in travel time due to reduction in speed from $65 \mathrm{mph}$ to $45 \mathrm{mph}$ in the & 0.0068 \\
work zone $(1 / 45-1 / 65)$ & $\mathrm{hr} / \mathrm{mile}$ \\
User cost for passenger car $(\$ 12.41 / \mathrm{hr} \times 0.0068 \mathrm{hr} \times 8,950)$ & $\$ 759$ \\
User cost for single-unit truck $(\$ 19.88 / \mathrm{hr} \times 0.0068 \mathrm{hr} \times 153)$ & $\$ 21$ \\
User cost for multiple-unit truck $(\$ 23.92 / \mathrm{hr} \times 0.0068 \mathrm{hr} \times 997)$ & $\$ 163$ \\
Total User cost per day per lane-mile & $\$ 943$ \\
\hline
\end{tabular}

Table 5-41 shows the user costs in Year 2000 constant dollar for the warranty and control pavements. The warranty project has a smaller work-zone duration resulting in lower user costs.

Table 5-41 Medium-Term User Costs, Comparison Set 3

\begin{tabular}{|l|c|c|}
\hline & $\begin{array}{c}\text { Warranty Project 3 } \\
\text { (R-22925) }\end{array}$ & $\begin{array}{c}\text { Control Project 3 } \\
\text { (R-22912) }\end{array}$ \\
\hline Work zone duration per lane-mile & 8 days & 11 days \\
\hline Total User cost & $\$ 7,543$ & $\$ 10,371$ \\
\hline User EUAC/lane-mile & $\$ 1,694$ & $\$ 2,330$ \\
\hline
\end{tabular}

The IRI values were plotted against pavement age and the areas bounded by the fitted exponential models were determined, as shown in Figures 5-49 and 5-50. The shaded region indicates the area considered for evaluating effectiveness of the treatments. 


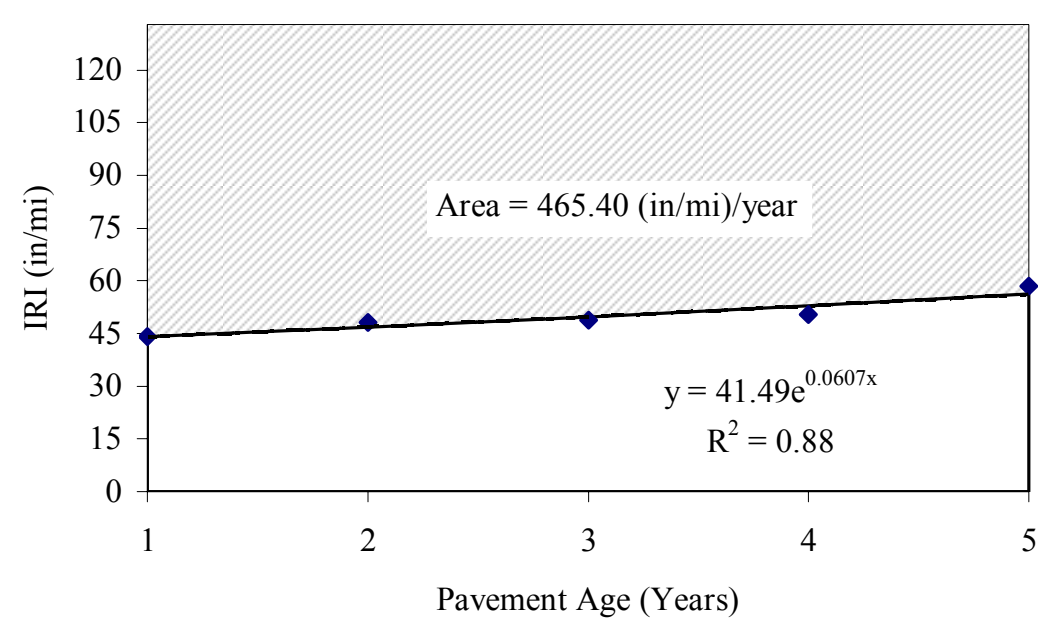

Figure 5-49 Area bounded by IRI-Age curves of Warranty Pavement, Comparison Set 3

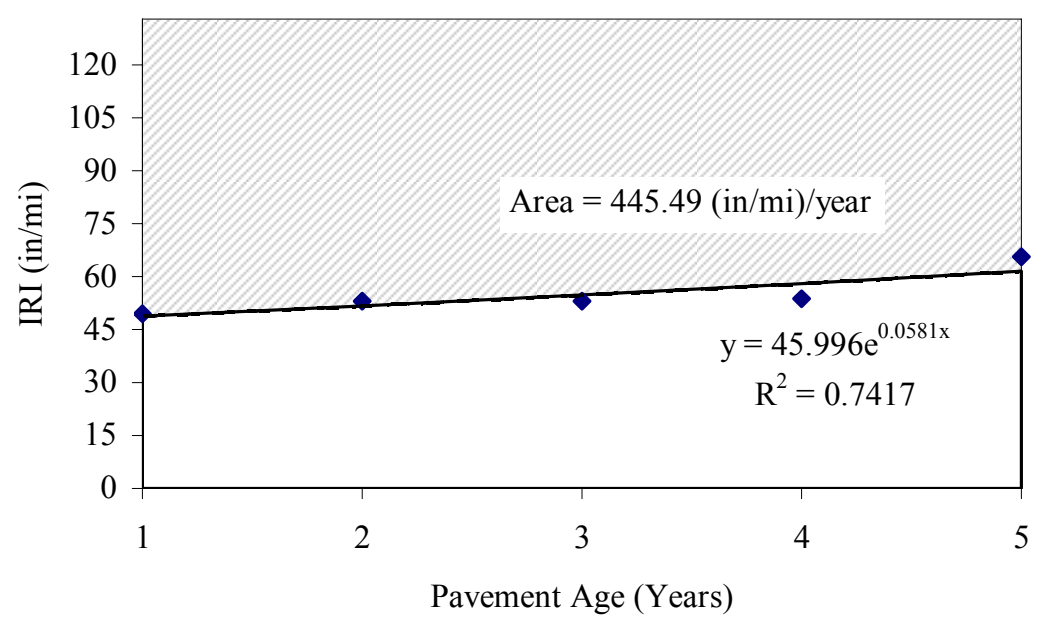

Figure 5-50 Area bounded by IRI-Age curves of Control Pavement, Comparison Set 3

Figures 5-51 and 5-52 show the trend of the IRI values corresponding to the cumulative ESALs over the warranty period for warranty and control pavement respectively. Linear trend lines were considered for both warranty and control pavements to determine the effectiveness. 


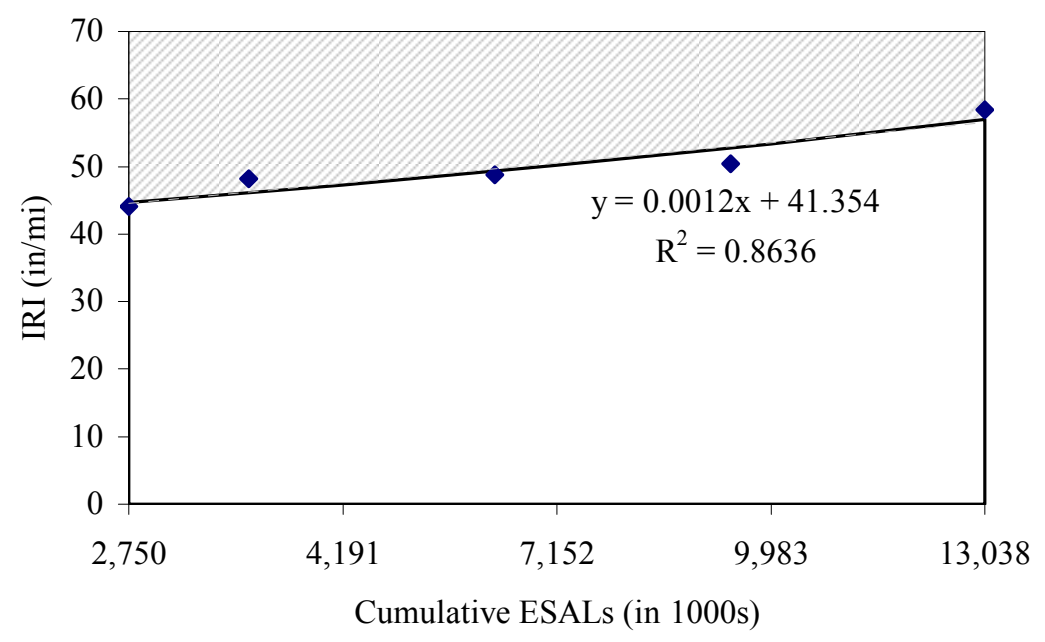

Figure 5-51 Area bounded by IRI-ESAL curve of Warranty Pavement, Comparison Set 3

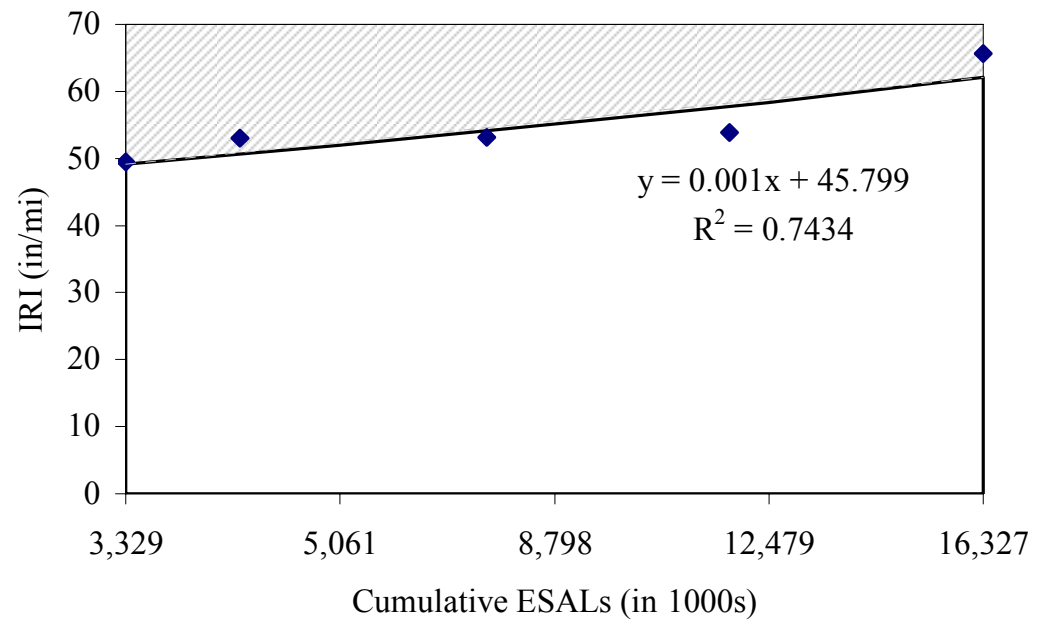

Figure 5-52 Area bounded by IRI-ESAL curve of Control Pavement, Comparison Set 3 
Similarly, the PQI values were plotted to determine the area bounded by the curve. Figures 5-53 and 5-54 show the PQI values with respect to the age of the pavements. Exponential models were fitted for both warranty and control pavements.

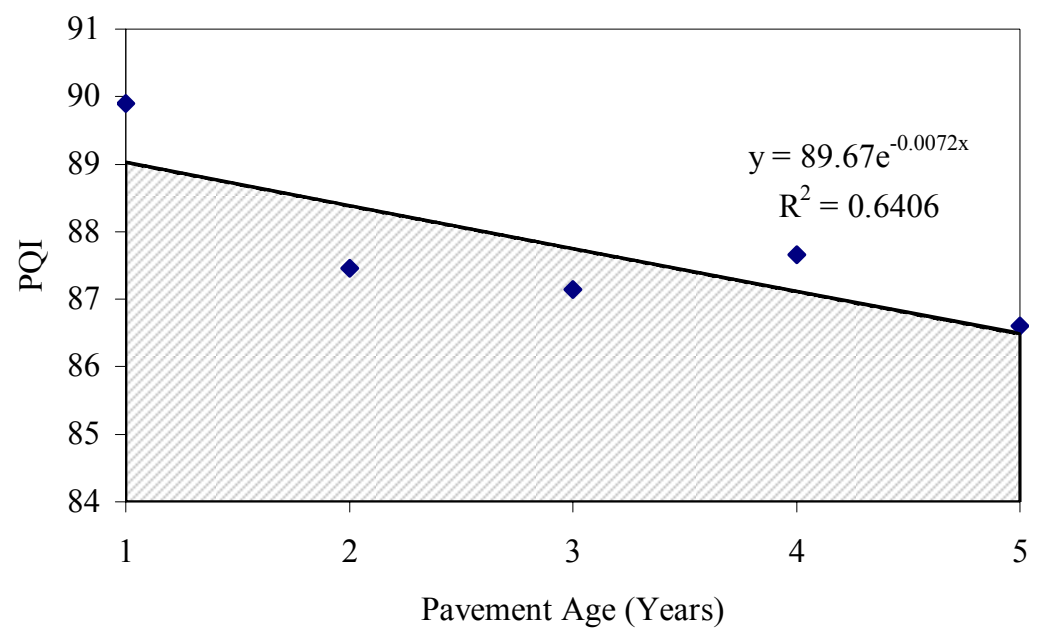

Figure 5-53 Area Bounded by PQI-Age curve of Warranty Pavement, Comparison Set 3

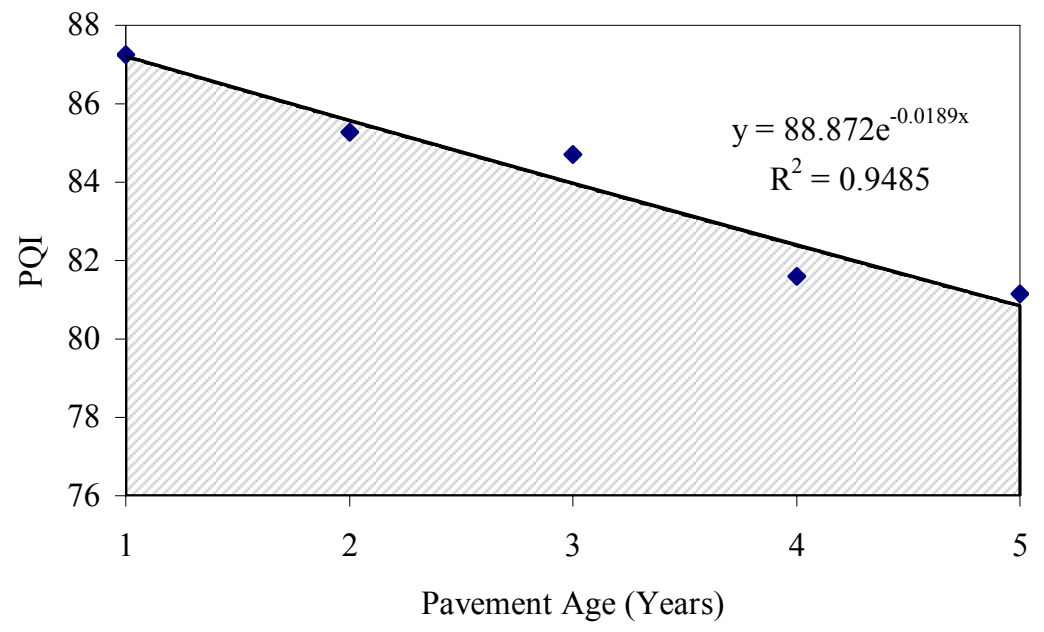

Figure 5-54Area Bounded by PQI-Age curve of Control Pavement, Comparison Set 3 
Effectiveness of the treatments was also determined based on the cumulative volume of traffic. The PQI trends with respect to the cumulative ESALs are shown in Figure 5-55 and 5-56. Exponential trend lines were drawn to determine the area bounded by the curves.

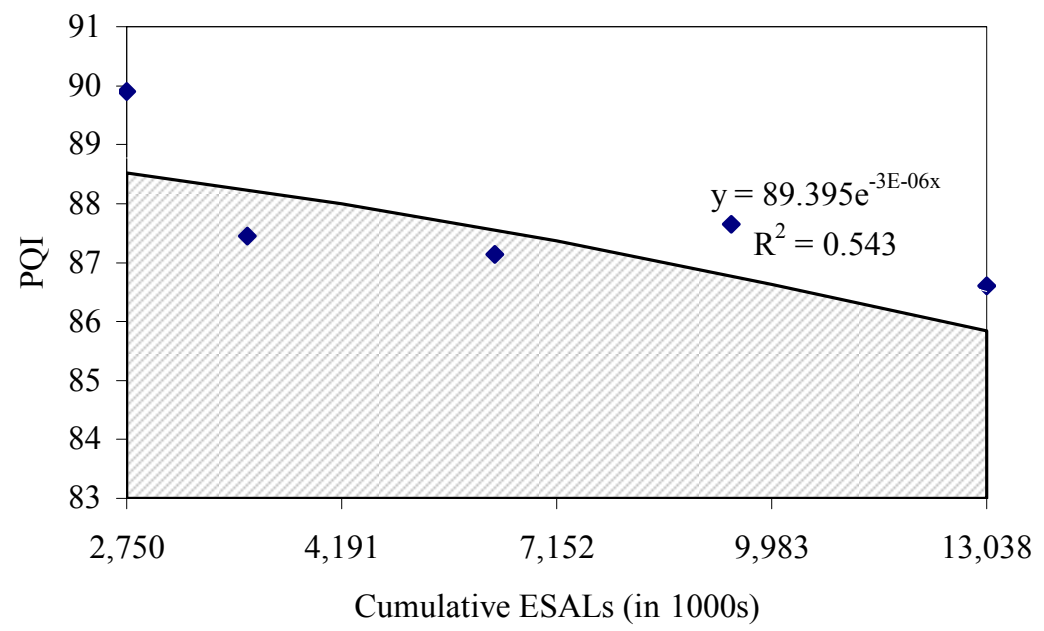

Figure 5-55 Area Bounded by PQI-ESAL curve of Warranty Pavement, Comparison Set 3

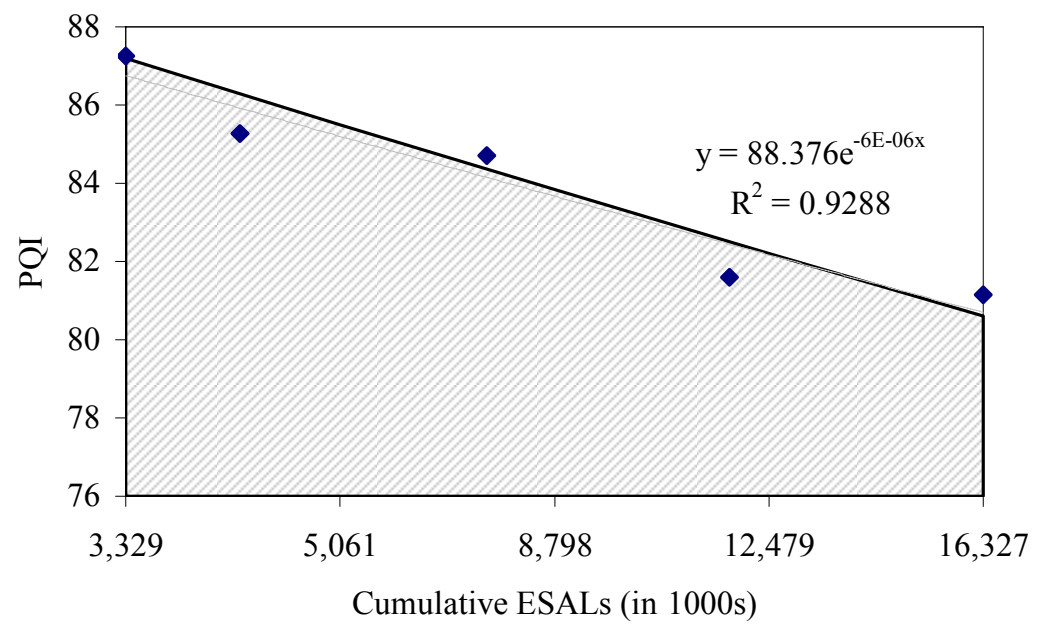

Figure 5-56 Area Bounded by PQI-ESAL curve of Control Pavement, Comparison Set 3 
The effectiveness of the treatments were then weighed against their costs. The results of the overall analysis are shown in Table 5-42. The cost-effectiveness of the pavements were determined using agency costs only, and then on the basis of both agency and user costs.

Table 5-42 Medium Term Cost-effectiveness Evaluation, Comparison Set 3

\begin{tabular}{|l|c|c|c|c|}
\hline \multirow{2}{*}{ Cost-effectiveness } & \multicolumn{2}{|c|}{ Agency Cost only } & \multicolumn{2}{c|}{ Agency Cost + User Cost } \\
\cline { 2 - 5 } & $\begin{array}{c}\text { Warranty } \\
\text { (R-22925) }\end{array}$ & $\begin{array}{c}\text { Control } \\
\text { (R-22912) }\end{array}$ & $\begin{array}{c}\text { Warranty } \\
\text { (R-22925) }\end{array}$ & $\begin{array}{c}\text { Control } \\
\text { (R-22912) }\end{array}$ \\
\hline $\begin{array}{l}\text { Area bounded by the IRI-Age } \\
\text { curve/EUAC (\$1000) }\end{array}$ & 29.61 & 37.59 & 26.73 & 31.42 \\
\hline $\begin{array}{l}\text { Area bounded by the IRI- } \\
\text { ESAL curve/EUAC }\end{array}$ & 77.05 & 122.23 & 69.55 & 102.15 \\
\hline $\begin{array}{l}\text { Area bounded by the PQI- } \\
\text { Age curve/EUAC (\$1000) }\end{array}$ & 22.33 & 28.35 & 20.16 & 23.69 \\
\hline $\begin{array}{l}\text { Area bounded by the PQI- } \\
\text { ESAL curve/EUAC }\end{array}$ & 71.78 & 91.41 & 64.79 & 76.39 \\
\hline
\end{tabular}

It is seen that even though the warranty pavement exhibited superior condition throughout the warranty period, the control project is more cost-effective than the warranty project. This could be largely attributed to the relatively high initial and total costs associated with the warranty project.

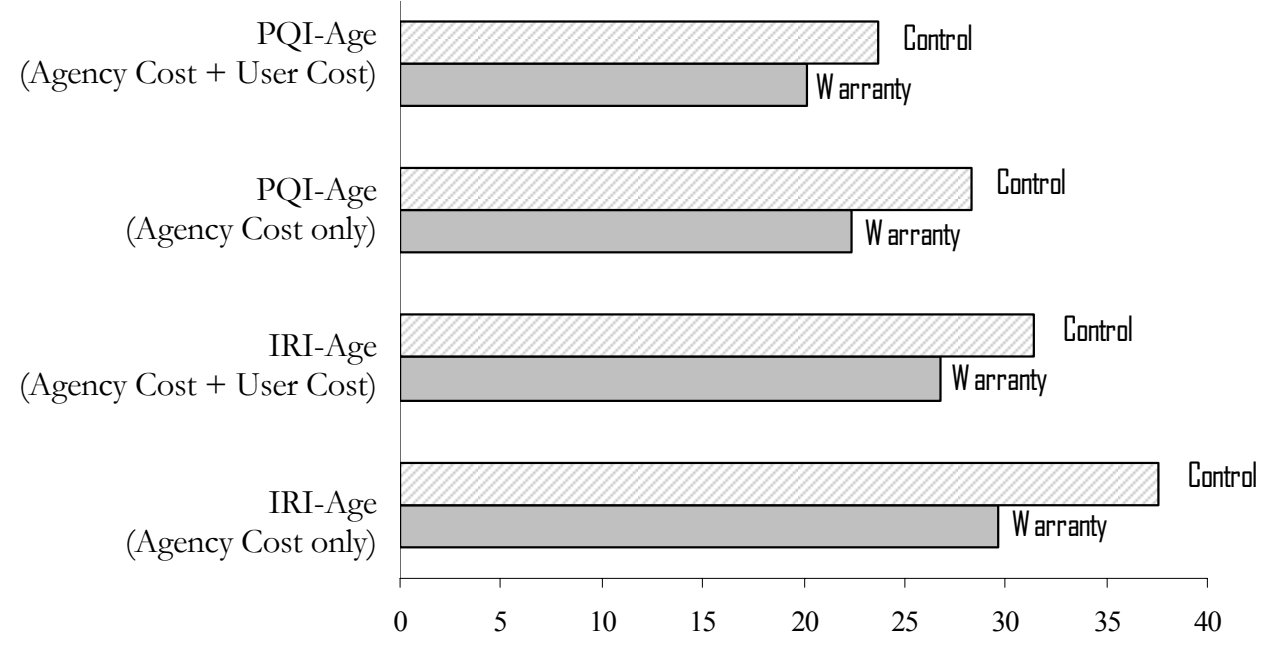

IRI-Years per $\$ 1000$ EUAC or PQI-Years per $\$ 1000$ EUAC

Figure 5-57 Medium-Term Cost-Effectiveness based on Performance and Time, Comparison Set 3 
PQI-ESAL

(Agency Cost + User Cost)

PQI-ESAL (Agency Cost only)

IRI-ESAL

(Agency Cost + User Cost)

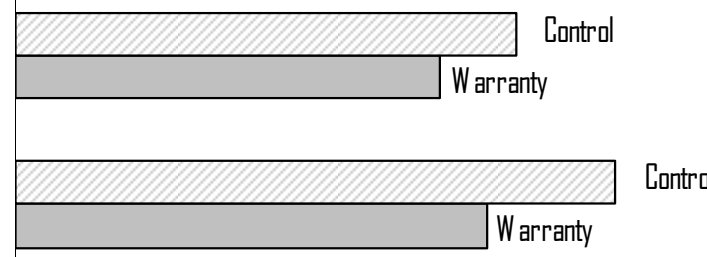

IRI-ESAL (Agency Cost only)

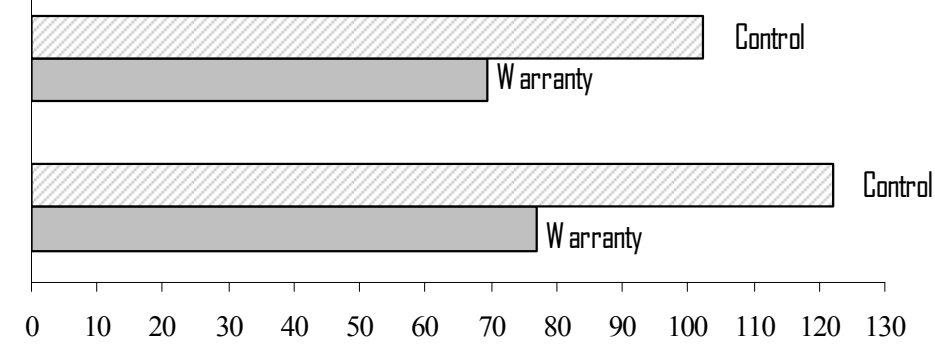

IRI-ESALs per $\$ 1000$ EUAC or PQI-ESALs per $\$ 1000$ EUAC

Figure 5-58 Medium-Term Cost-Effectiveness based on Performance and Load, Comparison Set 3

The results show that the medium-term cost-effectiveness of the warranty project was, on the average, approximately $30 \%$ lower that of the traditional project. Based on IRI and PQI load-curves, the values for warranty project were approximately $60 \%$ and $27 \%$ lower, respectively, compared to the traditional project.

\section{Long-Term Cost-Effectiveness Evaluation for Comparison Set 3}

The long-term evaluation of cost-effectiveness was performed over the projected treatment lives. The agency and user costs of warranty and control projects are shown Table 5-43 and Table 5-44, respectively. The costs are shown in Year 2000 constant dollar. The agency cost of the warranty project was higher than that of the control project.

Table 5-43 Long-Term Agency Costs, Comparison Set 3

\begin{tabular}{|l|c|c|}
\hline & $\begin{array}{c}\text { Warranty Project 3 } \\
\text { (R-22925) }\end{array}$ & $\begin{array}{c}\text { Control Project 3 } \\
\text { (R-22912) }\end{array}$ \\
\hline Construction Cost/lane-mile & $\$ 425,488$ & $\$ 316,276$ \\
\hline Maintenance Cost/lane-mile & $\$ 5,717^{*}$ & $\$ 6,718$ \\
\hline Total agency cost/lane-mile & $\$ 431,205$ & $\$ 322,993$ \\
\hline EUAC/lane-mile & $\$ 27,602$ & $\$ 29,050$ \\
\hline
\end{tabular}

\footnotetext{
* Applicable only to warranty pavements after expiration of the warranty period.
} 
Table 5-44 Long-Term User Costs, Comparison Set 3

\begin{tabular}{|l|c|c|}
\hline & $\begin{array}{c}\text { Warranty Project 3 } \\
\text { (R-22925) }\end{array}$ & $\begin{array}{c}\text { Control Project 3 } \\
\text { (R-22912) }\end{array}$ \\
\hline Work zone duration per lane-mile & 8 days & 11 days \\
\hline Total user cost per lane-mile & $\$ 7,543$ & $\$ 10,371$ \\
\hline User EUAC/lane-mile & $\$ 483$ & $\$ 933$ \\
\hline
\end{tabular}

The overall cost-effectiveness of the pavements were then determined The effectiveness in terms of area were determined by integrating the performance models fitted over the projected treatment service lives of the pavements. Table 5-45 indicates the overall cost-effectiveness of the warranty and control projects based on agency costs only, and also the sum of agency and user costs. Figures 5-59 and 5-60 show the relative cost-effectiveness of warranty and control projects based on treatment lives and age, respectively.

Table 5-45 Long Term Cost-effectiveness Evaluation, Comparison Set 3

\begin{tabular}{|l|c|c|c|c|}
\hline \multirow{2}{*}{ Cost-effectiveness } & \multicolumn{2}{|c|}{ Agency Cost only } & \multicolumn{2}{c|}{ Agency Cost + User Cost } \\
\cline { 2 - 5 } & $\begin{array}{c}\text { Warranty } \\
\text { (R-22925) }\end{array}$ & $\begin{array}{c}\text { Control } \\
\text { (R-22912) }\end{array}$ & $\begin{array}{c}\text { Warranty } \\
\text { (R-22925) }\end{array}$ & $\begin{array}{c}\text { Control } \\
\text { (R-22912) }\end{array}$ \\
\hline $\begin{array}{l}\text { Average Service life/EUAC } \\
(\$ 1000)\end{array}$ & 0.91 & 0.52 & 0.71 & 0.38 \\
\hline $\begin{array}{l}\text { Area bounded by the IRI-Age } \\
\text { curve/EUAC (\$1000) }\end{array}$ & 94.52 & 67.00 & 74.23 & 49.38 \\
\hline $\begin{array}{l}\text { Area bounded by the PQI- } \\
\text { Age curve/EUAC (\$1000) }\end{array}$ & 71.09 & 36.93 & 55.83 & 27.21 \\
\hline
\end{tabular}
Average Treatment Life
(Agency Cost + User Cost)

Average Treatment Life

(Agency Cost only)

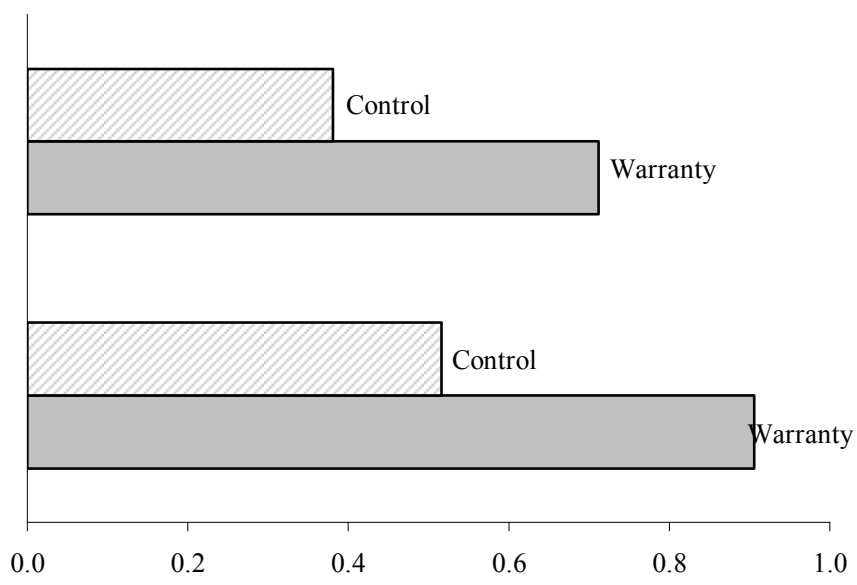

Years per $\$ 1000$

Figure 5-59 Long-Term Cost-Effectiveness based on Treatment Life Only, Comparison Set 3 


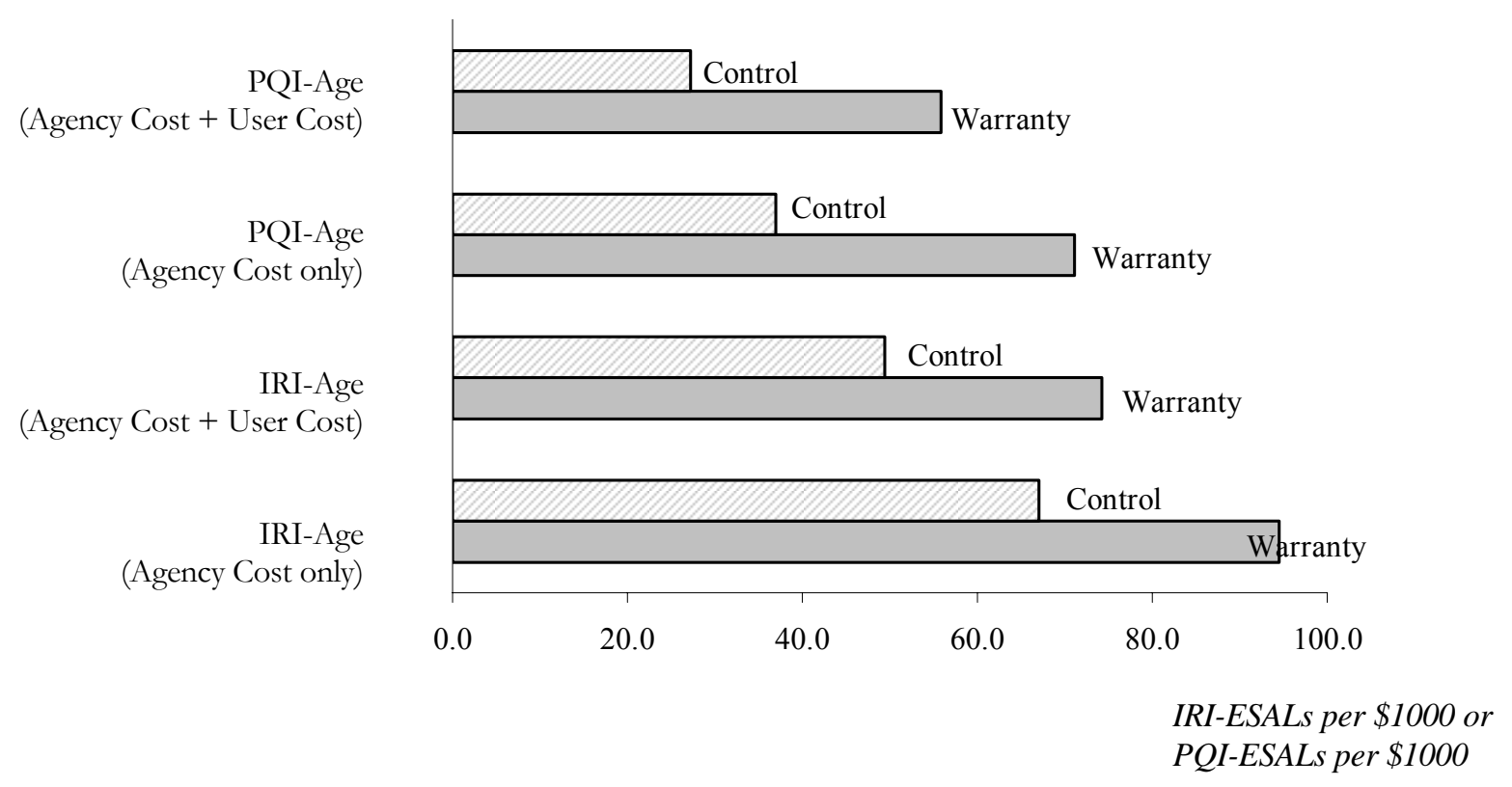

Figure 5-60 Long-Term Cost-Effectiveness based on Performance and Time, Comparison Set 3

The results of the long-term analysis show that the warranty project has higher values of costeffectiveness, compared to the control project. This suggests that in the long term, the warranty contract under investigation was more cost-effective than the traditional (control) project.

\subsubsection{Summary of the Analysis Results for Comparison Set 3}

The pair-wise comparison of the warranty and (control) traditional projects indicated that warranty pavement exhibited better pavement performance in terms of IRI, PSI, rutting, and PCR. The agency costs of the warranty pavement was higher than that of the control pavement, but had lower user costs. In the medium term, the warranty project was found to be less cost-effective than the control (traditional) project. However, over the long term (projected treatment service lives), the warranty project was found to be more cost-effective. 


\subsection{Comparison Set 4 (Warranty Project: R-23390 and Control Project R-21607)}

\subsubsection{General Contract Information for Comparison Set 4}

The fourth warranty project that was investigated in the present study (Contract R-23390) was awarded in January 1998 and the warranty period was completed in June 1999. As such, the project is evaluated based on the data corresponding to the first four years after construction. The project is located on I-74 from SR 9 to Middleton in Shelby County, Greenfield. The project begins from Milepost 112.42 and ends at 123.43, for a length of 11.01 miles had similar treatment (work activity), and functional class (Table 5-46)

Table 5-46 Characteristics of Projects Constituting Comparison Set 4

\begin{tabular}{|l|c|c|}
\hline & $\begin{array}{c}\text { Warranty Project 4 } \\
\text { (R-23390) }\end{array}$ & $\begin{array}{c}\text { Control Project 4 } \\
\text { (R-21607) }\end{array}$ \\
\hline Work Description & J-300 Road Reconstruction & J-300 Road Reconstruction \\
\hline Functional Class & $\begin{array}{c}\text { Four-lane Rural } \\
\text { Interstate }\end{array}$ & $\begin{array}{c}\text { Four-lane Rural } \\
\text { Interstate }\end{array}$ \\
\hline NHS & Yes & Yes \\
\hline Length (miles) & 11.01 & 3.54 \\
\hline Surface Type & $\begin{array}{c}\text { HMA over } \\
\text { Crack-and-seat PCC }\end{array}$ & $\begin{array}{c}\text { HMA over } \\
\text { Crack-and-seat PCC }\end{array}$ \\
\hline Thickness of new surface & 1.00 inch & 0.625 inch \\
\hline AADT in Year 2002 & 21,826 & 33,595 \\
\hline Percentage trucks & $27 \%$ & $28 \%$ \\
\hline
\end{tabular}

\subsubsection{Medium-term Performance Analysis for Comparison Set 4}

The average pavement condition of both pavements in terms of IRI, PSI, rutting, and PCR, was investigated to determine which pavement was superior in this respect only.

Comparison of Performance on Basis of International Roughness Index (IRI).

Table 5-47 and Figure 5-61 show the average IRI values of the warranty project and the control project measured for first 4 years of pavement life. The IRI values of the warranty pavement were very low compared to those of the control project, and is suggestive of superior condition of the warranty pavement. 
Table 5-47 IRI of Constituent Pavements, Comparison Set 4

\begin{tabular}{|c|c|c|}
\hline \multirow{2}{*}{$\begin{array}{c}\text { Age } \\
\text { (years) }\end{array}$} & \multicolumn{2}{|c|}{ IRI (in/mi) } \\
\cline { 2 - 3 } & $\begin{array}{c}\text { Warranty Project 4 } \\
\text { (R-23390) }\end{array}$ & $\begin{array}{c}\text { Control Project 4 } \\
\text { (R-21607) }\end{array}$ \\
\hline 1 & 31.53 & 54.25 \\
\hline 2 & 39.63 & 56.00 \\
\hline 3 & 44.08 & 56.25 \\
\hline 4 & 55.24 & 61.13 \\
\hline
\end{tabular}

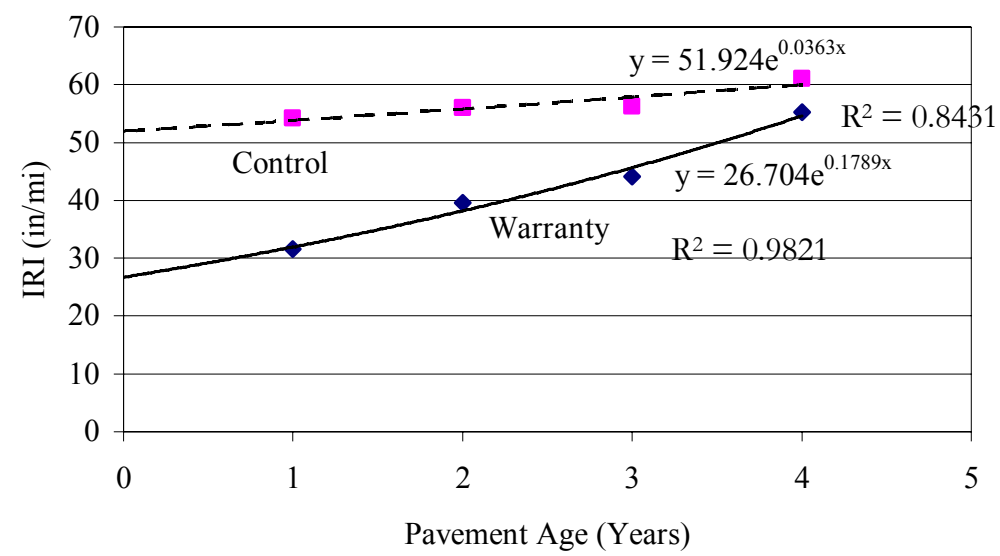

Figure 5-61 IRI Trends of Warranty and Control Pavements, Comparison Set 4

Figure 5-62 shows the deterioration of the pavements with respect to the accumulate traffic loading on the pavements. The figure shows that the difference in the pavement condition of the warranty and control project appeared to be more perceptible in the first three years of the pavement life.

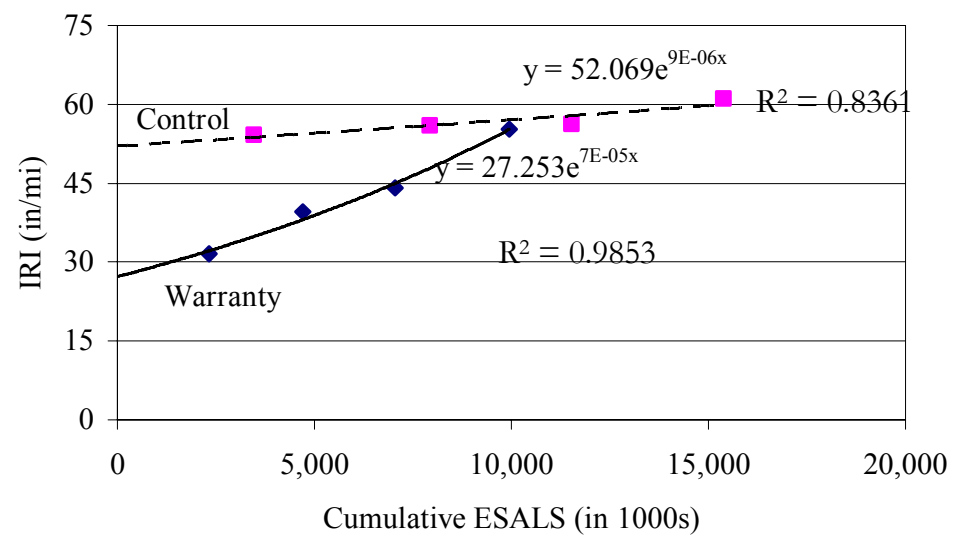

Figure 5-62 Comparison of Load-based Deterioration (IRI) Curves, Comparison Set 4 
Table 5-48 Results of $t$-test for IRI of Comparison Set 4

\begin{tabular}{lcc}
\hline & $\begin{array}{c}\text { Variable 1 } \\
\text { (Warranty) }\end{array}$ & $\begin{array}{c}\text { Variable 2 } \\
\text { (Control) }\end{array}$ \\
\hline Mean & 42.6196 & 56.9075 \\
Variance & 97.7946 & 8.7159 \\
Observations & 4 & 4 \\
Hypothesized Mean Difference & 0 & \\
Degrees of freedom & 3 & \\
$t$ Statistic & -4.0346 & \\
$\mathrm{P}(\mathrm{T}<=t)$ one-tail & 0.0137 & \\
$t$ Critical one-tail & 2.3534 & \\
\hline
\end{tabular}

Table 5-48 shows the results of the one-tailed t-test at 5\% significance level. As seen from the table, the $t$ statistic -4.0346 was less than the negative critical value of 2.3534 , clearly indicating the null hypothesis can be rejected. Therefore, there was a significant difference in the mean IRI values of the warranty and control projects. In other words, the warranty project had lower values compared to the control project during the first four years after construction.

\section{Comparison of Performance on basis of Present Serviceability Index (PSI)}

Table 5-49 and Figure 5-63 show the average PSI values of the warranty and control project. The warranty project showed remarkable pavement performance with high PSI values. In comparison, PSI values of the control project were much lower. Exponential trend lines were fitted and extrapolated to determine the PSI values immediately after construction. As seen from the figure, the warranty project had higher initial values.

Table 5-49 PSI of Constituent Pavements in Comparison Set 4

\begin{tabular}{|c|c|c|}
\hline \multirow{2}{*}{$\begin{array}{c}\text { Age } \\
\text { (years) }\end{array}$} & \multicolumn{2}{|c|}{ PSI } \\
\cline { 2 - 3 } & $\begin{array}{c}\text { Warranty Project 4 } \\
\text { (R-23390) }\end{array}$ & $\begin{array}{c}\text { Control Project 4 } \\
\text { (R-21607) }\end{array}$ \\
\hline 1 & 4.39 & 4.00 \\
\hline 2 & 4.25 & 3.97 \\
\hline 3 & 4.17 & 3.97 \\
\hline 4 & 3.99 & 3.89 \\
\hline
\end{tabular}


Figure 5-64 presents the trend of pavement performances in relation to the cumulative ESALs. Even though the warranty pavement consistently exhibits superior performance (confirmed by the subsequent $t$-test), it has a higher rate of deterioration. If such trends are projected into the future, it may be expected that the warranty pavement would exhibit inferior performance after 5 years.

Table 5-50 indicates the results of the $t$-test for PSI values of the warranty and control projects. The pair-wise comparison clearly indicates that the PSI values of the warranty project were higher than those of control project, as the $t$ statistic was greater than the critical value.

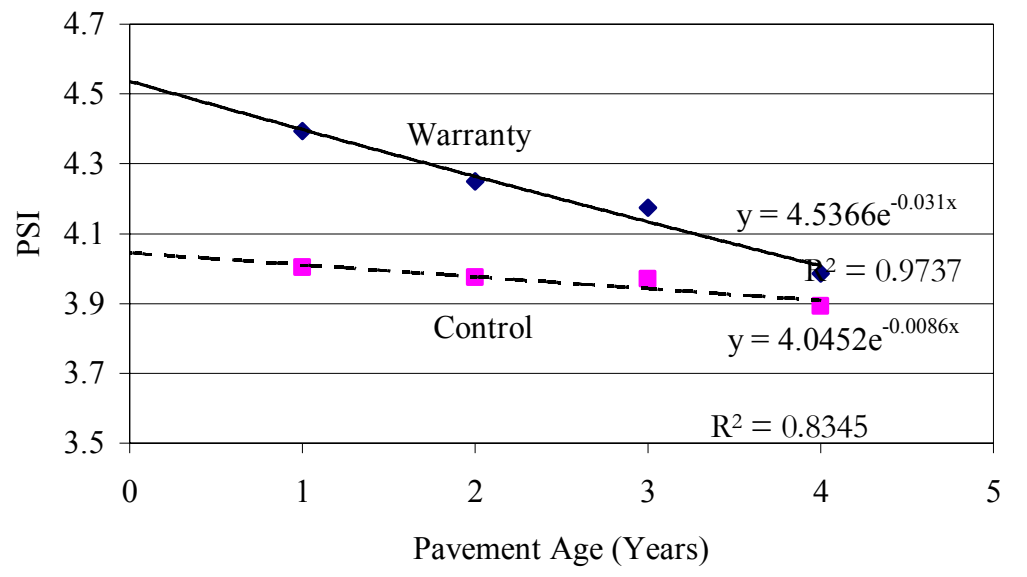

Figure 5-63 PSI Trends of Warranty and Control Pavements in Comparison Set 4

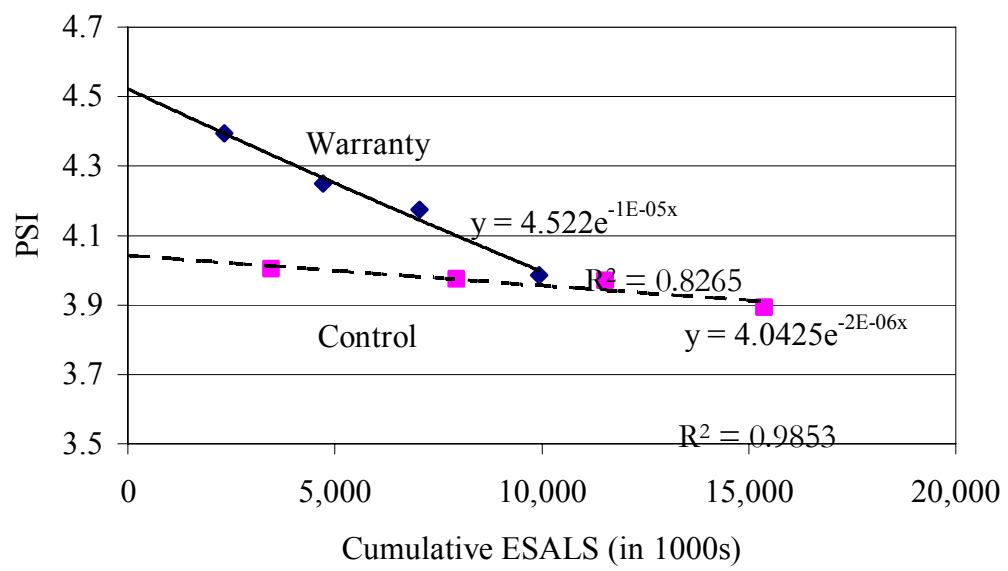

Figure 5-64 Comparison of Load-based Deterioration (PSI) Curves, Comparison Set 4 
Table 5-50 Results of t-test for PSI of Comparison Set 4

\begin{tabular}{lcc}
\hline & $\begin{array}{c}\text { Variable 1 } \\
\text { (Warranty) }\end{array}$ & $\begin{array}{c}\text { Variable 2 } \\
\text { (Control) }\end{array}$ \\
\hline Mean & 4.2010 & 3.9597 \\
Variance & 0.0288 & 0.0023 \\
Observations & 4 & 4 \\
Hypothesized Mean Difference & 0 & \\
Degrees of freedom & 3 & \\
$t$ Statistic & 3.8801 & \\
$\mathrm{P}(\mathrm{T}<=t)$ one-tail & 0.0152 & \\
$t$ Critical one-tail & 2.3534 & \\
\hline
\end{tabular}

\section{Comparison of Performance on basis of Rutting}

The average rutting depths (in inches) of the pavements over the first four years are shown in Table 5-51 and Figure 5-65. The trends in rut depth is fairly consistent for the warranty project, while some variation was evident in the case for the control project.

Table 5-51 Rut Depth of Constituent Pavements, Comparison Set 4

\begin{tabular}{|c|c|c|}
\hline \multirow{2}{*}{$\begin{array}{c}\text { Age } \\
\text { (years) }\end{array}$} & \multicolumn{2}{|c|}{ Rut Depth (in) } \\
\cline { 2 - 3 } & $\begin{array}{c}\text { Warranty Project 4 } \\
\text { (R-23390) }\end{array}$ & $\begin{array}{c}\text { Control Project 4 } \\
\text { (R-21607) }\end{array}$ \\
\hline 1 & 0.07 & 0.05 \\
\hline 2 & 0.09 & 0.14 \\
\hline 3 & 0.09 & 0.13 \\
\hline 4 & 0.05 & 0.11 \\
\hline
\end{tabular}




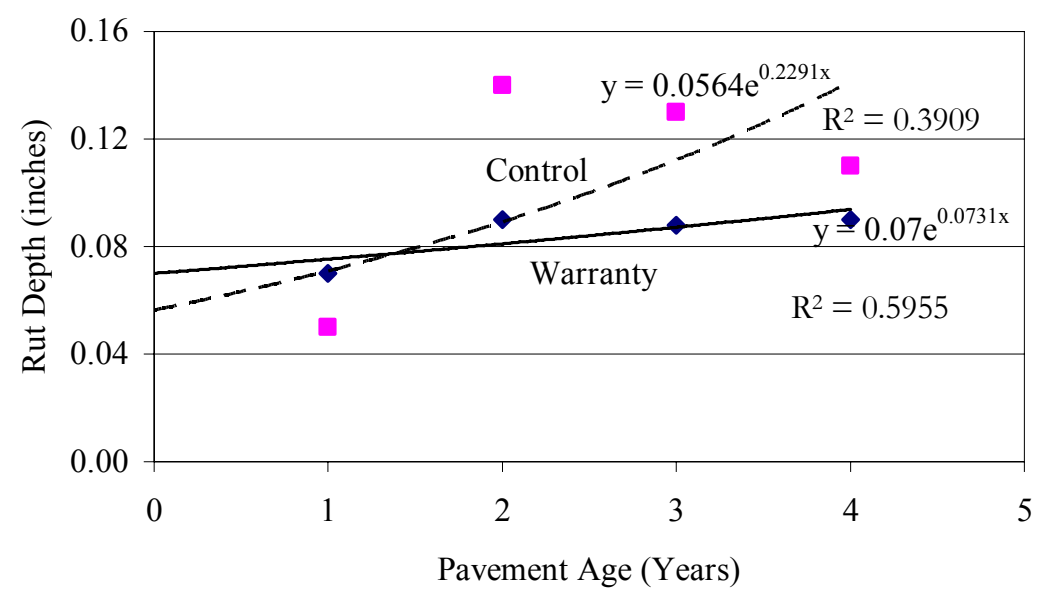

Figure 5-65 Time-based Rutting Trends of Warranty and Control Pavements, Comparison Set 4

The rut depths of the warranty and control pavements were also analyzed with respect to the volume of traffic. The difference in the rut depth is evident from Figure 5-66 indicating pavement deterioration with respect to the percentage of trucks carried by the pavements over the period.

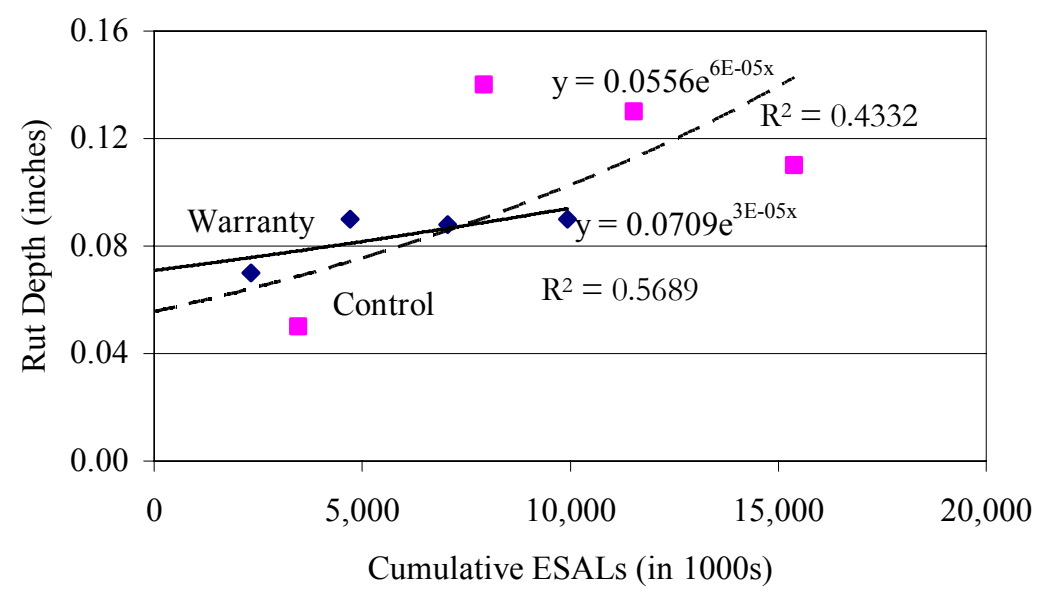

Figure 5-66 Load-based Rutting Trends of Warranty and Control Pavements, Comparison Set 4

The results of the t-test are shown in Table 5-52. The calculated $t$ statistic was lower than its critical value, $-4.5948<-2.3534$ at $\alpha=0.10$, clearly indicating the null hypothesis can be rejected. Hence there is a significant difference between the mean rut depths of warranty and control pavements. 
Table 5-52 Results of t-test for Rutting depth, Comparison 4

\begin{tabular}{lcc}
\hline & $\begin{array}{c}\text { Variable 1 } \\
\text { (Warranty) }\end{array}$ & $\begin{array}{c}\text { Variable 2 } \\
\text { (Control) }\end{array}$ \\
\hline Mean & 0.0745 & 0.1075 \\
Variance & 0.0003 & 0.0016 \\
Observations & 4 & 4 \\
Hypothesized Mean Difference & 0 & \\
Degrees of freedom & 3 & \\
$t$ Statistic & -1.8286 & \\
$\mathrm{P}(\mathrm{T}<=t)$ one-tail & 0.0824 & \\
$t$ Critical one-tail & 1.6377 & \\
\hline
\end{tabular}

Comparison of Performance ion basis of Pavement Condition Rating (PCR)

The average PCR values for the warranty and the control project are shown in Table 5-53 and Figure 5-67. The warranty pavement indicated a low PCR value at Age 1 which may have been due to measurement error and was not included in the graph.

Table 5-53 PCR of Constituent Pavements, Comparison Set 4

\begin{tabular}{|c|c|c|}
\hline \multirow{2}{*}{$\begin{array}{c}\text { Age } \\
\text { (years) }\end{array}$} & \begin{tabular}{c}
$|c|$ \\
PCR \\
\cline { 2 - 3 }
\end{tabular} & Warranty Project 4 \\
(R-23390) & $\begin{array}{c}\text { Control Project 4 } \\
\text { (R-21607) }\end{array}$ \\
\hline 1 & 96.31 & 96.63 \\
\hline 2 & 100.00 & 94.88 \\
\hline 3 & 98.94 & 95.25 \\
\hline 4 & 100.00 & 93.13 \\
\hline
\end{tabular}

Figure 5-67 suggests that the warranty project had superior pavement condition compared to the control project. A PCR value of 100 indicates a perfect pavement condition. The PCR trends of the pavements in terms of accumulated traffic loading are shown as Figure 5-68. 


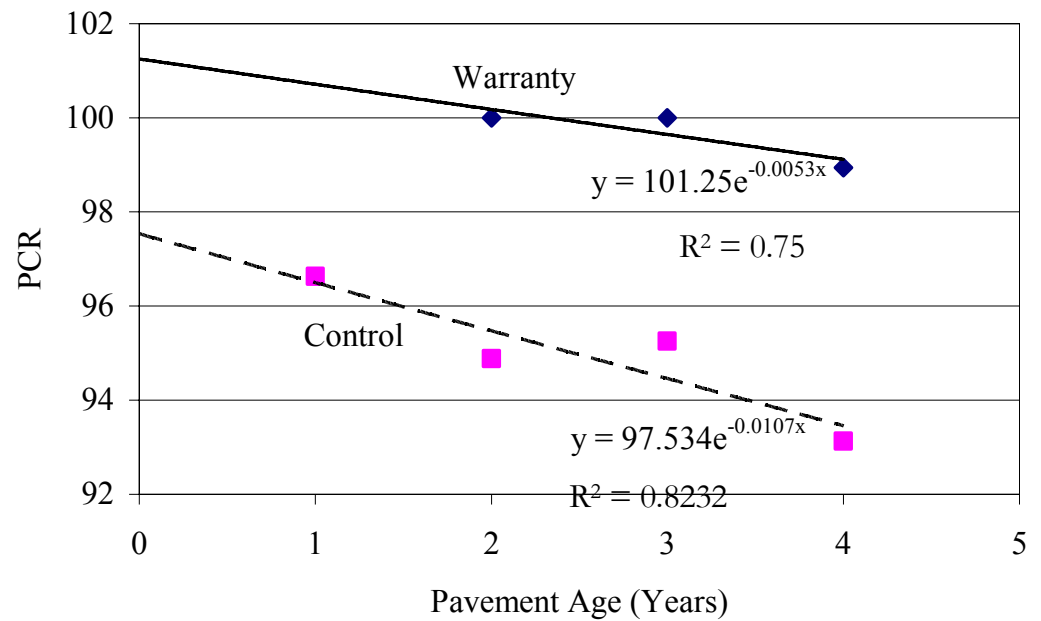

Figure 5-67 PCR Trends of Warranty and Control Pavements, Comparison Set 4

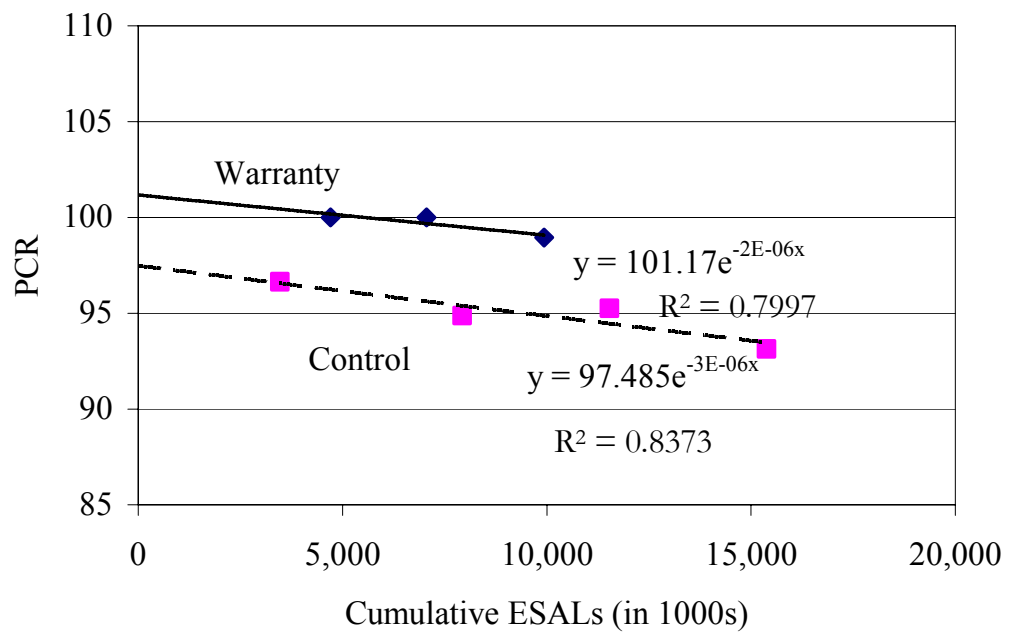

Figure 5-68 Comparison of Load-based Deterioration (PCR) Curves, Comparison Set 4

The results of the one-tailed t-test for PCR values of warranty and control project at $10 \%$ significance level are shown in Table 5-54. The null hypothesis can be rejected as seen from the $t$ statistic and the critical value. This implies that that warranty project had significantly higher PCR values as compared to the control project. 
Table 5-54 Results of $t$-test for PCR of Constituent Pavements, Comparison Set 4

\begin{tabular}{lcc}
\hline & $\begin{array}{c}\text { Variable 1 } \\
\text { (Warranty) }\end{array}$ & $\begin{array}{c}\text { Variable 2 } \\
\text { (Control) }\end{array}$ \\
\hline Mean & 98.8125 & 94.9725 \\
Variance & 3.0330 & 2.0759 \\
Observations & 4 & 4 \\
Hypothesized Mean Difference & 0 & \\
Degrees of freedom & 3 & \\
$t$ Statistic & 2.5073 & \\
$\mathrm{P}(\mathrm{T}<=t)$ one-tail & 0.0436 & \\
$t$ Critical one-tail & 2.3534 & \\
\hline
\end{tabular}

\subsubsection{Evaluation of Cost-Effectiveness for Comparison Set 4}

After the performance and the costs of the warranty and the control projects were determined, the overall assessment of cost-effectiveness of the warranty project was carried out over the medium-term and longterm.

\section{Medium-Term Cost-Effectiveness Evaluation for Comparison Set 4}

The medium-term evaluation was carried out over the warranty period. The final construction costs and the maintenance costs borne by the state agency during the warranty period, were taken into account. The various agency costs for the warranty and the control projects converted to Year 2000 constant dollar are shown in Table 5-55. The agency cost of the warranty project is higher than that of the control project.

Table 5-56 shows the user costs of warranty and control pavements based on the work zone duration. The costs are shown in Year 2000 constant dollar. The warranty pavement had very low user cost due to the lower construction period, and subsequently, lower work zone duration. 
Table 5-55 Medium-Term Agency Costs, Comparison Set 4

\begin{tabular}{|l|c|c|}
\hline & $\begin{array}{c}\text { Warranty Project 4 } \\
\text { (R-23390) }\end{array}$ & $\begin{array}{c}\text { Control Project 4 } \\
\text { (R-21607) }\end{array}$ \\
\hline Length (miles) & 11.01 & 3.51 \\
\hline Number of lanes & 4 & 4 \\
\hline Final Cost & $\$ 17,340,054$ & $\$ 4,624,801$ \\
\hline Final Cost/lane-mile & $\$ 393,734$ & $\$ 329,402$ \\
\hline Maintenance Costs/lane-mile (5 years) & $\$ 0$ & $\$ 1,073$ \\
\hline Total agency cost/lane-mile & $\$ 393,734$ & $\$ 330,474$ \\
\hline Agency EUAC/lane-mile & $\$ 88,443$ & $\$ 74,233$ \\
\hline
\end{tabular}

To determine the user costs, the same AADT and the percentage trucks were used for both warranty and control projects. The various user cost components for the warranty and control pavements are herein presented.

\begin{tabular}{|lc|}
\hline AADT per lane & 13,855 \\
Volume of passenger cars $(70 \%)$ per lane & 10,114 \\
Volume of Single-unit trucks $(4 \%)$ per lane & 337 \\
Volume of Multiple-unit trucks $(26 \%)$ per lane & 673 \\
Difference in travel time due to reduction in speed from $65 \mathrm{mph}$ to $45 \mathrm{mph}$ in the & 0.0068 \\
work zone $(1 / 45-1 / 65)$ & $\mathrm{hr} / \mathrm{mile}$ \\
& $\$ 858$ \\
User cost for passenger car $(\$ 12.41 / \mathrm{hr} \times 0.0068 \mathrm{hr} \times 10,114)$ & $\$ 46$ \\
User cost for single-unit truck $(\$ 19.88 / \mathrm{hr} \times 0.0068 \mathrm{hr} \times 337)$ & $\$ 110$ \\
User cost for multiple-unit truck $(\$ 23.92 / \mathrm{hr} \times 0.0068 \mathrm{hr} \times 673)$ & $\$ 1,014$ \\
Total User cost per day per lane-mile & \\
\hline
\end{tabular}

To evaluate the effectiveness of the pavements, the IRI values were plotted corresponding to the pavement age and the areas under the curves for the warranty and control projects were determined as shown in Figure 5-69 and 5-70, respectively. 
Table 5-56 Medium-Term User Costs, Comparison Set 4

\begin{tabular}{|l|c|c|}
\hline & $\begin{array}{c}\text { Warranty Project 4 } \\
\text { (R-23390) }\end{array}$ & $\begin{array}{c}\text { Control Project 4 } \\
\text { (R-21607) }\end{array}$ \\
\hline Work zone duration per lane-mile & 6 days & 19 days \\
\hline Total User cost & $\$ 6,081$ & $\$ 19,257$ \\
\hline User EUAC/lane-mile & $\$ 1,366$ & $\$ 4,326$ \\
\hline
\end{tabular}

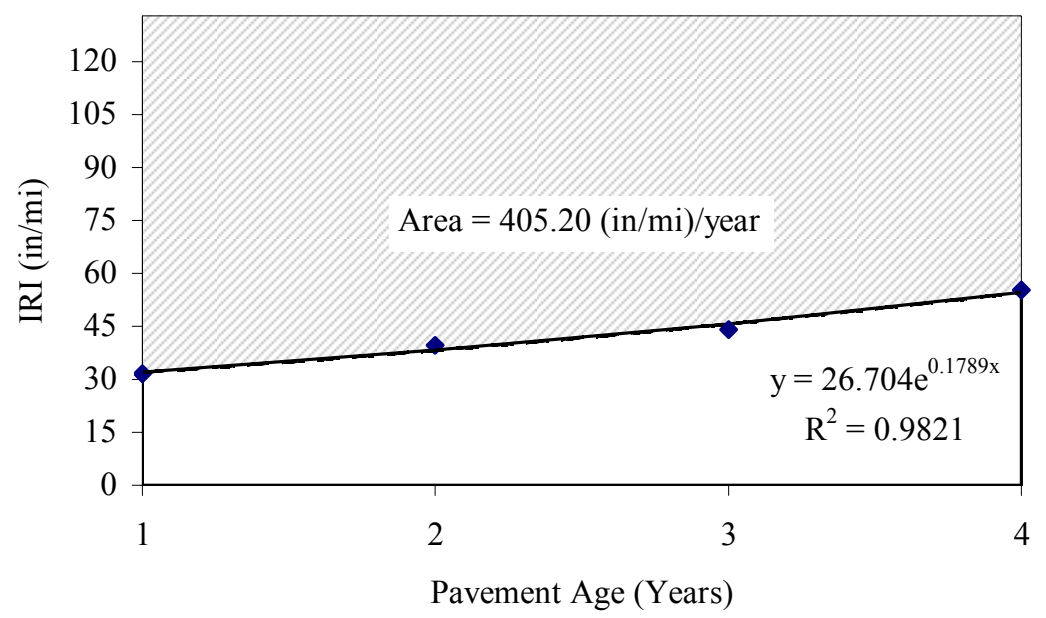

Figure 5-69 Area bounded by IRI-Age Curve of Warranty Pavement, Comparison Set 4

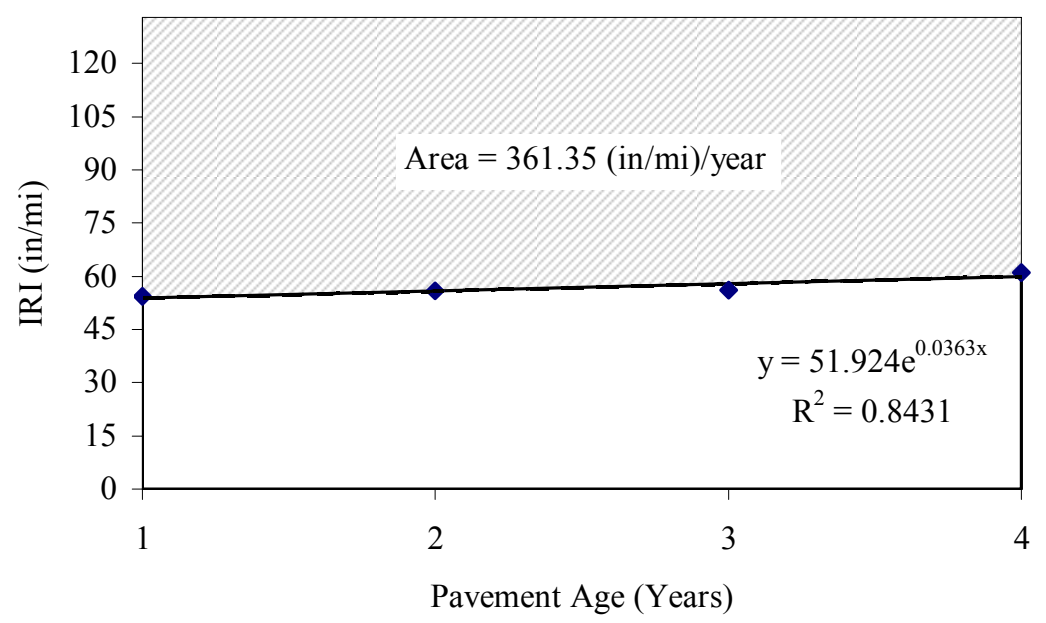

Figure 1-70 Area bounded by IRI-Age Curve of Control Pavement, Comparison Set 4 
Figures 5-71 and 5-72 show the areas under the IRI-ESAL curves for warranty and control pavements. For both pavements, trend lines of the linear form were selected to determine the effectiveness of the treatments.

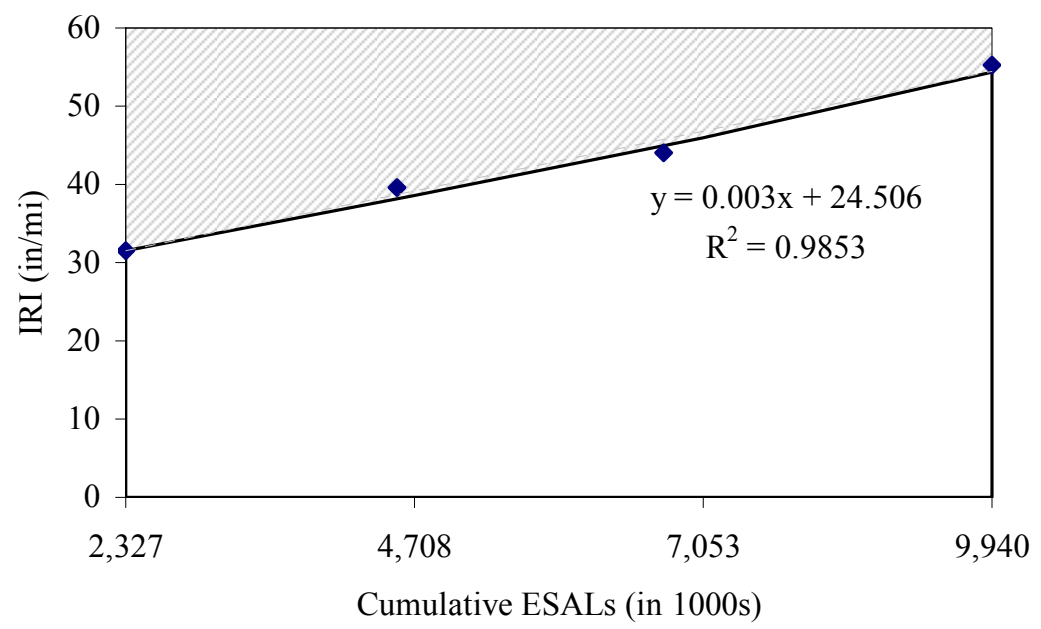

Figure 5-71 Area bounded by IRI-ESAL Curve of Warranty Pavement, Comparison Set 4

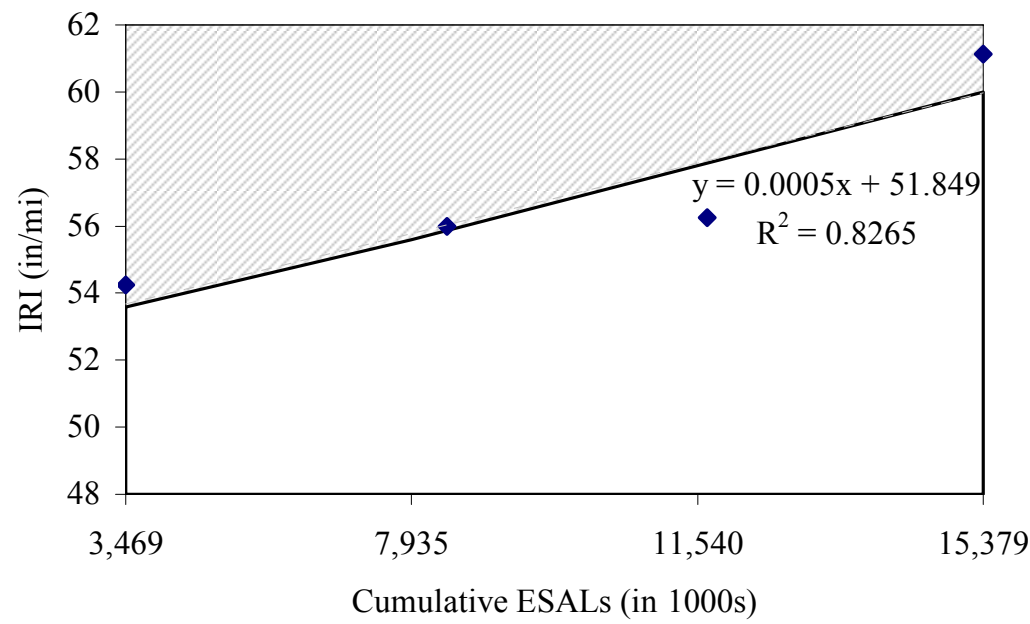

Figure 5-72 Area bounded by IRI-ESAL Curve of Control Pavement, Comparison Set 4

Similarly, the PQI values were also plotted with respect to the age and ESALs for both warranty and control pavements. Figures 5-73 and 5-74 presents the areas under the PQI-Age curves to determine the effectiveness, using exponential trend lines. 


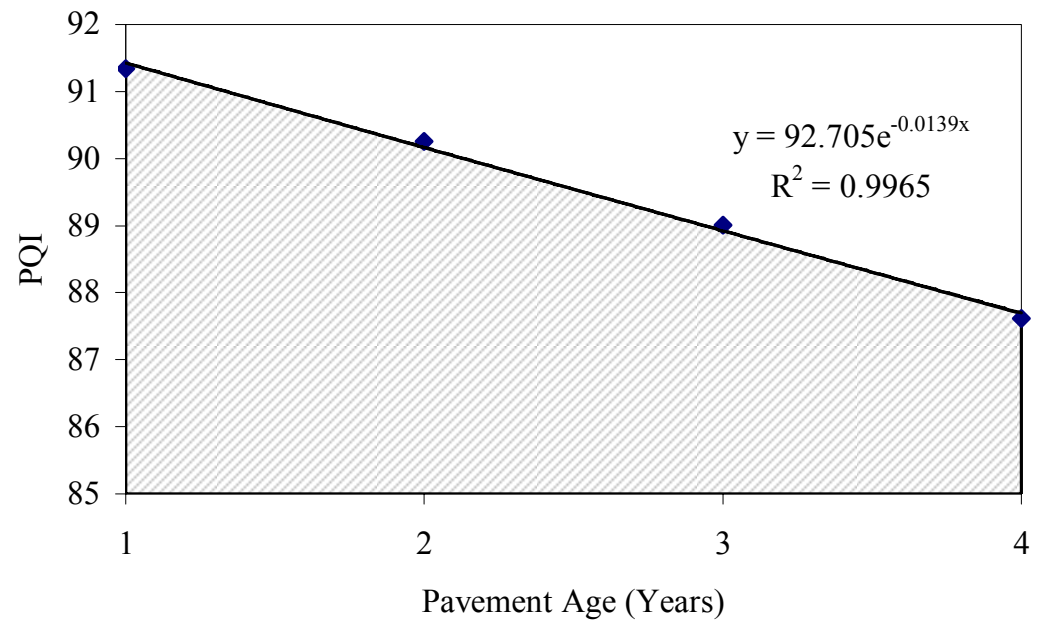

Figure 5-73 Area Bounded by PQI-Age Curve of Warranty Pavement, Comparison Set 4

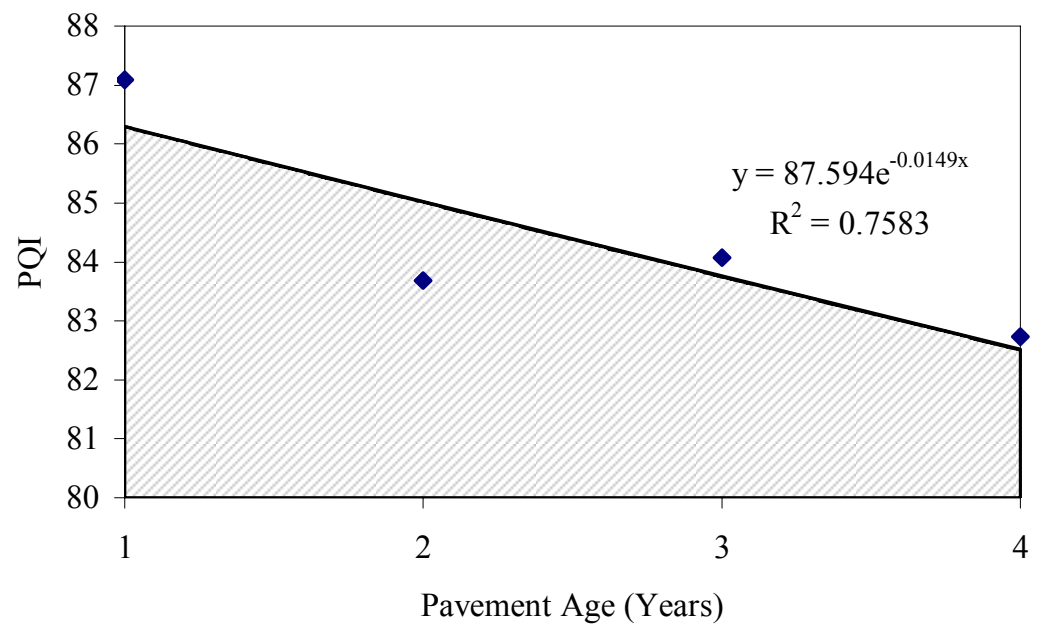

Figure 5-74 Area Bounded by PQI-Age Curve of Control Pavement, Comparison Set 4

The areas under the PQI-ESAL curves are shown in Figures 5-75 and 5-76 for the warranty and control pavements, respectively. 


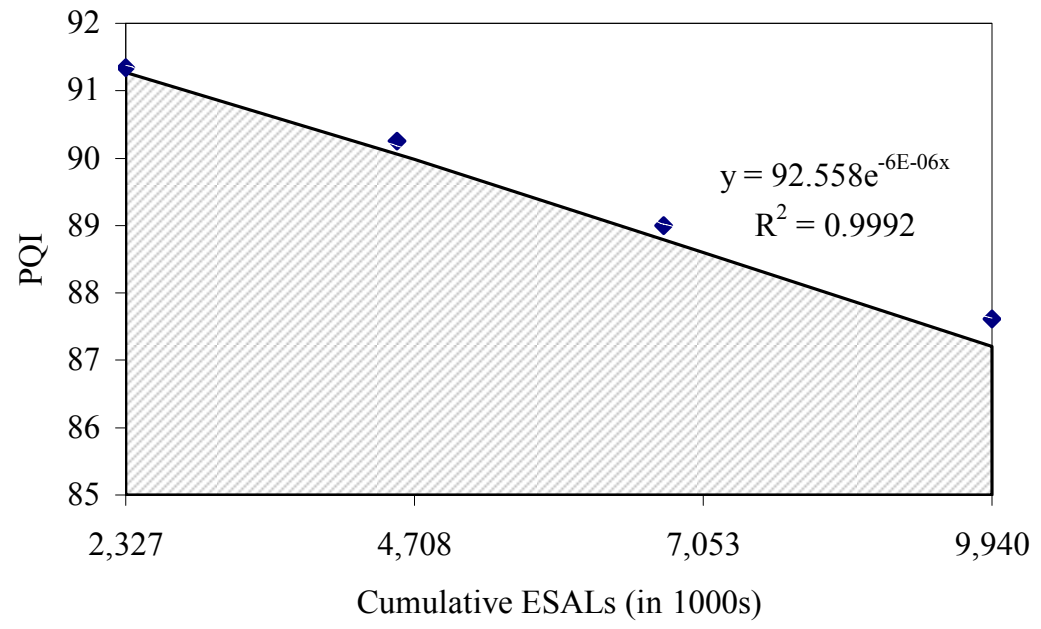

Figure 5-75 Area Bounded by PQI-ESAL Curve of Warranty Pavement, Comparison Set 4

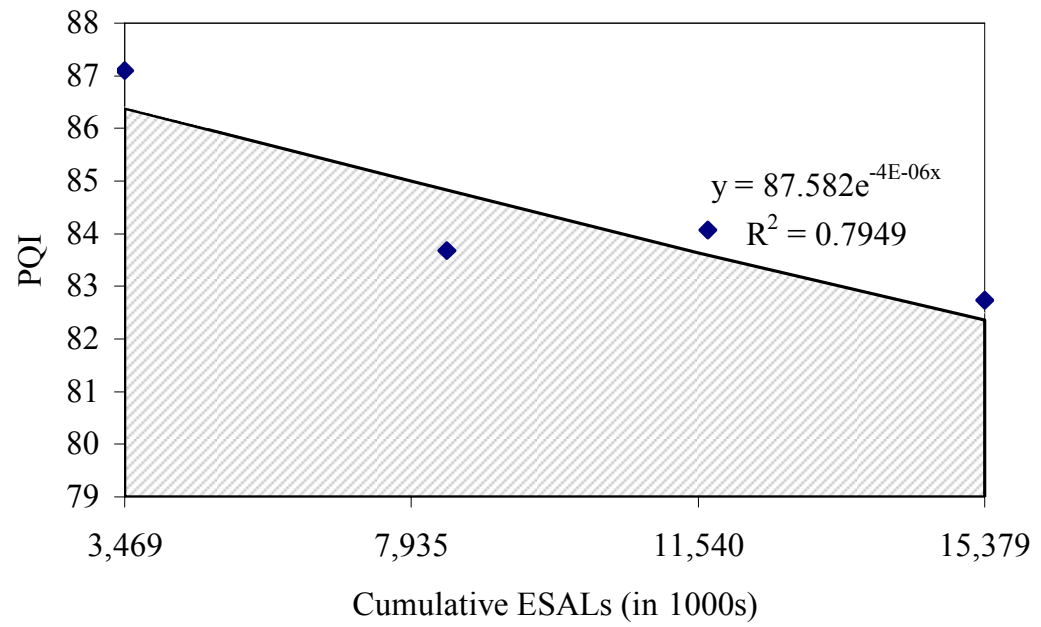

Figure 5-76 Area Bounded by PQI-ESAL Curve of Control Pavement, Comparison Set 4

The results of the overall analysis are shown in Table 5-57. The values for cost-effectiveness of the warranty project were lower than the control project as indicated in the above table. Thus, over the medium term, the warranty project was not cost-effective in comparison to the corresponding control project. Figures 5-77 and 5-78 show the comparison of cost-effectiveness of warranty and control projects based on time (pavement age) and traffic loading, respectively. 
Table 5-57 Medium Term Cost-effectiveness Evaluation, Comparison Set 4

\begin{tabular}{|l|c|c|c|c|}
\hline \multirow{2}{*}{ Cost-effectiveness } & \multicolumn{2}{|c|}{ Agency Cost only } & \multicolumn{2}{c|}{ Agency Cost + User Cost } \\
\cline { 2 - 5 } & Warranty (R-23390) & Control (R-21607) & Warranty (R-23390) & Control (R-21607) \\
\hline $\begin{array}{l}\text { Area bounded by the IRI-Age } \\
\text { curve/EUAC (\$100,000) }\end{array}$ & 3.51 & 5.71 & 3.47 & 5.34 \\
\hline $\begin{array}{l}\text { Area bounded by the IRI- } \\
\text { ESAL curve/EUAC }\end{array}$ & 8.61 & 21.67 & 8.51 & 20.29 \\
\hline $\begin{array}{l}\text { Area bounded by the PQI- } \\
\text { Age curve/EUAC (\$100,000) }\end{array}$ & 2.32 & 4.00 & 2.30 & 3.74 \\
\hline $\begin{array}{l}\text { Area bounded by the PQI- } \\
\text { ESAL curve/EUAC }\end{array}$ & 5.88 & 15.87 & 5.81 & 14.86 \\
\hline
\end{tabular}

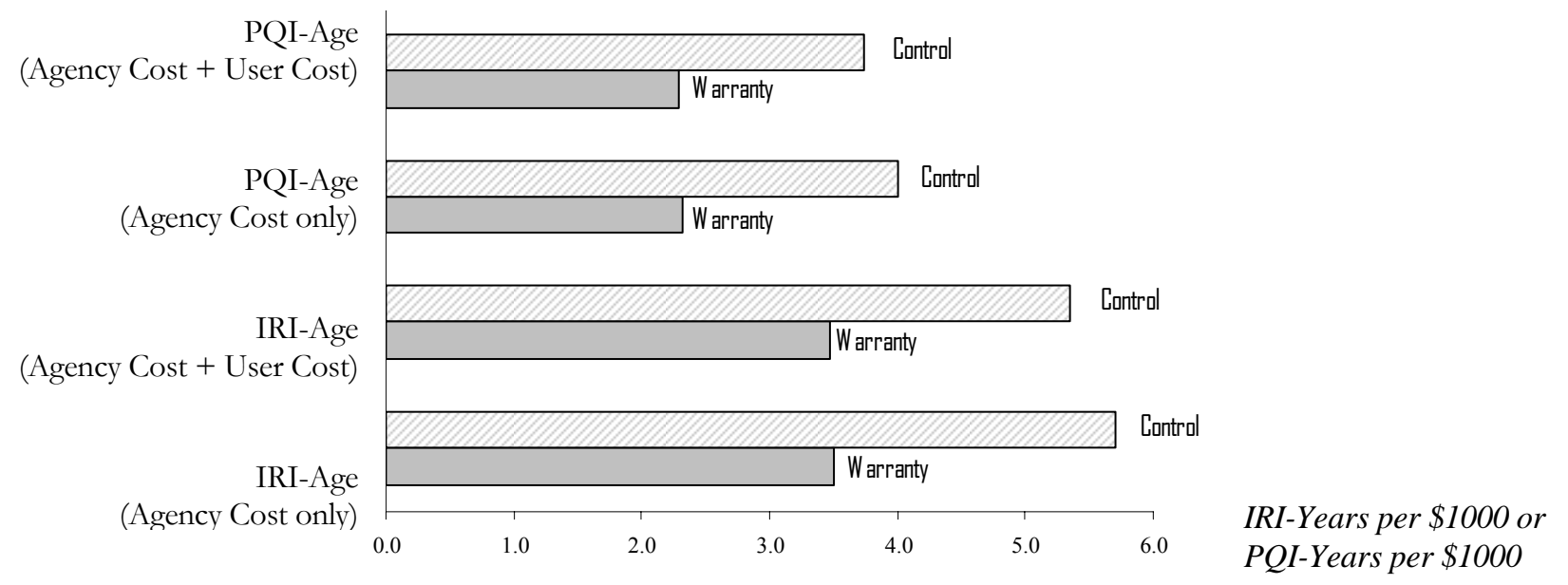

Figure 5-77 Medium-Term Cost-Effectiveness based on Performance and Time, Comparison Set 4

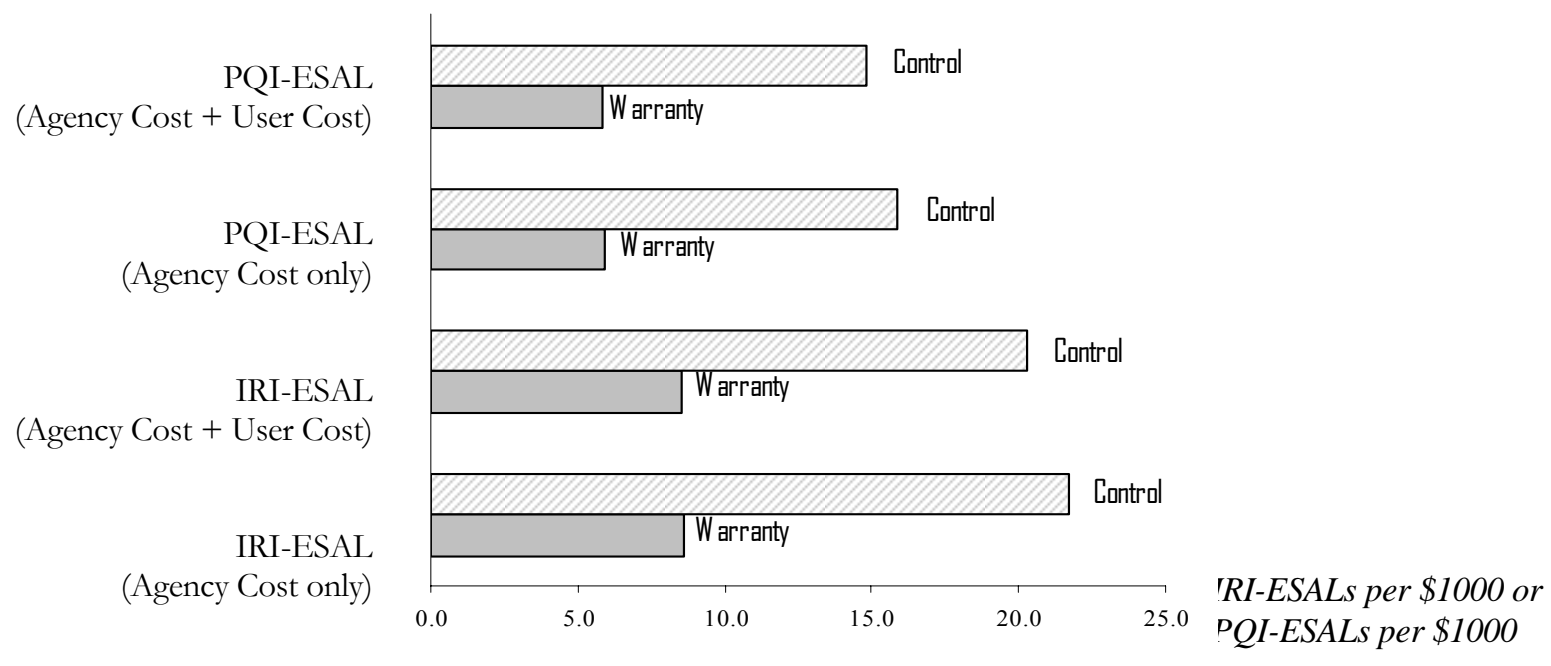

Figure 5-78 Medium-Term Cost-Effectiveness based on Performance and Load, Comparison Set 4 
The values of medium-term cost-effectiveness of the warranty project based on the performancetime curves were on an average 7\% lower than of the traditional project. Based on IRI and PQI load-curves, the values for warranty project compared to the traditional project were around $60 \%$ lower.

\subsubsection{Long-Term Cost-Effectiveness Evaluation for Comparison Set 4}

The long term evaluation of cost-effectiveness was carried out over the entire life of the pavement, based on the physical condition and service lives of the pavements. The agency and user costs computed over the life of the pavements are shown in Tables 5-58 and 5-59, respectively. The costs are shown in Year 2000 constant dollar.

Table 5-58 Long-Term Agency Costs, Comparison Set 4

\begin{tabular}{|l|c|c|}
\hline & $\begin{array}{c}\text { Warranty Project 4 } \\
(\mathrm{R}-23390)\end{array}$ & $\begin{array}{c}\text { Control Project 4 } \\
\text { (R-21607) }\end{array}$ \\
\hline Construction Cost/lane-mile & $\$ 393,734$ & $\$ 329,402$ \\
\hline Maintenance Cost/lane-mile & $\$ 5,884^{*}$ & $\$ 7,197$ \\
\hline Total agency cost/lane-mile & $\$ 399,618$ & $\$ 336,599$ \\
\hline EUAC/lane-mile & $\$ 25,580$ & $\$ 30,274$ \\
\hline
\end{tabular}

* Applicable only to warranty pavements after expiration of the warranty period.

Table 5-59 Long-Term User Costs, Comparison Set 4

\begin{tabular}{|l|c|c|}
\hline & $\begin{array}{c}\text { Warranty Project 4 } \\
\text { (R-23390) }\end{array}$ & $\begin{array}{c}\text { Control Project 4 } \\
\text { (R-21607) }\end{array}$ \\
\hline Work zone duration per lane-mile & 6 days & 19 days \\
\hline Total user cost per lane-mile & $\$ 6,081$ & $\$ 19,257$ \\
\hline User EUAC/lane-mile & $\$ 389$ & $\$ 1,732$ \\
\hline
\end{tabular}

After the agency and the user costs were computed, the overall cost-effectiveness of the pavements was determined. The areas were determined by integrating the models fitted for the medium-term evaluation over the projected service lives of the pavements. Table indicates the overall cost-effectiveness of the warranty and control projects based on agency costs only, and also the sum of agency and user costs. Figures 5-79 and 5-80 present the comparison of cost-effectiveness of warranty and control projects based on treatment lives and age, respectively. 
Table 5-60 Long Term Cost-effectiveness Evaluation, Comparison Set 4

\begin{tabular}{|l|c|c|c|c|}
\hline \multirow{2}{*}{ Cost-effectiveness } & \multicolumn{2}{|c|}{ Agency Cost only } & \multicolumn{2}{c|}{ Agency Cost + User Cost } \\
\cline { 2 - 5 } & $\begin{array}{c}\text { Warranty } \\
\text { (R-23390) }\end{array}$ & $\begin{array}{c}\text { Control } \\
\text { (R-21607) }\end{array}$ & $\begin{array}{c}\text { Warranty } \\
\text { (R-23390) }\end{array}$ & $\begin{array}{c}\text { Control } \\
\text { (R-21607) }\end{array}$ \\
\hline $\begin{array}{l}\text { Average Service life/EUAC } \\
(\$ 1000)\end{array}$ & 0.98 & 0.50 & 0.79 & 0.30 \\
\hline $\begin{array}{l}\text { Area bounded by the IRI-Age } \\
\text { curve/EUAC (\$1000) }\end{array}$ & 51.27 & 46.65 & 41.42 & 40.73 \\
\hline $\begin{array}{l}\text { Area bounded by the PQI- } \\
\text { Age curve/EUAC (\$1000) }\end{array}$ & 72.93 & 36.02 & 58.93 & 22.02 \\
\hline
\end{tabular}

Average Treatment Life (Agency Cost + User Cost)

Average Treatment Life

(Agency Cost only)

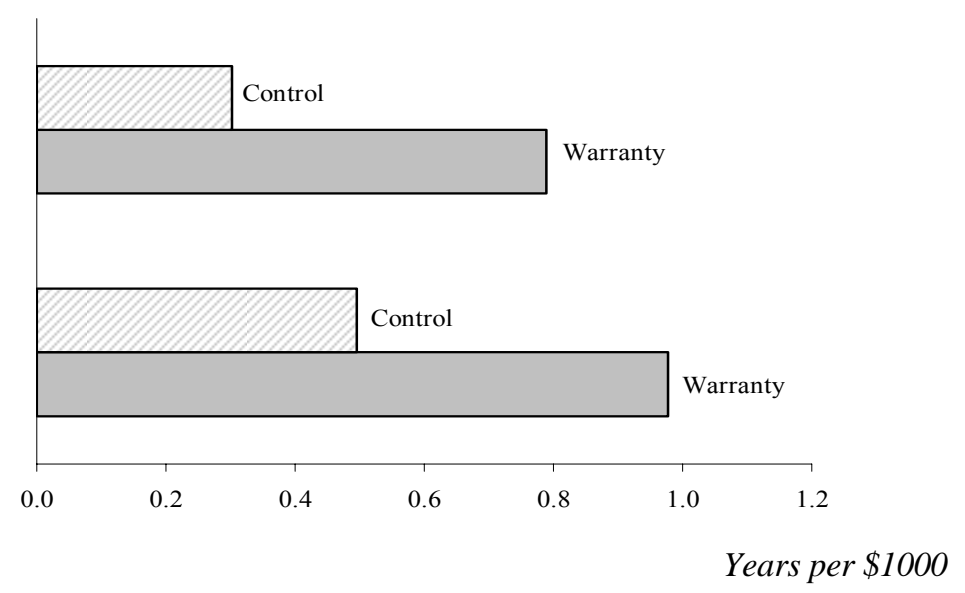

Figure 5-79 Long-Term Cost-Effectiveness based on Treatment Life Only, Comparison Set 4

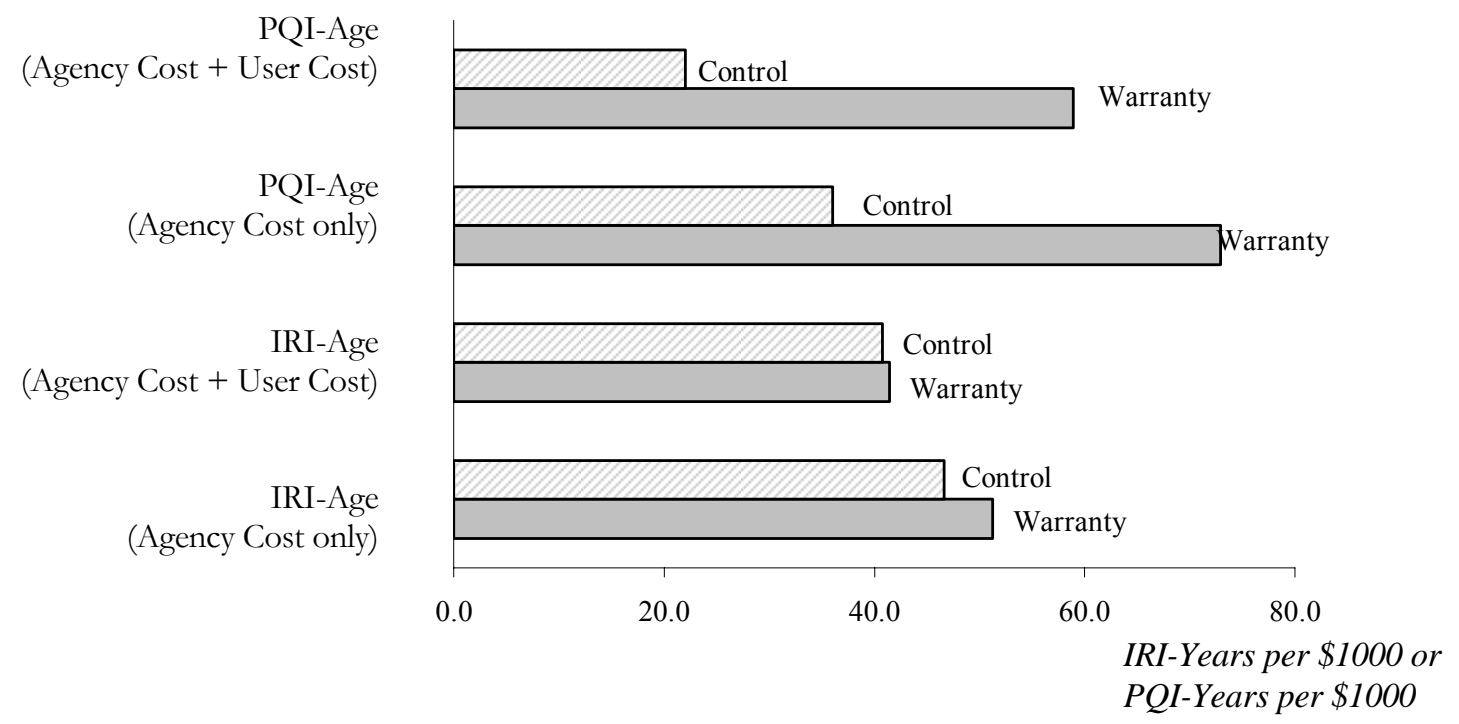

Figure 5-80 Long-Term Cost-Effectiveness based on Performance and Time, Comparison Set 4 
The results of the long-term analysis show that the warranty project has higher values of cost-effectiveness as compared to the control project.

\subsubsection{Summary of the Analysis Results for Comparison Set 4}

It was seen that the warranty pavement exhibited superior performance in terms of IRI, PSI, rutting, and PCR. The user cost of the warranty pavement was also found to be lower than that of the traditional project. However, the warranty project had a higher agency cost. The medium-term analysis indicated that the warranty project was not cost-effective as compared to the traditional project. However, over the projected treatment service lives, the warranty project was found to be more cost-effective.

\subsection{Comparison Set 5 (Warranty Project: R-23898 and Control Project R-22923)}

\subsubsection{General Contract Information for Comparison Set 5}

The fifth warranty project considered in the present study was awarded to rehabilitate a section of I-74 in December 1998 and was completed in November 1999. The project was evaluated on the basis of the data for the first three years of its warranty period. The road section was an urban interstate in Hendricks County, Crawfordsville in the Central region of the state. The project begun from milepost 64.95 and ended at 68.91 , a total length of 3.96 miles.

The control project was R-22923 in Hancock County, Greenfield located on I-70 from Sugar Creek to 0.4 mile east of Brandywine Creek. The contract segment begins at milepost 100.68 and ends at 104.08. The projects have very similar physical characteristics as shown in Table 5-61, thus enabling comparative analysis.

Table 5-61 Characteristics of Projects Constituting Comparison Set 5

\begin{tabular}{|c|c|c|}
\hline & $\begin{array}{c}\text { Warranty Project 5 } \\
\text { (R-23898) }\end{array}$ & $\begin{array}{c}\text { Control Project 5 } \\
\text { (R-22923) }\end{array}$ \\
\hline Work Description & Road Rehabilitation & Road Rehabilitation \\
\hline Functional Class & $\begin{array}{c}\text { Four-lane Urban } \\
\text { Interstate }\end{array}$ & $\begin{array}{c}\text { Four-lane Urban } \\
\text { Interstate }\end{array}$ \\
\hline NHS & Yes & Yes \\
\hline Length (miles) & 3.96 & 3.40 \\
\hline Surface Type & $\begin{array}{l}\text { HMA over } \\
\text { Crack-and-seat PCC }\end{array}$ & $\begin{array}{c}\text { HMA over } \\
\text { Crack-and-seat PCC }\end{array}$ \\
\hline Thickness of new surface & 0.60 inch & 0.625 inch \\
\hline AADT in Year 2002 & 36,212 & 45,274 \\
\hline Percentage Trucks & $25 \%$ & $20 \%$ \\
\hline
\end{tabular}




\subsubsection{Medium-term Performance Analysis for Comparison Set 5}

The physical condition of the pavements was analyzed based on IRI, PSI, rutting, and PCR to determine the effectiveness of the treatments of warranty and traditional projects.

Comparison of Performance on the basis of International Roughness Index (IRI)

Table 5-62 shows the weighted IRI values of the warranty project and the control project measured along the entire contract segments. Data for only 3 years was available for analysis.

Table 5-62 IRI of Constituent Pavements, Comparison Set 5

\begin{tabular}{|c|c|c|}
\hline \multirow{2}{*}{$\begin{array}{c}\text { Age } \\
\text { (years) }\end{array}$} & \multicolumn{2}{|c|}{ IRI (in/mi) } \\
\cline { 2 - 3 } & $\begin{array}{c}\text { Warranty Project 5 } \\
\text { (R-23898) }\end{array}$ & $\begin{array}{c}\text { Control Project 5 } \\
\text { (R-22923) }\end{array}$ \\
\hline 1 & 33.83 & 45.17 \\
\hline 2 & 44.02 & 54.67 \\
\hline 3 & 61.71 & 83.00 \\
\hline
\end{tabular}

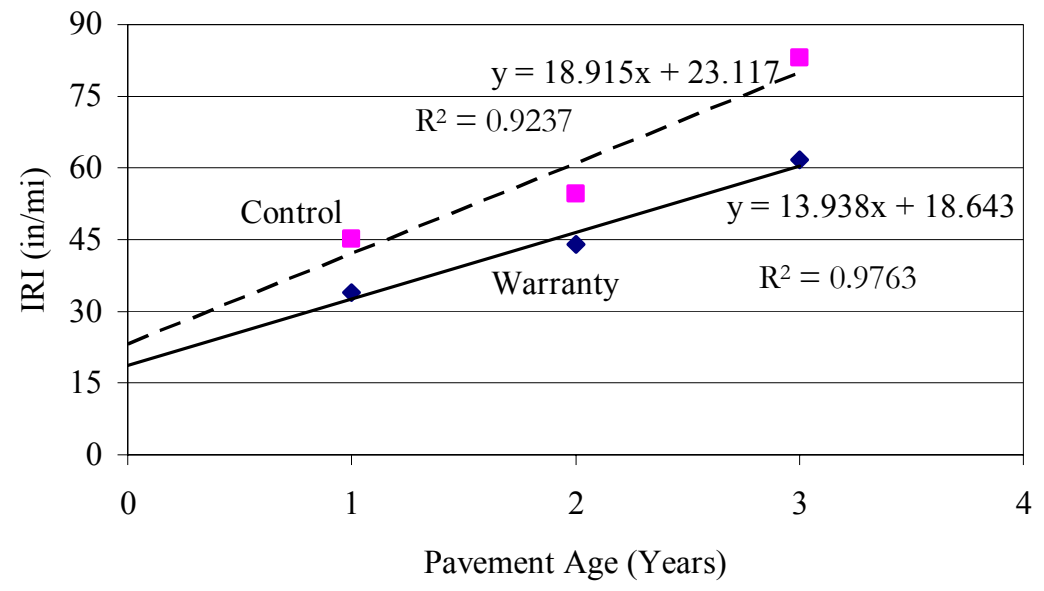

Figure 5-81 IRI Trends of Warranty and Control Pavements, Comparison Set 5

The performance trends of the pavements are shown in Figure 5-81. Linear trend lines were fitted and extrapolated to yield the IRI values immediately after construction. The control project had higher traffic in terms of the cumulative ESALs as indicated in Figure 5-82. The extrapolated trend lines indicate that the control project had slightly lower initial IRI compared to the warranty project. 


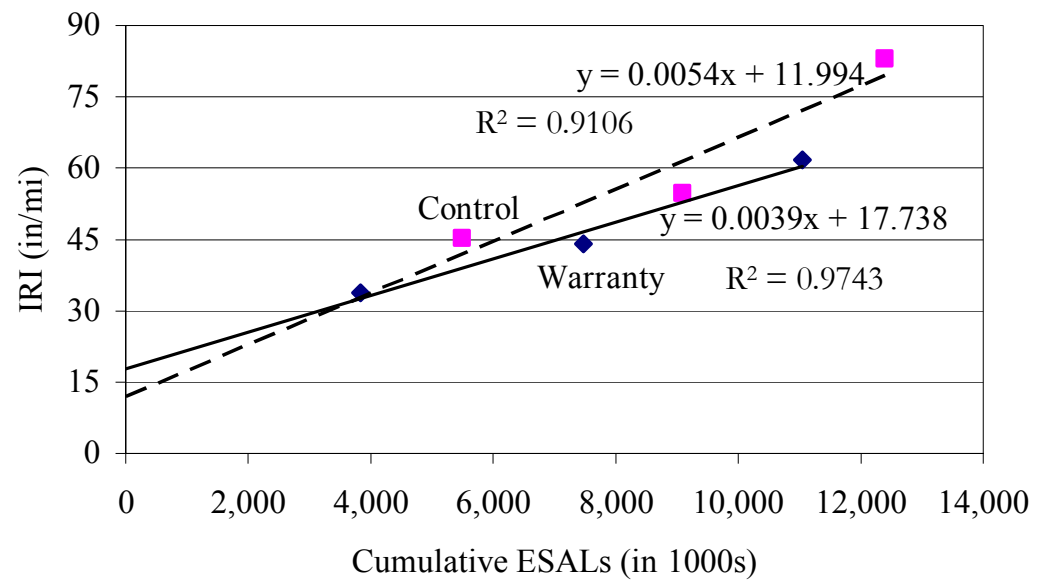

Figure 5-82 Comparison of Load-based Deterioration (IRI) curves, Comparison Set 5

Table 5-63 Results of t-test for IRI, Comparison Set 5

\begin{tabular}{ccc}
\hline & $\begin{array}{c}\text { Variable 1 } \\
\text { (Warranty) }\end{array}$ & $\begin{array}{c}\text { Variable 2 } \\
\text { (Control) }\end{array}$ \\
\hline Mean & 46.5203 & 60.9467 \\
Variance & 198.9881 & 387.3246 \\
Observations & 3 & 3 \\
Hypothesized Mean Difference & 0 & \\
Degrees of freedom & 2 & \\
$t$ Statistic & -4.1976 & \\
$\mathrm{P}(\mathrm{T}<=t$ ) one-tail & 0.0262 & \\
$t$ Critical one-tail & 2.9200 & \\
\hline
\end{tabular}

Table 5-63 shows the results of the one-tailed t-test for mean IRI values. The $t$ statistic -4.1976 was less than the negative critical value of 2.9200 , clearly indicating the null hypothesis can be rejected. Thus, we can assert with $95 \%$ that the warranty project had significantly lower IRI values than the control project.

\section{Comparison on basis of Present Serviceability Index (PSI)}

The PSI values for warranty and the control projects are shown in Table 5-64. The trend of PSI values over time were plotted (Figure 5-83). 
Table 5-64 PSI of Constituent Pavements, Comparison Set 5

\begin{tabular}{|c|c|c|}
\hline \multirow{2}{*}{$\begin{array}{c}\text { Age } \\
\text { (years) }\end{array}$} & \multicolumn{2}{|c|}{ PSI } \\
\hline & $\begin{array}{c}\text { Warranty Project } 5 \\
\text { (R-23898) }\end{array}$ & $\begin{array}{c}\text { Control Project } 5 \\
\text { (R-22923) }\end{array}$ \\
\hline 1 & 4.35 & 4.15 \\
\hline 2 & 4.17 & 4.00 \\
\hline 3 & 3.88 & 3.56 \\
\hline
\end{tabular}

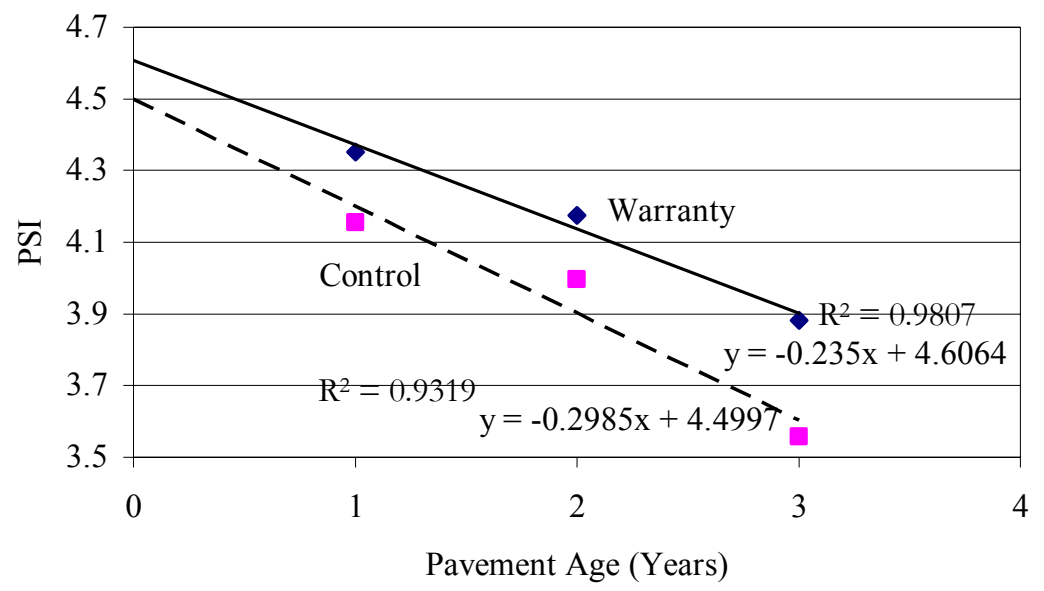

Figure 5-83 PSI Trends of Warranty and Control Pavements, Comparison Set 5

Figure 5-84 shows the increase in the distresses exhibited by the pavements with respect to the cumulative ESALs, established by the declining trend lines.

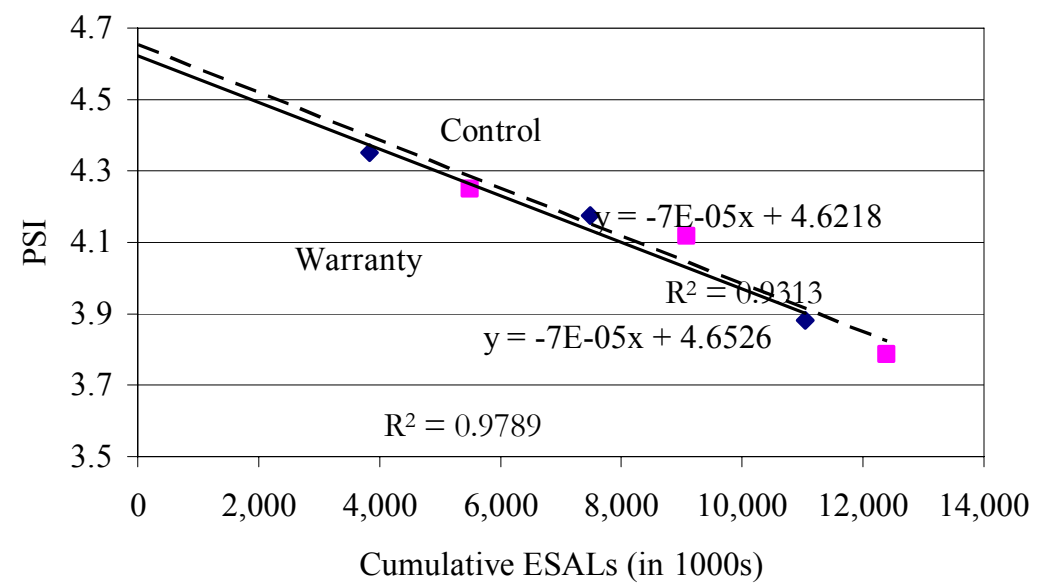

Figure 5-84 Comparison of Load-based Deterioration (PSI) curves, Comparison Set 5 
Table 5-65 presents the results of the t-test for the mean PSI values of the warranty and control projects. The $t$ statistic is greater than the critical value clearly indicating the null hypothesis can be rejected. In other words, the warranty project had higher PSI values than the control project.

Table 5-65 Results of t-test for PSI, Comparison Set 5

\begin{tabular}{ccc}
\hline & $\begin{array}{c}\text { Variable 1 } \\
\text { (Warranty) }\end{array}$ & $\begin{array}{c}\text { Variable 2 } \\
\text { (Control) }\end{array}$ \\
\hline Mean & 4.1363 & 3.9028 \\
Variance & 0.0563 & 0.0956 \\
Observations & 3 & 3 \\
Hypothesized Mean Difference & 0 & \\
Degrees of freedom & 2 & \\
$t$ Statistic & 5.0966 & \\
$\mathrm{P}(\mathrm{T}<=t)$ one-tail & 0.0182 & \\
$t$ Critical one-tail & 2.9200 & \\
\hline
\end{tabular}

\section{Comparison of Performance on basis of Rutting}

The average rutting depths in inches of the pavements over the first three years of the warranty period are shown in Table 5-66. The rut depth of the warranty project was same in the first two years and then increases in the third year. In comparison, the rut depths of control project were high and indicated a decreasing trend that may have been due to some maintenance.

Table 5-66 Rut Depth of Constituent Pavements in Comparison Set 5

\begin{tabular}{|c|c|c|}
\hline \multirow{2}{*}{$\begin{array}{c}\text { Age } \\
\text { (years) }\end{array}$} & \multicolumn{2}{|c|}{ Rut Depth (in) } \\
\cline { 2 - 3 } & $\begin{array}{c}\text { Warranty Project 5 } \\
\text { (R-23898) }\end{array}$ & $\begin{array}{c}\text { Control Project 5 } \\
\text { (R-22923) }\end{array}$ \\
\hline 1 & 0.07 & 0.16 \\
\hline 2 & 0.07 & 0.14 \\
\hline 3 & 0.12 & 0.12 \\
\hline
\end{tabular}




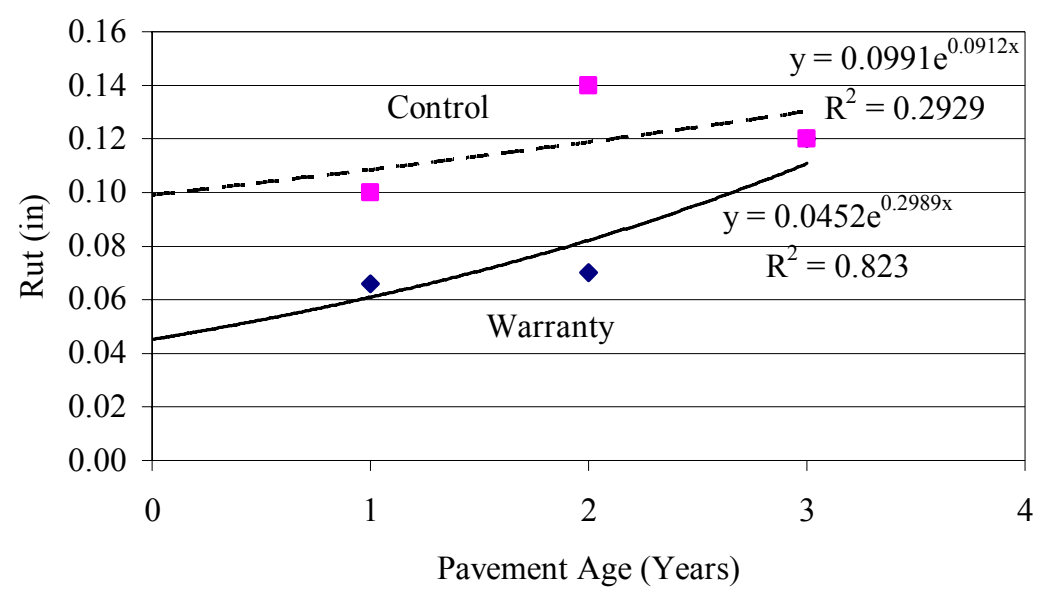

Figure 5-85 Rutting Trends of Warranty and Control Pavements, Comparison Set 5

Figure 5-85 shows the comparison of the rutting depths of the warranty and control projects. The difference in the rut depths is most significant in the first and second year of pavement life. The control project shows a decrease which may be due to measurement errors.

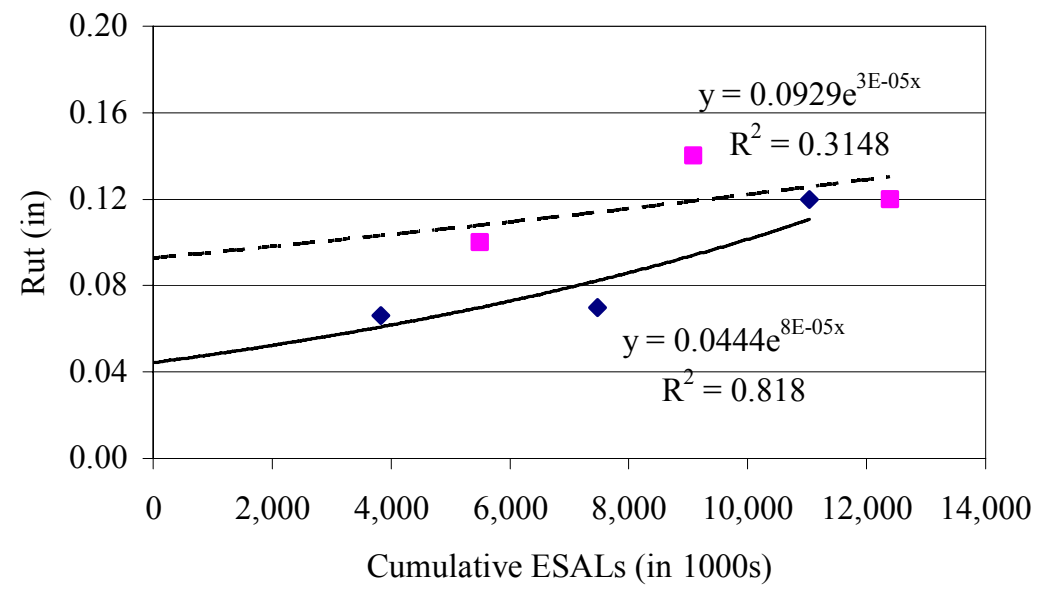

Figure 5-86 Comparison of Load-based Deterioration (Rut), Comparison Set 5

The results of the one-tailed t-test for rut depths are shown in Table 5-67 where the $t$ statistic is lower than the value critical value, $-1.9963<-1.8856$ at $\alpha=0.10$, indicating the null hypothesis can be rejected. This implies that there is a significant difference between the mean rut depths of warranty and control pavements. 
Table 5-67 Results of t-test for Rutting depth, Comparison 5

\begin{tabular}{ccc}
\hline & $\begin{array}{c}\text { Variable 1 } \\
\text { (Warranty) }\end{array}$ & $\begin{array}{c}\text { Variable 2 } \\
\text { (Control) }\end{array}$ \\
\hline Mean & 0.0850 & 0.1400 \\
Variance & 0.0009 & 0.0004 \\
Observations & 3 & 3 \\
Hypothesized Mean Difference & 0 & \\
Degrees of freedom & 2 & \\
$t$ Statistic & -2.5635 & \\
$\mathrm{P}(\mathrm{T}<=t)$ one-tail & 0.0622 & \\
$t$ Critical one-tail & 1.8856 & \\
\hline
\end{tabular}

\section{Performance Comparison on basis of Pavement Condition Rating (PCR)}

The PCR for the warranty and the control projects are shown in Table 5-68. The warranty pavement demonstrates excellent condition based on the overall rating, with very high values of PCR. The control project has higher value at age 3 compared to that at age 2 . Again, this may have been due to measurement error.

Table 5-68 PCR of Constituent Pavements, Comparison Set 5

\begin{tabular}{|c|c|c|}
\hline \multirow{2}{*}{$\begin{array}{c}\text { Age } \\
\text { (years) }\end{array}$} & \multicolumn{2}{|c|}{ PCR } \\
\hline & $\begin{array}{c}\text { Warranty Project } 5 \\
\text { (R-23898) }\end{array}$ & $\begin{array}{l}\text { Control Project } 5 \\
\text { (R-22923) }\end{array}$ \\
\hline 1 & 100.00 & 98.00 \\
\hline 2 & 99.44 & 96.33 \\
\hline 3 & 98.31 & 98.08 \\
\hline
\end{tabular}

Figure 5-87 and 5-88 show evidence of the warranty project yielding a higher quality pavement when compared to the performance of control project. Linear trend lines were fitted for both projects. 


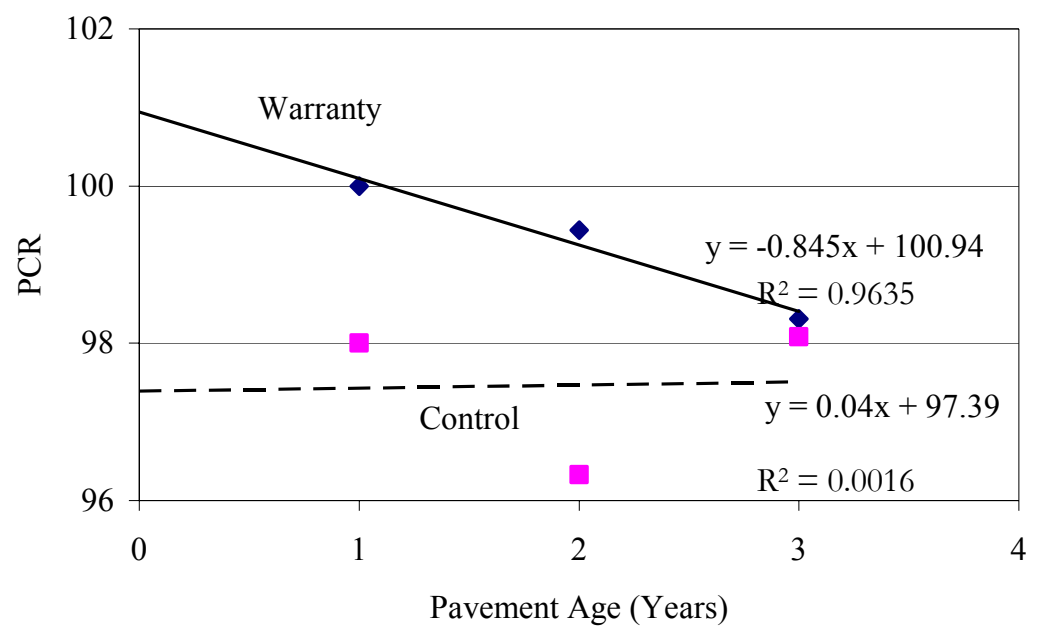

Figure 5-87 PCR Trends of Warranty and Control Pavements, Comparison Set 5

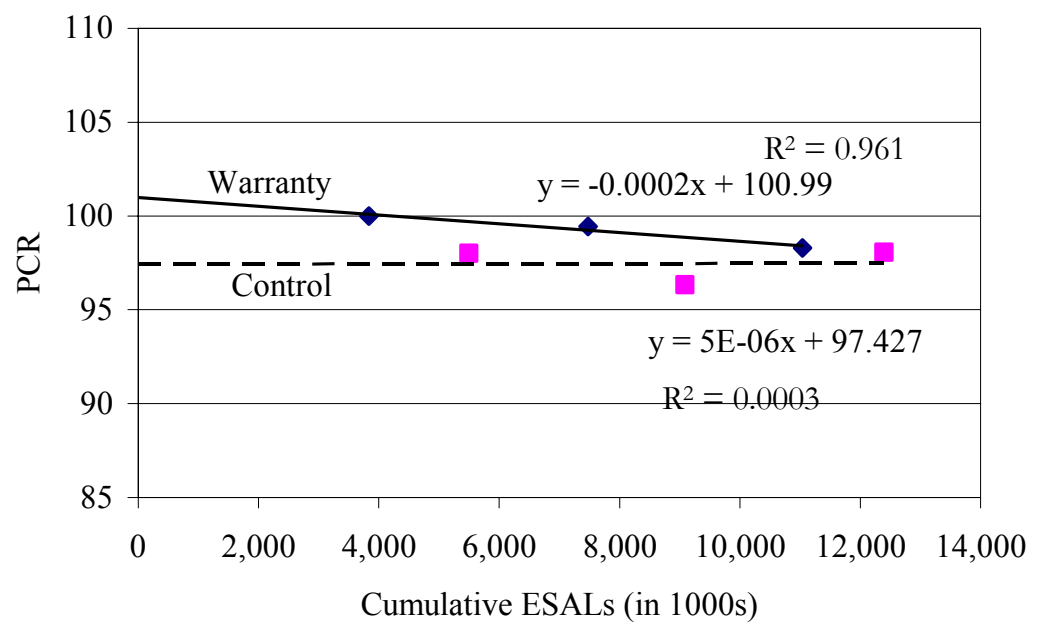

Figure 5-88 Comparison of Load-based Deterioration (PCR), Comparison Set 5

Table 5-69 indicates the results of the t-test for PCR values at 5\% significance level. The $t$ statistic is higher than the critical value, and lies outside the rejection region. Therefore, there is enough evidence that the warranty project had higher PCR than the control project. 
Table 5.69 Results of t-test for PCR of Constituent Pavements, Comparison Set 5

\begin{tabular}{lcc}
\hline & $\begin{array}{c}\text { Variable 1 } \\
\text { (Warranty) }\end{array}$ & $\begin{array}{c}\text { Variable 2 } \\
\text { (Control) }\end{array}$ \\
\hline Mean & 99.2500 & 97.4700 \\
Variance & 0.7411 & 0.9763 \\
Observations & 3 & 3 \\
Hypothesized Mean Difference & 0 & \\
Degrees of freedom & 2 & \\
$t$ Statistic & 2.1225 & \\
$\mathrm{P}(\mathrm{T}<=t)$ one-tail & 0.0839 & \\
$t$ Critical one-tail & 1.8856 & \\
\hline
\end{tabular}

\subsubsection{Evaluation of Cost-Effectiveness for Comparison Set 5}

The medium-term and long-term evaluation of cost-effectiveness are presented in the subsequent sections.

\section{Medium-Term Cost-Effectiveness Evaluation for Comparison Set 5}

The overall examination of cost-effectiveness of the warranty project was done by the comparing the benefits or effectiveness of the treatments over the entire warranty period with the total cost of the project. Table 5-70 summarizes the various agency costs for the warranty and the control project in Year 2000 constant dollar. The agency cost of the warranty project was slightly higher than that of the control project. To determine the user costs, the same AADT and the percentage trucks were used for both warranty and control projects. This provides a rational basis for comparison of the two projects. The user cost components are shown below.

Table 5-71 shows the user costs of warranty and control pavements, in Year 2000 constant dollar. The work zone duration of the warranty project was less than that of the control project resulting in lower user costs. 
Table 5-70 Medium-Term Agency Costs, Comparison Set 5

\begin{tabular}{|l|c|c|}
\hline & $\begin{array}{c}\text { Warranty Project 5 } \\
\text { (R-23898) }\end{array}$ & $\begin{array}{c}\text { Control Project 5 } \\
\text { (R-22923) }\end{array}$ \\
\hline Length (miles) & 3.96 & 3.40 \\
\hline Number of lanes & 4 & 4 \\
\hline Final Cost & $\$ 13,250,862$ & $\$ 10,663,583$ \\
\hline Final Cost/lane-mile & $\$ 836,544$ & $\$ 784,087$ \\
\hline Maintenance Costs/lane-mile (5 years) & $\$ 0$ & $\$ 1,254$ \\
\hline Total agency cost/lane-mile & $\$ 836,544$ & $\$ 785,341$ \\
\hline Agency EUAC/lane-mile & $\$ 187,911$ & $\$ 176,409$ \\
\hline
\end{tabular}

AADT per lane

Volume of passenger cars (77\%) per lane

15,686

Volume of Single-unit trucks (7\%) per lane

Volume of Multiple-unit trucks (16\%) per lane

Difference in travel time due to reduction in speed from $65 \mathrm{mph}$ to $45 \mathrm{mph}$ in the work zone $(1 / 45-1 / 65)$

User cost for passenger car $(\$ 12.41 / \mathrm{hr} \times 0.0068 \mathrm{hr} \times 15,686)$

User cost for single-unit truck $(\$ 19.88 / \mathrm{hr} \times 0.0068 \mathrm{hr} \times 347)$

User cost for multiple-unit truck $(\$ 23.92 / \mathrm{hr} \times 0.0068 \mathrm{hr} \times 731)$

Total User cost per day

$\$ 1,497$

Table 5-71 Medium-Term User Costs, Comparison Set 5

\begin{tabular}{|l|c|c|}
\hline & $\begin{array}{c}\text { Warranty Project 5 } \\
\text { (R-23898) }\end{array}$ & $\begin{array}{c}\text { Control Project 5 } \\
\text { (R-22923) }\end{array}$ \\
\hline Work zone duration per lane-mile & 17 days & 19 days \\
\hline Total User cost per lane-mile & $\$ 25,681$ & $\$ 32,052$ \\
\hline User EUAC/lane-mile & $\$ 6,443$ & $\$ 7,200$ \\
\hline
\end{tabular}


Figures 5-89 and 5-90 indicate the areas plotted for the IRI values of the projects. Exponential trend lines were fitted to determine the effectiveness (area enclosed by the curves).

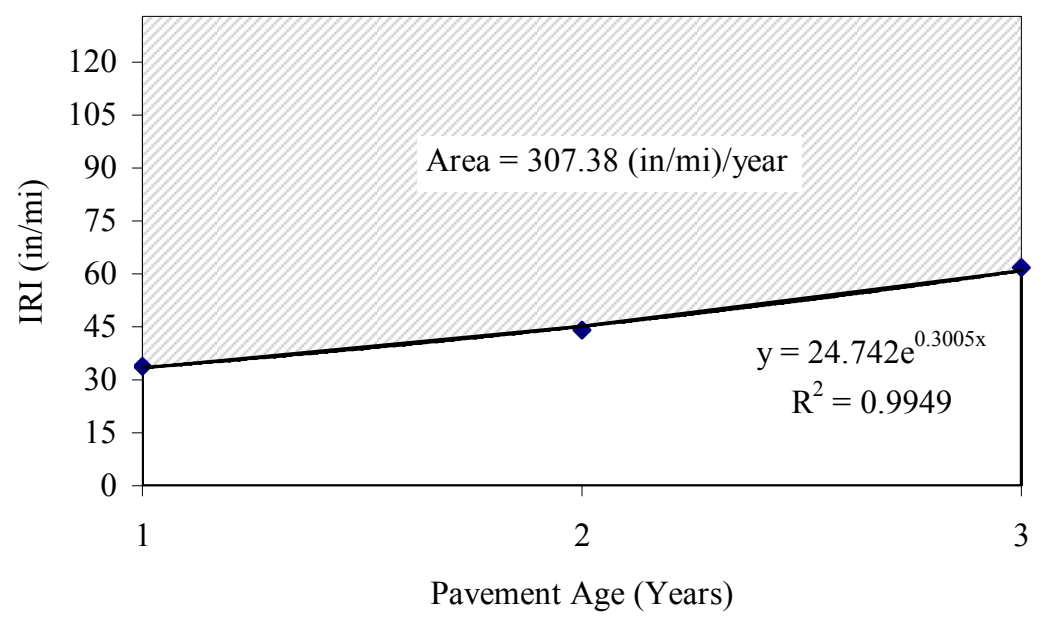

Figure 5-89 Area bounded by IRI-Age Curve of Warranty Pavement in Comparison Set 5

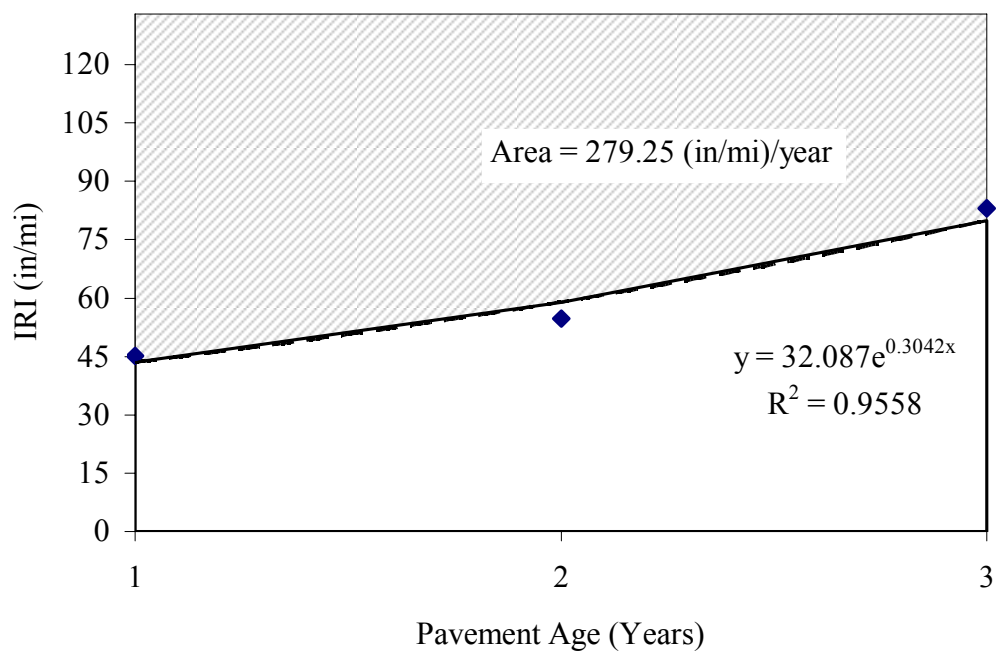

Figure 5-90 Area bounded by IRI-Age Curve of Control Pavement in Comparison Set 5

Effectiveness of the treatments was also determined on the basis of traffic loading. The IRI values were also plotted with respect to the cumulative ESALs as shown in Figures 5-91 and 5-92. 


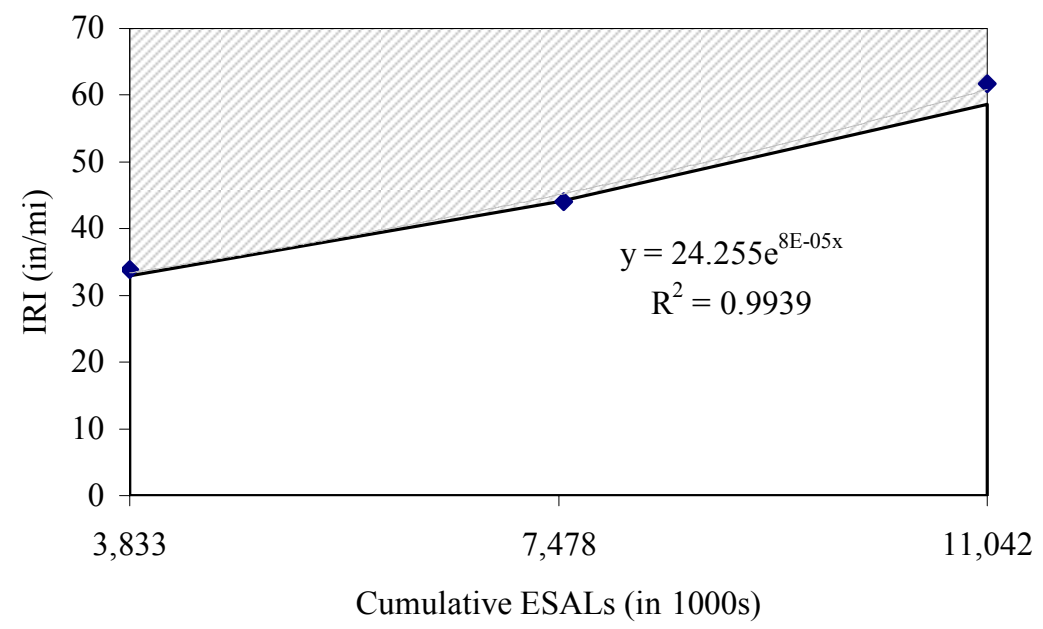

Figure 5-91 Area Bounded by IRI-ESAL Curve of Warranty Pavement in Comparison Set 5

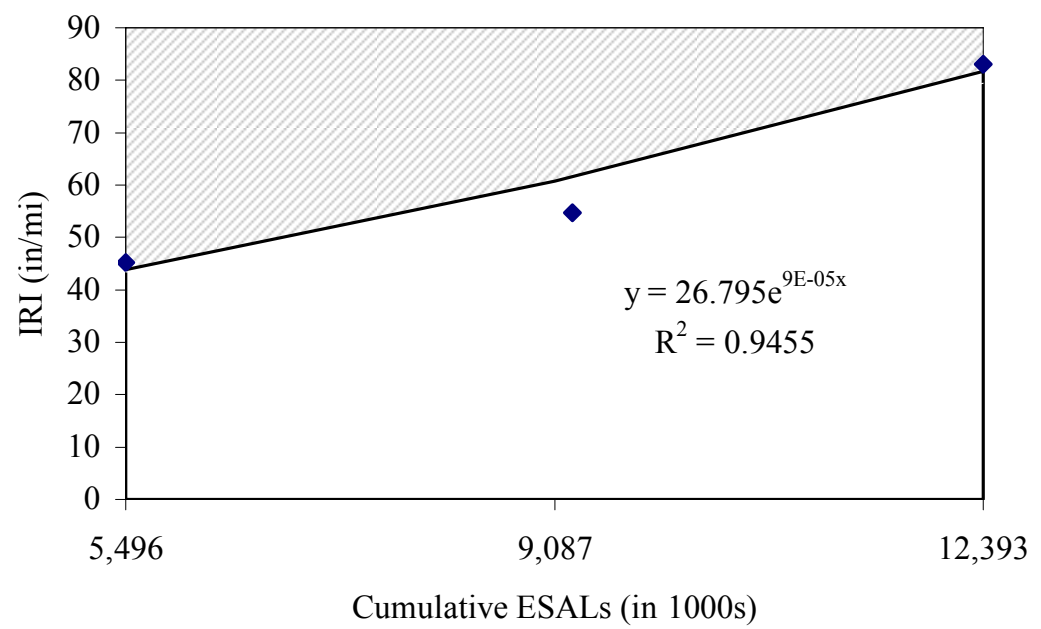

Figure 5-92 Area Bounded by IRI-ESAL Curve of Control Pavement in Comparison Set 5 
Figure 5-93 and 5-94 show the areas under the PQI-Age curves for the warranty and control pavements, respectively. The fitted trend lines are also shown along with the R-square values. To take into account the effect of traffic on the performance of the pavements, the PQI values were also plotted against the cumulative ESALs on the pavements as shown in Figures 5-95 and 5-96.

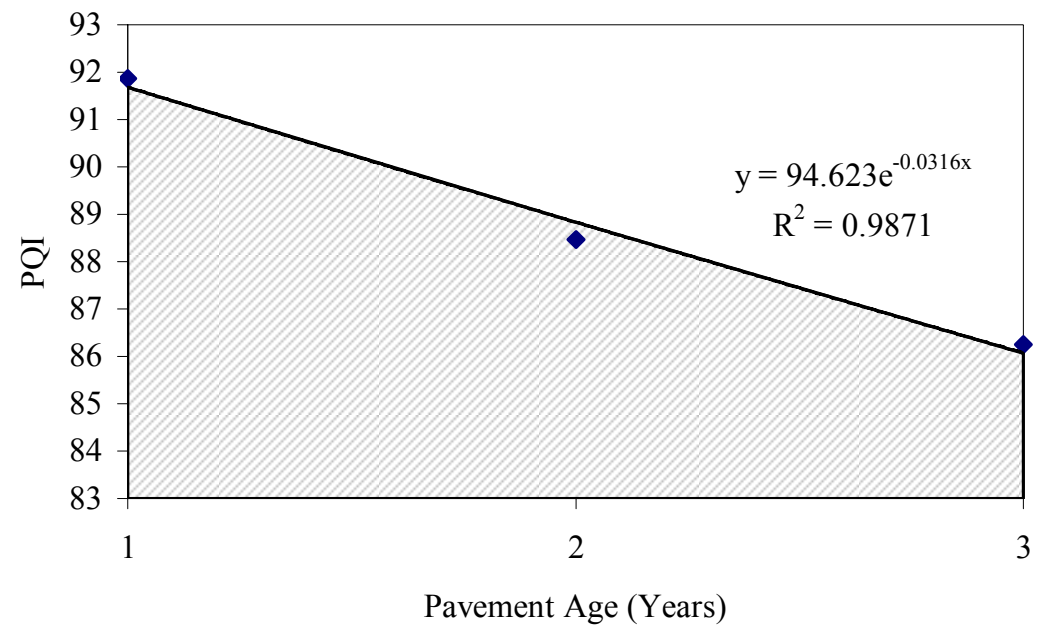

Figure 5-93 Area Bounded by PQI-Age Curve of Warranty Pavement in Comparison Set 5

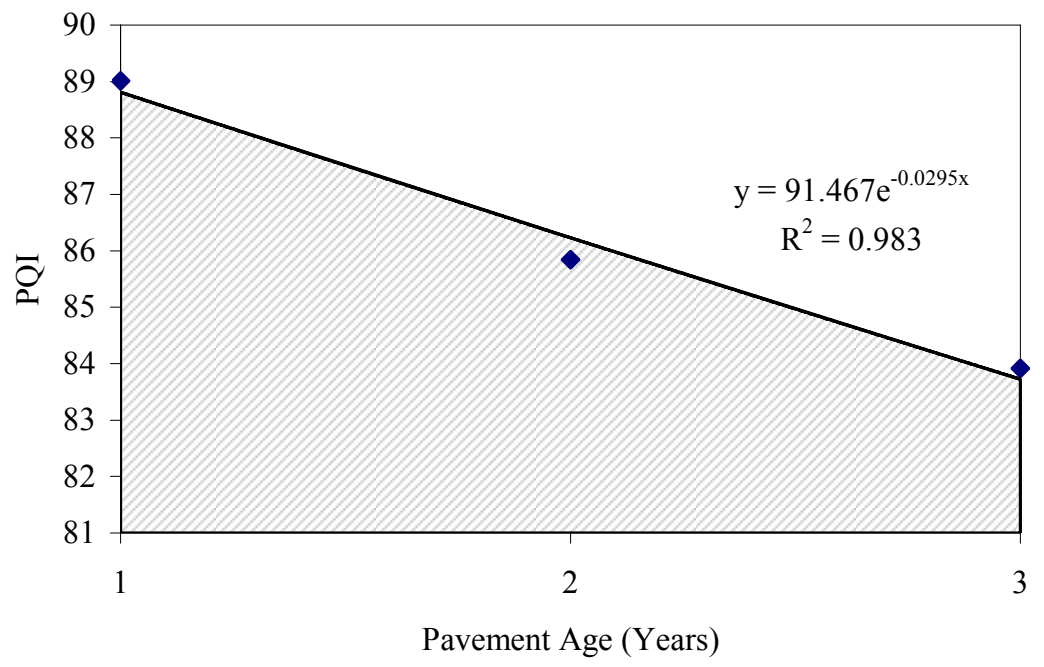

Figure 5.94 Area Bounded by PQI-Age Curve of Control Pavement in Comparison Set 5 


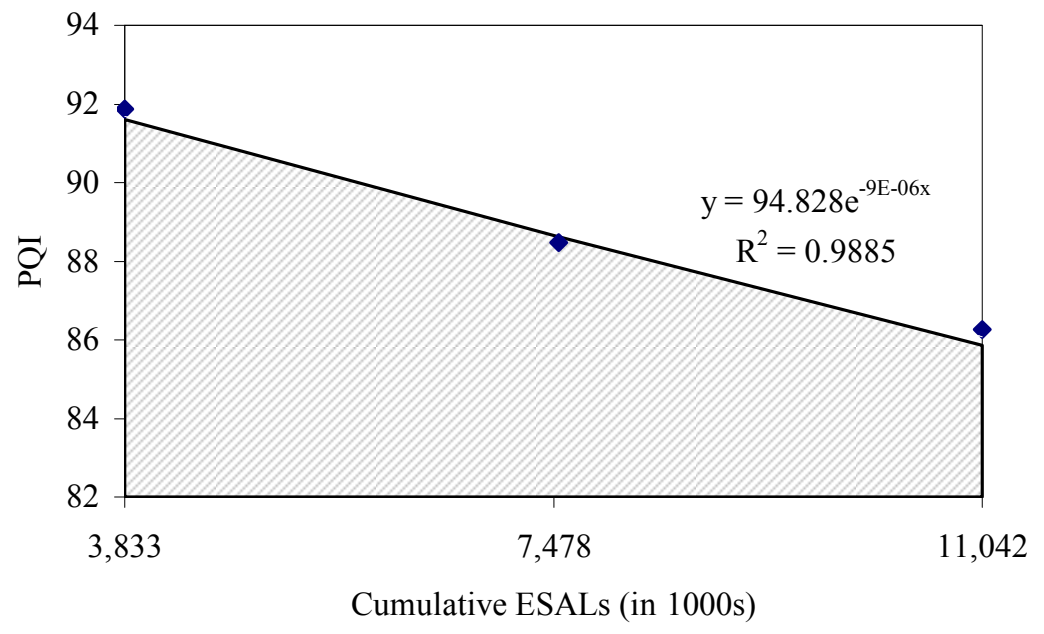

Figure 5-95 Area Bounded by PQI-ESAL Curve of Warranty Pavement in Comparison Set 5

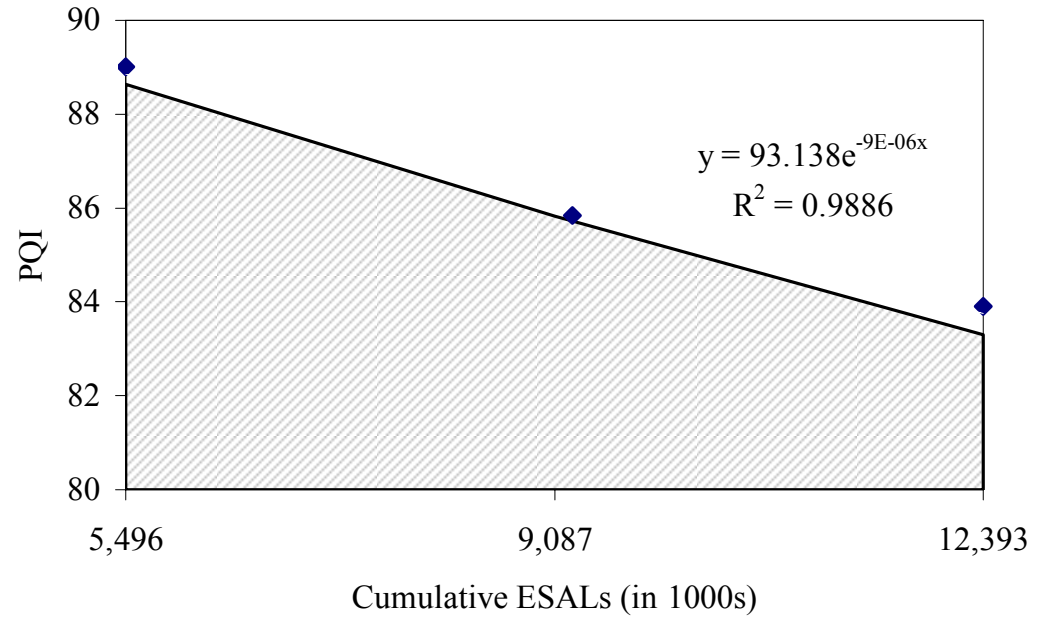

Figure 5-96 Area Bounded by PQI-ESAL Curve of Control Pavement in Comparison Set 5

After determining the effectiveness of the treatments, the overall cost-effectiveness was determined. The results of the overall assessment of the warranty and the control project are shown in Table 5-72. The warranty pavement showed some evidence of cost-effectiveness based on the IRI-Age and PQI-ESAL curves.

Figures 5-97 and 5-98 show the comparison of cost-effectiveness of warranty and control projects based on pavement age and traffic loading, respectively. 
Table 5-72 Medium-Term Cost-effectiveness Evaluation, Comparison Set 5

\begin{tabular}{|l|c|c|c|c|}
\hline \multirow{2}{*}{ Cost-effectiveness } & \multicolumn{2}{|c|}{ Agency Cost only } & \multicolumn{2}{c|}{ Agency Cost + User Cost } \\
\cline { 2 - 5 } & $\begin{array}{c}\text { Warranty } \\
\text { (R-23898) }\end{array}$ & $\begin{array}{c}\text { Control } \\
\text { (R-22923) }\end{array}$ & $\begin{array}{c}\text { Warranty } \\
\text { (R-23898) }\end{array}$ & $\begin{array}{c}\text { Control } \\
\text { (R-22923) }\end{array}$ \\
\hline $\begin{array}{l}\text { Area bounded by the IRI-Age } \\
\text { curve/EUAC (\$1000) }\end{array}$ & 0.95 & 1.00 & 0.93 & 0.97 \\
\hline $\begin{array}{l}\text { Area bounded by the IRI- } \\
\text { ESAL curve/EUAC }\end{array}$ & 3.53 & 4.40 & 3.46 & 4.29 \\
\hline $\begin{array}{l}\text { Area bounded by the PQI- } \\
\text { Age curve/EUAC (\$1000) }\end{array}$ & 0.55 & 0.62 & 0.54 & 0.60 \\
\hline $\begin{array}{l}\text { Area bounded by the PQI- } \\
\text { ESAL curve/EUAC }\end{array}$ & 1.97 & 2.12 & 1.93 & 2.07 \\
\hline
\end{tabular}

Figures 5-97 and 5-98 show the comparison of cost-effectiveness of warranty and control projects based on pavement age and traffic loading, respectively.

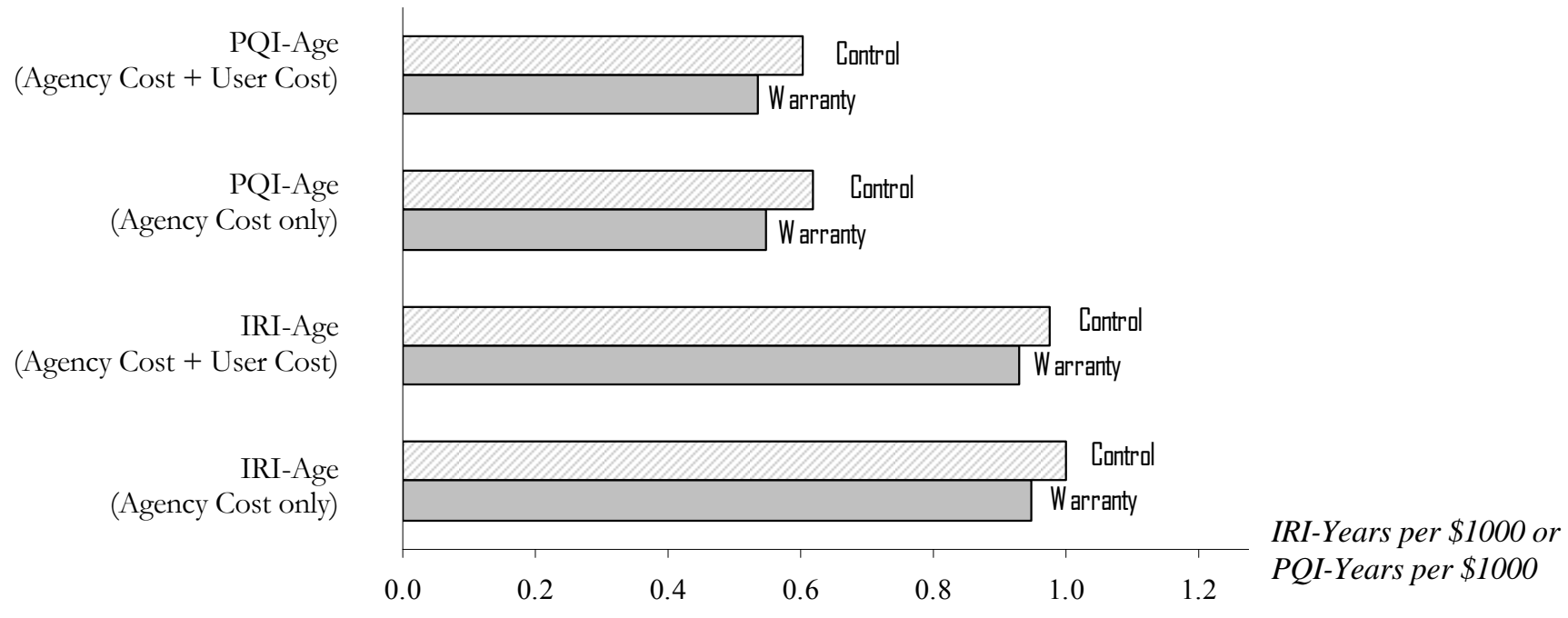

Figure 5-97 Medium-Term Cost-Effectiveness based on Performance and Time, Comparison Set 5 


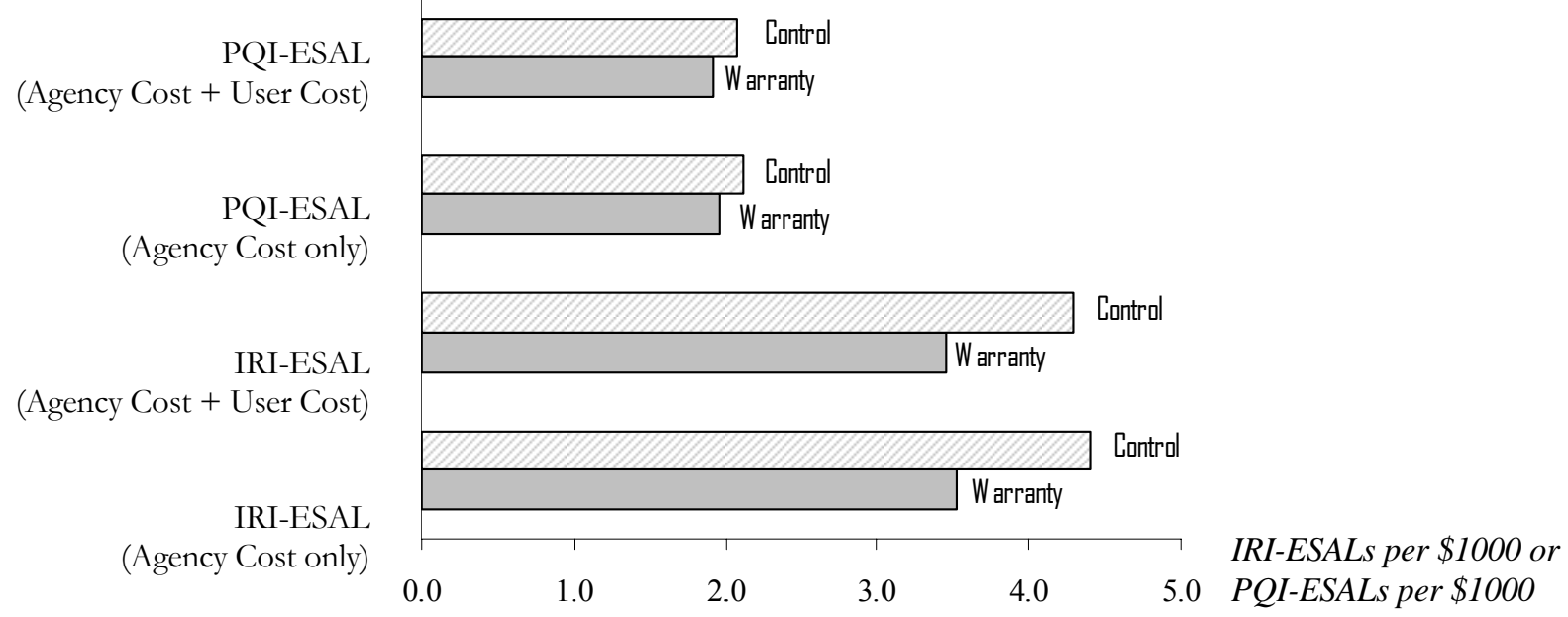

Figure 5-98 Medium-Term Cost-Effectiveness based on Performance and Load, Comparison Set 5

\subsubsection{Long-Term Cost-Effectiveness Evaluation for Comparison Set 5}

The long term evaluation of cost-effectiveness was carried out over the projected treatment life of the pavement. The agency and user costs for the warranty and control projects are shown in Tables 5-73 and 574. The costs are indicated in Year 2000 constant dollar.

Table 5-73 Long-Term Agency Costs, Comparison Set 5

\begin{tabular}{|l|c|c|}
\hline & $\begin{array}{c}\text { Warranty Project 5 } \\
\text { (R-23898) }\end{array}$ & $\begin{array}{c}\text { Control Project 5 } \\
\text { (R-22923) }\end{array}$ \\
\hline Construction Cost/lane-mile & $\$ 836,544$ & $\$ 784,087$ \\
\hline Maintenance Cost/lane-mile & $\$ 7,370^{*}$ & $\$ 8,414$ \\
\hline Total agency cost/lane-mile & $\$ 843,914$ & $\$ 792,501$ \\
\hline EUAC/lane-mile & $\$ 54,021$ & $\$ 71,278$ \\
\hline
\end{tabular}

* Applicable only to warranty pavements after expiration of the warranty period. 
Table 5-74 Long-Term User Costs, Comparison Set 5

\begin{tabular}{|l|c|c|}
\hline & $\begin{array}{c}\text { Warranty Project 5 } \\
\text { (R-23898) }\end{array}$ & $\begin{array}{c}\text { Control Project 5 } \\
\text { (R-22923) }\end{array}$ \\
\hline Work zone duration per lane-mile & 17 days & 19 days \\
\hline Total user cost per lane mile & $\$ 28,681$ & $\$ 32,052$ \\
\hline User EUAC/lane-mile & $\$ 1,836$ & $\$ 2,883$ \\
\hline
\end{tabular}

The agency and user cost of the warranty project were lower than that of the control project. After the agency and the user costs were computed, the overall cost-effectiveness of the pavements was determined. Table 5-75 indicates the overall cost-effectiveness of the warranty and control projects based on agency costs only, and then both agency and user costs.

Table 5-75 Long Term Cost-effectiveness Evaluation, Comparison Set 5

\begin{tabular}{|l|c|c|c|c|}
\hline \multirow{2}{*}{ Cost-effectiveness } & \multicolumn{2}{|c|}{ Agency Cost only } & \multicolumn{2}{c|}{ Agency Cost + User Cost } \\
\cline { 2 - 5 } & $\begin{array}{c}\text { Warranty } \\
\text { (R-23898) }\end{array}$ & $\begin{array}{c}\text { Control } \\
\text { (R-22923) }\end{array}$ & $\begin{array}{c}\text { Warranty } \\
\text { (R-23898) }\end{array}$ & $\begin{array}{c}\text { Control } \\
\text { (R-22923) }\end{array}$ \\
\hline $\begin{array}{l}\text { Average Service life/EUAC } \\
\text { (\$1000) }\end{array}$ & 0.46 & 0.21 & 0.30 & 0.15 \\
\hline $\begin{array}{l}\text { Area bounded by the IRI-Age } \\
\text { curve/EUAC (\$1000) }\end{array}$ & 82.31 & 34.91 & 53.77 & 24.08 \\
\hline $\begin{array}{l}\text { Area bounded by the PQI- } \\
\text { Age curve/EUAC (\$1000) }\end{array}$ & 28.55 & 14.29 & 18.65 & 9.86 \\
\hline
\end{tabular}

Figures 5-99 and 5-100 compare the cost-effectiveness of warranty and control projects based on treatment lives and time (age), respectively. The results of the long-term analysis show that the warranty project has higher values of cost-effectiveness as compared to the control project. Hence, it was more costeffective than the control project. The values of cost-effectiveness of the warranty project were almost twice those of the traditional project. 


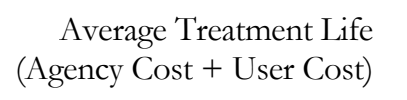

Average Treatment Life

(Agency Cost only)

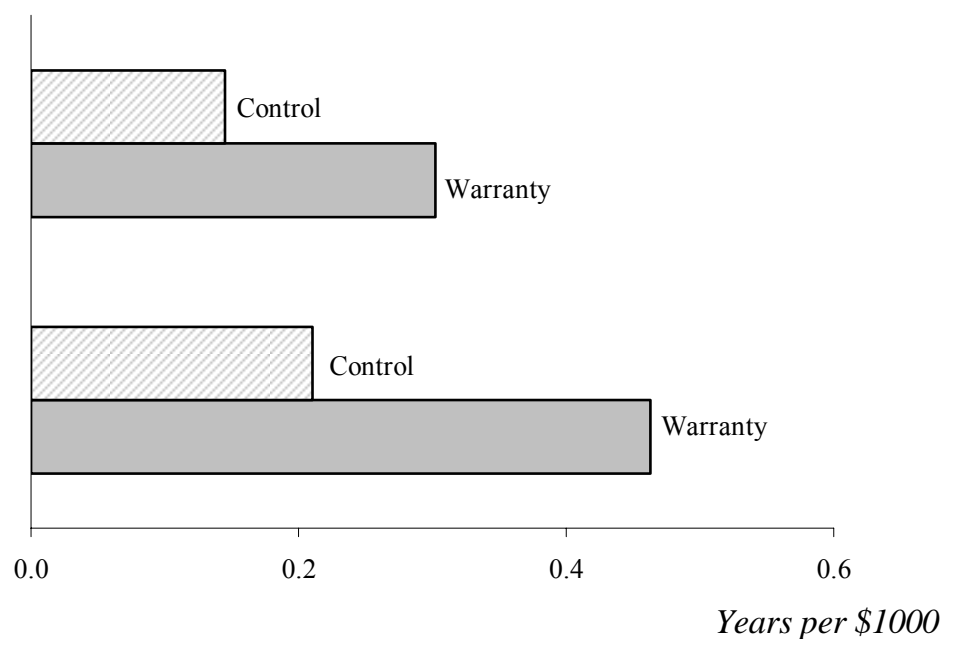

Figure 5-99 Long-Term Cost-Effectiveness based on Treatment Life Only, Comparison Set 5

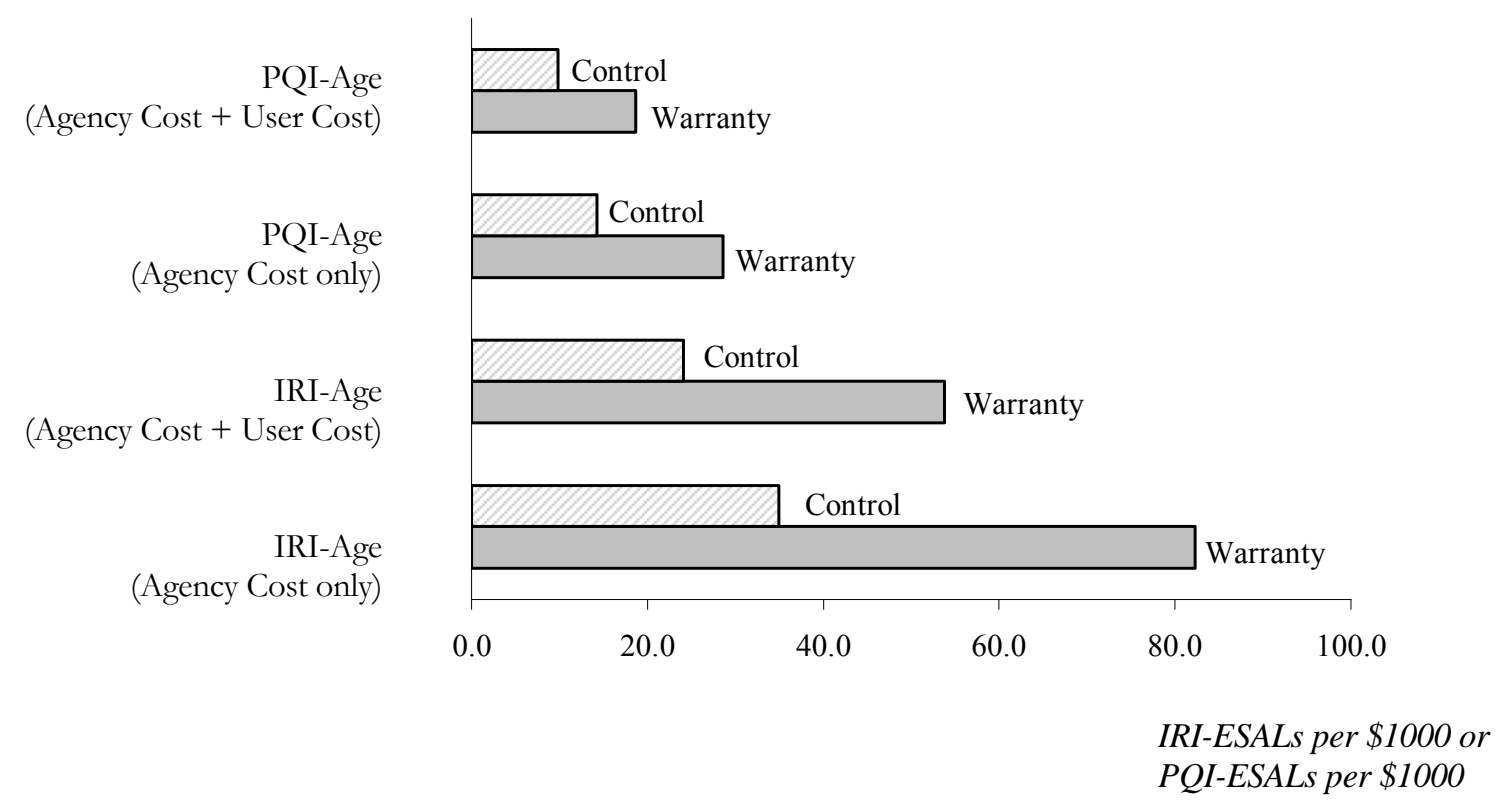

Figure 5-100 Long-Term Cost-Effectiveness based on Performance and Time, Comparison Set 5 


\subsection{Chapter Summary}

This chapter presents results of the comparison of effectiveness, costs, and cost-effectiveness of 5 sets of warranty and traditional projects. The performance of warranty projects in terms of pavement condition during the first five years after construction was found to be superior compared to the control projects. Statistical tests indicated all the warranty pavements had significantly lower IRI values compared to the corresponding control pavements, indicating better pavement performance. The test for rutting depth for Comparison Set 1 indicated that there was no significant difference in the rutting depths in the two pavement types at $80 \%$ level of confidence. On the other hand, there were significant differences in the rut depth of warranty and control projects for Comparison Sets 2 and 3 at 95\% confidence level, while significant differences for Comparison Sets 4 and 5 were evident at $90 \%$ confidence level. On the basis of rutting, four out of the five warranty pavements exhibited better performances than the corresponding traditional pavements. The tests for the PCR values demonstrated that with $95 \%$ confidence the warranty projects 1, 2, and 4 yielded better pavement performances. This can also be said for warranty projects 3 and 5 at levels of confidence $85 \%$ and $90 \%$, respectively.

The initial construction costs of the warranty projects were much higher than those of the corresponding control projects. However, agency maintenance costs for the warranty pavement were zero because the contractor was responsible for the pavement during the warranty period. Furthermore, the user cost during the construction phase was estimated to be much lower for warranty projects than the control projects due to the shorter work zone duration, which can be attributed to the typically included in warranty contracts to reward early project completion. All cost items were computed per lane-mile. However, there is a possibility that economy of scale due to difference in the length of the contract sections particularly for Comparison Sets 3 and 4 may have confounded the results. Based on performance and associated costs, an attempt was made to evaluate the cost-effectiveness of the warranty contracts.

The result of the medium term evaluation (5-year period for which data was available) indicated that the warranty projects are not cost-effective in comparison to the corresponding control (non-warranty) projects. The analysis involving warranty Project R-23898 presented some evidence that the warranty project is more cost-effective in the medium-term. On the other hand, the cost-effectiveness of all the warranty projects was unequivocally evident in the long-term evaluation process which involved not only pavement performance but also agency and user costs over the projected treatment lives. The results of the analysis imply that the potential benefits of warranty projects are more recognizable over a relatively long time period, rather than in the medium-term warranty period. 


\section{CHAPTER 6 AGENCY AND CONTRACTOR SURVEY}

\subsection{Introduction}

This chapter presents a discussion of the survey carried out as a part of the present study. The purpose of the survey was to gather information and gain insight into the current status of warranty provisions in highway contracting in Indiana based on the experiences of Indiana Department of Transportation (INDOT) and the construction industry. The warranty program in the state is at an initial stage. As such, it is important to identify the areas that may require modification to extend the practice of warranties to other work categories. The survey questionnaire was designed to address various aspects of warranty practice from the perspective of various stakeholders. The questionnaire was addressed at INDOT personnel and contractors who were directly involved with the warranty program.

The questionnaire was divided into various parts to gather information on the work description, warranty specifications, testing and quality control, and finally a general assessment of construction warranties. A copy of the questionnaire is provided in Appendix B of this report. The responses from INDOT and the contractors are presented and discussed in separate sections.

\subsection{INDOT Personnel Survey}

The questionnaire was sent to eleven INDOT personnel, and seven replies were received. Thus the response rate was $64 \%$. The responses to each question are herein discussed.

\section{Project Identification}

The first part of the questionnaire requested the respondent to identify the warranty contracts in which they had participated and to describe the warranty issues associated with the project.

\section{Location}

Five out of the seven respondents identified the warranty projects in terms of the contract. Two respondents provided exact locations of the contract section. The other two personnel indicated that they did not participate directly in any particular warranty project, but were involved in the development of the specifications for all contracts under the INDOT Pavement Warranty program. 


\section{Work Description}

All respondents provided a description of the warranty work and indicated that the use of warranty clauses was appropriate for the specific project. Indiana's warranty program extends over several different projects types, including pavement marking, PCCP and hot mix asphalt (HMA) overlays, and full-depth HMA pavements. The projects identified were performance-based warranties.

\section{Warranty Specifications}

The respondents stressed the importance for the highway agency to develop appropriate warranty specifications to address all issues that would ensure successful implementation and prevent conflicts with the contractor.

\section{Adequacy of Warranty Specifications}

The responses suggested that the specifications of the warranty provisions were adequate and welldefined for the warranty period ( 5 years). The requirements and performance criteria were clearly stated in the contract document. One respondent pointed out discrepancies in the special provisions related to the payment of some types of "contraction” joints and concrete coring procedures.

\section{Modifications}

The respondents were asked to indicate any area in the warranty specifications that required modification or clarification. None of the INDOT personnel provided a response.

\section{Problems}

Two of the seven respondents highlighted certain problems or issues related with the warranty specifications with respect to the project they were involved with. One of them pointed out that there was no method of corrective action for thin pavement prescribed in the special provisions. The other issue pertained to the pavement subbase: the respondent pointed out that if the contractor can show that any pavement failure is due to the failure of the subbase or underdrain, the warranty becomes void. This situation was perceived by the respondent as a potential problem.

\section{Quality Control (QC) and Quality Assurance (QA)}

The respondents indicated that as part of the warranty procedure, a contractor is required to prepare a Quality Control (QC) plan for each warranty item and submit such plan to INDOT. The QC plan must cover all aspects of production method, equipment and materials, and maintenance activities to be 
undertaken during the warranty period. It should address details of proposed methods of quality control, sampling, testing, and calibration.

\section{Contractor Requirements}

The contractor is required to provide all test results to INDOT after construction. Most respondents indicated that in the past, contractors had followed warranty specifications, although a few minor problems related to paving had been encountered. There have been two instances related to inadequate surface friction of the completed warranty pavement.

\section{Remedial Action}

If the contractor does not meet the requirements and performance criteria, the contractor is required to undertake remedial work specified in the warranty provisions. The questionnaire survey helped identify the appropriate remedial action to be taken by the contractor to address any problem areas. In all cases, the contractor performed the necessary work in a satisfactory manner within the specified time frame.

\section{Quality Control Inspection}

The questionnaire was designed to identify any differences in QC/QA of materials in a warranty and traditional contract. Unlike the case of traditional contracts, INDOT is not required to perform any testing of the work items in a warranty contract. The respondents indicated that in warranty contracts, the contractor paid greater attention to the performance of the warranty item with minimal supervision. INDOT does not require any QC on warranty contracts.

\section{Contractor Innovation}

For warranty contracts, INDOT is interested in the performance of the end product and not so much on the production process. This provides freedom for the contractors in the use of materials and construction methods. The responses to the survey indicated that warranty projects, unlike traditional projects are characterized by contractor innovation. There were instances when the contractor followed special construction joint procedures and used various binder types to address the issue of joint raveling under traffic. One respondent also mentioned improvement in the job mix due to contractor innovation.

\section{Conflicts}

A Conflict Resolution Team (CRT) is formed to solve all disputes between INDOT and the contractor in case of warranty contracts. The CRT consists of two INDOT representatives, two contractor representatives, and a member mutually agreed by INDOT and the contractor. None of the responses indicated any previous occurrence of conflict between INDOT and the contractor. 


\section{Overall Judgment}

All the respondents were of the opinion that the warranty concept was effective in ensuring a quality end product. In warranty projects, there is a shift in responsibilities from INDOT to the contractor with respect to maintenance and inspection, and as such there is reduced staffing requirement on the part of INDOT.

\section{Performance}

The responses to the questionnaire indicated that the performance of the warranty projects was generally perceived as superior to traditional projects. In most cases, the contractor placed greater emphasis on quality, and worked to produce a better finished product at the first place, rather than making repairs during the warranty period.

\section{Advantages of Warranty Contracts}

Several advantages associated with the warranty contracts were identified based on the experiences of the INDOT personnel. The respondent indicated that warranty pavements definitely result in superior quality of the end product, fewer agency personnel are required for field testing and inspection, and maintenance responsibility of INDOT is greatly reduced. One respondent also indicated that warranty projects are associated with shorter construction times.

\section{Disadvantages of Warranty Contracts}

The survey also highlighted concerns about the higher costs of warranty contracts and longer warranty periods. Most respondents opined that the pavement warranty period of 5 years was short and therefore recommended periods ranging from 10 to 15 years. One respondent also raised the issue of lack of agency control over materials used in construction.

\section{Screening Process}

The final part of the questionnaire survey was to throw more light on the need for a screening process to ensure that appropriate projects are chosen for warranties. The responses suggested that it was imperative that warranty projects should be devoid of conditions that could lead to premature failure of pavements resulting from subbase failure. Another respondent pointed out the need for proper screening of contractors during the bidding process to ensure that conscientious contractors are awarded warranty contracts. 


\subsection{Results of the Contractor Survey}

The questionnaire was sent to seven contractors. Four responses were received. Their responses are hereby presented and discussed.

\section{Project Identification}

The questionnaire requested the respondent to identify the warranty projects in which they had been (or were) involved and provide answers based on such projects.

\section{Location}

Three out of the four respondents provided exact referencing information for the warranty. The fourth respondent indicated no direct involvement in a warranty project, but involvement in estimation of bid amounts for two projects that had warranty provisions.

\section{Work Description}

The responses to the description of the work done were mentioned by all respondents. The type of warranty work included HMA mainline pavement, full-depth HMA overlay with rubblization, and erosion control and seeding.

\section{Warranty Specifications}

The contractors presented their view point on warranty specifications with respect to the work done.

\section{Adequacy of Warranty Specifications}

The respondents indicate that for some project types, specifications were poor defined, citing erosion control and seeding projects as an example. As such, the respondents suggested that certain project types were not appropriate for warranty. The contractor also mentioned that in some cases, further clarifications to warranty clauses were desired. According to respondents, the specifications for HMA projects were well-defined, based on measurable parameters for evaluation. However, a respondent indicated that the warranty period for asphalt pavements was too long.

\section{Problems}

The contractors also brought up some of the challenges and problems they faced during the course of warranty work. According to the respondents, the greatest challenge was that the contractors had no prior experience with warranties and were unsure about what additional cost would be incurred for better performance to minimize the risk of a five-year warranty. In their opinion, educating the project staff on the requisite specifications was also a mammoth task. Another issue was the difficulty of convincing 
sub-contractors that the warranty work was solely their responsibility. As such, the general contractor for the warranty had to be responsible for the work done by the sub-contractor.

\section{Surety Bond}

For warranty contracts, the contractor is required to provide a warranty bond for five years along with the performance bond. INDOT requires a surety for the warranty, which is reflective of the amount needed to replace the surface course if found necessary. None of the responding contractors stated that they had faced difficulty in securing the bond.

\section{Quality Control and Quality Assurance}

The quality control (QC) methods adopted for the warranty item are defined in the contractor's QC plan. No discrepancies were identified during INDOT’s Independent Assurance Testing (IAT). The warranty testing and control procedure was generally perceived by respondents as being more rigorous compared to that for traditional projects. However, one respondent indicated that there was little difference between the two. One respondent indicated that in a previous project, some remedial action to ensure quality included treatment of centerline joint with special sealant. This had been done to meet the performance criteria established by INDOT.

\section{Contractor Innovation}

The responding contractors indicated that there was little scope for contractor innovation as INDOT specifications had to be followed. This is in sharp contrast to the responses from INDOT personnel.

\section{Overall Judgment}

\section{Advantages of Warranty Contracts}

The responding contractors perceived warranties as a way of addressing quality control and where they have complete control of the entire construction process. In their opinion, this ensures proper utilization of materials and equipment which results in a better quality product.

\section{Disadvantages of Warranty Contracts}

The responding contractors indicated certain issues associated with the warranty program. From their responses, it is seen that the main cause of concern is that the presence of various extenuating sire conditions that could lead to pavement failure, and they are apprehensive that they could unfairly held responsible for such failures. A way to address this issue is to allow the contractor to design all pavement sections including subbase, or to involve the contractor in preliminary engineering studies that ascertain the integrity of the underlying layers. Warranties may also decrease competition among contractors. The 
respondents expressed concern that excessive use of warranties could lead to greater risk and extended liability for the contractors.

\subsection{Chapter Summary}

The questionnaire was designed to solicit opinions and perceptions of experts at the state agency and the construction industry who had experience in the use of construction warranties. The perceptions of the respondents provided better understanding of warranty practice in Indiana and highlighted the benefits and possible limitations associated with the use of warranties. The responses to the survey also indicated several issues and concerns which need to be addressed for successful implementation of warranties in Indiana in the future. Based on the survey, it is evident that warranties are perceived to yield superior quality end products. The INDOT personnel indicated some instances of contractor innovation and greater construction speed. In most cases, warranty specifications were perceived to be adequate, and the contractors were seen to place greater emphasis on quality control on warranty projects compared to traditional projects. The survey showed that both agency and contractors share the same concerns relating to premature pavement failure resulting from subbase or subgrade problems. The agency and contractor seem to differ on the length of pavement warranties: the agency personnel perceive the current warranty periods as being too short, while the contractors perceive that it is too long. The questionnaire survey also showed that both agency and contractor perceive the need for great care in selecting projects for warranties, as all types of work may not be appropriate for warranty specifications. At the time of reporting, there were indications that INDOT is forming a committee to ensure an effective screening process for warranty projects. 


\section{CHAPTER 7 SUMMARY, CONCLUSIONS AND RECOMMENDATIONS}

This chapter summarizes the results of the analyses carried out for evaluation of cost-effectiveness of warranty contracts in Indiana, and also provides recommendation for future research.

\subsection{Summary of the Methodology}

The study was based on a comparative analysis of warranty contracts and similar traditional contracts to determine the relative costs, effectiveness and cost-effectiveness of the two contracting systems in the medium-term and long-term. For each warranty project, the selected control (traditional) project for comparison had similar work, surface type, functional class, to provide a rational basis for comparison. For the purposes of the study, "effectiveness" was defined in terms of pavement performance measured in terms of IRI, PSI, rutting, and PCR. The cost analysis involved computation of agency and user costs for the warranty and traditional projects.

Statistical analyses were carried out to obtain a rational basis for evaluating the effectiveness of the warranty and traditional contracts, and subsequently to determine if the use of warranty contracts leads to significant improvement in pavement quality. Specifically, tests of statistical significance were carried out for various performance indicators - IRI, PSI, rutting, and PCR - to determine if warranty pavements exhibited significantly different pavement performance. The cost-effectiveness analysis was carried in both medium and long term. The medium-term analysis was based on the 5-year warranty period. Effectiveness was measured in two alternative ways: as the average pavement condition after treatment, and as the area under the performance curves. Effectiveness was then weighed vis-à-vis project costs (agency and user) to estimate the overall cost-effectiveness. The long-term cost-effectiveness evaluation was carried out on the basis of the projected treatment life. Service lives were estimated from the performance models based on the pavement condition during the warranty period and established thresholds. In this case, effectiveness was measured in terms of the average service life and area under the performance curves. The summary of results are herewith presented for each comparison pair. 


\subsection{Summary of Results for Each Comparison Pair}

\section{Comparison Pair 1}

On the basis of pavement condition only, the comparative analysis of the warranty and traditional projects in comparison pair 1 indicates that warranty pavement exhibited better performance. This was determined on the basis of IRI and PCR performance indicators. No significant difference was found in the case of pavement rutting. On the basis of costs, the warranty project had a higher construction cost (per lane-mile per inch) but lower user cost compared to the traditional project. In the medium term, the warranty project is $30 \%$ less cost-effective than the traditional project when only agency cost is considered in the analysis, and is $27 \%$ less cost-effective than the traditional project when both agency and user costs are considered in the analysis. In the long-term, however, the results were different: on the basis of service life, the warranty project is 39\% more cost-effective than the traditional project when only agency cost is considered in the analysis, and is $56 \%$ more cost-effective than the traditional project when both agency and user costs are considered in the analysis. On the basis of area under the curve (which reflects long-term effectiveness in terms of both service life and pavement condition), the warranty project is $29 \%$ more cost-effective than the traditional project when only agency cost is considered in the analysis, and is $48 \%$ more cost-effective than the traditional project when both agency and user costs are considered in the analysis.

\section{Comparison Pair 2}

The analysis for comparison pair 2 indicated that on the basis of performance only, the warranty project pavement exhibited better pavement performance in terms of all three performance indicators (IRI, rutting, and PCR). On the basis of cost only, the warranty project was also found to have lower user cost but had higher initial agency costs compared to the traditional project. In the medium term, it was found that the warranty project is $46 \%$ less cost-effective when only agency cost is considered and $42 \%$ less cost effective when both agency and user costs are considered. On the basis of service life, the warranty project was found to be $17 \%$ more cost-effective when only agency cost is considered in the analysis, and is $33 \%$ more cost-effective when both agency and user costs are considered. On the basis of area under the curve (which represents both service life and pavement condition benefits), the warranty project is $17 \%$ more cost-effective than the traditional project when only agency cost is considered in the analysis, and is $33 \%$ more cost-effective than the traditional project when both agency and user costs are considered. 


\section{Comparison Pair 3}

For comparison pair 3, it was seen that the warranty pavement exhibited better pavement performance in terms of all three performance indicators. The agency costs of the warranty pavement was higher than that of the control pavement, but had lower user costs. The medium-term analysis showed that the warranty project, compared with its traditional counterpart, is $21 \%$ less cost-effective when only agency cost was considered and 15\% less cost-effective when both agency and user costs were considered. For long-term evaluation involving service life as a measure of effectiveness, the warranty project was found to exhibit $75 \%$ higher cost-effectiveness when only agency cost was considered in the analysis, and $87 \%$ higher cost-effectiveness when both agency and user costs were considered. For long-term evaluation involving the area bounded by the performance curve, it was found that the warranty project is $41 \%$ more cost-effective than the traditional project when only agency cost is considered in the analysis, and is $50 \%$ more cost-effective when both agency and user costs are considered.

\section{Comparison Pair 4}

It was determined that the warranty pavement in comparison set 4 exhibited superior pavement performance in terms of all three performance indicators, compared to its traditional counterpart. The user cost of the warranty pavement was also found to be lower than that of the traditional project. However, on the basis of agency costs, the warranty project had a higher cost. In the medium term, the warranty project exhibited 39\% less cost-effectiveness when only agency cost was considered and 35\% less cost-effectiveness when both agency and user costs were considered. On the basis of long-term evaluation expressed in terms of service life, the warranty project was found to be $96 \%$ more costeffective when only agency cost is considered in the analysis, and is $163 \%$ more cost-effective when both agency and user costs are considered. On the basis of long-term effectiveness expressed in terms of area bounded by the curve, it was determined that the warranty project is only $10 \%$ more cost-effective than the traditional project when only agency cost is considered in the analysis, and is $2 \%$ more costeffective when both agency and user costs are considered.

\section{Comparison Pair 5}

In the medium term, the warranty project was found to be $5 \%$ less cost-effective when only agency cost was considered and 4\% less cost-effective when both agency and user costs were considered. On the basis of service life, the warranty project exhibited $119 \%$ higher cost-effectiveness when only agency cost is considered in the analysis, and is $100 \%$ higher cost-effectiveness when both agency and user costs are considered. In long-term evaluation involving effectiveness measured in terms of the area bounded by the performance curve, the warranty project was found to be $136 \%$ more cost- 
effective than the traditional project when only agency cost is considered in the analysis, and $123 \%$ more cost-effective than the traditional project when both agency and user costs are considered.

\subsection{Summary for All Comparison Sets and Discussion}

Performance:

The performance of warranty projects in terms of pavement condition during the first five years after construction was found to be superior compared to the control projects, as statistical tests indicated that all the warranty pavements had significantly lower IRI values compared to their traditional counterparts. The test involving rutting for Comparison Pair 1 indicated that there was no significant difference in the rutting depths across the two pavements even at $80 \%$ level of confidence. On the other hand, there were significant differences in the rut depth of warranty and control projects for comparison pairs 2 and 3 at 95\% confidence level, and significant differences for comparison pairs 4 and 5 were evident only at 90\% confidence level. Specifically, four out of the five warranty pavements exhibited higher rutting performance compared to their traditional counterparts. The tests for the PCR values demonstrated that at $95 \%$ confidence the warranty projects 1,2 , and 4 yielded better pavement performances. Similar findings were obtained for warranty projects in comparison pairs 3 and 5 at levels of confidence 85\% and $90 \%$, respectively.

For each of the two pavements in each comparison pair, trend lines were fitted and extrapolated to yield pavement condition immediately after construction (age 0), as evidenced in Figure 2. It was seen that the warranty pavements show much higher initial pavement performance (lower IRI and higher PCR values) compared to the traditional pavement. It has been determined from past research that initial smoothness is often a reliable predictor of subsequent pavement life (Smith et al., 1997); this may explain for the relatively superior subsequent pavement performance and greater service life (projected) subsequently exhibited by the warranty pavements compared to their traditional counterparts.

\section{Costs}

The initial construction costs of the warranty projects were much higher than those of the corresponding control projects. However, agency maintenance costs for the warranty pavement were relatively little because the contractor is responsible for the pavement upkeep during the warranty period. Furthermore, the user cost during the construction phase was estimated to be much lower for warranty projects than the control projects due to the shorter contract duration and work-zone duration which, in turn, could be attributed to incentives typically included in warranty contracts to reward early project completion. 
Table 7-1 Summary of Medium-Term Cost-effectiveness Evaluation

\begin{tabular}{|l|c|c|c|c|c|}
\hline & \multicolumn{1}{|c|}{$\begin{array}{c}\text { Measure of } \\
\text { Medium-term Cost-effectiveness }\end{array}$} & \multicolumn{2}{c|}{ Agency Cost only } & \multicolumn{2}{c|}{ Agency Cost + User Cost } \\
\cline { 3 - 6 } & Warranty & Traditional & Warranty & Traditional \\
\hline $\begin{array}{l}\text { Comparison Pair 1 } \\
\text { Warranty (R-22232) } \\
\text { Control (R-21607) }\end{array}$ & Area bounded by the IRI-Age curve/EUAC & 2.67 & 4.41 & 2.62 & 4.22 \\
\hline $\begin{array}{l}\text { Comparison Pair 2 } \\
\text { Warranty (R-22854) } \\
\text { Control (R-21602) }\end{array}$ & Area bounded by the IRI-Age curve/EUAC & 8.10 & 15.02 & 7.67 & 13.25 \\
\hline $\begin{array}{l}\text { Comparison Pair 3 } \\
\text { Warranty (R-22925) } \\
\text { Control (R-22912) }\end{array}$ & Area bounded by the IRI-Age curve/EUAC & 29.61 & 37.59 & 26.73 & 31.42 \\
\hline $\begin{array}{l}\text { Comparison Pair 4 } \\
\text { Warranty (R-23390) } \\
\text { Control (R-21607) }\end{array}$ & Area bounded by the IRI-Age curve/EUAC & 3.51 & 5.71 & 3.47 & 5.34 \\
\hline $\begin{array}{l}\text { Comparison Pair 5 } \\
\text { Warranty (R-23898) } \\
\text { Control (R-22923) }\end{array}$ & Area bounded by the IRI-Age curve/EUAC & 0.95 & 1.00 & 0.93 & 0.97 \\
\hline
\end{tabular}

Areas are expressed in units of IRI-years/\$1000, per lane-mile

Table 7-2 Summary of Long-Term Cost-effectiveness Evaluation

\begin{tabular}{|c|c|c|c|c|c|}
\hline & \multirow{2}{*}{$\begin{array}{c}\text { Measure of Long-term } \\
\text { Cost-effectiveness }\end{array}$} & \multicolumn{2}{|c|}{ Agency Cost only } & \multicolumn{2}{|c|}{ Agency Cost + User Cost } \\
\hline & & Warranty & Traditional & Warranty & Traditional \\
\hline $\begin{array}{l}\text { Comparison Pair } 1 \\
\text { Warranty (R-22232) }\end{array}$ & $\begin{array}{l}\text { Average Service life/EUAC } \\
\text { (Years per } \$ 1000 \text { ) }\end{array}$ & 0.43 & 0.31 & 0.28 & 0.18 \\
\hline Control (R-216027) & $\begin{array}{l}\text { Area bounded by the IRI-Age curve/EUAC } \\
\text { (IRI-Years per } \$ 1000 \text { ) }\end{array}$ & 48.78 & 37.87 & 31.99 & 21.63 \\
\hline $\begin{array}{l}\text { Comparison Pair } 2 \\
\text { Warranty (R-22854) }\end{array}$ & $\begin{array}{l}\text { Average Service life/EUAC } \\
\text { (Years per } \$ 1000 \text { ) }\end{array}$ & 0.54 & 0.46 & 0.40 & 0.30 \\
\hline Control (R-21602) & $\begin{array}{l}\text { Area bounded by the IRI-Age curve/EUAC } \\
\text { (IRI-Years per } \$ 1000 \text { ) }\end{array}$ & 84.62 & 48.64 & 62.88 & 31.84 \\
\hline $\begin{array}{l}\text { Comparison Pair } 3 \\
\text { Warranty (R-22925) }\end{array}$ & $\begin{array}{l}\text { Average Service life/EUAC } \\
\text { (Years per } \$ 1000 \text { ) }\end{array}$ & 0.91 & 0.52 & 0.71 & 0.38 \\
\hline Control (R-22912) & $\begin{array}{l}\text { Area bounded by the IRI-Age curve/EUAC } \\
\text { (IRI-Years per } \$ 1000 \text { ) }\end{array}$ & 94.52 & 67.00 & 74.23 & 49.38 \\
\hline $\begin{array}{l}\text { Comparison Pair } 4 \\
\text { Warranty (R-23390) }\end{array}$ & $\begin{array}{l}\text { Average Service life/EUAC } \\
\text { (Years per } \$ 1000 \text { ) }\end{array}$ & 0.98 & 0.50 & 0.79 & 0.30 \\
\hline Control (R-21607) & $\begin{array}{l}\text { Area bounded by the IRI-Age curve/EUAC } \\
\text { (IRI-Years per } \$ 1000 \text { ) }\end{array}$ & 51.27 & 46.65 & 41.42 & 40.73 \\
\hline \multirow{2}{*}{$\begin{array}{l}\text { Comparison Pair } 5 \\
\text { Warranty (R-23898) } \\
\text { Control (R-22923) }\end{array}$} & $\begin{array}{l}\text { Average Service life/EUAC } \\
\text { (Years per } \$ 1000 \text { ) }\end{array}$ & 0.46 & 0.21 & 0.30 & 0.15 \\
\hline & $\begin{array}{l}\text { Area bounded by the IRI-Age curve/EUAC } \\
\text { (IRI-Years per } \$ 1000 \text { ) }\end{array}$ & 82.31 & 34.91 & 53.77 & 24.08 \\
\hline
\end{tabular}

\section{Cost-effectiveness}

It was seen that when the comparative analysis is carried out over a relatively short period of 5-years, the warranty pavement contracts are, on the average, $27-30 \%$ less cost-effective than their traditional counterparts. However, when the comparative analysis is carried out over the long term (treatment service life), the warranty contracts are found to be, on the average, approximately 70 to $90 \%$ more costeffective on the basis of service life, and 58 to $65 \%$ more cost-effective on the basis of both service life and pavement condition. 
The study results suggest that the superiority of warranty projects over traditional projects is more discernible when both cost and effectiveness are viewed over the entire life of the pavement treatment rather than the short-term. Also, the superior long-term cost-effectiveness of warranty projects is more manifest when both agency and user cost are used in the analysis rather when only agency cost is used.

\subsection{Results of the Questionnaire Survey}

A survey was also conducted as a part of the study to get an insight into agency and industry perspectives on the use of warranties in highway construction. The responses to the questionnaire highlighted a number of benefits and concerns shared by the agency personnel and the contractors. Besides indicating superior performance of warranty pavements, the agency respondents indicated that warranty projects were associated with lower levels of agency resources for testing and inspection, and reduced construction time. Also, the responding contractors perceived a number of benefits associated with the warranty provisions: it offered them complete control of the entire construction process, resulting in more effective utilization of materials and equipment to produce a better quality product.

Certain concerns which should be taken into account for successful implementation of warranties were also voiced. The agency personnel were of the opinion that the warranty period of 5 years was not enough to a guarantee a pavement that could last for 10 to 15 years. Some respondents also felt that the reduced agency control over materials and processes was not a very good idea. On the other hand, the main cause of concern for the responding contractors was that various unforeseen site conditions could lead to pavement failure, and the respondents indicated the need for their absolution from any responsibility in such cases. Also, there was some apprehension among responding contractors that warranties could decrease competition among contractors, as smaller firms could likely be eliminated from the bidding process due to the requirement of the warranty bond.

\subsection{Limitations}

The main limitation of the study was the small data set. There were only a limited number of warranty contracts available for examination, and as such the results of the analysis may not be a true representation of all warranty contracts. The maintenance requirements of the warranty pavements after the end of the warranty period were considered to be the same as traditional projects. This may not necessarily be the case, given the fact the warranty projects indicated better pavement performance, and may require lesser post-warranty maintenance work as compared to similar traditional projects of the same age. Further data collection and research may be necessary to throw more light on this issue. At this point, it is also not known what rehabilitation strategies would be undertaken once the warranty pavement reaches terminal serviceability. Another limitation of the study was the inability to include 
friction data as a performance indicator for the comparative analysis. Currently, project level friction data is collected annually on warranty projects employing a special protocol for that purpose (warranty protocol), while inventory (network level) friction data is collected employing a different protocol (inventory protocol). Due to differences in data formats arising from these different testing protocols, it was not possible to carry out the comparison of warranty and traditional projects using friction as a performance indicator.

\subsection{Implementation Issues and Recommendations for Future Work}

The results of this study may influence future decision criteria for selecting warranty projects and may also influence the selection of criteria for post-implementation evaluation of warranty projects and innovative contracting systems in general. The study shows that evaluation criteria that can affect the evaluation outcome include the temporal scope of the analysis (medium-term vs. long-term) and measure of effectiveness (service life vs. average pavement condition vs. both). Other important analytical aspects such as the cost types considered in the analysis (agency costs only versus both agency and user cost) can affect the outcome of the comparative analysis between the two alternative contracting systems.. As with any LCCA-based analysis, the discount rate could also affect the outcome of the comparison process. These considerations confirm (or could supplement) general guidelines and considerations that have been discussed in previous research (Shober et al., 1996; Anderson and Russell, 2001; FHWA, 2002a; FHWA, 2002b; Thompson et al., 2002; Hastak et al. 2003).

As more and more warranty projects reach their warranty expiration dates, a plethora of data is expected to become available to enable more insightful investigations of the costs and effectiveness of warranty projects. Future research in this area could examine the cost-effectiveness of warranty projects on the basis of accumulated traffic loading expressed in terms of load spectra rather than ESALs. The surveys carried out in the present study showed that the current 5-year warranty period is perceived by the Owners (agency engineers) as being too short but is seen as being too long by the Contractors. As such, further research could be carried out to identify the pareto optimal warranty period for each contract type and facility type, such that all parties to the warranty process would achieve maximum possible benefit at minimal overall cost. Finally, future studies may examine the impacts of uncertainty of the input variables such as discount rate and pavement service life. Such probabilistic analysis may throw more light on the sensitivity of the choice of the best contracting system with respect to various evaluation factors and criteria, for any given contract type and facility type.

In the present study, estimation of the long-term effectiveness (service life) of warranty and traditional contracts was done using extrapolation of pavement condition data that span a relatively short period of time. This is because Indiana warranty practice started only fairly recently. As actual long-term pavement condition data becomes available, future research could be based on such as well as field- 
measured data maintenance and rehabilitation costs and effectiveness, so that warranty cost-effectiveness may be more reliably assessed not only over the warranty period or even treatment life, but also over entire pavement life.

The issue of quality assurance could be addressed in effectiveness analysis in future research. Specifically, it would be useful to include the extent to which material quality specifications are being achieved or how far they deviate from the standards. Such specifications include particle size distribution envelopes for various pavement surface and base mixes, minimum degree of compaction, and other tests on material ingredients as well as finished or laid mixes. Furthermore, the additional cost of materials used in warranty projects that surpass the standard material specifications could be documented and considered in future research. A future study could also provide a definitive value to the long-term overall costs saved by INDOT due to the increased service life of warranty pavements from 15 to 25 years.

Other future work could include evaluation of other project types such as warranty concrete pavements and erosion control projects. Currently, relatively little data are available for such projects. Another recommendation pertains to the use of friction data as a performance indicator for comparing warranty and traditional projects. It is recommended that a unified protocol be adopted for collection of friction data at both network and project levels. If this is done, future cost-effectiveness comparison analyses could be extended to include friction as a performance indicator.

A survey of surety companies could also be carried out to get their perspective on the practice of warranties and to address the concerns associated with securing bonds for warranties, particularly for smaller construction firms who are obviously at a disadvantage in the bidding process for warranty projects. It is also important to understand that work in the absence of warranty, the contractors may perform work of no less quality. In fact, it has been argued that under the traditional contracting system, stronger enforcement of existing specifications could yield better pavements at lower cost.

In analyzing the benefits associated with warranties, it is essential to understand the consequences of failure of the contractor to undertake remedial action. In such cases, the state or local agency may have to perform the required work at their expense. This could further increase the cost of the contract, even when the warranty performance bond is forfeited. Furthermore, the expected workzone user costs associated with pavement replacement or other remedial works in cases of warranty violation needs to be considered in the overall analysis.

While there is evidence that warranties yield superior quality of pavements, it would be appropriate take due cognizance of other factors (besides extended contractor responsibility) that may also be partly responsible for superior warranty performance such as higher standards of design and performance. Future studies could investigate this issue in greater detail.

Finally, the move to the use of warranties was initiated in an attempt to provide road users with better levels of service, to address staffing problems in the state agencies, and to reduce the costs of 
agency maintenance. As such, the projects for warranty should be selected with great care, as all types of work may not be appropriate for warranty specifications. As is the case for all innovative contracting and procurement techniques, the concerns of all the participants in the highway construction industry need to be solicited and addressed, to enhance effective implementation of warranties in highway contracting practice. 


\section{REFERENCES}

American Association of State Highway and Transportation Officials (AASHTO), Report on the 1990 European Asphalt Study Tour, Washington, D.C., (1991).

American Association of State Highway Officials, "Primer on Contracting for the Twenty-first Century", A Report of the Contract Administration Task Force of the AASHTO Subcommittee on Construction, Washington, D.C., (2001).

AI-Omari, B., and Darter, M., "Relationships between International Roughness Index and Present Serviceability Rating, Transportation Research Record 1435, Transportation Research Board, National Research Council, Washington, D.C. (1994).

Anderson, S. D., and Russell, J. R., "Guidelines for Warranty, Multi-Parameter, and Best Value Contracting,” NCHRP Report 451, (2001).

Aschenbrener, T.B., and DeDios, R.E., Materials and Workmanship Warranties for Hot Bituminous Pavement, Report No. CDOT-DTD-2001-18, Cost-Benefit Evaluation Committee, Colorado Department of Transportation, (2001).

Cox, D.O., Molennar, K.R., Ernzen, J.J., Henk, G., Matthews, T.C., Smith, N., Levy, A., Williams, R.C., Gee, F., Kolb, J., Sanderson, L., Whited, G.C., Wight, J.W., and, Yakowenko, G., Contract Administration: Technology and Practice in Europe , Report No. FHWA-PL-03-002, Office of International Programs, Federal Highway Administration, US Department of Transportation, Washington D.C., (2002).

DeStazio, T.D., Does This Road have a Warranty?” The Asphalt Contractor, Cygnus Business Media, WI, (1999a).

DeStazio, T.D., Get a Guarantee for Your Guarantee The Asphalt Contractor, Cygnus Business Media, WI, (1999b).

Federal Highway Administration (FHWA). (2002a). "Summary of Pavement Warranty Activities in WRC Area (Western US),” Program Administration, US Dept. of Transportation, Washington, D.C.

Federal Highway Administration (FHWA). (2002b). "Summary of Pavement Warranty Activities in MRC Area”, Program Administration, US Department of Transportation, Washington, D.C.

Federal Highway Administration, “European Asphalt Pavement Warranties Scanning Tour” Executive Summary, (2002b).

Federal Highway Administration (FHWA), Federal-Aid Policy Guide, US Department of Transportation, Washington D.C., (1995).

Federal Highway Administration (FHWA), Highway Statistics 1993-1999, US Department of Transportation, Washington, D.C., (1993-1999).

Federal Highway Administration (FHWA), Indiana Asphalt Pavement Project as Easy as ABC, FOCUS, US Department of Transportation, Washington, D.C., (1996).

Federal Highway Administration (FHWA), Pavement Warranties: Learning from the European Experience, FOCUS, US Department of Transportation, Washington, D.C., (2003a). 
Federal Highway Administration (FHWA), Pavement Warranties Yield Innovation, Quality, FOCUS, US Department of Transportation, Washington, D.C., (2003b).

Federal Highway Administration (FHWA), "Summary of Pavement Warranty Activities in WRC Area (western US),” Program Administration, US Department of Transportation, Washington, D.C., (2002).

Federal Highway Administration (FHWA), "Summary of Pavement Warranty Activities in MRC Area”, Program Administration, US Department of Transportation, Washington, D.C., (2002).

Gallivan, V. L., Huber, G. R., and Flora, W. F., Benefits of Warranties to Indiana, Presented in $83^{\text {rd }}$ Annual Meeting of Transportation Research Board, Washington, D.C., (2004).

Gannon, E. J., Weyers, R. E., and Cady, P. D. (1995). Cost Relationships for Concrete Bridge Protection, Repair, and Rehabilitation. Transportation Research Record 1490. Transportation Research Board, Washington D.C.

Gulen, S., Nagle, J., Weaver, J., and Gallivan, V., Determination of Practical ESALs per Truck Values on Indiana Roads, JTRP Report No. FHWA/IN/JTRP-2000/23, INDOT Division of Research, Indiana (2000).

Hancher, D.E., Contracting Methods for Highway Construction,” Transportation Research News 205, Transportation Research Board, National Research Council, Washington, D.C., (1999).

Hancher, D.E., NCHRP Synthesis of Highway Practice 195: Use of Warranties in Road Construction, Transportation Research Board, National Research Council, Washington, D.C., (1994).

Harp, D.W., Innovative Contracting Practices - The new way to undertake public works projects, HMAT/Hot mix Asphalt Technology Winter: 6-10 (1990).

Hastak, M., Minkarah, I., Cui, Q., and Bayraktar, M., The Evaluation of Warranty Provisions on ODOT Construction Projects, Report No. FHWA/OH-2003/19, Ohio Department of Transportation, Columbus, OH (2003).

Hughes, C.S., Managing Quality, A2F03: Committee on Management of Quality Assurance, Millennium Paper Series, Transportation Research Board, National Research Council, Washington, D.C., (2000).

Huang, Y H., Pavements Analysis and Design, Prentice Hall, Englewood Cliffs, New Jersey, (1993).

Hudson, W.R., Monismith, C.L., Dougan, C.E., and Visser, W., Use of PMS Data for Performance Monitoring With Superpave as an Example, Volume 1, Texas Research and Development, Inc. Infrastructure and Systems Engineering, Austin, TX, (2002)

Indiana Department of Transportation (INDOT), Pavement Surface Report, Indianapolis, IN (2001).

Indiana Department of Transportation (INDOT), Warranty Project Distress Manual, Indianapolis, IN, (2002).

Indiana Department of Transportation (INDOT), “Pavement and Underdrain Design Elements,” The Indiana Design Manual, Chapter 52, On-line Version, (1998).

http://www.in.gov/dot/div/contracts/standards/dm/Part\%205\%20Vol.\%202/Ch\%2052/ch52.htm 
Johnson, A. M., Use of Design/Build and Warranties in Highway Construction - Guidelines for Program Implementation, Final Report, Minnesota Department of Transportation, Minnesota, (1999).

Krebs, S.W., Duckert, B., Schwandt, S., Volker, J., Brokaw, T., and Shemwell, W., and Waelti, G., Asphaltic Pavement Warranties, Five-Year Progress Report, Wisconsin Department of Transportation, Madison,WI (2001).

Labi, S. Impact Evaluation of Highway Pavement Maintenance, Ph. D. Dissertation, Purdue University, West Lafayette, Indiana, (2001).

Labi, S., and Sinha, K.C., The Effectiveness of Maintenance and Its Impact on Capital Expenditures, Final Report, FHWA/IN/JTRP-2002, West Lafayette, Indiana, (2002).

Lamptey, G., Ahmed, M., Labi, S., and Sinha, K. C., Life Cycle Cost Analysis for INDOT Pavement Design Procedures, Draft Final Report FHWA/IN/JTRP/2004, West Lafayette, IN, (2004).

Lee, D.B., Jr, Fundamentals of Life-Cycle Cost Analysis, Transportation Research Record 1812, Transportation Research Board, National Research Council, Washington, D.C., (2002).

New Jersey Department of Transportation (NJDOT), Road User Cost Manual, Trenton, New Jersey, (2001).

Ohio Department of Transportation (ODOT), Implementation of Warranted Items in State of Ohio Construction Projects, Columbus, OH, (1999).

Ohio Department of Transportation (ODOT), Implementation of Warranted Items in State of Ohio Construction Projects, Columbus, OH , (2000).

Saito M., V.L. Anderson and Sinha K.C. (1988), Bridge Replacement Cost Analysis. Transportation Research Record 1180, Transportation Research Board, Washington, D.C.

Shober, S.F., Whited, G.C., and McMullen, K.W., Wisconsin Department of Transportation's Asphalt Pavement Warranties, Transportation Research Record 1543, Transportation Research Board, National Research Council, Washington, D.C., (1996).

Smith, K.D., Smith, K.L., Hoerner, T.E., Darter, M.I. (1997). "Effect of Initial Pavement Smoothness on Future Smoothness and Pavement Life.” Transportation Research Record 1570, Transportation Research Board, National Research Council, Washington D.C.

Thompson, B.P., Anderson, S.D, Russell, J.R., and Hanna, A.S., "Guidelines for Warranty Contracting for Highway Construction”, ASCE Journal of Management in Engineering, Vol. 18, No. 3, pp 129-137 (2002).

Walls, J., III, and Smith, M.R., Life-Cycle Cost Analysis in Pavement Design-Interim Technical Bulletin, Report No. FHWA-SA-98-079, Federal Highway Administration, US Department of Transportation, Washington, D.C., (1998).

Vitale, J. D. (1997). The Development of Optimal Policies in the Programming of Bridge Rehabilitation and Replacement Activities for Indiana. M. S. Thesis. Purdue University, Indiana. 
APPENDIX A

Warranty Contracts in Indiana as of January 2003

\begin{tabular}{|c|c|c|c|c|c|}
\hline Contract Number & Description & Date of Letting & \begin{tabular}{|c|}
$\begin{array}{c}\text { Construction } \\
\text { Year }\end{array}$ \\
\end{tabular} & \begin{tabular}{|c|}
$\begin{array}{c}\text { Completion } \\
\text { Date }\end{array}$ \\
\end{tabular} & $\begin{array}{c}\text { Warranty } \\
\text { Status }\end{array}$ \\
\hline R-22232 - I-70 & HMA/C\&S PCC & January 1996 & 1996 & July 1996 & Complete \\
\hline R-22925 - I-69 & $\begin{array}{l}\text { HMA/Rubblized } \\
\text { PCC }\end{array}$ & February 1997 & 1997 & August 1997 & Complete \\
\hline R-22854 - I-65 & HMA/C\&S PCC & December 1996 & 1997 & August 1997 & Complete \\
\hline R-23390 - I-74 & HMA/C\&S PCC & January 1998 & 1998 & \begin{tabular}{|c|} 
September \\
1998
\end{tabular} & 4-years \\
\hline$R-23500$ - 65 & $\begin{array}{l}\text { HMA/Rubblized } \\
\text { PCC }\end{array}$ & & 1998 & August 1999 & 3-years \\
\hline R-23898 - I-74 & HMA/C\&S PCC & December 1998 & 1999 & \begin{tabular}{|c|} 
September \\
1999
\end{tabular} & 3-years \\
\hline R-24327 - I-65 & $\begin{array}{l}\text { HMA/Rubblized } \\
\text { PCC }\end{array}$ & & 2001 & June 2002 & 1-year \\
\hline R-24568 & $\begin{array}{l}\text { Warranted erosion } \\
\text { control slopes }\end{array}$ & November 2000 & & & \\
\hline R-24568 & $\begin{array}{l}\text { Warranted erosion } \\
\text { control side ditches }\end{array}$ & November 2000 & & & \\
\hline B-24698 & $\begin{array}{l}\text { Warranted erosion } \\
\text { control slopes }\end{array}$ & July 2000 & & & \\
\hline B-24698 & $\begin{array}{l}\text { Warranted erosion } \\
\text { control side ditches }\end{array}$ & July 2000 & & & \\
\hline R-23735 & $\begin{array}{l}\text { Warranted erosion } \\
\text { control slopes }\end{array}$ & April 2000 & & & \\
\hline R-23735 & $\begin{array}{l}\text { Warranted erosion } \\
\text { control side ditches }\end{array}$ & April 2000 & & & \\
\hline R-25808 & $\begin{array}{l}\text { HMA/Rubblized } \\
\text { PCC }\end{array}$ & January 2002 & 2002-2003 & & \\
\hline R-25142 - I-64 & $\begin{array}{l}\text { HMA/Rubblized } \\
\text { PCC }\end{array}$ & January 2003 & 2003 & & \\
\hline RS-25883 - Sr-28 & Micro-surfacing & May 2002 & 2002 & $\begin{array}{c}\text { November } \\
2002 \\
\end{array}$ & $\begin{array}{l}\text { Warranty in } \\
\text { progress }\end{array}$ \\
\hline R-26262 - I-70 & Micro-surfacing & June 2002 & 2002 & $\begin{array}{c}\text { October } \\
2002 \\
\end{array}$ & $\begin{array}{l}\text { Warranty } \\
\text { cancelled }\end{array}$ \\
\hline R-24550 - I-65 & PCC & & 2003 & & \\
\hline R-26484 - I-69 & PCC & January 2003 & 2003 & & \\
\hline
\end{tabular}




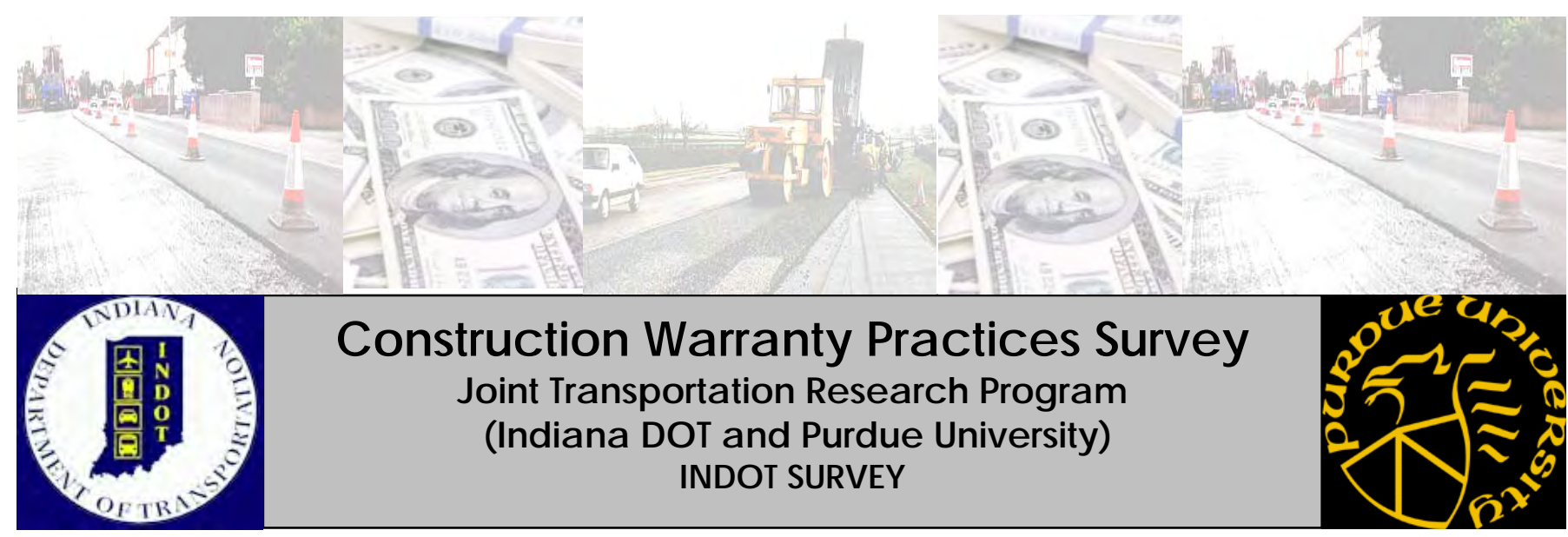

\section{GENERALINFORMATION}

Name and title of the respondent:

INDOT Division:

E-mail address:

\section{PURPOSE OFTHISQUESIONNAIRE}

The purpose of this questionnaire is to obtain information on your experiences, observations and evaluations, if any, on the use of construction warranties on projects that you have been involved with. This study is evaluating the cost-effectiveness of using warranties on INDOT projects.

\section{QUESIONNAIRE}

\section{A. WARRANTY PROJ ECTS IDENTIRCATION}

1. Please list the warranty projects you have worked on. If you have worked on more than one project, please identify your responses by project. With each project list the type of warranties (i.e. pavement, erosion control, etc.).

2. Was the warranty(s) appropriate for the project? (Yes / No) Please elaborate. 


\section{Survey of Current Constuction Warranty Practices}

\section{B. ADEQUACY OF WARRANTY SPECIFCATIONS}

3. Was the warranty specification well-defined? (Yes / No) Please elaborate.

4. If 'No' in Question 3, which areas of the specification need clarification and modification?

5. What types of problems did you experience with the specification?

\section{QUALTY CONTROL/ASSURANCE DURING CONSTRUCTION}

6. Did the contractor meet the requirements of the Warranty specification? (Yes / No) Please elaborate.

7. If 'No' in Question 6, did the contractor undertake remedial action? (Yes / No) Please elaborate. 


\section{Survey of Current Constuction Warranty Practices}

8. Describe the Quality Control inspection program for the warranty items.

9. How different is the QC inspection from a traditional contract?

10. Were you satisfied with the Quality Assurance inspection performed at the site by INDOT? (Yes / No) Please elaborate.

11. Please indicate your opinion on the warranty concept where INDOT has lesser responsibilities for Quality Control and maintenance activities compared to the traditional concept. (Good idea/Bad idea). Please give reasons.

\section{CONTRACTOR INNOVATION AND PERFORMANCE}

12. Was there any contractor innovation due to the warranty clause? (Yes / No) Please elaborate. 


\section{Survey of Current Constuction Warranty Practices}

13. Are you satisfied with the overall performance and quality of the contractor's work? (Yes / No) Please elaborate.

14. Do you believe that the contractor put greater emphasis on quality in the Warranty project than they would have done in a traditional project? (Yes / No) Please elaborate.

\section{CONFICTS}

15. Did the Conflict Resolution Team (CRT) resolve any issue between INDOT and the contractor? (Yes / No) Please elaborate

\section{E. YOUR OVERALJUDGEMENT}

16. Do you think that Warranty contracts are a good alternative to improve quality? (Yes / No) Please elaborate. 


\section{Survey of Current Constuction Warranty Practices}

17. Based on your experiences, what are the advantages of Warranty contracts?

18. Based on your experiences, what are the disadvantages of Warranty contracts?

19. Do you think that a proper screening process is needed to ensure the selection of appropriate projects for Warranty specification? (Yes / No) Please elaborate.

Please return the questionnaire in one of the following ways:

1. Email: psingh@purdue.edu

2. Regular Mail: Priyanka Singh

School of Civil Engineering

1284 Civil Engineering Building

Purdue University

West Lafayette IN 47906

If you have any questions, please contact Dr. Bob McCullouch at 765 494-0643

THANK YOU FOR YOUR ASSISTANCE! 


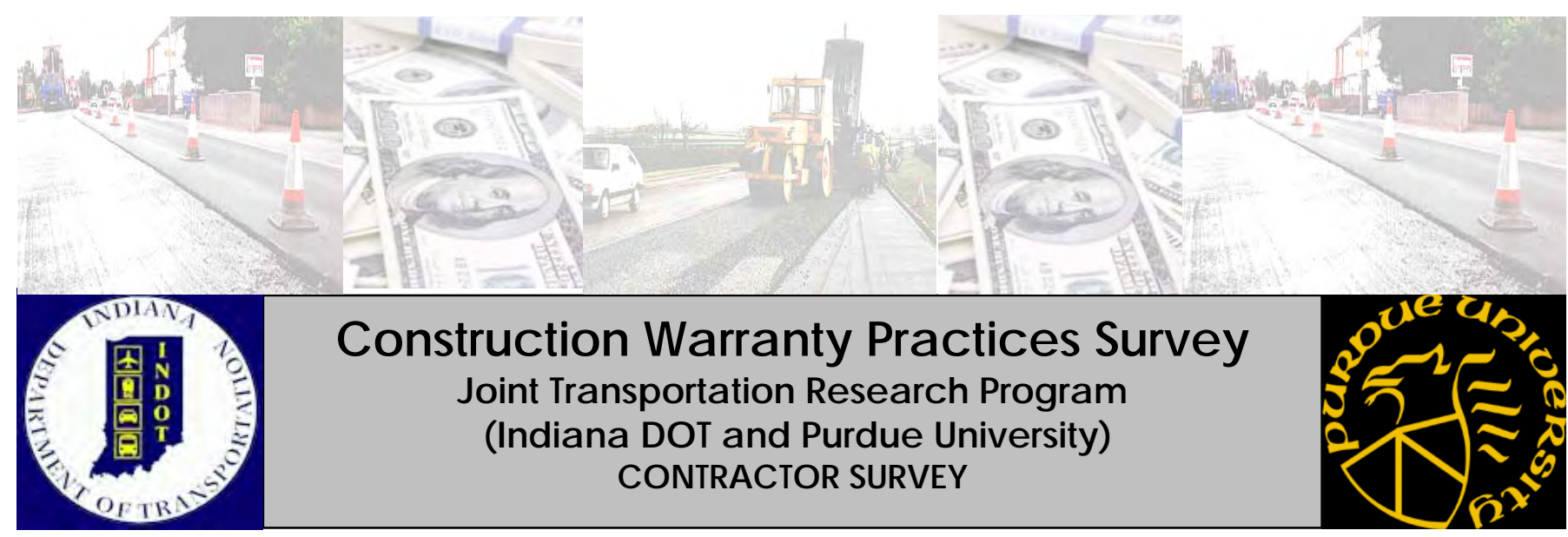

\section{GENERALINFORMATION}

Name and title of the respondent:

Company:

E-mail address:

\section{PURPOSE OFTHISQUESIONNAIRE}

The purpose of this questionnaire is to obtain information on your experiences, observations and evaluations, if any, on the use of construction warranties on projects that you have been involved with. This study is evaluating the cost-effectiveness of using warranties on INDOT projects.

\section{QUESIONNAIRE}

\section{A. WARRANTY PROJ ECTS IDENTIRCATION}

1. Please list the warranty projects you have worked on. If you have worked on more than one project, please identify your responses by project. With each project list the type of warranties (i.e. pavement, erosion control, etc.).

2. Was the warranty(s) appropriate for the project? (Yes / No) Please elaborate. 


\section{Survey of Current Constuction Warranty Practices}

\section{B. ADEQUACY OF WARRANTY SPECIFCATIONS}

3. Was the warranty specification well-defined? (Yes / No) Please elaborate.

4. If 'No' in Question 3, which areas of the specification need clarification and modification?

5. What types of problems did you experience with the specification?

\section{BOND ISSUES}

6. Did you encounter any problem while securing bonds for the Warranty period? (Yes / No) Please elaborate.

7. What was the percentage difference in the bond amount in the warranty contract compared to a traditional contract? 


\section{Survey of Current Constuction Warranty Practices}

\section{QUALTY CONTROL/ASSURANCE DURING CONSTRUCTION}

8. How did you perform Quality Control on the project?

9. Were any discrepancies identified during quality checks? (Yes / No) Please elaborate.

10. Did you undertake any remedial action due to Quality control issues? (Yes / No) Please elaborate.

11. How would you compare the level of testing and quality checks between Warranty and traditional projects you have participated in?

\section{E. CONPUCTS}

12. Were there any conflicts on the contract over the warranty items? Did the Conflict Resolution Team (CRT) resolve any issue between you and INDOT? (Yes / No) Please elaborate 


\section{Survey of Current Constuction Warranty Practices}

\section{F. GENERAL ISSUES}

13. Does the warranty clause allow for more innovation? (Yes / No) Please elaborate.

14. Do you think that INDOT's selection process for the successful bidder for Warranty projects is fair? (Yes / No) Please elaborate.

(n)

15. Based on your experiences, what are the advantages of Warranty contracts?

16. Based on your experiences, what are the disadvantages of Warranty contracts?

Please return the questionnaire in one of the following ways:

1. Email: psingh@purdue.edu

2. Regular Mail: Priyanka Singh

School of Civil Engineering 1284 Civil Engineering Building

Purdue University

West Lafayette IN 47906

If you have any questions, please contact Dr. Bob McCullouch at 765 494-0643

A response by January 16 would be greatly appreciated. THANK YOU FOR YOUR ASSISTANCE! 